\section{$U S-C E-C$ Property of the}

United States Governme-

\title{
Load Rating of Permanent Bridges on U.S. Army Installations
}

by James C. Ray, WES

Terry R. Stanton, U.S. Army Center for Public Works

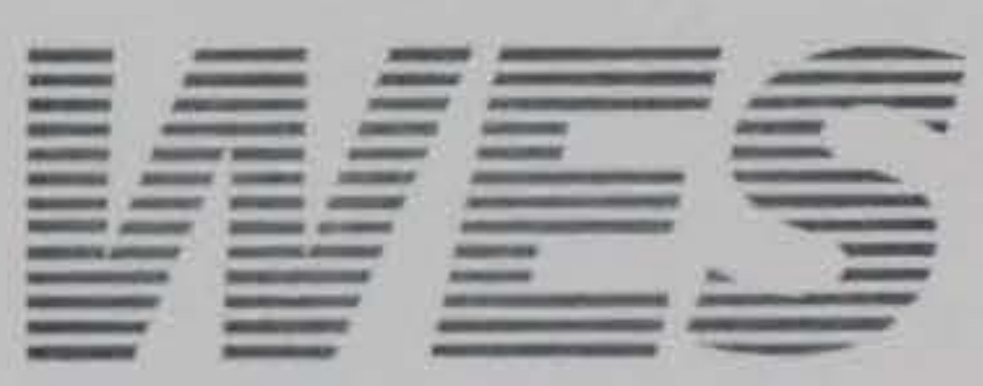

Approved For Public Release; Distribution Is Unlimited

Research Library

US Army Engineer Waterways

Experiment Station

Vicksburg. Mississippi 
The contents of this report are not to be used for advertising, publication, or promotional purposes. Citation of trade names does not constitute an official endorsement or approval of the use of such commercial products.

The findings of this report are not to be construed as an official Department of the Army position, unless so designated by other authorized documents. 


\section{Load Rating of Permanent Bridges on U.S. Army Installations}

by James C. Ray

U.S. Army Corps of Engineers

Waterways Experiment Station

3909 Halls Ferry Road

Vicksburg, MS 39180-6199

Terry R. Stanton

U.S. Army Center for Public Works

Fort Belvoir, VA 22315-3862

Final report

Approved for public release; distribution is unlimited 


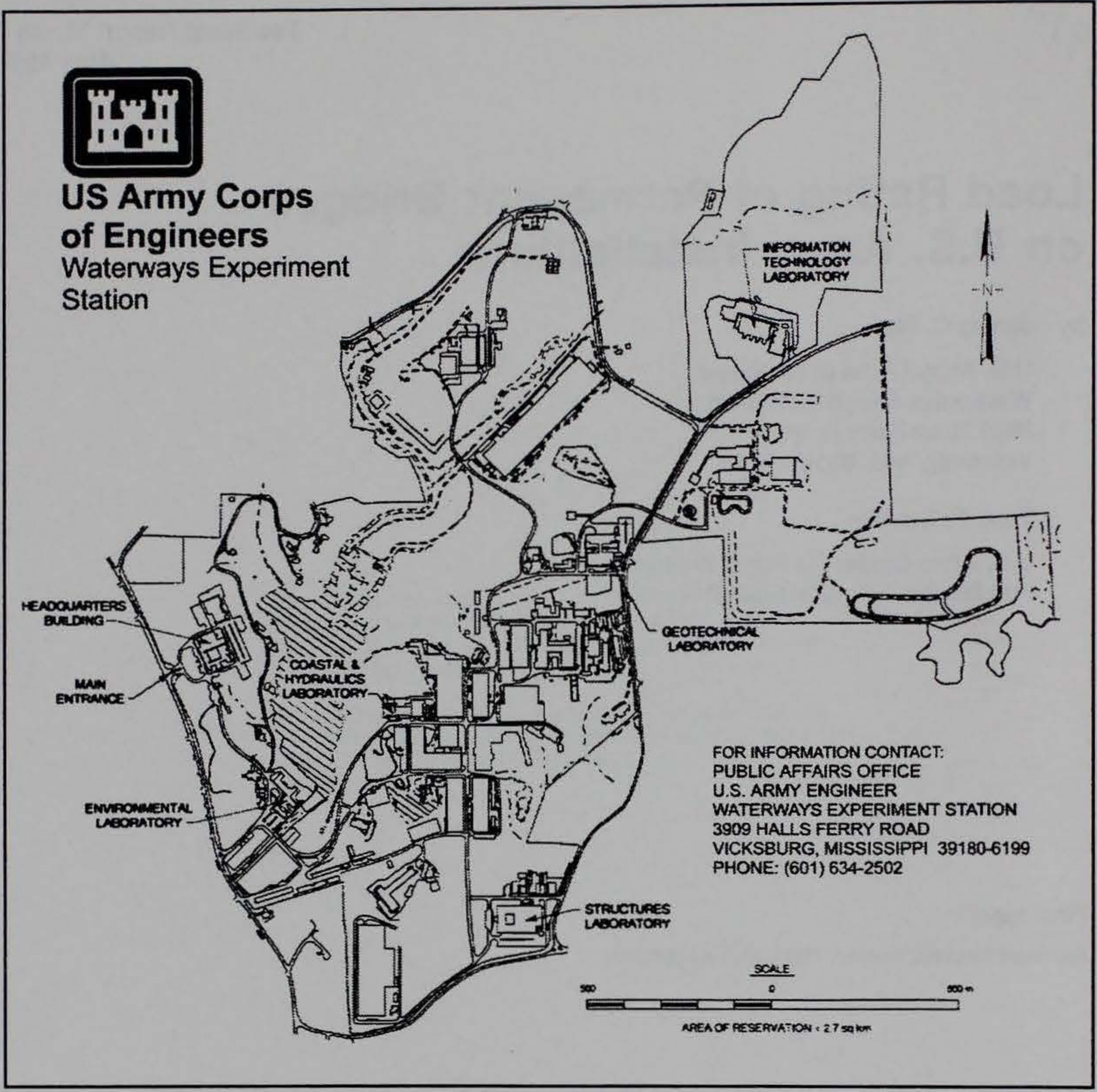

\section{Waterways Experiment Station Cataloging-in-Publication Data}

Ray, James C.

Load rating of permanent bridges on U.S. Army installations / by James C. Ray, Terry R.

Stanton ; prepared for U.S. Army Center for Public Works.

184 p. : ill. ; $28 \mathrm{~cm}$. - (Technical report ; SL-98-3)

Includes bibliographical references.

1. Military bridges - Design and construction. 2. Bridges - Design and construction.

I. Stanton, Terry R. II. United States. Army. Corps of Engineers. II. U.S. Army Engineer Waterways Experiment Station. III. Structures Laboratory (U.S. Army Engineer Waterways Experiment Station) IV. US Army Center for Public Works. V. Title. VI. Series: Technical report (U.S. Army Engineer Waterways Experiment Station) ; SL-98-3.

TA7 W34 no.SL-98-3 


\section{Contents}

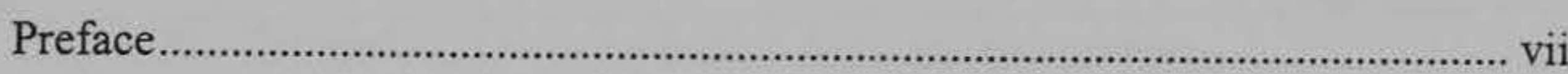

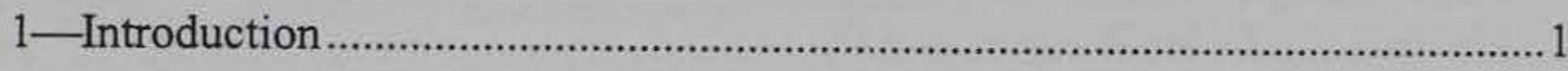

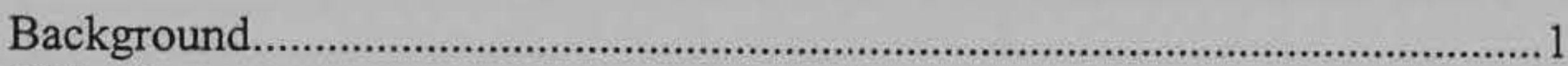

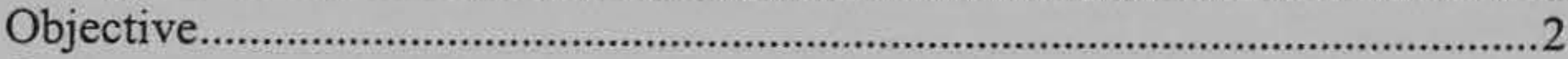

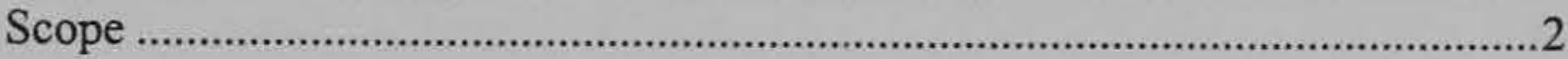

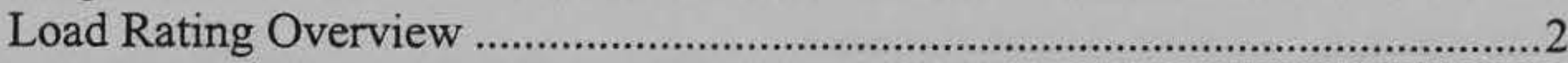

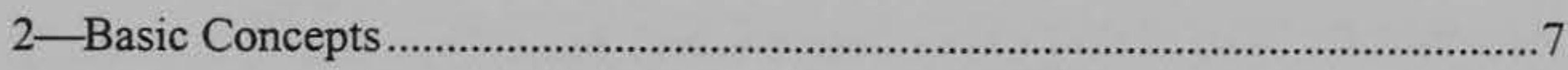

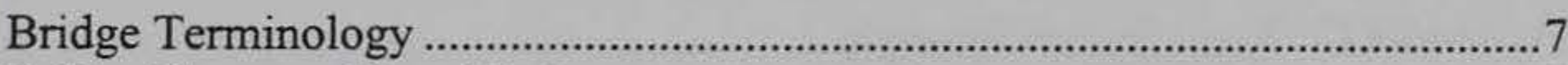

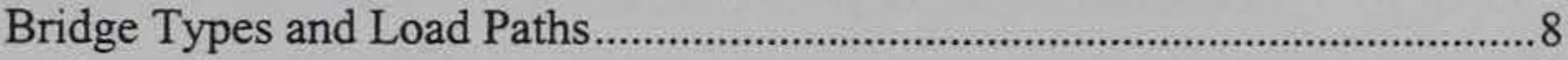

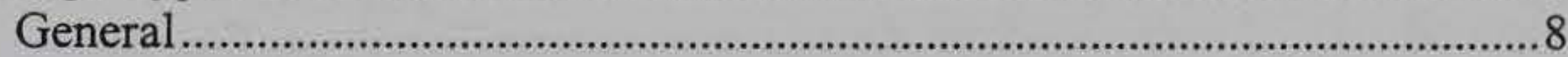

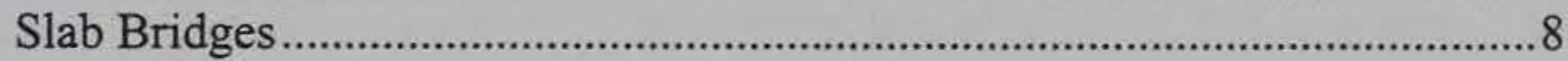

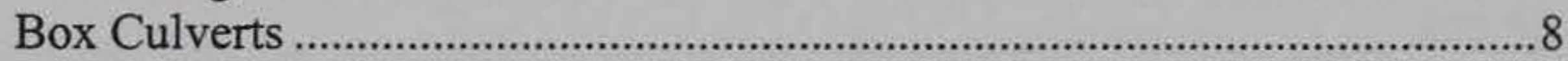

Multi-Girder Bridges ............................................................................ 9

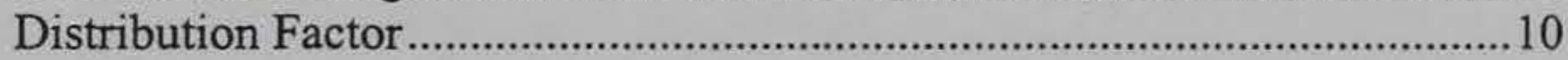

Two-Girder or Truss Bridges............................................................................

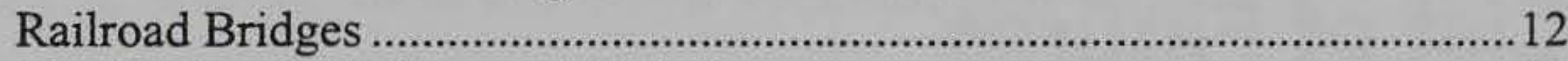

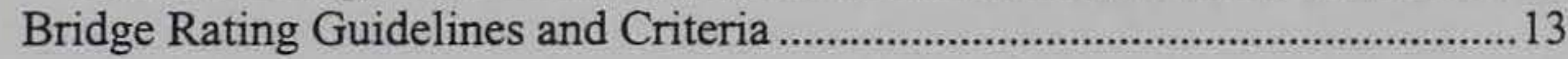

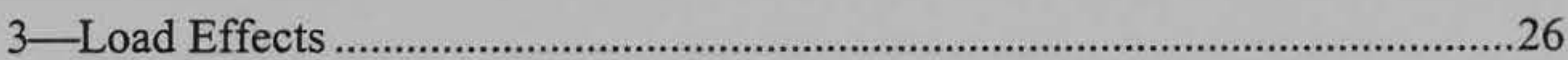

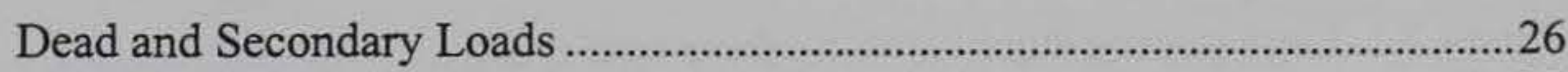

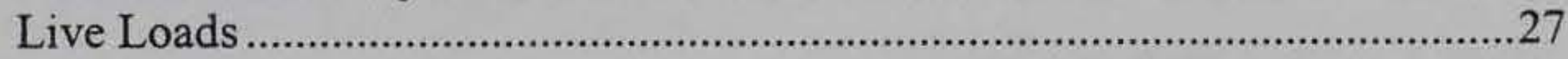

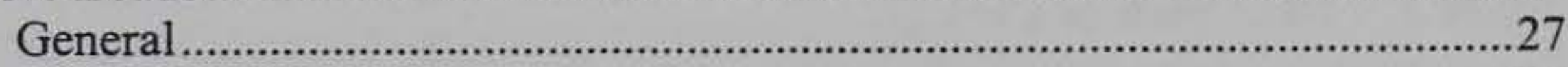

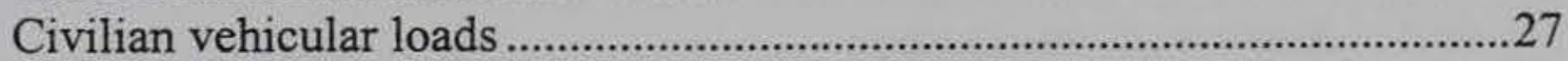

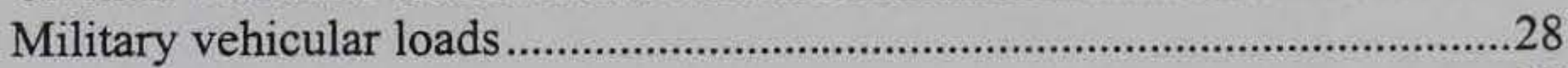

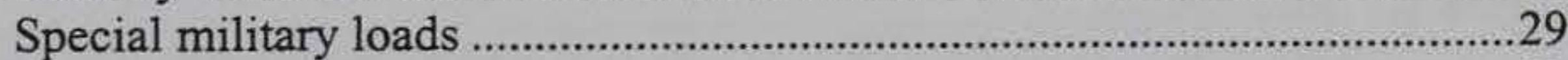

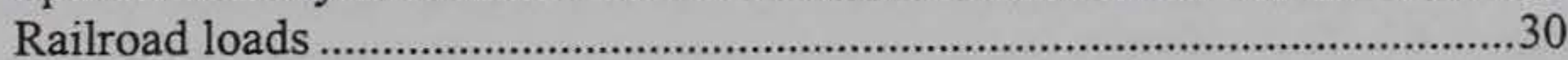

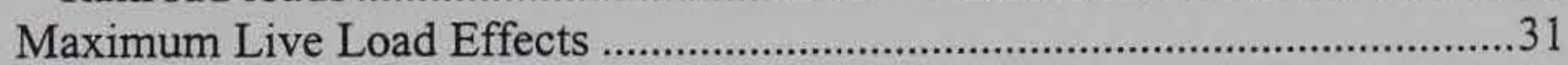

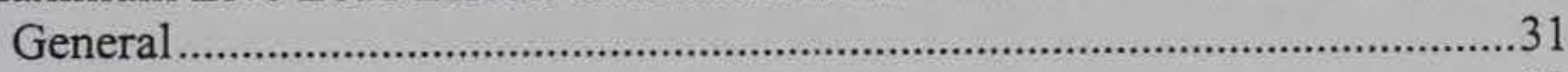

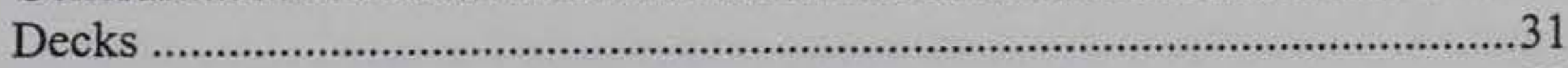

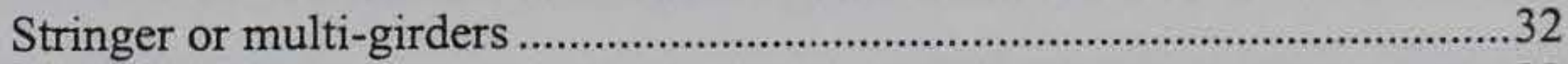

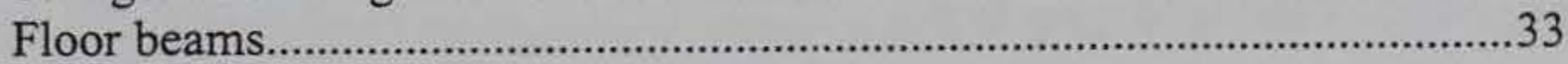

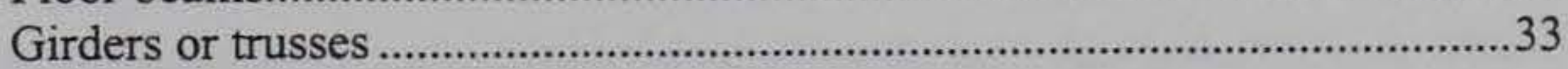




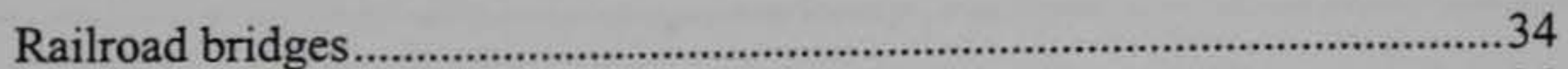

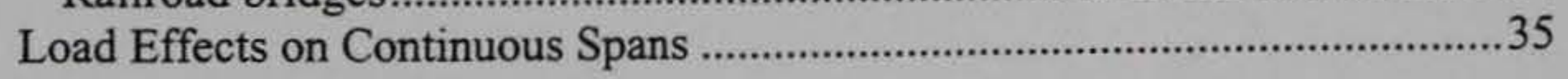

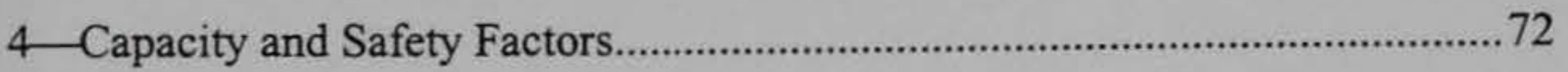

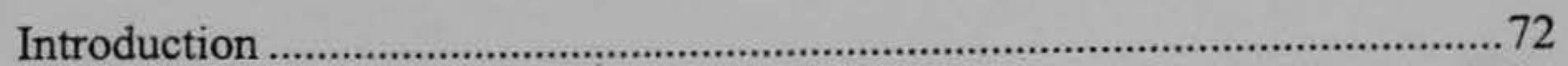

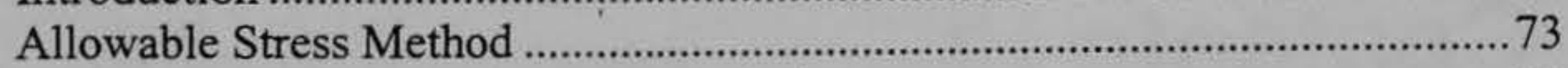

Load Factor (Ultimate Strength) Method..........................................................

Load and Resistance Factor Rating (LRFR) Method ........................................74

Railroad Bridges........................................................................................

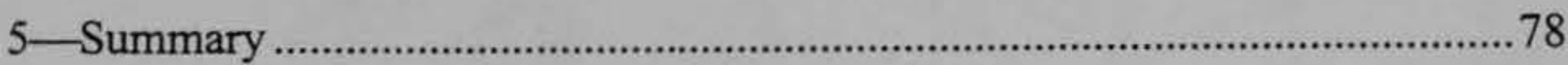

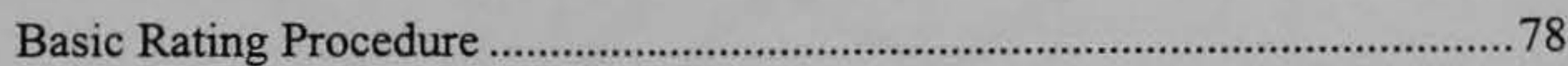

Military Load Classification (MLC) …………………………………….......

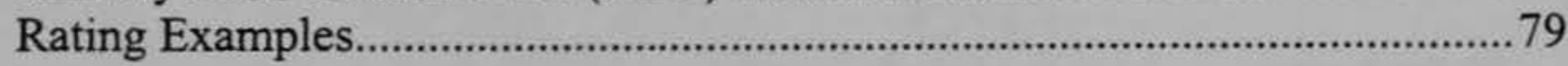

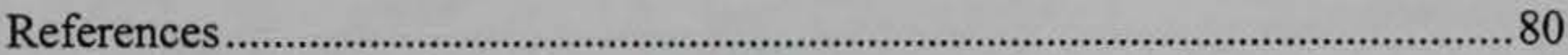

Appendix A: Timber Bridge Example ................................................................

Appendix B: Steel Multi-Girder, Concrete Deck Example .................................. B1

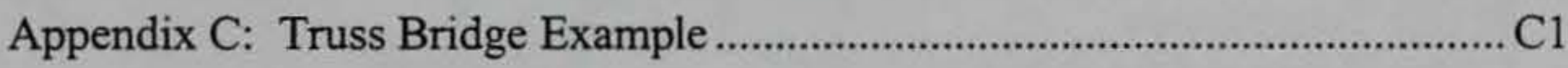

Appendix D: Continuous-Span Reinforced Concrete Tee-Beam Example........D1

SF 298

\section{List of Figures}

Figure 1. Basic design loads for a bridge........................................................

Figure 2. Load posting signs resulting from load rating..................................... 6

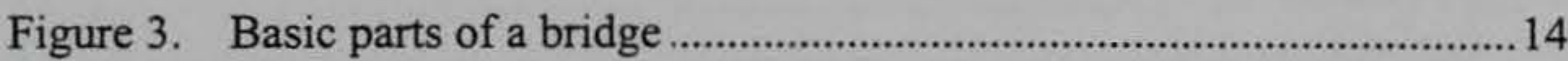

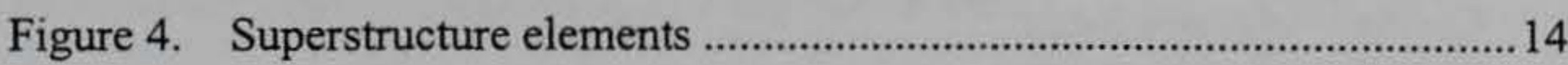

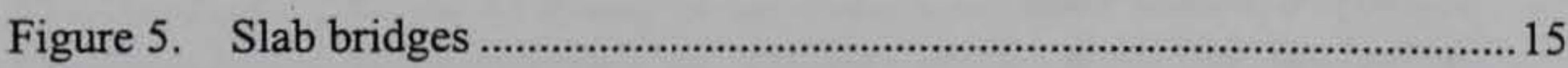

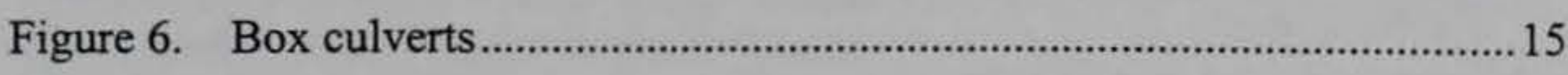

Figure 7. General load path for a multi-girder bridge ………….......................16

Figure 8. Longitudinal and transverse load distribution ....................................17

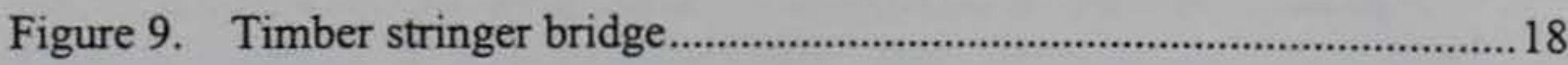

Figure 10. Steel multi-girder / concrete deck bridge .......................................... 18

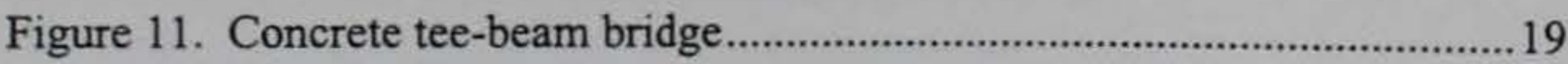


Figure 12. Prestress / posttension girder bridge .................................................19

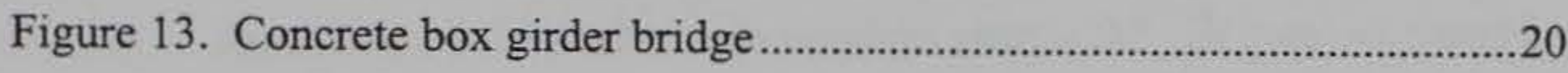

Figure 14. Steel girder bridge ………..........................................................2. 20

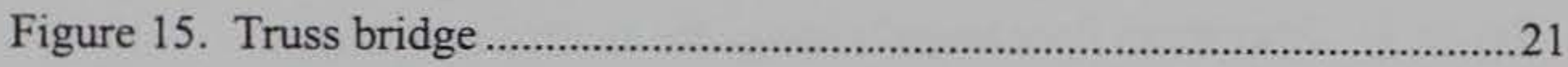

Figure 16. Railroad bridges ........................................................................21

Figure 17. Transverse load distribution through decks......................................2

Figure 18. General load path for a girder or truss bridge ...................................23

Figure 19. General load path for an open deck railroad bridge ...........................24

Figure 20. General load path for ballast deck railroad bridges.............................25

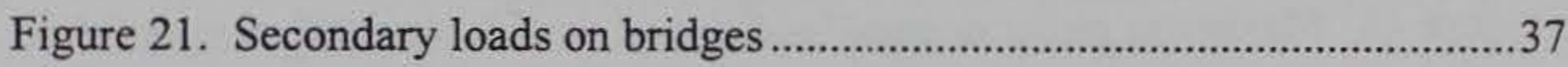

Figure 22. Civilian live loads (reference [1]) ………………............................38

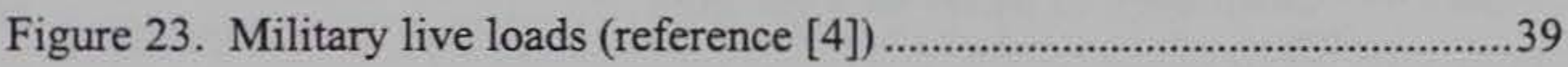

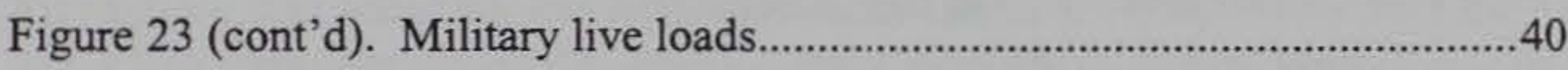

Figure 24. Moment and shear curves for HET overlaid onto standard MCL

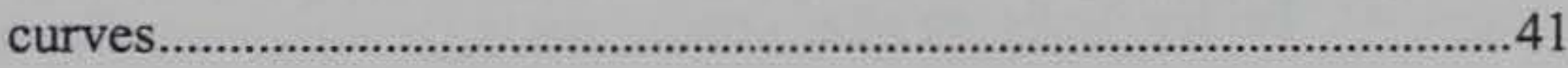

Figure 25. Heavy Equipment Transport System (HETS) ....................................42

Figure 26. Model G515T-1500 general purpose army locomotive, 120 tons each...

Figure 27. Common commercial locomotive, Model SD40-2, 184 tons each ...44

Figure 28. 140 ton special purpose flat car; 188 tons with 2 M1A1 tanks ..........45

Figure 29. AMC ammo box car, 130 tons each ................................................46

Figure 30. Comparison of E80 train to worst-case army trains ............................47

Figure 31. Equivalent E-loadings for typical army trains, based on bending

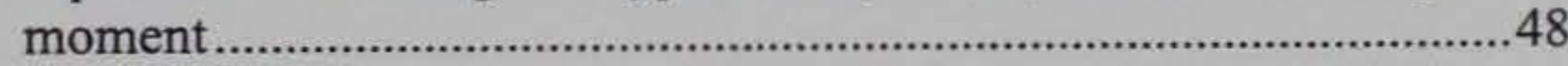

Figure 32. Equivalent E-loadings for typical army trains, based on endspan

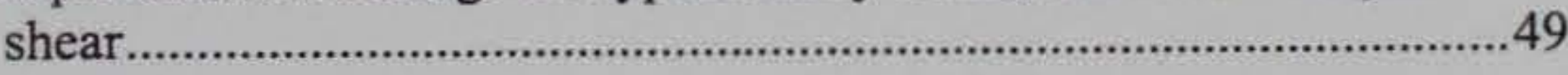

Figure 33. Maximum deck loadings ……………………............................5

Figure 34. Maximum stringer or multi-girder loadings....................................51

Figure 35. Vehicle placement for maximum load effects on elements ..............52

Figure 36. Maximum stringer or girder moments for civilian live loads (reference [1])

Figure 37. Maximum stringer or girder shears for live loads (reference [1]).....54

Figure 37 (cont'd). Maximum stringer or girder shears for live loads .................55

Figure 38. Maximum longitudinal bending moments for military live loads ....56

Figure 38 (cont'd). Maximum longitudinal bending moments for military live 
Figure 39. Maximum endspan shears for military live loads ...........................58

Figure 39 (cont'd). Maximum endspan shears for military live loads ...............59

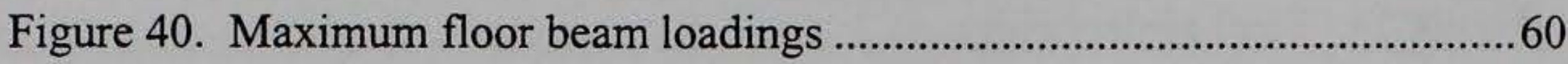

Figure 41. Maximum floor beam loadings for civilian live loads

(reference [1])

Figure 41 (cont'd). Maximum floor beam loadings for civilian live loads

Figure 42. Maximum floor beam loadings for military live loads (source: WES derived)

Figure 42 (cont'd). Maximum floor beam loadings for military live loads (source: WES derived)

Figure 43. Maximum girder or truss loadings (shown for bending moment only)

Figure 44. Calculation of wheel lines per truss ...............................................66

Figure 45. Load distribution in railroad bridges ...........................................67

Figure 46. Comparison of simple and continuous span bridges .......................68

Figure 47. Bridge decks are often continuous in the transverse direction..........69

Figure 48. Moving load analysis on continuous spans .....................................70

Figure 49. Moving load analysis by hand ..................................................... 71

Figure 50. Allowable stress compared to load factor method ...........................76

Figure 51. Rating factor equation for three different load rating methods (vehicular bridges only) 


\section{Preface}

The work reported herein was sponsored by the U.S. Army Center for Public Works (USACPW), Fort Belvoir, Virginia. Mr. Terry Stanton, USACPW, was both Program Monitor and Technical Monitor.

All work was carried out by Mr. James C. Ray, Structural Mechanics Division (SMD), Structures Laboratory (SL), U.S. Army Engineer Waterways Experiment Station (WES) and Mr. Terry Stanton, USACPW. Report Preparation was accomplished by Ms. Jennifer Bennett, (WES). The work at WES was conducted under the general supervision of Dr. Bryant Mather, Director, SL; Mr. John Ehrgott, Assistant Director; and Dr. Reed Mosher, Chief, SMD.

At the time of this report, the Director of WES was Dr. Robert W. Whalin. The Commander was Col. Bruce K. Howard, EN. 


\section{Introduction}

\section{Background}

It is widely known that the United States owns and maintains many bridges throughout its highway system. However, it may come as a surprise to most that the Department of the Army owns and maintains over 1500 bridges. These bridges are on U.S. military installations throughout the world and carry pedestrians, civilian and military vehicles, and trains.

Like the U.S. infrastructure, these bridges require continual inspection, maintenance, and load capacity assessment. The American Association of State Highway and Transportation Officials (AASHTO) has provided numerous technical guidelines for the inspection, maintenance, and load rating of bridges on the U.S. Highway system. The American Railway Engineering Association (AREA) provides similar guidelines for railroad bridges and the Army has technical manuals to address temporary theater-of-operations bridges. However, past experience has shown that these criteria are not completely applicable to bridges on military installations and that they provide inconsistent levels of safety. Table 1 demonstrates that usage-wise installation bridges fall somewhere between a conventional highway or railroad bridge, and a temporary theater-ofoperations bridge. Most importantly, they have very different traffic volumes and traffic types depending upon their location and purpose on the installation. Those bridges that are in areas open to the public must carry the same civilian loadings as conventional highway bridges (although generally in much lower volumes) and at the same time carry heavy and frequent loadings from military wheeled and tracked vehicles. Yet, those bridges in training areas (i.e., not open to public) typically carry only military vehicles. Likewise, most railroad bridges on installations are off of the mainline and must only accommodate lighter and much less frequent military trains entering and leaving the installation. In summary, installation bridges are widely varied in their usage levels and do not fall easily under any conventional load rating guidelines. This variation has produced a wide dispersion of load rating methods and levels of safety among military installations.

Army Regulation, AR420-72, provides a greater uniformity in the load rating procedures and policies by stipulating specific guidelines. These guidelines are based heavily upon those set forth by the AASHTO in References [1] through [3]. To aid in the adoption of these guidelines and to train 
installation engineers who might be inexperienced in bridge load rating, the USACPW funded the SL-WES to develop a short course entitled, "Load Rating of Bridges on Military Installations." Since the course began, the U.S. Army Corps of Engineers has also begun participating in the course. This report provides a summary of the material developed for the course and, at the same time, documents the load rating methodology.

\section{Objective}

The objective of this work was to provide uniformity in the procedures and policies for determining the load capacity of bridges on U.S. Army Installations, and also to provide a common reference for this information.

\section{Scope}

It is recognized that many installation engineers have very little experience in bridge load rating. Therefore, the first part of this report presents a general overview of bridges and corresponding engineering concepts. The overview includes basic bridge types, bridge elements, bridge loadings and optimal load placement, load paths through bridges, load distribution concepts, and load rating guidelines and criteria. While it is provided in the actual Load Rating course, a review of basic structural mechanics is not provided herein since these concepts are well documented in the literature. The last part of this report presents detailed load rating examples utilizing the methodology described herein.

\section{Load Rating Overview}

The sole purpose of bridge load rating is to determine the allowable load capacity of an in-service bridge. Specifically: How big of a vehicle (or train) can safely utilize the bridge? As shown in Figure 1, bridges are originally designed for three basic classes of loads: self-weight, known as "dead load"; vehicular (or usage) loads, known as "live loads"; and "secondary loads", such as wind, snow, etc. Therefore, the required capacity of each individual bridge element (i.e., the members making up the bridge as a whole) may be expressed as:

$$
\text { Required Member Capacity }=\text { Dead }+ \text { Live }+ \text { Secondary Loads }
$$

For load rating purposes, a method is needed for evaluating the bridge's ability to carry specific live loads, and for evaluating whether there is a need to restrict traffic loadings on the bridge. For this, Equation 1 can be worked backwards and solved for the allowable live load as:

Allowable Live Load = Member Capacity - Dead Load - Secondary Loads. (2) 
Secondary loads are of a temporary and sporadic nature, and it is unlikely that they will be present on the bridge at the same time as a worst-case live load. Therefore, secondary loads can usually be neglected in a load rating analysis and the portion of the member capacity that was provided for these loads may now be utilized to carry additional live load. For load rating, the basic equation thus becomes:

$$
\text { Allowable Live Load = Member Capacity }- \text { Dead Load Effect. }
$$

From this equation, the portion of total member capacity available to carry live load is the capacity remaining after the dead load effect is carried. Allowable live load is often conveniently expressed in terms of a "Rating Factor" (RF), which is basically the ratio of the expression above as follows:

$$
\mathrm{RF}=\frac{\text { Available Capacity }}{\text { Applied Live Load }}=\frac{\text { Member Capacity }- \text { Dead Load Effect }}{\text { Applied Live Load Effect }}
$$

In most cases, the member capacity and the dead load effect (the numerator) does not change. By simply adjusting the applied live load effect (the denominator), several vehicular loadings can be evaluated quickly to determine if any restriction is needed. Paragraph 6.5 of Reference [1] provides the above equation in the following generic form:

$$
R F=\frac{C-A_{1} D}{A_{2} L(1+I)}
$$

where: $C=$ Member Capacity

$D=$ Dead load effect on the member

$L=$ Live load effect on the member

$I=$ Impact factor for live load

$A_{1}=$ Factor for dead loads

$A_{2}=$ Factor for live loads

Each of these variables will be discussed in detail in the following chapters.

It is extremely important to understand that a RF must be obtained for each critical bridge element, for each possible mode of stress, and for each of the desired Rating and Posting vehicles. (These terms will be discussed in the following chapters.) For example, refer to the bridge and rating summary shown in Table 2. In this case there are three different spans that must be evaluated. If just the superstructures are considered for the two girder (approach) spans, both the deck and girders must be evaluated for shear and bending for each of the vehicles. For the truss span, the deck, stringers, and floor beams must be evaluated for shear and bending. However, the truss elements need only be evaluated for tension or compression. This example makes it easy to see why many software packages are available to conduct these calculations. But once all RFs are obtained, the element with the smallest RF becomes the "controlling element" and the overall bridge rating is based only on its capacity. For many small or simple bridges (such as those on many Army installations), once this 
controlling element is determined, follow-on analyses need only consider that element.

In Equation 5 above, a RF less than 1.0 means that the element or bridge cannot carry the desired live load and a restriction is required. A RF greater than, or equal to, 1.0 means that it is sufficient for the desired live load and no restriction is required. For example, in Table 2 the RF for the bottom chord in the truss span is 0.4 for one of the rating vehicles. This means that the bottom chord of the truss is only capable of carrying $40 \%$ of that vehicle's gross vehicle weight (and that is what would be posted). Likewise, the girders in the 40 -foot span have a bending RF of 1.10 for one of the rating vehicles. This RF means that the girders in this span are capable of carrying $110 \%$ of that vehicle's gross vehicle weight. A typical civilian posting sign is shown in Figure 2a. This type of sign should only be posted on the bridge if the RFs are less than 1.0 for any of the posting vehicles. The allowable weights (in tons) shown on these signs are obtained by multiplying the total weight (in tons) of the rating or posting vehicle by the controlling (i.e. lowest) RF as follows:

$$
\text { Allowable Weight }=(\mathrm{RF})(\text { Vehicle Weight in tons })
$$

Note in Figure 2a that the allowable weight of the longer truck is larger than that for the shorter trucks. This is common and logical for shorter span bridges, where the trucks may be longer than the bridge span. In that case, the total load of the longer truck will never be completely on the bridge span at the same time; whereas, the total load of the shorter truck can be completely on the span at one time.

Figure $2 \mathrm{~b}$ shows typical military load class (MLC) posting signs. These signs are required on all bridges on military installations that carry military traffic. The signs show wheeled and tracked, one- and two-way classifications. The meaning of these terms and MLC calculation will be discussed in the following chapters.

\section{Table 1}

Comparison of Bridges

\begin{tabular}{|l|l|l|l|}
\hline & Highway Bridges & $\begin{array}{l}\text { Theater of } \\
\text { Operations Bridges }\end{array}$ & $\begin{array}{l}\text { Military Installation } \\
\text { Bridges }\end{array}$ \\
\hline Service Life & $50+$ years & 1 to 5 years & $50+$ years \\
\hline $\begin{array}{l}\text { Military Traffic } \\
\text { Volume }\end{array}$ & Essentially 0 & $100-5,000$ per day & $0-500$ per day \\
\hline $\begin{array}{l}\text { Civilian Traffic } \\
\text { Volume }\end{array}$ & $>100,000$ per day & 0 & $0-10,000$ per day \\
\hline Vehicle Speeds & $>65$ mph & 25 mph & $25-55$ mph \\
\hline Train Types & Cooper E-80 & Cooper E-series & Army specific \\
\hline $\begin{array}{l}\text { Fatigue } \\
\text { Susceptibility }\end{array}$ & High & Low & Low to Medium \\
\hline Guidelines Available & AASHTO & TM5-312 & Mixed \\
\hline
\end{tabular}


Table 2

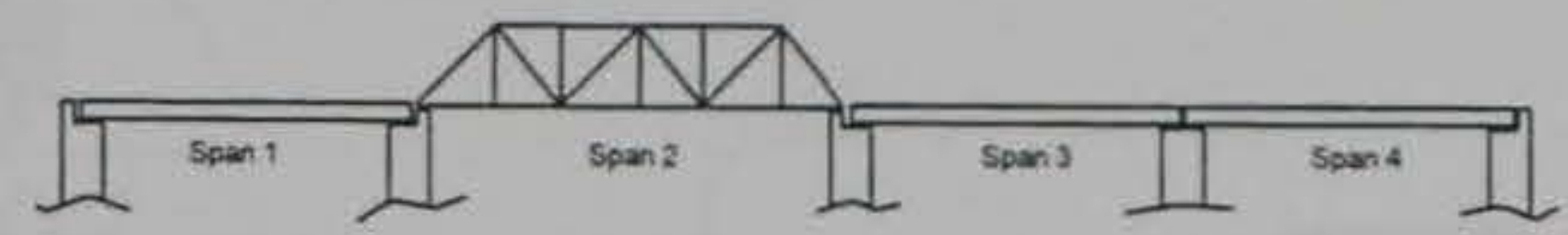

Example Bridge Rating Factor Summary

\begin{tabular}{|c|c|c|c|c|c|}
\hline Bridge Element & $\begin{array}{l}\text { H } 20 \\
\text { Vehicle }\end{array}$ & $\begin{array}{l}\text { HS } 20 \\
\text { Vehicle }\end{array}$ & $\begin{array}{l}\text { Type } 3 \\
\text { Vehicle }\end{array}$ & $\begin{array}{l}\text { Type } 352 \\
\text { Vehicle }\end{array}$ & $\begin{array}{l}\text { Type 3-3 } \\
\text { Vehicle }\end{array}$ \\
\hline \multicolumn{6}{|l|}{ Girder Span } \\
\hline Deck (bending) & 4.49 & 4.49 & 8.45 & 9.27 & 8.99 \\
\hline \multicolumn{6}{|l|}{ Deck (shear) } \\
\hline Girders (bending) & 1.00 & 1.05 & 1.10 & 1.16 & 1.05 \\
\hline \multicolumn{6}{|l|}{ Girders (shear) } \\
\hline \multicolumn{6}{|l|}{ Truss Span } \\
\hline Deck (bending) & 4.33 & 4.33 & 8.15 & 8.94 & 8.66 \\
\hline \multicolumn{6}{|l|}{ Deck (shear) } \\
\hline Stringers (bending) & 1.37 & 1.37 & 2.01 & 2.20 & 2.44 \\
\hline \multicolumn{6}{|l|}{ Stringers (shear) } \\
\hline Floorbeams (bending) & 1.79 & 1.79 & 1.99 & 1.99 & 2.31 \\
\hline \multicolumn{6}{|l|}{ Floorbeams (shear) } \\
\hline Top cord & 0.51 & 0.40 & 0.60 & 0.46 & 0.45 \\
\hline \multicolumn{6}{|l|}{ Bottom cord } \\
\hline \multicolumn{6}{|l|}{ Verticals } \\
\hline \multicolumn{6}{|l|}{ Diagonals } \\
\hline Controlling RF & 0.51 & 0.40 & 0.60 & 0.46 & 0.45 \\
\hline
\end{tabular}

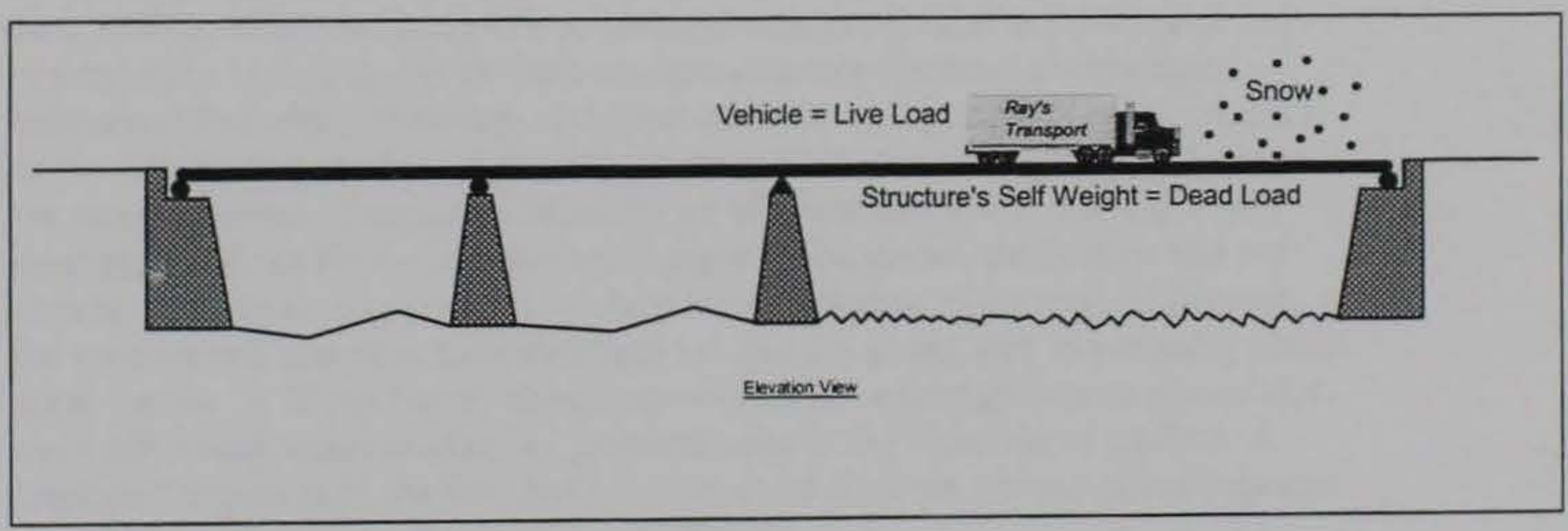

Figure 1. Basic design loads for a bridge 


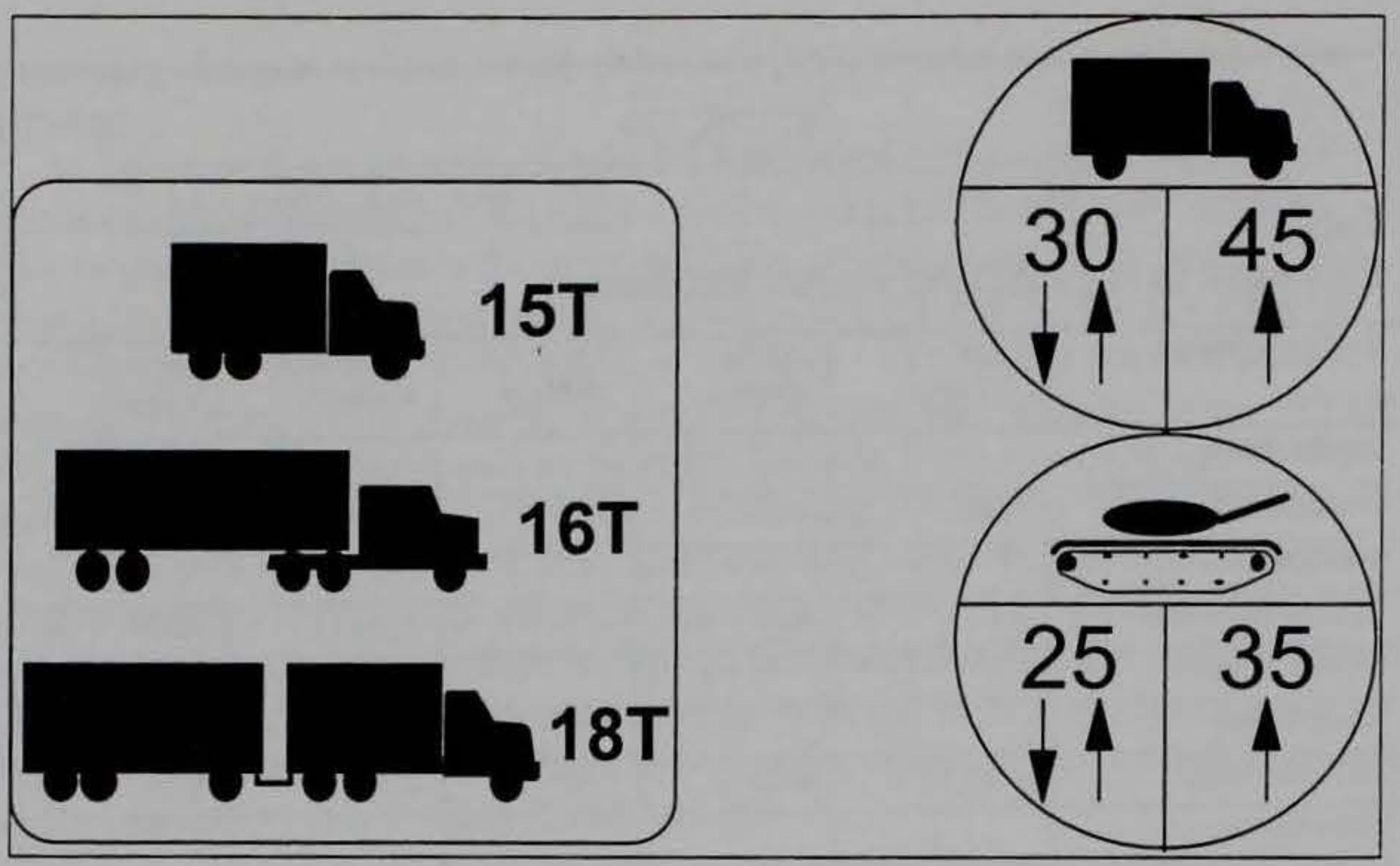

a. Civilian Posting Sign

b. Military Load Class Signs

Figure 2. Load posting signs resulting from load rating 


\section{Basic Concepts}

\section{Bridge Terminology}

Bridges are composed of many different members, referred to as "elements." The most basic elements of a bridge are the substructure, superstructure, and deck, as shown in Figure 3. The substructure supports the superstructure and deck, and consists of the abutments and intermediate piers or pile bents. These elements are supported on spread footings or piles. Substructure elements are generally oversized from the load-carrying standpoint since they must also withstand such additional forces as buoyancy, stream flow, debris and barge impact, and wind. As a result, they seldom control (i.e., limit the live load capacity) in a load rating analysis and are thus not discussed in detail herein. However, if for any reason the substructure is suspect, it should be checked. This is consistent with the recommendations of Reference [1]. An exception to this rule is timber bent caps and piles, where cap shear or lateral-torsional buckling of the exposed portion of the piles may control. These should always be checked.

One of the elements of the bridge superstructure will generally control in a load rating analysis. Typical superstructure elements and their proper terminology are shown in Figure 4. They are usually constructed from timber, steel (either rolled stock or built-up plate) or concrete (either reinforced or prestressed). A "girder" is the largest superstructure element, always spans between substructure elements, and most often runs longitudinally (i.e., parallel to the direction of traffic). A "truss" can be used in place of a girder and serves the same purpose. Trusses are basically an efficient method of making a very deep girder. Like the bottom and top flanges of the girder, the bottom and top chords of the truss act primarily to resist bending forces in the span. Likewise, the vertical and diagonal truss members act like the girder web to primarily resist shear forces. A "floor beam" always spans between either girders or trusses and most often runs transversely (i.e., perpendicular to the direction of traffic). A "stringer" is generally the smallest superstructure element, always spans between floor beams, and most often runs longitudinally.

Figure 4 shows all of the elements connected together at their ends. This is accomplished with either bolts, rivets (old bridges only), or welds. Although not shown, another means of connection is to lay the members over the top of each other; i.e., stringers on top of floor beams and floor beams on top of girders. 
The superstructure elements support the deck, which provides the surface over which the traffic travels. Decks are usually either timber (plank or laminated), steel grid, or concrete. They span either longitudinally or transversely, depending upon the supporting superstructure configuration. "Overlays", usually of asphalt or concrete, are often used on top of decks to provide moisture protection and a wearing surface. While not structural elements, they constitute a significant added dead load on the bridge and must be considered in the load rating. The same is true for such appurtenances (i.e., attachments) as railing, lighting, sidewalks, utilities, etc.

\section{Bridge Types and Load Paths}

\section{General}

Bridges are generally described in terms of their superstructure type and the primary material composing the superstructure. The bridges in the following paragraphs are described in this manner. From the analytical standpoint, it is also important to understand the manner in which the bridge carries vehicular loadings from the bridge deck down to its substructure. This is referred to as the bridge's "load path" and will also be discussed for each bridge type in the following paragraphs.

\section{Slab Bridges}

One of the most basic bridges is a slab bridge, as shown in Figure 5. Unlike all other bridge types, the deck of a slab bridge is the only element composing the superstructure. As demonstrated in Figure 5, the load path is very simple. The wheel loadings are carried through the slab, in a longitudinal direction (parallel to traffic), directly out to the substructure supports for the slab bridge. Because this type of bridge spans longitudinally between its supports, the main reinforcing in a slab bridge also runs longitudinally.

\section{Box Culverts}

A box culvert (Figure 6) is basically an extension of a slab bridge, where the top slab (or roof) is made integral with its substructure supports, which consist of the culvert walls and floor. Since they are integral, all of the elements act together as a frame to support the loads. As shown in Figure 6, loads are distributed to the box culvert elements only through the surrounding soil. The degree to which wheel loads are spread out over the top slab depends primarily upon the amount of soil cover. In addition to wheel loadings, each of the culvert elements must also support the loadings imposed by the surrounding backfill. 


\section{Multi-Girder Bridges}

Multi-Girder bridges are a very common modern bridge type. Multiple girders span longitudinally from substructure- to substructure element. The girders may be timber, steel, or concrete (reinforced or prestressed). A deck, usually timber or reinforced concrete, spans transversely between the girders.

The load path for these bridges is demonstrated in Figure 7. In this figure, typical multi-girder bridge has been separated into its separate elements. It can be seen that a vehicle may be at any position on the bridge deck. For load rating purposes, the vehicle must be located at the position on the deck (both longitudinally and transversely) to produce the worst-case loading for each of the elements to be rated. Note that the worst-case position for the deck rating will not be the worst-case position for the girder rating. The positions will also be different for consideration of moment or shear effects. The exact manner in which to place loads in order to maximize load effects will be discussed in detail in Chapter 3.

Referring to the end view of Figure 8, it can be seen that the deck serves to spread out the wheel loads, effectively transmitting them over and down to the girders. In the side view it can be seen that the deck also serves to distribute the wheel load out in a longitudinal direction. However, this effect is generally ignored in load ratings. The girders share in the loads to varying degrees, with one carrying more of the load than the others due to its closer proximity to the applied loads vary. This girder will be the "controlling girder"; i.e., the bridge will only be as strong as the member with the most load or the weakest member. The exact amount of load that the controlling girder must carry is determined by a "distribution factor", which in the following section.

A timber multi-girder bridge is demonstrated in Figure 9. This type is very common on many military installations. A more common name for it is "timber stringer bridge." However, in keeping with the terminology discussed above, it should actually be referred to as a timber multi-girder bridge since the superstructure beams span from substructure to substructure. Long bridges of this type, over multiple pile bents, are also referred to as "timber trestles." The decks of these bridges are almost always constructed from transversely-laid timber and are very often overlaid with sacrificial "treadways" to provide a protective wearing surface.

A steel multi-girder bridge is shown in Figure 10. While inconsistent with the terminology used herein, this type is also often referred to as a "steel stringer bridge." The deck types may of course vary; but that shown in Figure 10 is reinforced concrete and is the most common for steel multi-girder bridges. These decks act as continuous one-way spans across the tops of the girders. The upper steel flanges may or may not be embedded into the concrete deck. If fully embedded, the flange is considered to be fully braced against lateral-torsional buckling (discussed later). In addition, the concrete deck may be made to act compositely with the steel girders through shear studs on top of the girders, referred to as "composite construction." The shear studs serve to transfer horizontal shear stress, and thus longitudinal bending stresses, between the girders and the deck, allowing them to both share in carrying the superstructure loads.

The extent to which the composite section shares in the superstructure loads will depend upon whether the girders were "unsupported" or "supported" during construction of the bridge. The most common method of construction is 
unsupported, wherein the girders alone support their own weight plus that of the wet deck concrete prior to curing of the deck concrete (i.e., before the deck and girders effectively become composite). In this case, the composite section is considered to only carry live loads and any "superimposed" dead loads such as asphalt overlays, railing, and utilities. If it is desired to utilize the composite section to carry all loads, then supported construction is used. In this method, the girders are fully supported along their length during bridge construction, keeping all stresses out of the girders until full composite action is achieved.

A concrete "tee-beam" or "tee-girder" bridge is shown in Figure 11 and is similar to the steel girder bridge described above, except concrete beams (either conventionally reinforced or prestressed) are used in place of the steel girders. Because they are poured monolithically with the deck, the concrete girders are effectively shaped like T's with the deck comprising the upper flange. The primary conventional or prestressed reinforcing will always run parallel to the direction of the girder.

A "prestressed girder bridge" is shown in Figure 12. Prestressed girders are very efficient and because tensile stresses are inherently low in them, cracking is practically nonexistent, which greatly improves durability. These girders are almost always precast and are prestressed in one of two ways: pretensioning or posttensioning. With pretensioning, the prestressing wires are tensioned by jacking against the ends of the wires prior to concrete placement. Once the concrete has cured, the ends of the wires are released from the jacks and the tensile stresses are effectively transferred into the girder. With posttensioning, the concrete is cast around the untensioned wires, which are generally separated from the concrete by ducts. Once cured and in place on the bridge, the prestress wires are tensioned by jacking against the ends of the girders. Once the girders are placed on their substructure support on the jobsite, the concrete deck is formed and cast on top of them. Most often, the girders have loops of reinforcing protruding out their top that act as shear studs to form a composite deck. As with the composite steel girder bridge described above, the composite action may be for live load only, depending upon whether supported or unsupported construction was used. It is also common to make these girders continuous over one or more supports after placement in the field. This can be accomplished through a variety of means, with the most common being external posttensioning at the girder ends or by making the deck continuous over the supports and providing negative moment reinforcing (usually not prestressed) in the deck itself.

A very efficient type of concrete girder bridge is the "concrete box girder." These take many shapes and may be single- or multiple celled. Two common shapes are shown in Figure 13. These bridges behave in the same manner as the other concrete girder bridges discussed above. They may be conventionally reinforced or prestressed (pre- or posttensioned). While they can be cast in place, they are most often precast. Because of their deep box-like shape, they are very good at resisting torsional forces and are thus good for bridges in curves.

\section{Distribution Factor}

The distribution factor (DF) accounts for the fact that vehicle loads are spread out transversely to all bridge members, which share in carrying the loads 
to varying degrees. This concept is demonstrated in Figure 14. This factor is one of the biggest variables in bridge analysis and greatly affects the results.

As demonstrated in Figure 14, there are several factors that affect the degree of distribution to members. Deck stiffness, determined by its material type and thickness has a significant effect. A non-stiff deck will essentially act like paper and will be ineffective in spreading the load well. A stiff deck will greatly spread the load, meaning each girder will carry a much smaller percentage of load; i.e., a small DF. The stiffness of the members supporting the deck (such as stringers) also affects the DF. Stiff members will act like hard points and attract more load than a softer member. Member spacing also has a significant effect on the DF. As members get farther apart, the wheel loads begin to appear more like point loads on simple spans. Obviously, tire and axle widths also contribute to this effect. The number of traffic lanes is also a factor. With two lanes of traffic, two wheel loads will effectively feed into the same stringer, whereas only one wheel load would have contributed if there were only one traffic lane.

The above discussion provides the concept of DFs and the variables that affect them. Specific values for DFs are provided in Reference [3] in Table 3.23.1. A study of this table will reveal that the same factors as discussed above are accounted for in the table. These values are quite generic in their usage and are thus conservative. DFs significantly affect the results of analytical load rating and thus their choice is very important. If more accurate and/or less conservative results are desired, a more accurate DF may be obtained through 3dimensional analysis or load testing of the bridge. However, in most cases, the DFs in Reference [3] will provide sufficient and conservative results. Use of DFs will be demonstrated in greater detail in Chapter 3.

\section{Two-Girder or Truss Bridges}

As opposed to the multi-girder bridges discussed above, the bridge in Figure 15 only has two main girders spanning from substructure to substructure. Because these girders support the entire superstructure, they are usually very large. The girders are most often constructed from built-up plates, but may sometimes be large rolled shapes. They support the "floor system", which is composed of floor beams and stringers. The floor system in turn supports the deck. The bridge in Figure 15 is a "through-girder" bridge in that vehicles actually drive between the girders. This is most efficient when under-bridge clearances are restricted. When this is not the case, another common method is to place the floor system and deck completely on top of the deep girders.

As previously discussed, a truss bridge (Figure 16) works in the exact same manner as the girder bridge discussed above. The lighter-weight truss allows for spanning of larger gaps. As shown in Figure 16, a truss is composed of top and bottom chords that are connected together by vertical and diagonal members. These members support the floor system. Lateral bracing is also provided to keep the longitudinal truss members parallel as they undergo lateral forces from wind.

The general load path for a girder or truss bridge is shown in Figure 17. With these bridges, the loadings are spread out and transferred through the deck into the stringers. The stringers span between and are supported by the successive floor beams. As a result, the floor beams only receive loads through 
the end reactions of the stringers (i.e., their supports). Floor beam loadings thus appear as a series of point loads (at the spacing of the stringers) over the length of the floor beam. Because they are only loaded through the stringers, worst-case floor beam loadings are obtained by maximizing the stringer reactions. The exact manner in which to place loads in order to maximize load effects will be discussed in detail in Chapter 3.

Floor beams are supported at their ends by the longitudinal girders or trusses. As a result, the girders or trusses only receive loads through the support reactions of the floor beams and thus, worst-case loadings are produced on these members by maximizing the support reactions on one end of the floor beams. This is accomplished by placing the vehicle longitudinally on the bridge to produce the worst-case bending moment or shear and transversely on the bridge to produce the highest floor beam support reactions on the controlling girder or truss. The exact manner in which to place loads in order to maximize load effects will be discussed in detail in Chapter 3.

\section{Railroad Bridges}

Railroad bridges have the same superstructure types as the vehicular bridges described above, except of course, their decks are different. As shown in Figure 18 , there are two types of decks for railroad bridges: "open" or "ballast". With an open deck, the crossties transfer the rail loads directly into the superstructure. With a ballast deck, the crossties are supported on regular railway ballast (rocks), which is contained within the some form of "pan." With this type of bridge, the regular railway ballast is just continued across the bridge. This makes for easy track maintenance, but makes inspection of the bridge superstructure very difficult.

The load paths in railroad bridges are very similar to those for vehicular bridges, except they are actually easier since the lateral position of loads is always fixed due to the rails on which the train must run. The load path for an open deck railroad bridge is shown in Figure 19. The rails spread the wheel loadings out longitudinally to the crossties, which transfer directly into the stringers. In most cases, the stringers are centered or symmetrically placed directly beneath the rails so as to keep bending and shear stresses very low in the crossties. From the stringers downward through the bridge, the load paths are the same as for vehicular bridges.

The load path for a ballast deck railroad bridge is demonstrated in Figure 20. The wheel loads are spread out longitudinally through the rails to the crossties, which are supported by the deep ballast. The ballast serves to spread the loads out uniformly down to the supporting deck and superstructure elements. Specific distribution factors and worst-case loading methods for these bridge types will be discussed in detail in Chapter 3. 


\section{Bridge Rating Guidelines and Criteria}

As previously discussed, there are numerous guidelines and criteria for the load rating of bridges. For military installations, specific doctrine for this purpose is found in Army Regulation 420-72, entitled, "Surfaced Areas, Railroad Tracks, Bridges, Dams and Associated Appurtenances." This regulation should always be the starting point for any load rating analysis. It will provide the necessary references to follow. For vehicular bridges, the AR stipulates the use of the analytical criteria set forth by the American Association of State Highway and Transportation Officials, specifically, that in the "Manual for Condition Evaluation of Bridges" [1]. This manual contains the most recent and state-ofthe-art criteria for highway bridges and has thus also been adopted for military installations. For steel and concrete vehicular bridges, the AR recommends the use of the recently developed "Load and Resistance Factor Rating" (LRFR) method, as opposed to the more familiar "Allowable Stress" method or "Ultimate Strength" method (discussed in Chapter 4). Guidelines for the LRFR method are provided in the AASHTO manual entitled, "Guide Specifications for Strength Evaluation of Existing Steel and Concrete Bridges" [2]. This method has not yet been applied to timber bridges, and thus the conventional Allowable Stress method must still used for them. References [1] and [2] provide only a limited amount of detailed analytical criteria. For detailed criteria, these references refer the user to the AASHTO design manual entitled, "Standard Specifications for Highway Bridges" [3].

Specific vehicular live loadings to be used with the above criteria must be found in two different locations: Reference [1] specifies the civilian vehicular loadings and Reference [4] specifies the military wheeled and tracked vehicular loadings. It is very important to emphasize that only the vehicular loading in Reference [4] should be used. The analytical criteria in this reference are intended for temporary bridges and thus have reduced safety margins that are not applicable to permanent bridges on military installations.

For railroad bridges, both analytical criteria and train loadings come from the American Railway Engineering Association (AREA) manual entitled, "Manual for Railway Engineering" [5]. Much of its analytical criteria are very similar to that for vehicular bridges as discussed above. Specific adaptation of the Reference [5] loadings to Army trains will be discussed in Chapter 3.

All of the above-mentioned references were adopted/modified from industryspecific criteria such as References [6] through [8]. While not specifically required for the load rating procedures discussed herein, they can provide greater insight to the origins of the criteria in References [1] through [4]. 


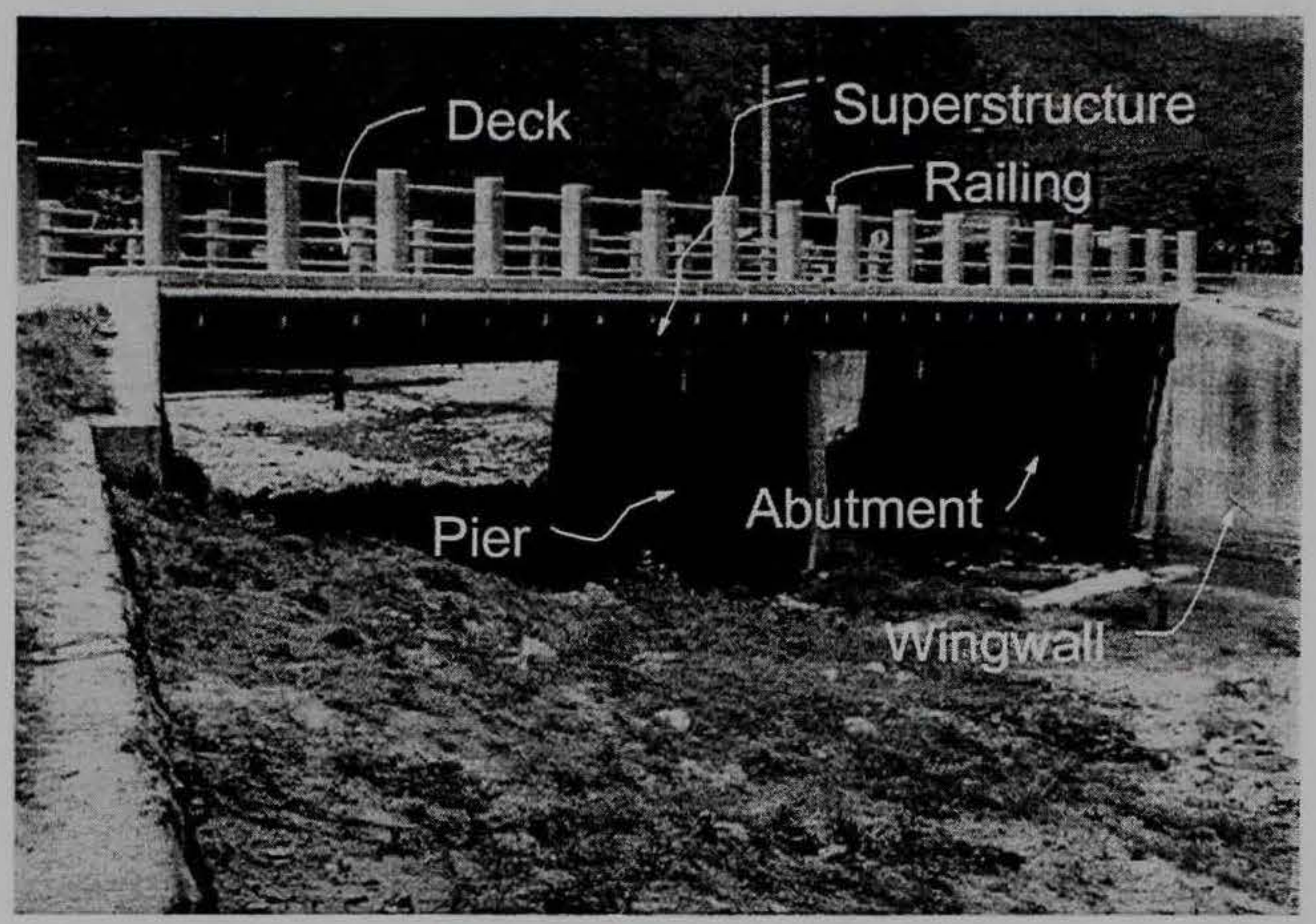

Figure 3 . Basic parts of a bridge

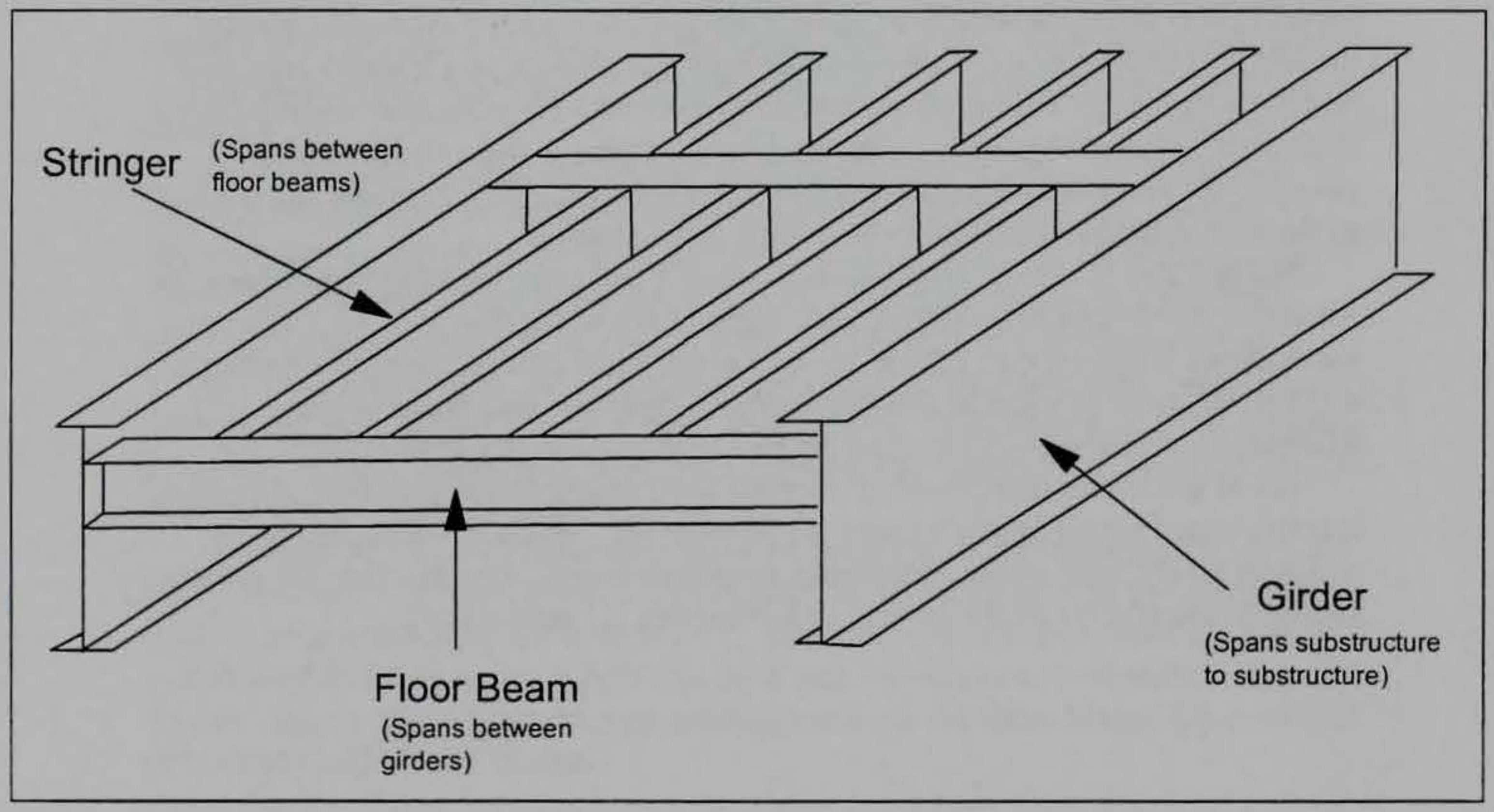

Figure 4. Superstructure elements 


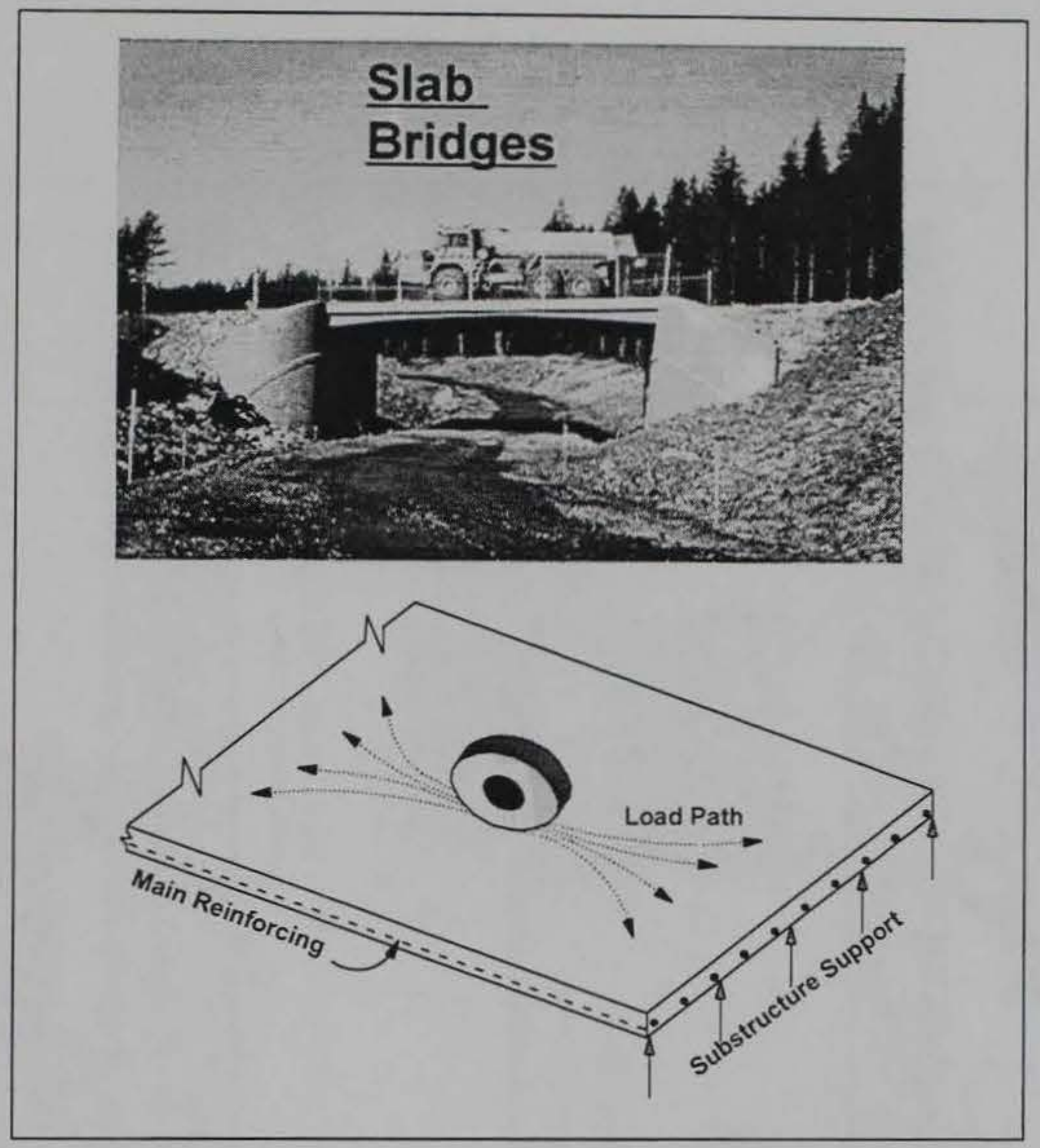

Figure 5. Slab bridges

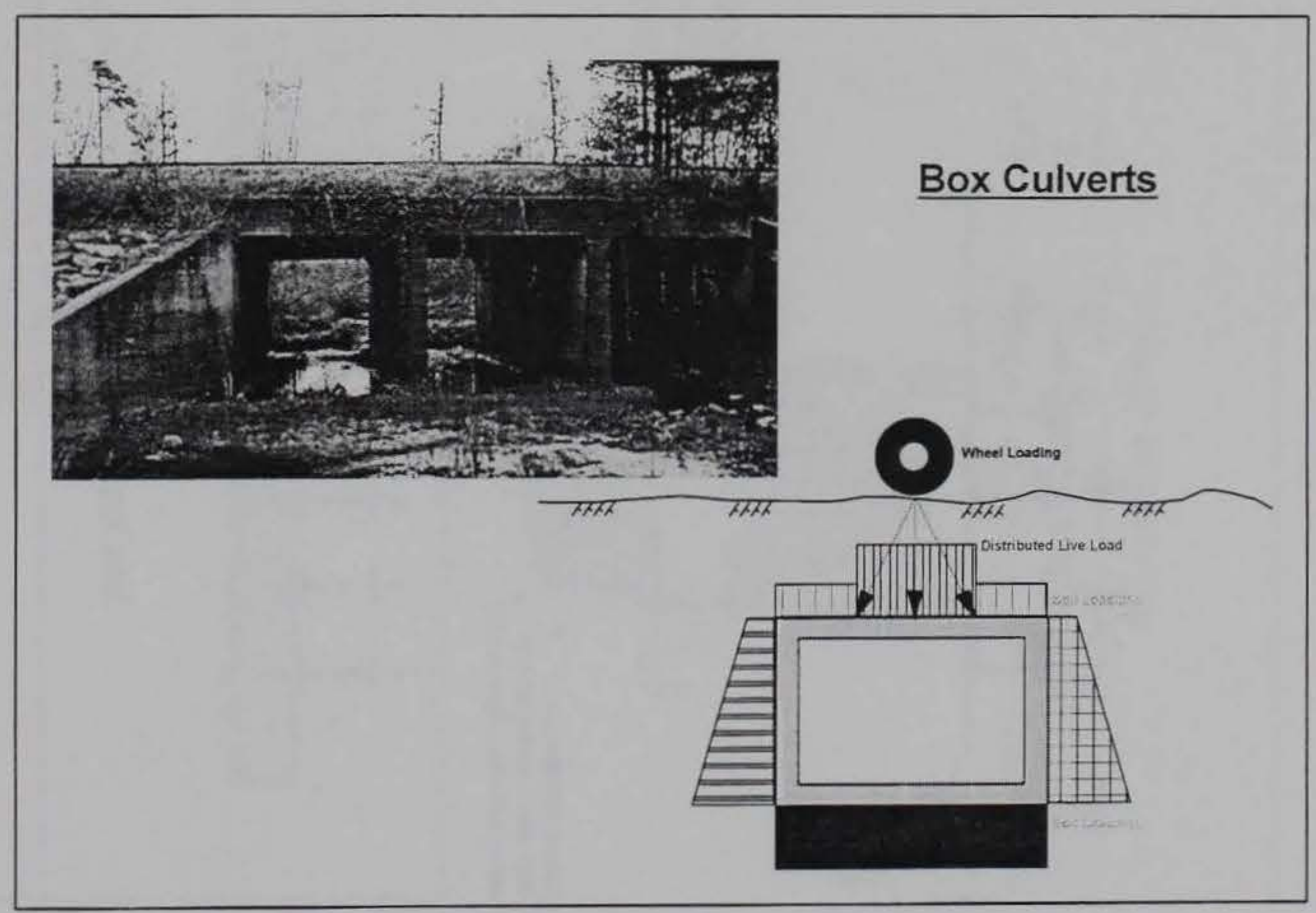

Figure 6. Box Culverts 

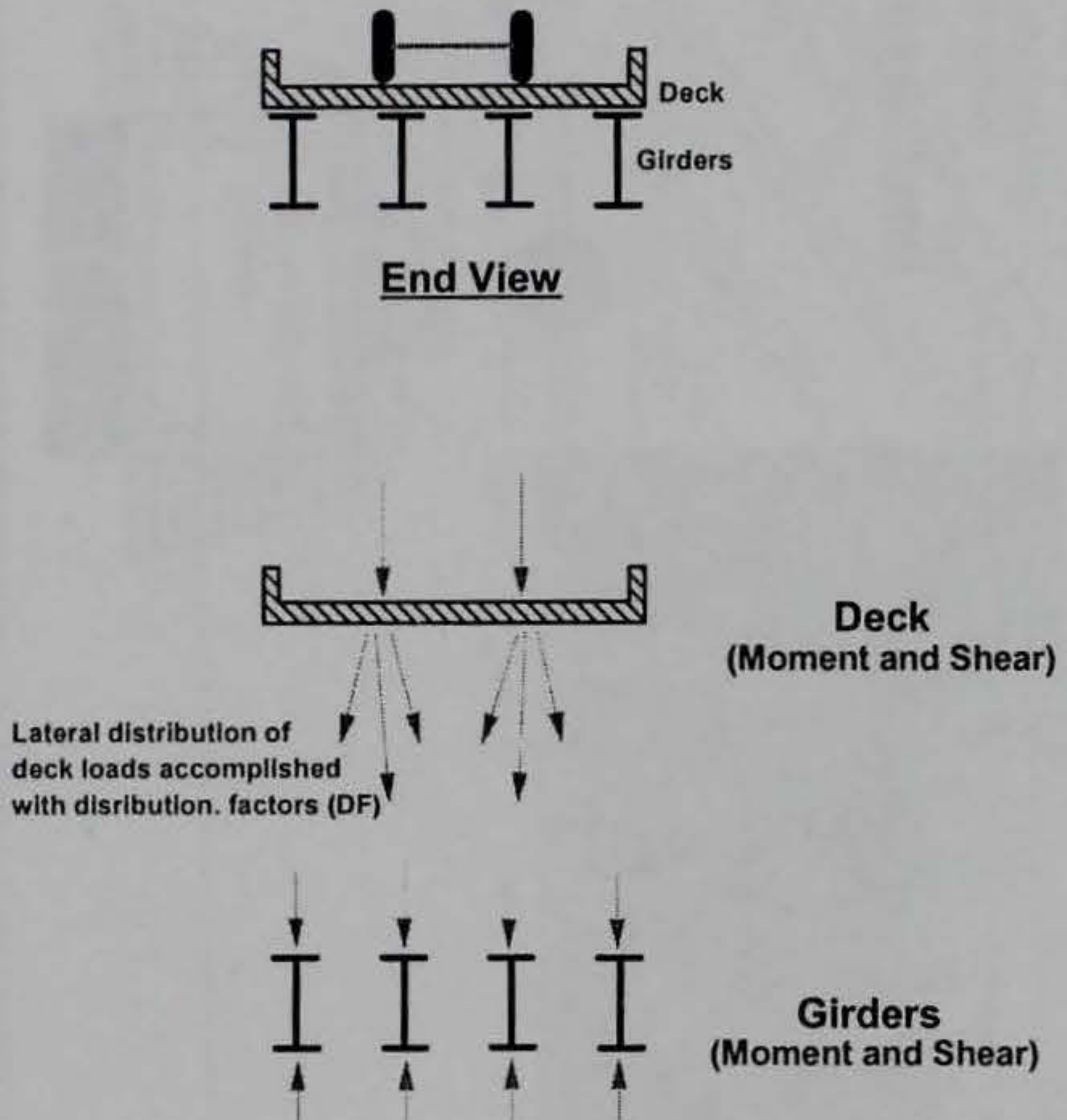

End View

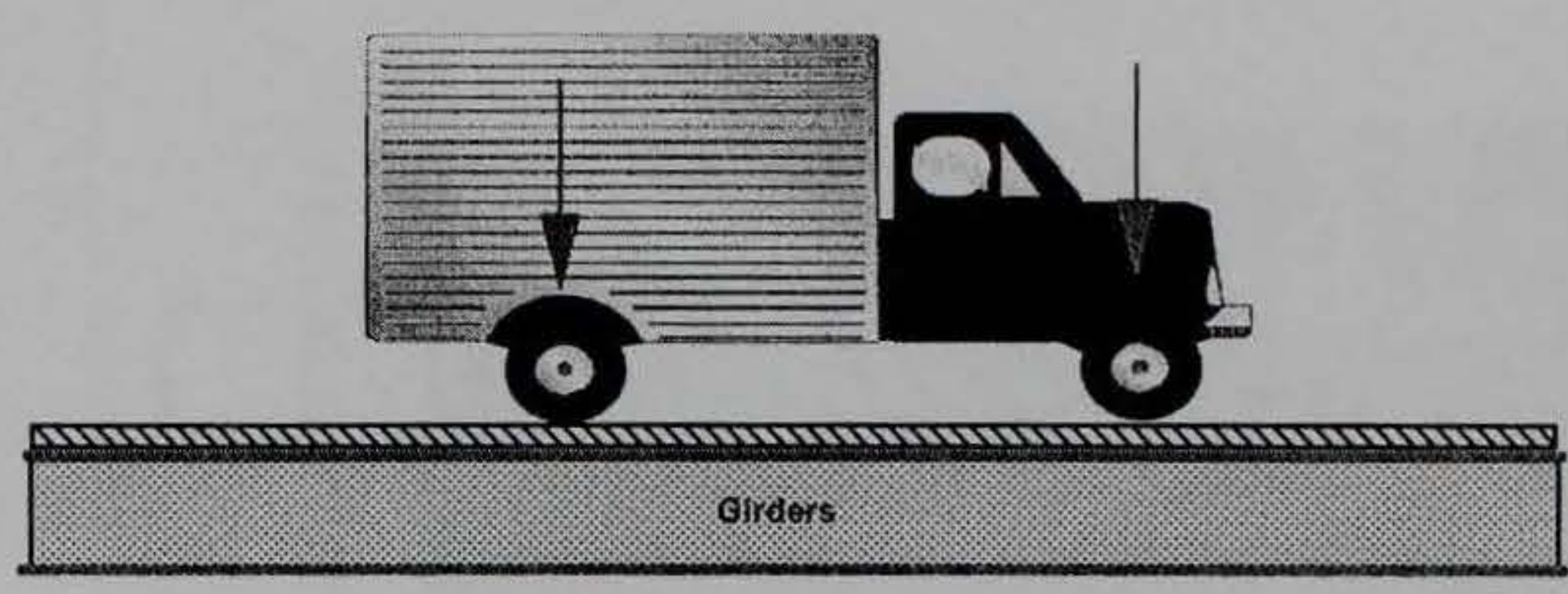

Side View

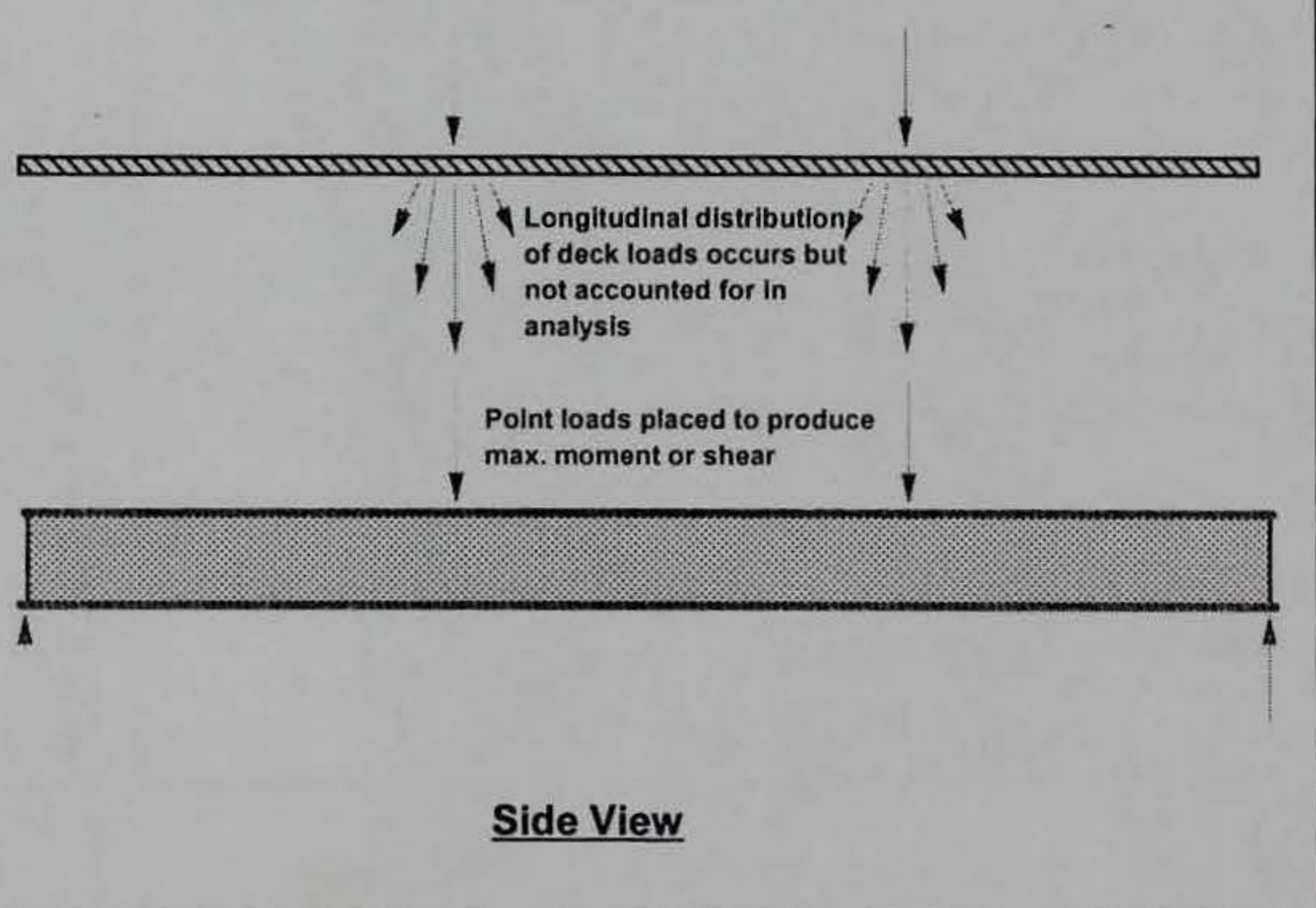

Figure 7. General load path for a multi-girder bridge 


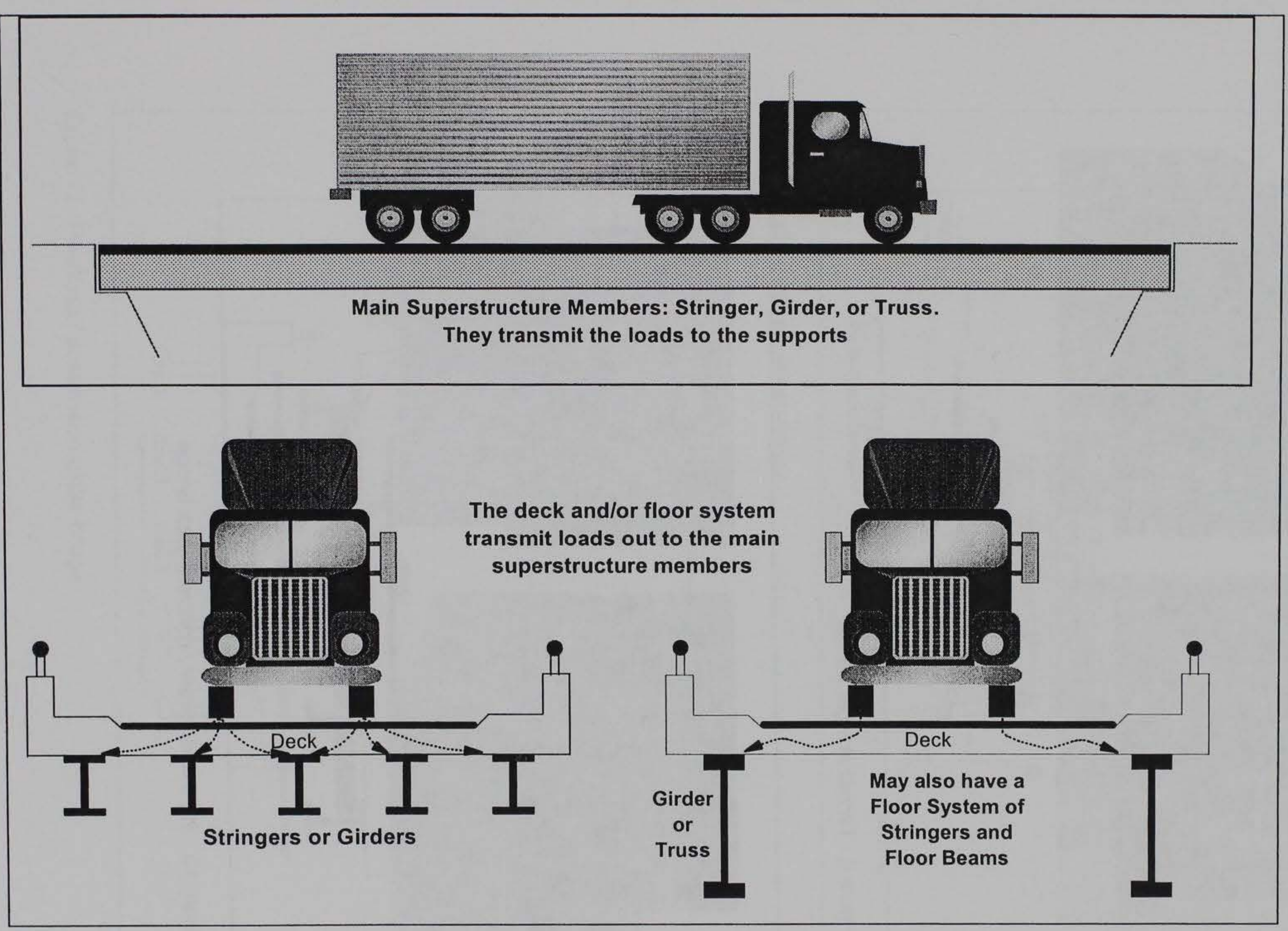

Figure 8. Longitudinal and transverse load distribution 


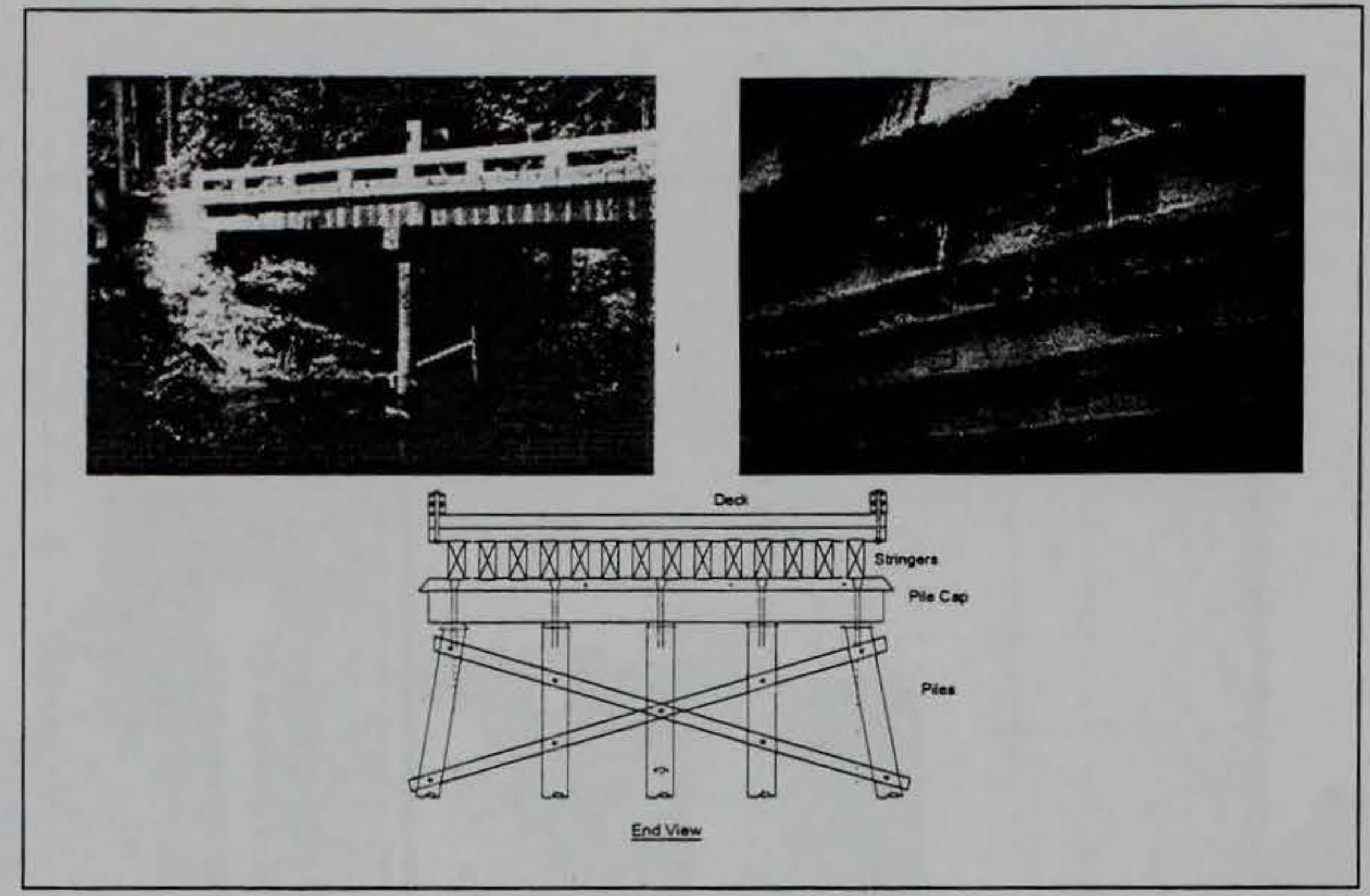

Figure 9. Timber stringer bridge

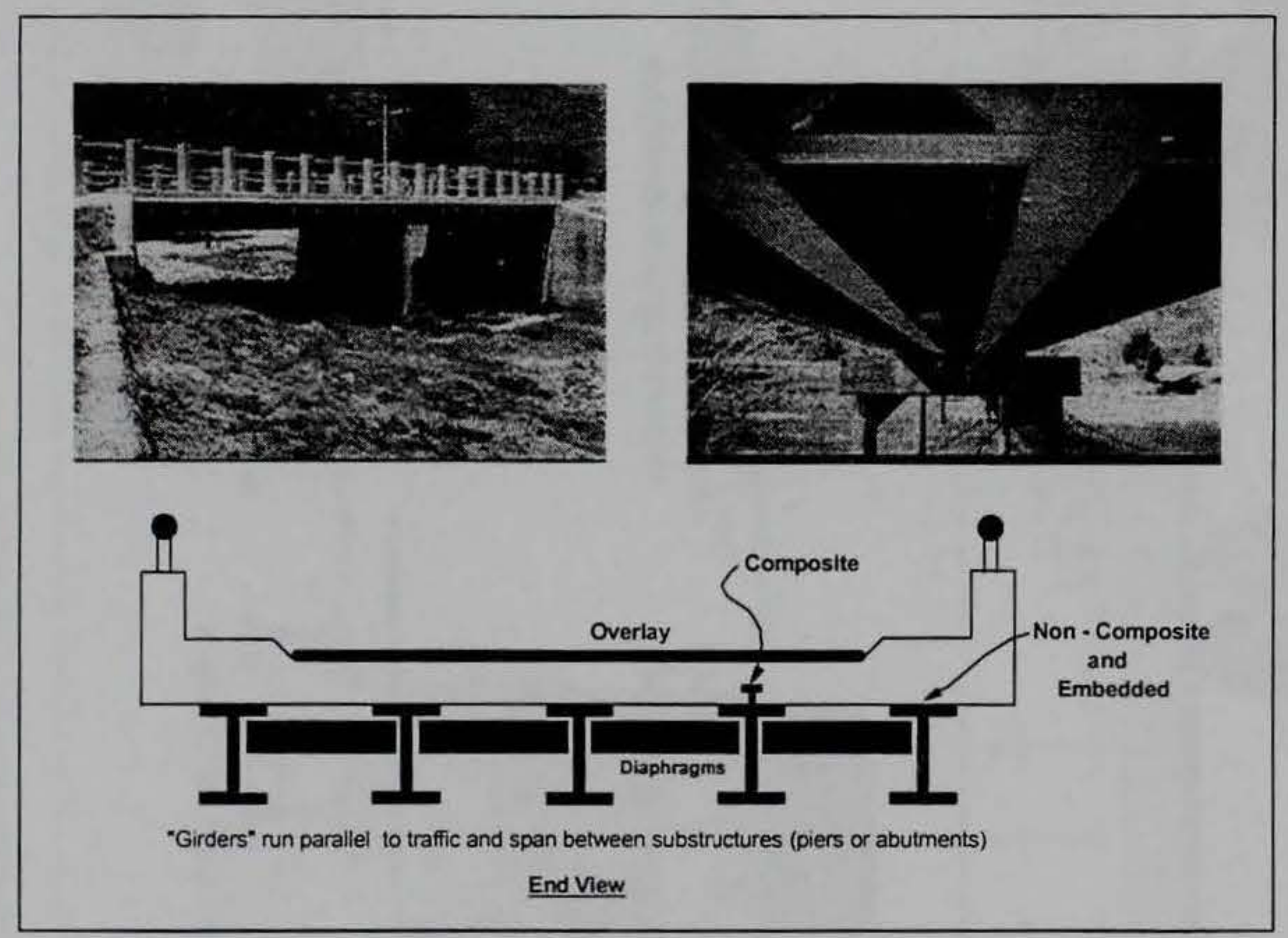

Figure 10. Steel multi-girder / concrete deck bridge 


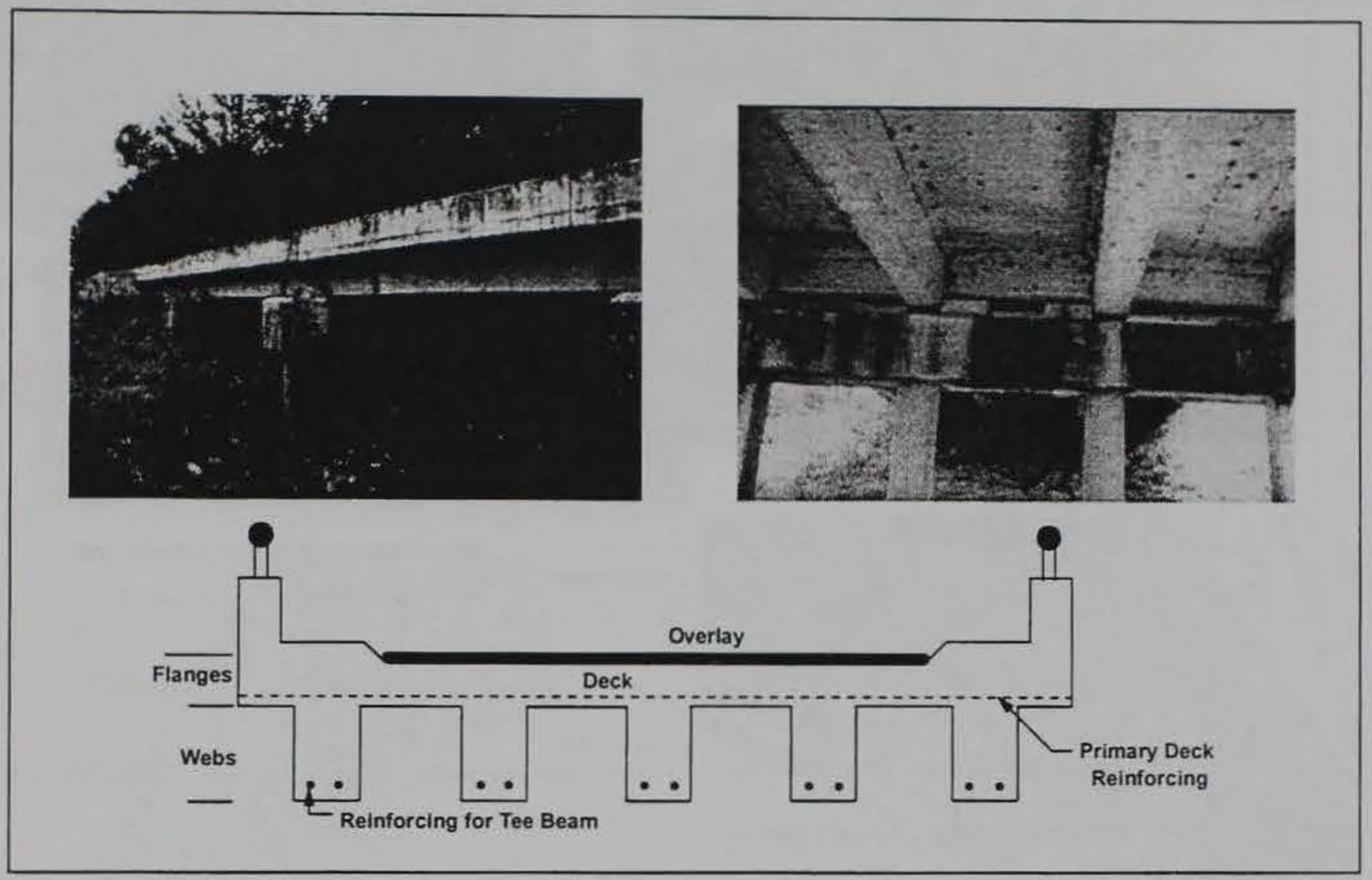

Figure 11. Concrete tee-beam bridge

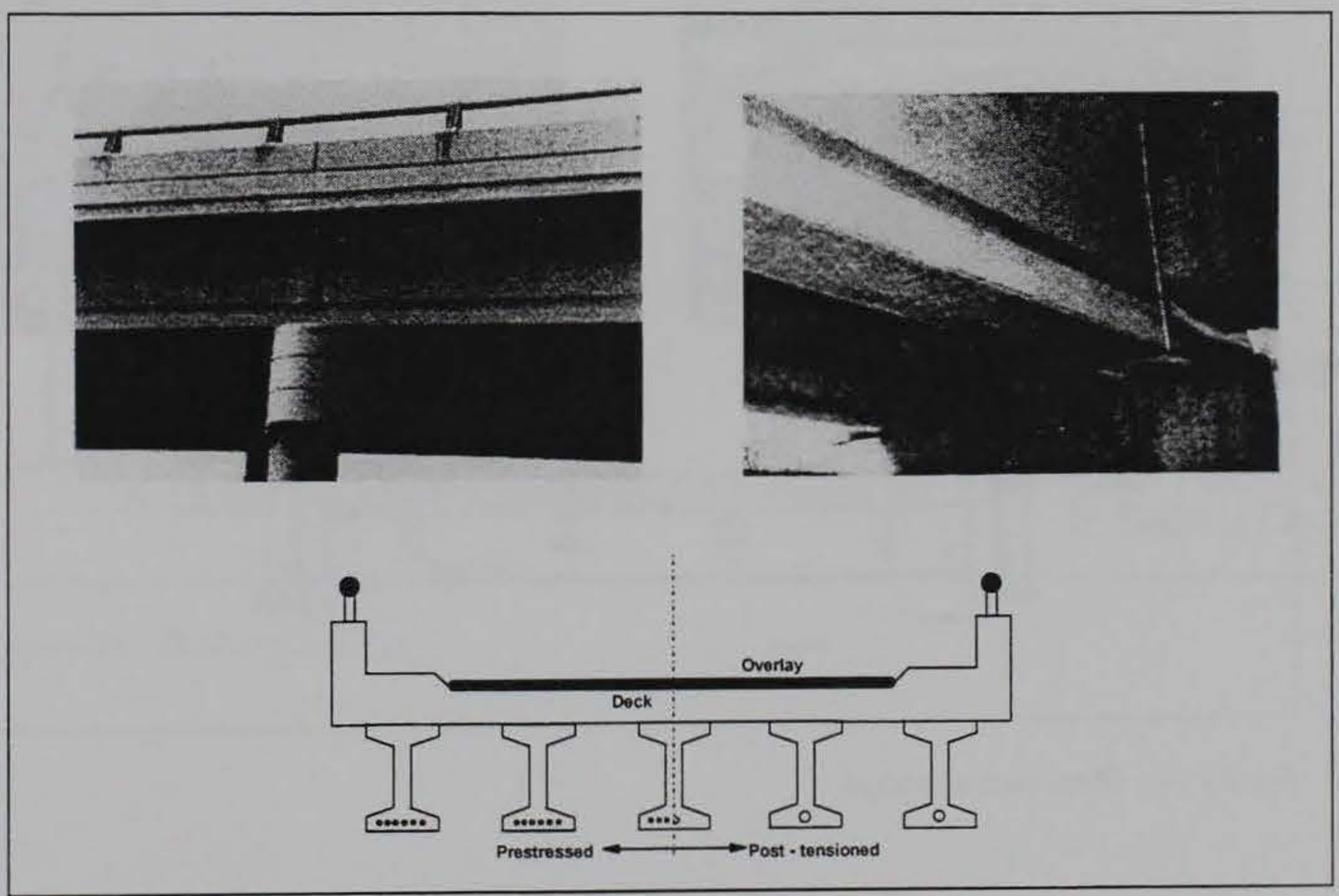

Figure 12. Prestress / posttension girder bridge 


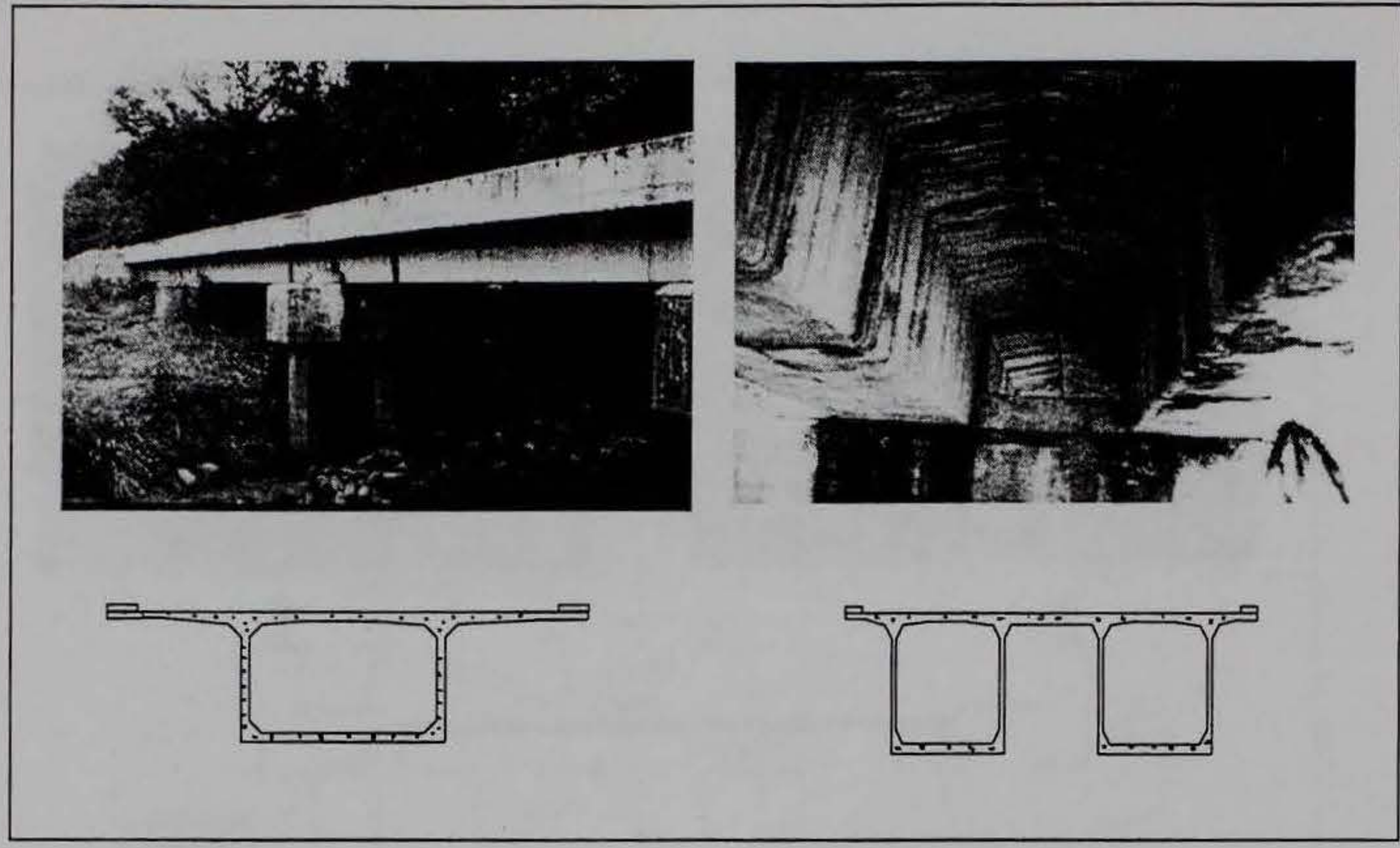

Figure 13. Concrete box girder bridge

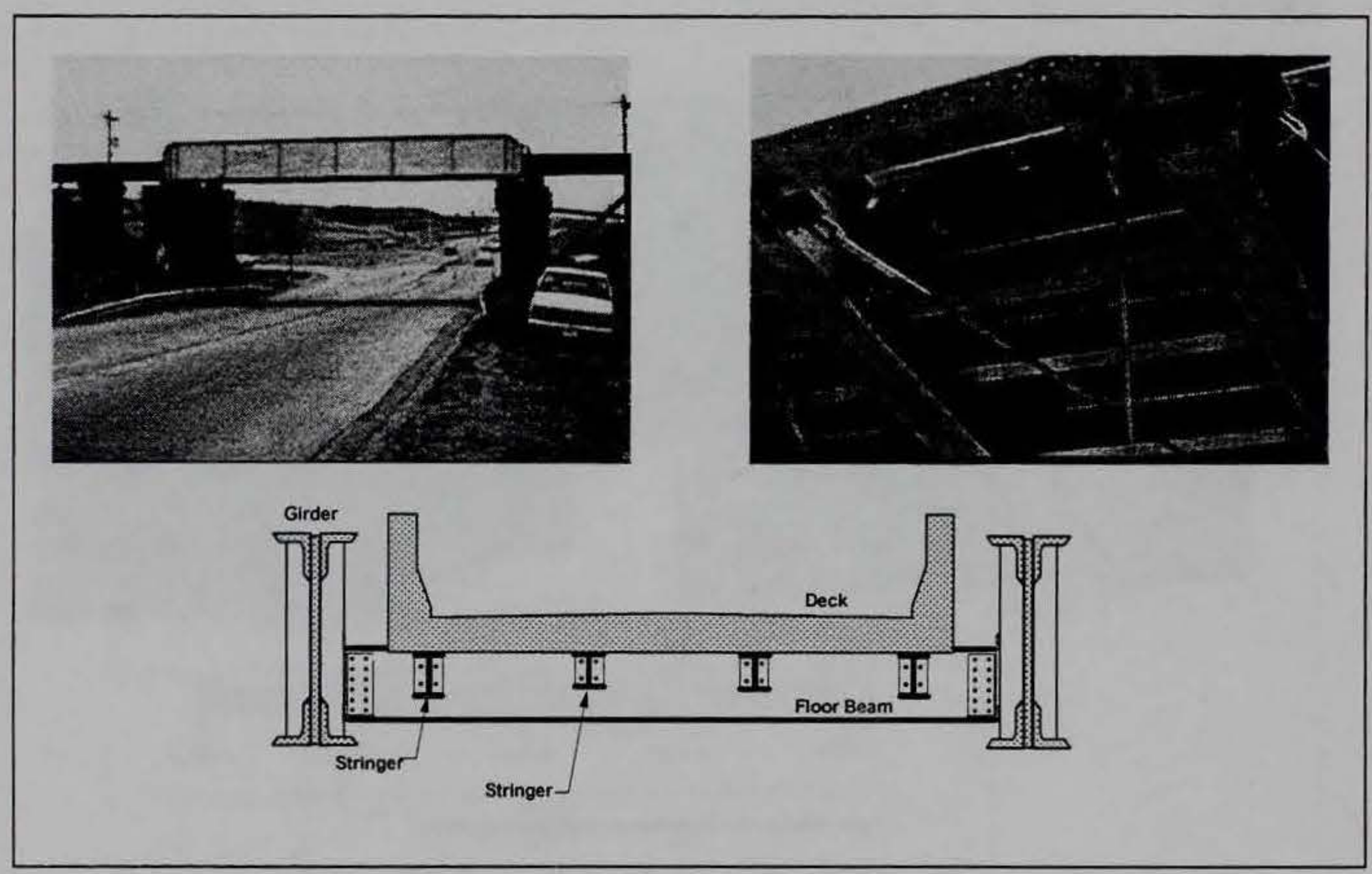

Figure 14. Steel girder bridge 


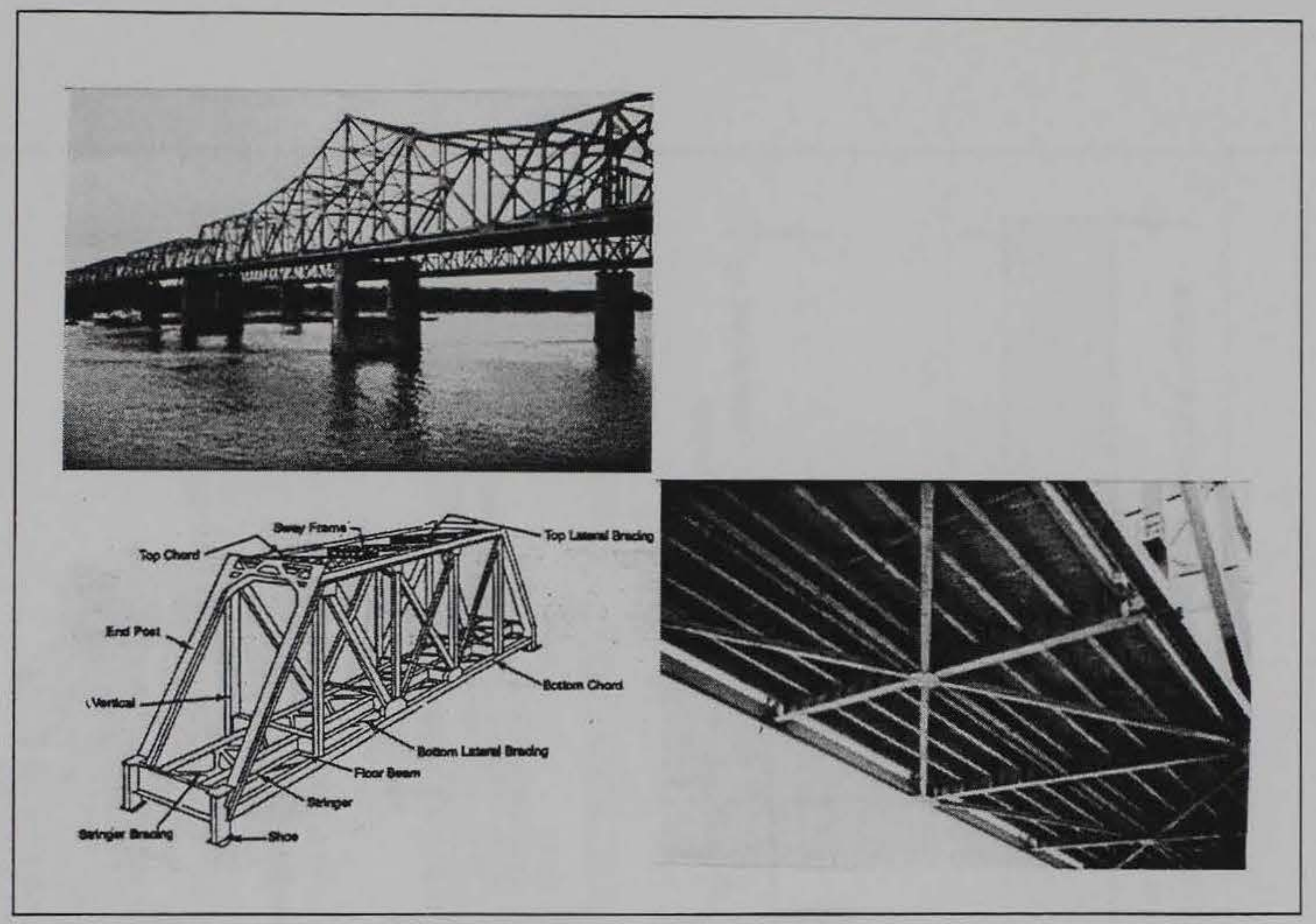

Figure 15. Truss bridge

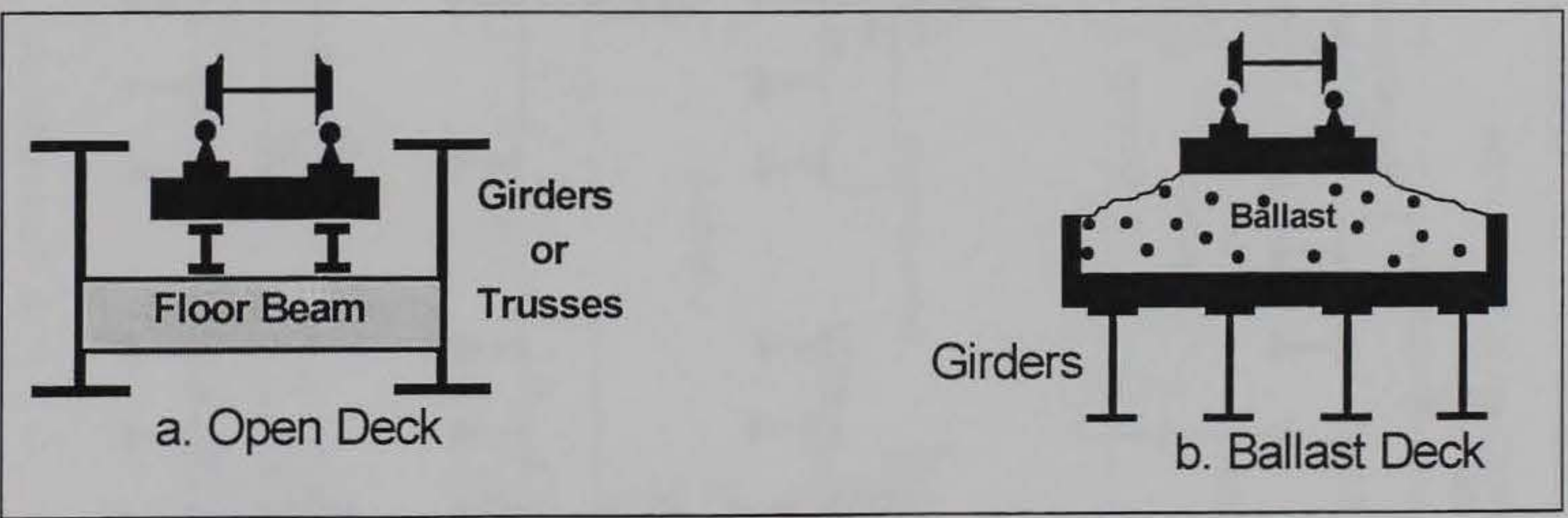

Figure 16. Railroad bridges 


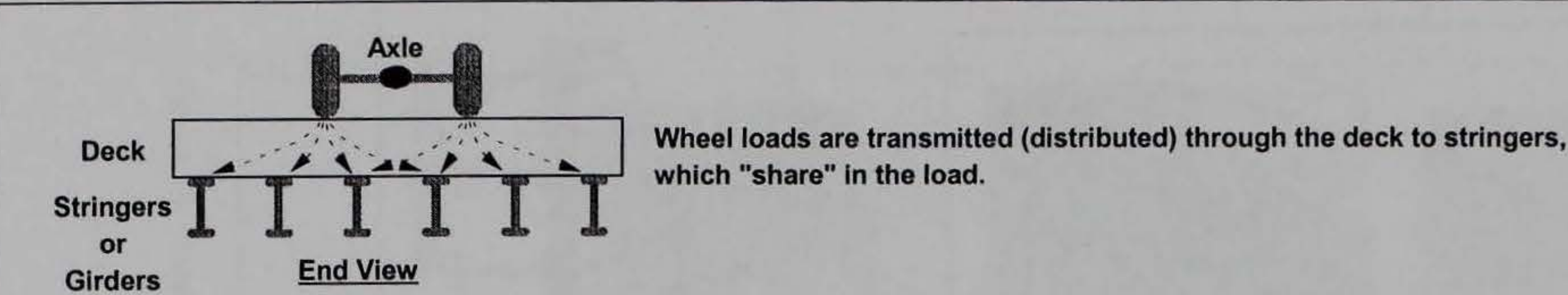

a. Concept
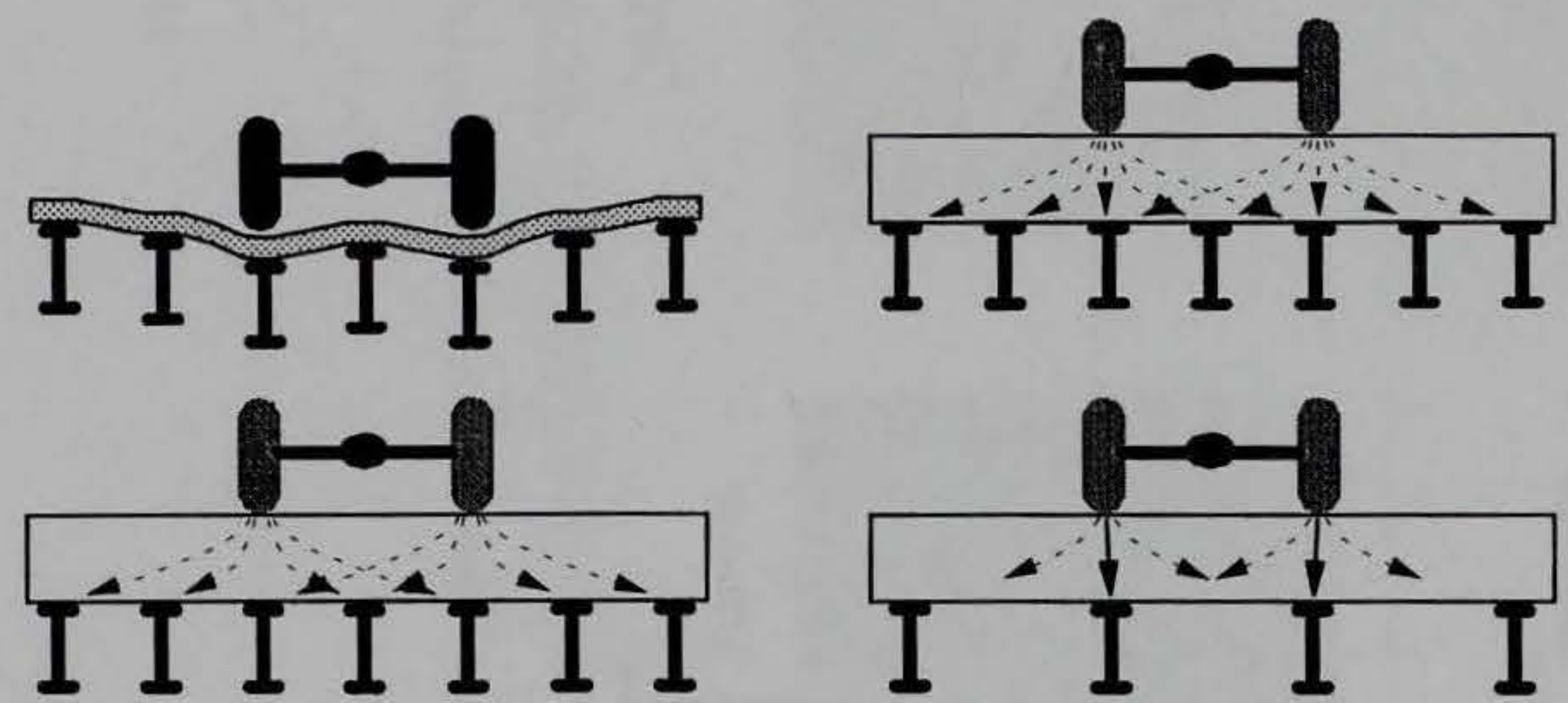

Deck stiffness: Determined by Type and Thickness

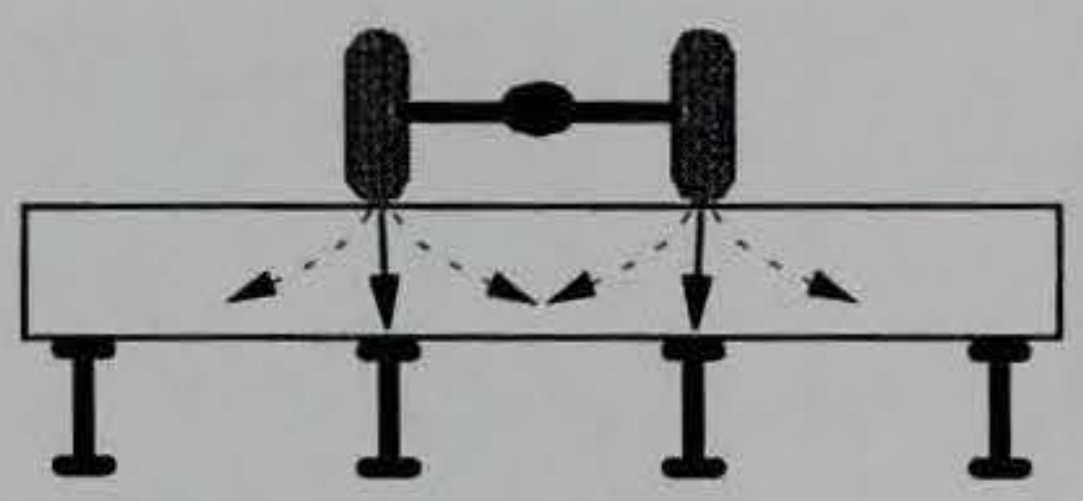

\section{Stringer spacing}
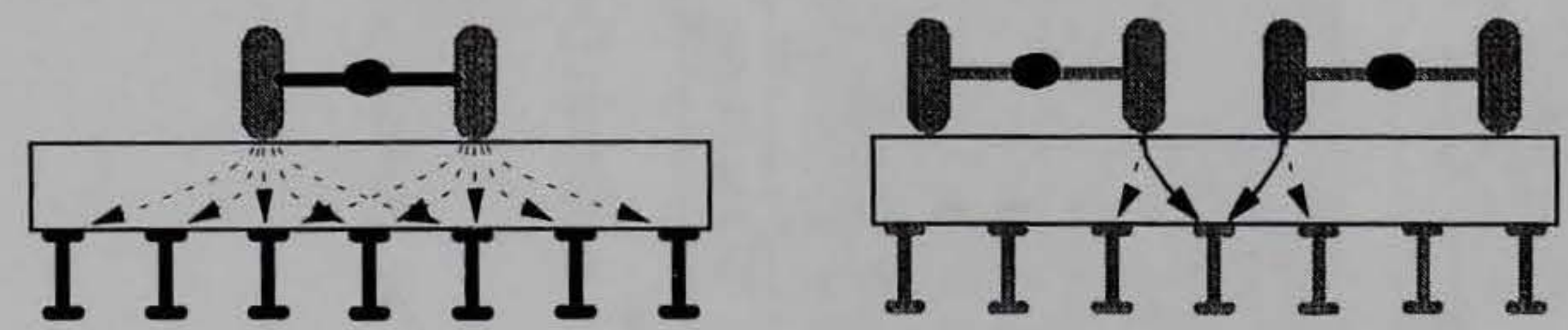

Number of traffic lanes

b. Factors Affecting Load Distribution

Figure 17. Transverse load distribution through decks 


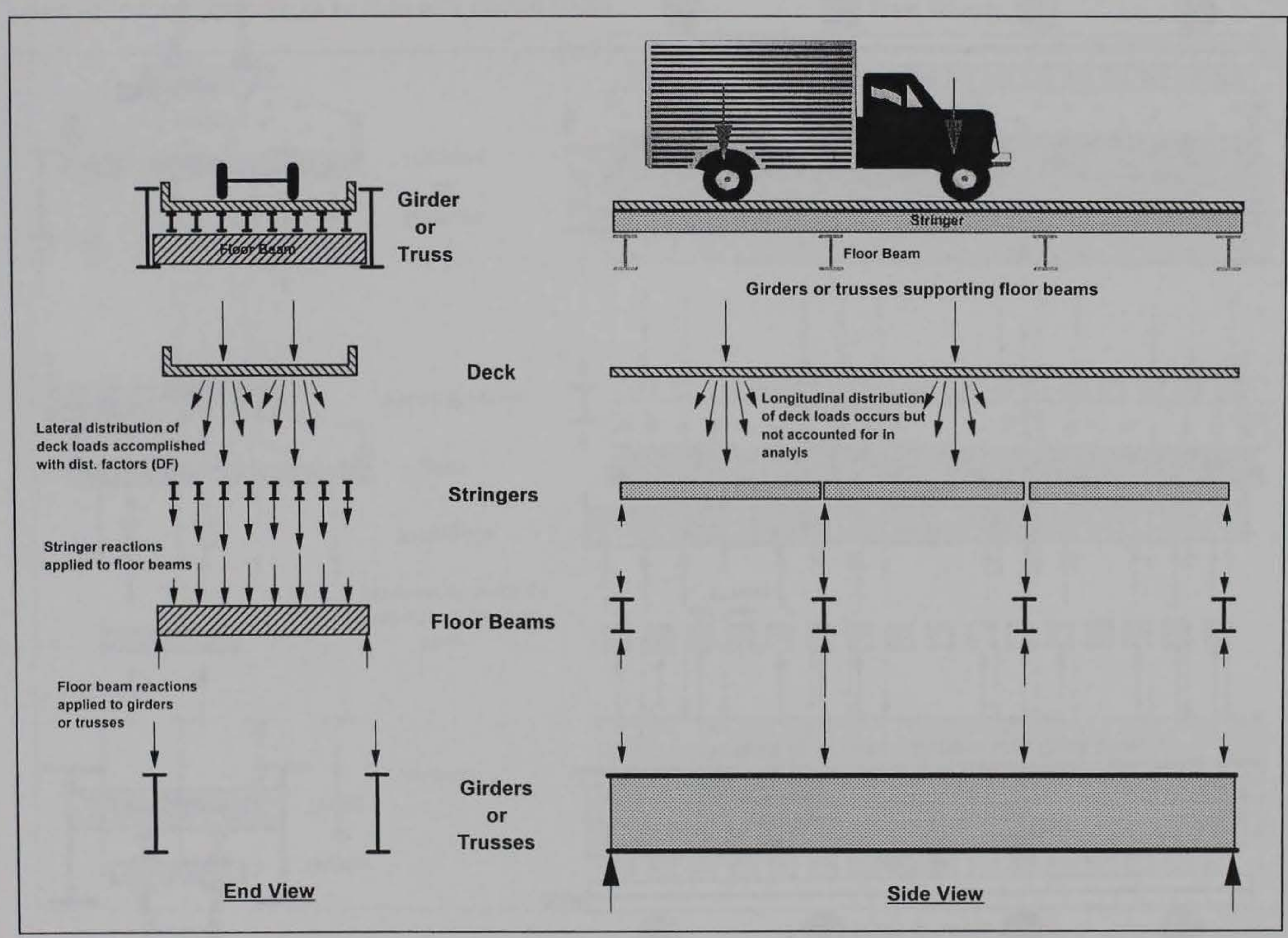

Figure 18. General load path for a girder or truss bridge 


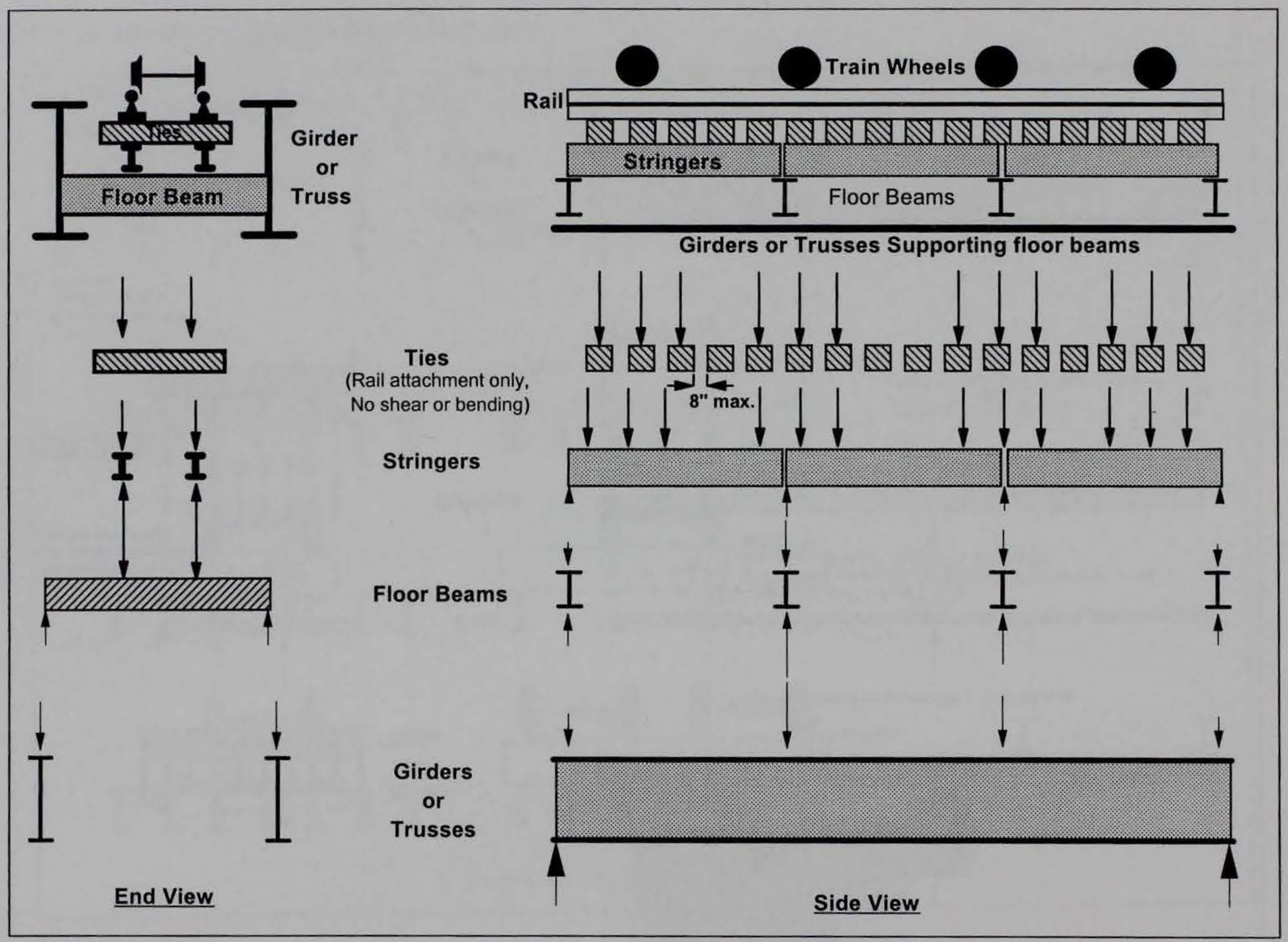

Figure 19. General load path for an open deck railroad bridge 

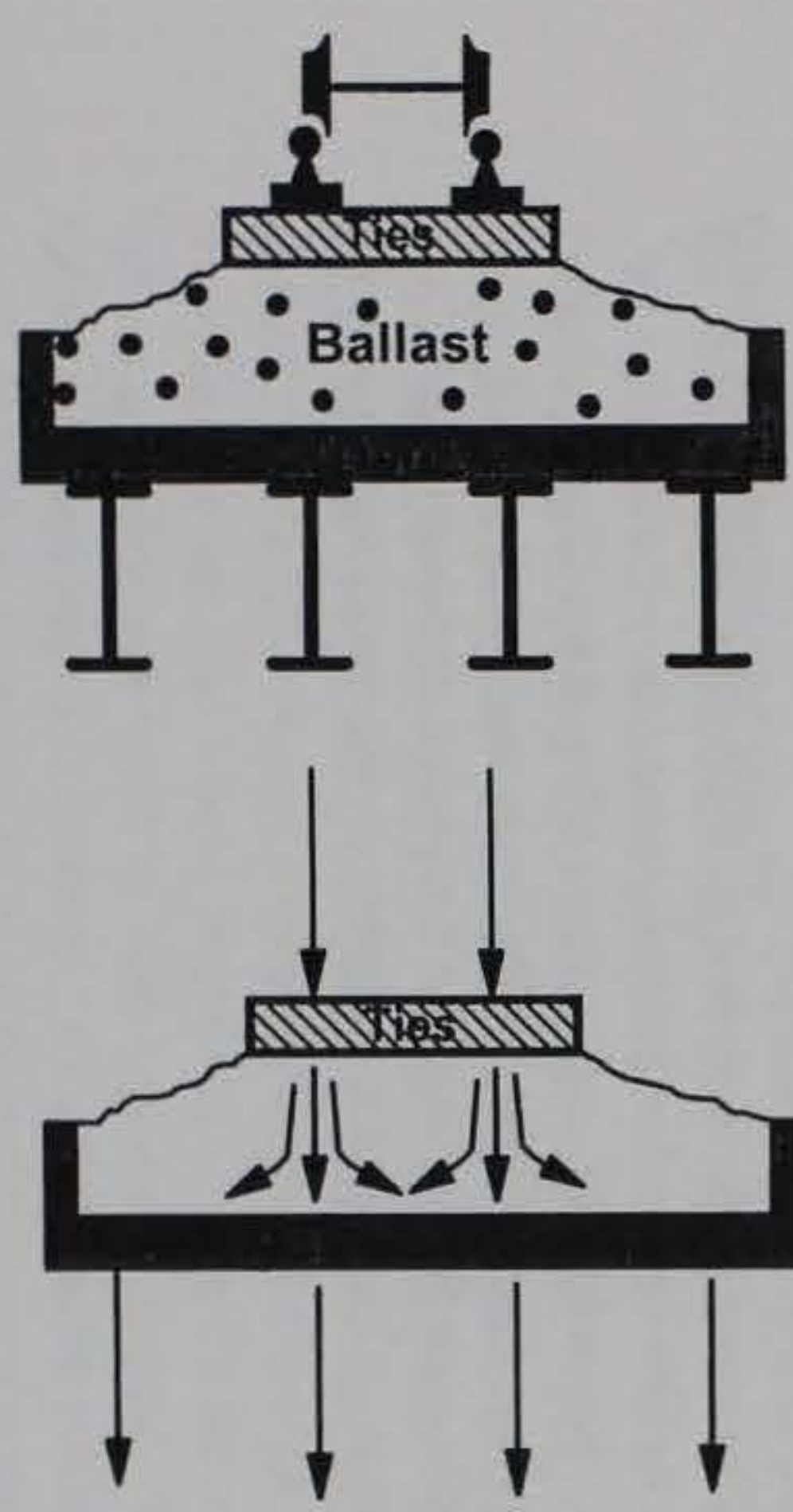

Deck

$$
\text { I I I I }
$$

Girders
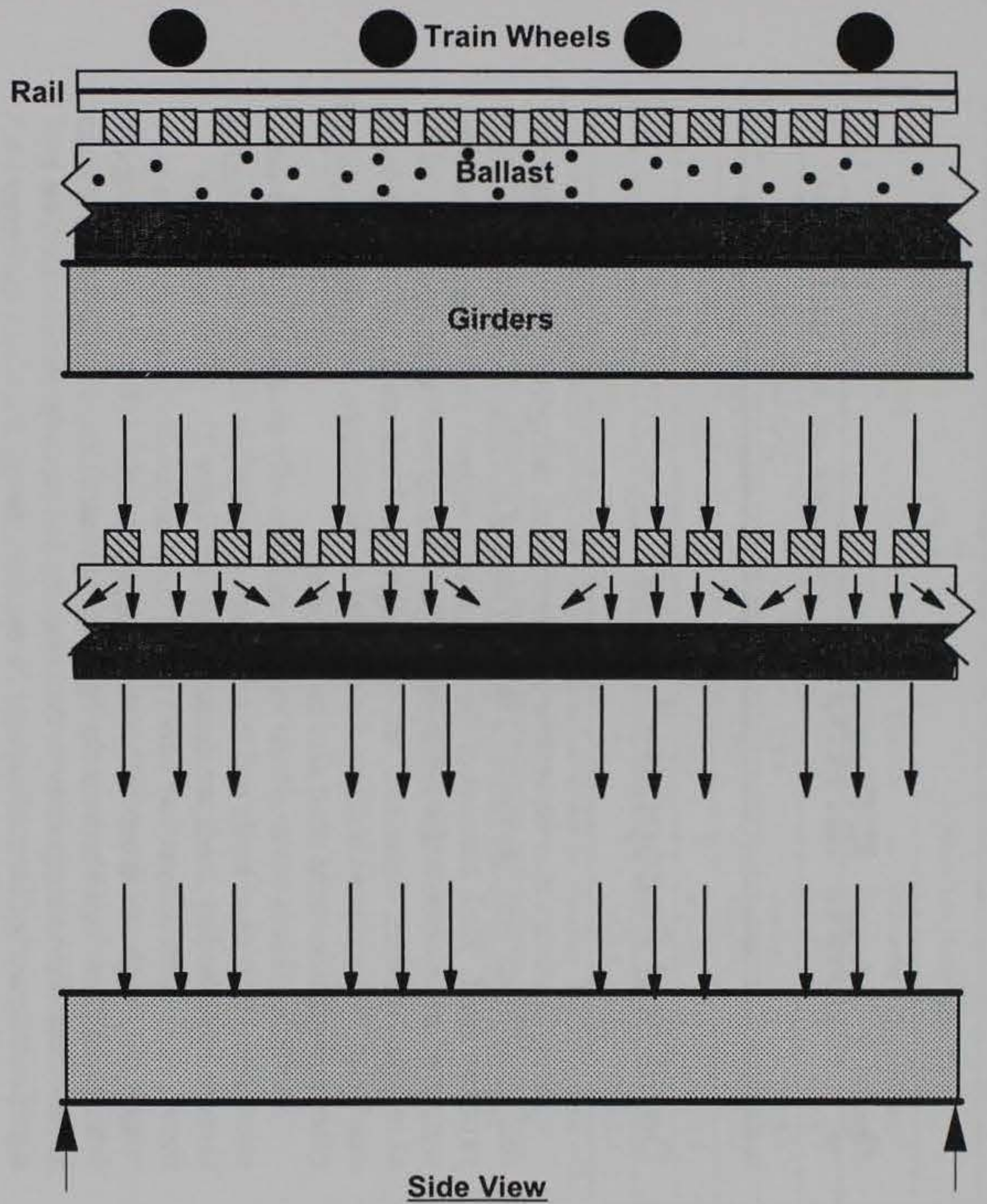

Figure 20. General load path for ballast deck railroad bridges 


\section{Load Effects}

\section{Dead and Secondary Loads}

Bridge loadings may be broken into three basic categories: dead loads, secondary loads, and live loads. The dead load of a bridge is the weight of the structure itself. Each element of the bridge must support its own weight plus the weight of any elements that it supports. The weights of all appurtenances, such as railings, utilities, curbs, etc., are often significant and must also be included as dead load. For railroad bridges, the weights of the railings, crossties, ballast, and other rail-specific items must also be included.

Secondary loads cover a wide variety and basically encompass all sources of stress other than dead loads and those from vehicular live loads. The main sources of secondary loads are demonstrated in Figure 21. Referring to this figure, expansion/contraction forces result from temperature changes and agerelated shrinkage and creep within the bridge elements. If members are properly detailed and bearings are properly designed and maintained, these forces should not develop. Wind loads on both the structure and passing vehicles may be a significant source of lateral loading. Buoyancy, stream flow, and ice/barge impact forces affect mainly the substructure elements. Braking/traction forces from vehicles can produce longitudinal forces in the bridge, while lateral centrifugal forces can result from vehicles traversing a curved bridge. Snow loads and earthquake loads are also considered secondary loads. While secondary loads have a significant impact on the design of bridges, they are considered intermittent loads and thus are generally not considered in load rating analyses on vehicular bridges, as per Reference [1].

Reference 5 does not differentiate between design loads and rating loads for railroad bridges. Therefore, unlike vehicular bridges, secondary loads must be considered for these bridges. Specifically, secondary railroad loadings include centrifugal forces from trains in curves, wind on the train and bridge, nosing of the locomotive (i.e., lateral steerage forces against the rails), and increased impact from steam locomotives. The specific references for these loadings are summarized in Table 2. 


\begin{tabular}{|c|c|c|c|}
\hline \multirow[b]{2}{*}{ Loading ${ }^{1}$} & \multicolumn{3}{|c|}{ Article \# in Reference 5} \\
\hline & $\begin{array}{l}\text { Timber } \\
\text { Chap. } 7\end{array}$ & $\begin{array}{c}\text { Concrete } \\
\text { Chap. } 8\end{array}$ & $\begin{array}{c}\text { Steel }^{3} \\
\text { Chap. } 15\end{array}$ \\
\hline Dead Load from track, ties, ballast, etc. & 2.5 .2 & $2.2 .3(\mathrm{~b})$ & 7.3.3.1 \\
\hline Centrifugal force & 2.5.4 & 2.2.3(e) & 7.3.3.1 \\
\hline Wind on structure ${ }^{2}$ & 2.5 .5 .1 & $2.2 .3(\mathrm{~h})$ & 7.3 .3 .5 \\
\hline Wind on Train ${ }^{2}$ & 2.5 .5 .2 & $2.2 .3(\mathrm{i})$ & 7.3 .3 .5 \\
\hline Nosing of locomotive ${ }^{2}$ & 2.5 .5 .3 & NA & NA \\
\hline Impact & NA & 19.3.4 & 7.3.3.3 \\
\hline
\end{tabular}

1. Reference 5 stipulates the use of these loadings for rating as well as design. However, their importance will be bridge and locale dependent. Thus, apply at the discretion of the engineer.

2. Article 2.5.5.3, Reference 5, stipulates: Because of the limited duration of these loads, lateral forces from wind and nosing need not be considered with stringers. Thus, these forces are only applicable to rails and lateral bracing.

3. Note that this is the only chapter that differentiates between rating and design loads.

\section{Live Loads}

\section{General}

Live loads consist of the moving transient traffic on the bridge, including cars, trucks, trains, and pedestrians. Since there are countless varieties of live load traffic on any bridge, generic representative loadings are defined for which the bridge can be designed and load rated. Bridges on military installations will be exposed to four basic live load types: civilian vehicles (cars and trucks); military vehicles (wheeled and tracked); trains, and pedestrians. The generic vehicles defined to represent these loadings are presented in the following paragraphs. While they must be inspected for safety and integrity, pedestrian bridges do not require load rating and are thus not discussed herein.

\section{Civilian vehicular loads}

Civilian vehicular loads include cars and trucks. Obviously, truck traffic will produce much heavier loads than cars, and thus trucks are considered the controlling loads for analysis. There are countless types, sizes, and weights of trucks on the roads today, and obviously a bridge cannot be analyzed for each one of the specific trucks expected to use the bridge. Therefore, Reference 1 provides the generic trucks shown in Figure 22 for use in bridge "rating" and "posting." Bridges must be both rated and posted. The distinction between rating and posting is discussed in the following paragraphs.

A bridge is rated in order to directly compare its existing load capacity to its original design capacity, and thus obtain an indication of its current state of deterioration. To obtain a direct comparison, the vehicles for which the bridge was originally designed must also be used in the load rating analysis. The most 
common rating truck shown in Figure $22 \mathrm{a}$ is referred to as the HS20. It is the same as that used for the design of U.S. and many foreign bridges. In addition, a load rating using the HS20 truck is required for input to the National Bridge Inventory (NBI), which is now a requirement for all installation bridges within the U.S.

The HS truck in Figure 22a was originally derived in 1944. It is a hypothetical vehicle intended to represent the heaviest truck loading on highway bridges. The axle loadings (in kips) and spacings (in feet) are shown in Figure 22a. For the HS20, the spacing of the additional axle varies between 14- and 30 feet in order to maximize the load effect on the bridge (discussed in a later section). The effects from the single HS20 loading must also be compared to the "lane loading" shown in Figure 22a. The lane loading represents the effect of multiple HS20 trucks on a span at one time and generally will not control for span lengths less than 150 feet.

The posting vehicles shown in Figure $22 \mathrm{~b}$ are used to actually determine the load limit that will be posted on the bridge. Rating vehicles are generally not used for this purpose. The posting vehicles are referred to as Type 3, Type 3-S2, and Type 3-3, and are intended to more realistically represent the actual trucks using the bridge. Many states have derived their own posting vehicles, referred to as "State Legal Loads." If an installation bridge is within a state that has its own legal loads, they should be used along with or in lieu of the posting vehicles shown in Figure 22b.

Based on the above descriptions, bridges with civilian traffic should be load rated for at least four different trucks: the HS20 for rating and NBI reporting purposes, and the three "Type" trucks (or equivalent state legal loads) for posting purposes. The maximum live load effects from these vehicles will be discussed in the following section and their use demonstrated in the load rating examples of the appendices.

\section{Military vehicular loads}

Military vehicles are quite different from civilian vehicles. They include both wheeled (i.e., rubber tired) trucks and tracked vehicles such as tanks. Because bridges on military installations must often carry high volumes of these vehicles, the Military Load Classification (MLC) must be determined in addition to the civilian load ratings discussed above. The MLC describes the maximum type and size of military vehicle that may safely use the bridge.

As with civilian vehicles, the hypothetical military vehicles shown in Figure 23(Reference [4]) have been defined according to a Standard NATO Agreement (STANAG). They were developed to represent all military vehicles used by the participating NATO countries. All real vehicles are related to the hypothetical vehicles through an analytical process (not discussed herein) involving the comparison of the bending moments and shears produced by the actual vehicle on various span lengths to those produced by the hypothetical vehicles. The real vehicle's MLC is placarded on its front grill in a specific location. The allowable MLC is also posted on all bridges that must carry military traffic. A specific vehicle may cross all bridges that have higher posted MLCs than itself.

The hypothetical vehicles in Figure 23 are grouped according to their "Class" (Column 1). For each Class, there is an associated hypothetical wheeled and 
tracked vehicle. For tracked vehicles, the Class directly relates to its total weight (in tons). For wheeled vehicles, the Class is not exactly the same as the weight, but represents a wheeled vehicle that produces a similar load effect (i.e., span moment or shear) to that of the same Class tracked vehicle. Specific axle loadings (in tons) and spacings for these vehicles are shown in Columns 2 and 3 of Figure 23. The maximum load to be expected for any axle on the vehicle is shown in Column 4. The maximum live load effects from these vehicles will be discussed in the following section and their use demonstrated in the load rating examples of the appendices.

\section{Special military loads}

In recent years, it has been found that some of the newer and larger vehicles in the U.S. inventory are not well represented by the hypothetical vehicles shown in Figure 23. While MLCs have been applied to these vehicles, their load effects (i.e., span bending moment and shear) only correspond to those from the specified hypothetical vehicle for spans within a very narrow range. The Heavy Equipment Transport (HET) System, used for hauling the M1 tank over roads, is a specific and one of the most extreme examples of this problem.

The HET has an assigned MLC of 95 . As for all military vehicles, this was determined by calculating the bending moments produced by the HET and overlaying these values onto the standard moment and shear curves from the hypothetical vehicles, as demonstrated in Figure 24. The highest Class to which the HET curve corresponds is Class 95 (linearly interpolated between the Class 90 and 100 curves) at span lengths of 200 feet and greater. The HET has therefore been assigned MLC 95. However, the HET moment curve only corresponds to this large of an MLC for spans greater than 200 feet. For shorter spans, which are much more common on military installations, it corresponds to considerably smaller Classes.

As an example, the bending moment actually produced by the HET on a 30 foot span corresponds to that produced by a Class 70 vehicle on the same span length (Refer to Figure 24). Therefore, if the stated MLC of 95 is used indiscriminately for the HET (as is often done), a bridge with a 30 -foot span will be designed and/or rated for the bending moment for a Class 95 hypothetical vehicle, which from Figure 24 is approximately 740 foot-kips. However, in actuality, the HET only produces a bending moment of approximately 560 footkips, which corresponds to an MLC of 70. This effect has been demonstrated in Figure 25, which shows the equivalent MLC for the HET on various span lengths.

The reason for the discrepancy can be understood when the HET and Class 95 hypothetical vehicles are compared as in Figure 25. Although they both have similar total weights ( 115.7 tons for the loaded HET compared to 110 tons for the Class 95), the HET is 21.75 feet longer and has four more axles over its length. Additionally, the loadings on each axle are lower. As a result of these differences, the HET loadings are better spread out over short spans. Only spans greater in length than 61.75 feet (the length of the HET) will see all of the HET loading at one time; i.e., the HET will not completely fit on spans shorter than this. 
To address the above discrepancy in a load rating for the HET, the Equivalent MLC chart in Figure 25 should be used. For the span length under consideration, determine the equivalent MLC for the HET on that span length. Use the actual moment and shear values for that MLC. This process will be demonstrated in the load rating examples in the Appendices.

As can also be seen in Figure 25, the HET has eight wheels across its trailer axles as opposed to four on the hypothetical vehicles. The additional wheels should serve to better distribute the trailer loadings out transversely to a bridge's longitudinal load carrying members (such as stringers and girders); i.e., the percentage of total load to each member, as represented by Distribution Factors, should be less. Research is underway to develop more accurate and generic DFs for the HET. But until these results are obtained, If the standard DFs from Reference 3 prove to be too conservative, more detailed 3-dimensional analyses (such as with finite elements) or actual load tests may be conducted to specifically address the load effect of the vehicle on the specific bridge.

\section{Railroad loads}

In order to understand the requirements for Army rail lines, it is important to first understand those for the commercial rail lines as follows: Commercial rail lines must support high volumes of heavy freight traffic on a daily basis. For these lines, Reference [5] stipulates that their bridges should be designed to carry the loadings from the generic (hypothetical) Cooper " $E$ " series of loading, with the heaviest being that from the E 80 loading. The E 80 loading was developed long ago when steam trains were much heavier than the diesel trains of today. To account for this, Reference [5] stipulates that "bridges shall be rated for the Cooper series of loading or for the maximum train that the specific bridge must carry. For purposes of reporting, these trains shall be converted to equivalent $E$ loadings." Specific trains are converted to equivalent E-loadings by comparing the load effects (i.e., applied shear and moment) from the specific train to that for the $\mathrm{E} 80$ as follows:

$$
\text { Equivalent } \mathrm{E}-\text { Loading }=\frac{\text { Load effect from actual train }}{\text { Load effect from E80 train }}(80) \text {, }
$$

where the term "load effect" may be either applied shear or bending moment.

The new Army Regulation, AR420-72 states that the above loading methodology should also be used for Army railroad bridges. The heaviest and most typical locomotives and rail cars utilizing Army railroads are depicted in Figures 26 through 29. There axle loadings are compared to the E80 loading in Figure 30 and it can be seen that their axle loadings are significantly lower than those from the E80. The midspan bending moments and endspan shears produced by these trains on various span lengths are provided in Figures $31 \mathrm{a}$ and $32 \mathrm{a}$, respectively. Additionally, these values have been converted using Equation 7 to Equivalent E-loadings and plotted in Figures $31 \mathrm{~b}$ and $32 \mathrm{~b}$. 


\section{Maximum Live Load Effects}

\section{General}

From basic strength of materials, it is known that for a point load on a beam, maximum bending moment occurs when the load is at the midspan and the maximum shear will occur when the load is at or near the end of the span. The same general principals are applied in the application of vehicular live loadings to bridge elements. Except, the problem becomes somewhat more complicated with multiple loads such as from a series of truck axles. Vehicular live loadings and the manners in which their loads are transmitted through the bridge, from the wheel contact points down to the substructure, were demonstrated previously. Each live loading must be placed on the bridge in order to maximize the load effect (moment and shear) in each of the elements considered in the analysis. This location will be different for each element type. Obviously, the vehicle location to produce maximum bending moment in a transverse floor beam will be different from that for a longitudinal girder. Reference [3] (Article 3.23) provides specific guidance for the loading of all elements. A summary for the most common bridge elements is in the following paragraphs.

\section{Decks}

The maximum loading locations for bridge decks are demonstrated in Figure 33. The stringers support the deck. Along the length of the bridge (i.e., longitudinally), the deck essentially has an infinite span length compared to its transverse span between stringers or girders. Thus, its strength in the longitudinal direction is neglected and the deck is considered to only span transversely between the supporting stringers or girders. Therefore, the longitudinal location of the live load is irrelevant for decks. The lateral location of the wheel line (i.e., half the axle load) is the important parameter.

Referring to the end view of Figure 33, it can be seen that for normally spaced stringers (spacing less than axle width), the deck is considered loaded by a single point load, which is actually one wheel of the live load. Therefore, the maximum bending moment in a deck span is produced by placing the maximum wheel load at the center of the longest span between stringers or girders. Since the deck spans multiple girders, which are the deck's supports, the deck is essentially a continuous span beam across its supports and should be considered as such in calculating the resulting bending moment. The continuous beam diagrams in Reference [6] provide an excellent aid for this purpose. For simplicity in these calculations, the moment-reducing effect of the wheel load at the other end of the axle on the same continuous span is often conservatively neglected. The maximum shear is produced on a deck span by placing the wheel load at the support. Therefore, the resulting shear will be equal to the applied wheel load.

For civilian loads, obtain the maximum wheel loads from the rating and posting vehicles in Figure 22 by dividing the axle loads by 2 . For military loads, use the maximum axle loads of column 4 , Figure 23 . Note that the axle loads in 
Figure 23 are in tons. Thus, the wheel load (i.e. one-half the axle load) in kips will equal to the axle load in tons.

\section{Stringers or multi-girders}

The maximum loading locations for longitudinally-spanning stringers or multi-girders are demonstrated in Figure 34. These elements support the deck and thus all loads come through the deck. As with any simple beam, the maximum bending moment will be produced in a simply-supported stringer or girder when the live load is near the midspan. Because multiple point loadings of different magnitudes are involved, the maximum moment will not be at exactly midspan. A general rule in this case is that the maximum moment will occur under the heaviest axle when that axle is the same distance from the midspan as the truck's center of gravity, as demonstrated in Figure 35). These maximum values may be determined analytically with simple beam theory. However, these values have been pre-calculated and are provided in Figures 36 and 37 for civilian loadings [1], and Figures 38 and 39 for military loadings [4]. Note carefully that the military loading values are for axle loadings, as opposed to wheel lines for the civilian loadings. A wheel line loading represents one side of the vehicle only, and is thus one-half of an axle loading.

Referring to the "End View" of Figure 34, it can be seen that the live load effects are shared among individual stringers because the deck serves to disperse, or distribute the loading outward to all stringers, to varying degrees. Conceptually, the effect on an individual stringer is maximized by placing a wheel line load directly over that stringer. Accounting for this load distribution analytically can be quite complex. Fortunately, calculational aids have been provided in Table 3.23.1 of Reference [3] in the form of Distribution Factors (DFs), which were previously discussed in Chapter 2 of this report. The appropriate DF (depending upon deck and stringer type, and stringer spacing) should be multiplied by the maximum bending moment. The resulting value represents the maximum moment that a single stringer should experience.

Figure 34 also demonstrates that the maximum endspan shear will occur when the truck's heaviest axle is at the support and will equal to the support reaction. These values are easily calculated by hand using conventional static beam analysis techniques, but can also be determined from the equations shown in Figure 37[1]. These equations can also be used for calculating the maximum shears at any point, $x$, on the span. Note that there are span length limits outside of which these equations are not valid. For spans outside of these limits, solutions must be calculated by hand.

Maximum endspan shears from military loadings are provided in Figure 39. Note carefully that these values are for axle loadings (as opposed to wheel lines) and the units are in tons.

Distribution of shear loadings is different than for bending moment. Because stringers will be very stiff near their supports, very little distribution of shear loadings near the supports will occur. However, shear loadings out from the supports will be distributed similar to that for moment. Article 3.23.1.2 of Reference 3 provides specific guidance for the distribution of shear loadings. 


\section{Floor beams}

The maximum loading locations for floor beams are demonstrated in Figure 40. A floor beam acts as a simple beam to support the stringers, which in turn support the deck. Therefore, the floor beam can only receive loads from the support reactions of the stringers. Referring to the "Side View" of Figure 40, it can be seen that the live load must be placed so as to maximize the stringer support reactions. These reactions is can be maximized analytically, much by trial and error, or through the aid of the pre-calculated tables in Figure 41 for civilian loads, and Figure 42 for military loads. These maximum reactions are used for calculation of both bending moment and shear in the floor beam. Referring to the "End View" of Figure 40, the maximum bending moment will occur when the axle loads are as close to the center of the floor beam as possible. The following equation (Reference [1]) may be used, along with the maximum reactions discussed above to calculate the maximum floor beam bending moment:

$$
\begin{aligned}
& M=\frac{(L-3)^{2} R}{2 L}, \text { for one-lane loading; and } \\
& M=\left(L-9+\frac{2.25}{L}\right) R, \text { for two-lane roadways; }
\end{aligned}
$$

where: $M=$ Moment in transverse beam,

$R=$ Maximum reaction (Tabular value from Figures 41 and 42),

$L=$ Span of transverse beam, in feet.

Maximum shear will occur when the axle is as close to the edge as possible. The axle load distance from the edge of the bridge is limited by Reference [1] to 2.0 feet between the wheel centerline and the inside curb. The following equation from Reference [1] may be used, along with the maximum reactions from Figures 41 or 42 to calculate the maximum floor beam shear:

$$
\begin{aligned}
& V=\left(1+\frac{W-9}{C}\right) R, \text { for one-lane loading; and } \\
& V=\left(1+\frac{W-18}{C}\right)^{2} R, \text { for two-lane loading; }
\end{aligned}
$$

where: $W=$ Width of roadway, in feet;

$C=$ Length of floorbeam between supports, in feet.

\section{Girders or trusses}

The maximum loading locations for girders or trusses are demonstrated in Figure 43. As previously discussed, girders and trusses are similar in the way that they receive and carry loads. They support the floor system, which is composed of the deck, stringers, and floor beams. Therefore, all loading is 
transmitted to girders or trusses through the support reactions of the floor beams. However, in the longitudinal direction (refer to the "Side View" of Figure 43), it is simpler to neglect this effect and consider the live load directly supported by the girder or truss. Since these members span longitudinally between substructure elements the same as the girders of a multi-girder bridge, the maximum bending moments and shears will be produced in the same manner. Therefore, for girders, the maximum live load moments and shears will be taken from Figures 36 through 39 . For trusses, the maximum axial loads in each truss member can be found from the Appendices of Reference 1 .

As demonstrated in the "Side View" of Figure 43, the girders or trusses will share to varying degrees in caring the total live load effect, depending upon the lateral position of the live load on the deck. The only way that they would share equally in carrying the live load would be if vehicle drove exactly along the centerline of the bridge. This will rarely, if ever be the case. Conceptually, the worst-case loading will be produced in a single girder or truss (i.e., on one side of the bridge) by placing the live load as close to the edge of the bridge as possible. Reference [1] provides a generic equation to represent the maximum percentage of live load for a single girder or truss. This value is referred to as "wheel lines per truss" or "distribution factor" (DF) and should be multiplied by the maximum load effects as described above. The generic equation is as follows:

$$
\begin{aligned}
& \text { Wheel lines per truss }=\left(1+\frac{W-9}{C}\right) \text {, for one-lane loading and } \\
& \text { Wheel lines per truss }=\left(1+\frac{W-18}{C}\right)^{2} \text {, for two-lane loading. }
\end{aligned}
$$

This equation is for a vehicle location of 2.0 feet between the wheel centerline and the inside curb. If other limiting scenarios must be considered, the equation can be easily derived by summing moments about one of the girders or trusses as demonstrated in Figure 44. Once calculated, the DF should be multiplied by the maximum bending moments or shears as discussed above.

\section{Railroad bridges}

Since railroad bridges have essentially the same structural makeup as vehicular bridges, the load effects will be maximized in the same way also; i.e., place loads near midspan for maximum bending moment and at or near the supports for maximum shear. Laterally, railroad bridges are much easier to consider since the lateral position of trains is maintained by the rails. Because of this fact, longitudinal load-carrying members (stringers or multiple girders) are placed symmetrically beneath the rail locations. Reference [5] provides specific guidance for the distribution of train loadings. This guidance is summarized as follows:

For timber bridge members: Cross-tie size and stringer arrangement beneath the rails will usually be such that the track loads will be equally distributed (laterally) to all stringers. If for some reason, this situation is suspect, Reference [5] provides an approximate analysis procedure for stringer distribution. For 
Ballast Deck Bridges, the live load is assumed distributed laterally over a width equal to the length of the tie plus twice the depth of ballast below the base of the tie, as demonstrated in Figure 45a. Along the length of a stringer, each axle loading is assumed to be spread out over three ties. This is only true if the recommended maximum clear space between ties does not exceed 8 inches for Open Deck Bridges and 24 inches for Ballast Deck Bridges.

For Concrete bridge members: Axle loads are to be distributed longitudinally over 3 feet plus the depth of ballast under the tie, plus twice the effective depth of slab; but not to exceed the axle spacing (Refer to Figure 45b). Laterally, the live load from a single track over ballasted deck is assumed to have uniform distribution over a width equal to the length of track tie plus the depth of ballast below the bottom of the tie, unless limited by the extent of the structure (Refer to Figure 45c).

For Steel bridge members: Where two or more longitudinal beams per rail are properly diaphramed and symmetrically spaced beneath the rail, they are assumed to share equally in carrying the load. For Open Deck Bridges, axle loads are assumed to be distributed equally along the length of the beam (i.e., longitudinally) through all ties or fractions thereof within a distance of 4 feet, but not to exceed 3 ties (Figure $45 \mathrm{~d}$ ). For ballasted deck bridges, each axle load is to be distribute longitudinally over 3 feet plus the minimum depth between the bottom of the tie and top of the beam; but not to exceed 5 feet or the minimum axle spacing (Figure $45 \mathrm{e}$ ).

\section{Load Effects on Continuous Spans}

All of the previous discussions of maximum load effects have been only for simple span bridge members. However, bridge members can also be continuous over their supports for two or more spans; i.e., continuous span. A continuousspan multi-girder bridge is compared to a similar simple-span bridge in Figure 46. Continuous spans serve to spread out and share applied loads with adjacent spans, thereby reducing the overall effect of the loads at any one location; i.e., shear, moment, and deflection. Figure 47 demonstrates that bridge decks, supported by the main superstructure members, are often continuous span.

While not as easy as simple-span beam analysis, calculation of load effects on continuous span beams is fairly routine for statically-applied loads, such as dead load. Conventional structural analysis techniques, such as the Moment Distribution and Slope Deflection methods, may be performed by hand with reasonable ease for these problems. Many pre-calculated solutions also exist for common static load and span combinations [6].

However, the problem becomes more difficult with continuous span bridge members since they must carry moving loads (i.e., live loads). Figure 48 demonstrates that loading effects at any location on the span will vary with each position of the live load on the span. For example, the position of the truck that would produce the maximum moment at the middle of span 1 will be completely different than that for the maximum negative moment at support $\mathrm{A}$.

The same conventional structural analysis techniques as mentioned above can also be used for a moving load analysis. Multiple solutions for a moving point load can be used to generate influence lines, which lead to maximum shear 
and moment envelopes for the span configuration. This process is demonstrated in Figure 49 for a simple span beam. While the same type of solution can be achieved for any continuous span combination, it will be very tedious and time consuming. Computerized solutions to these problems are highly recommended. Many programs already exist for this purpose and may be purchased at reasonable prices. 


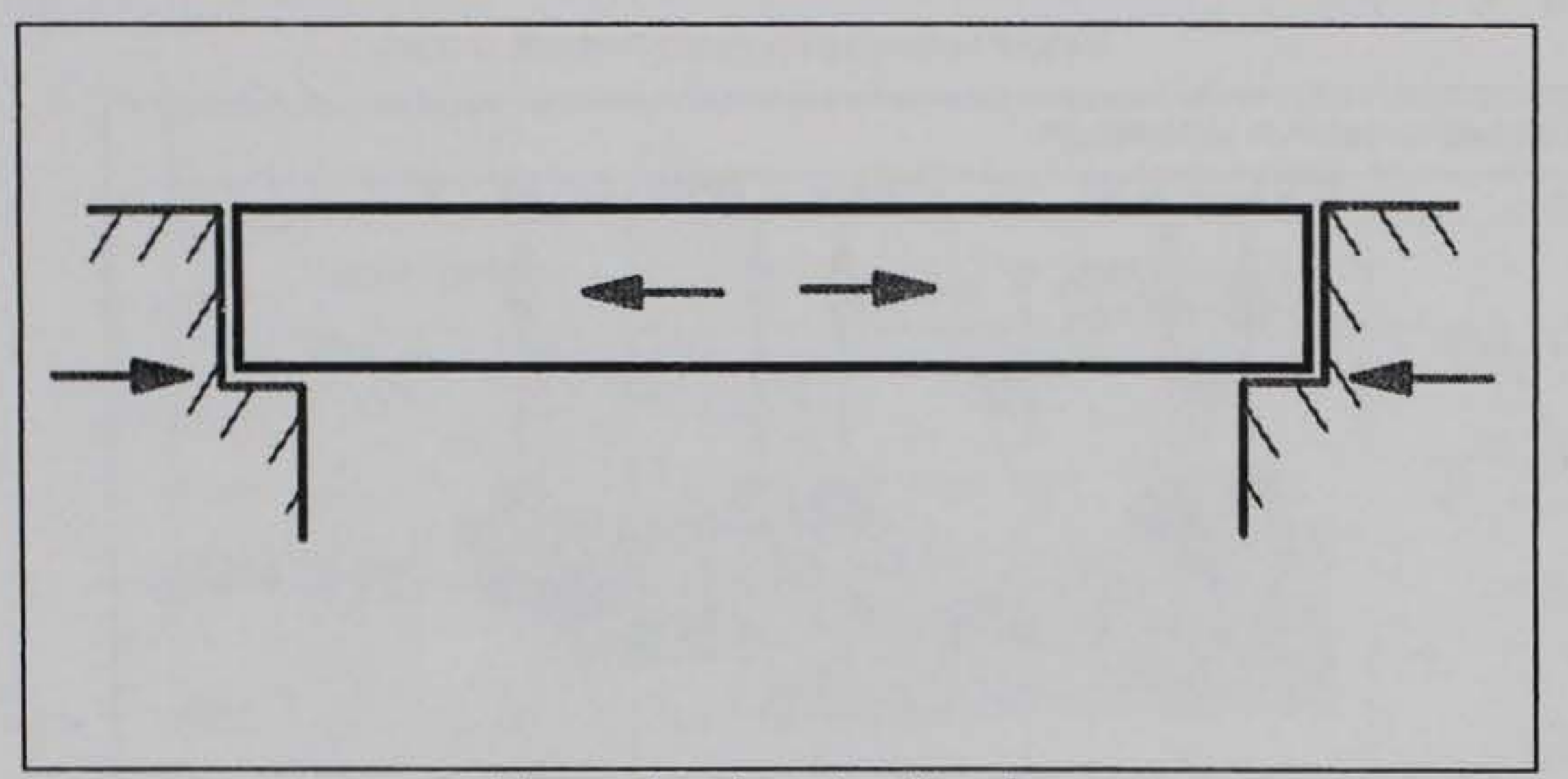

a. Expansion / contraction forces

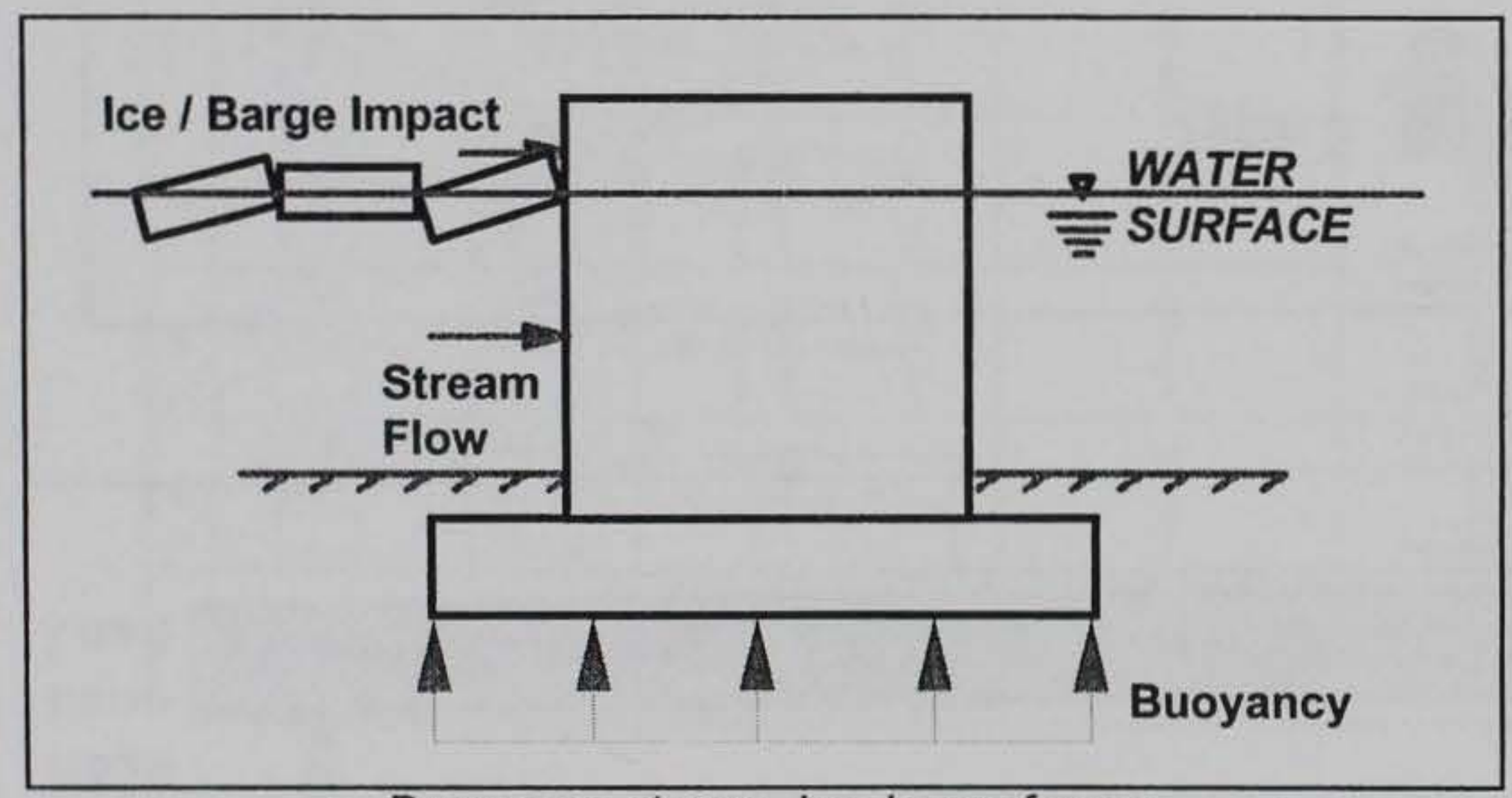

c. Buoyancy, stream, ice, barge forces

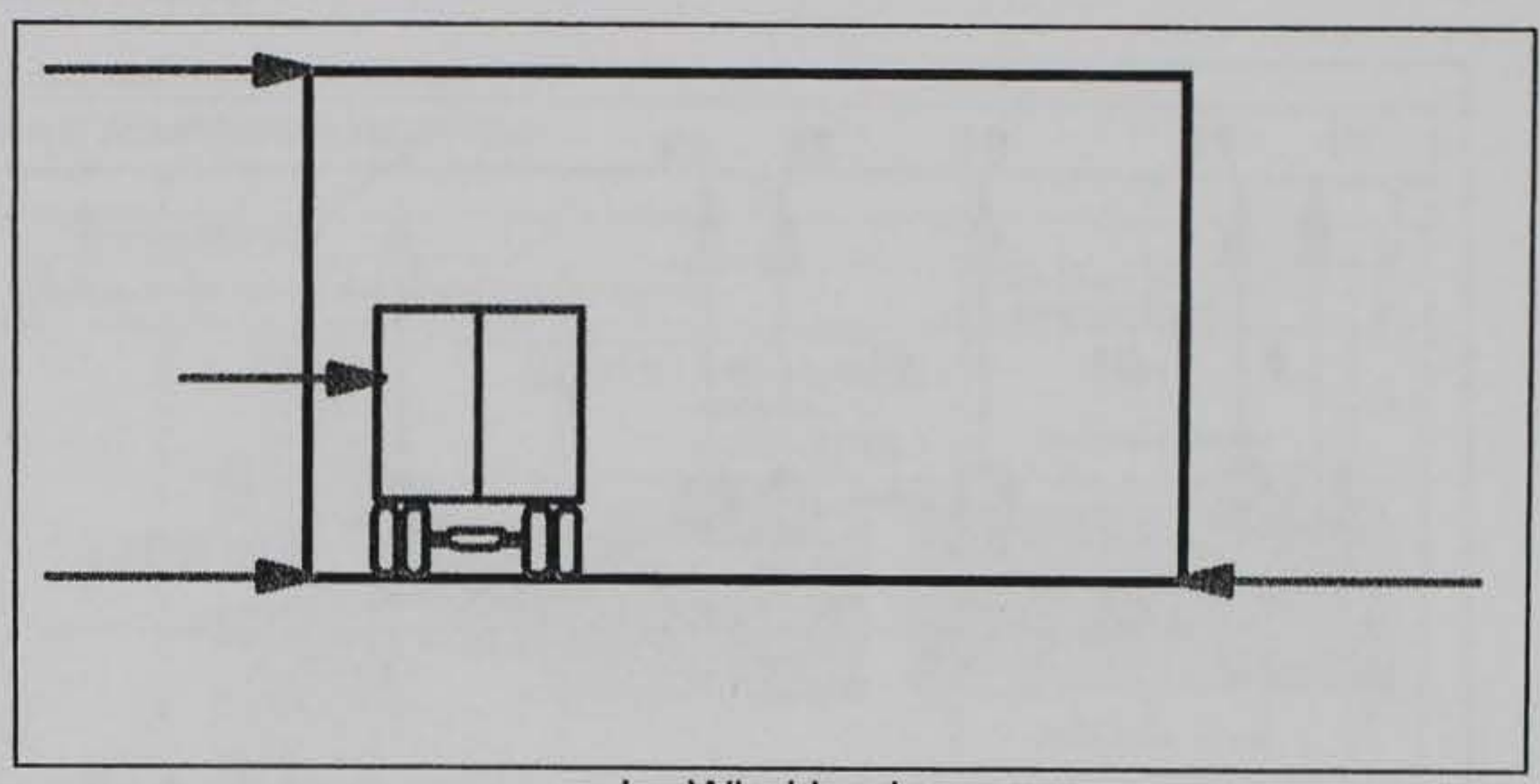

b. Wind loads

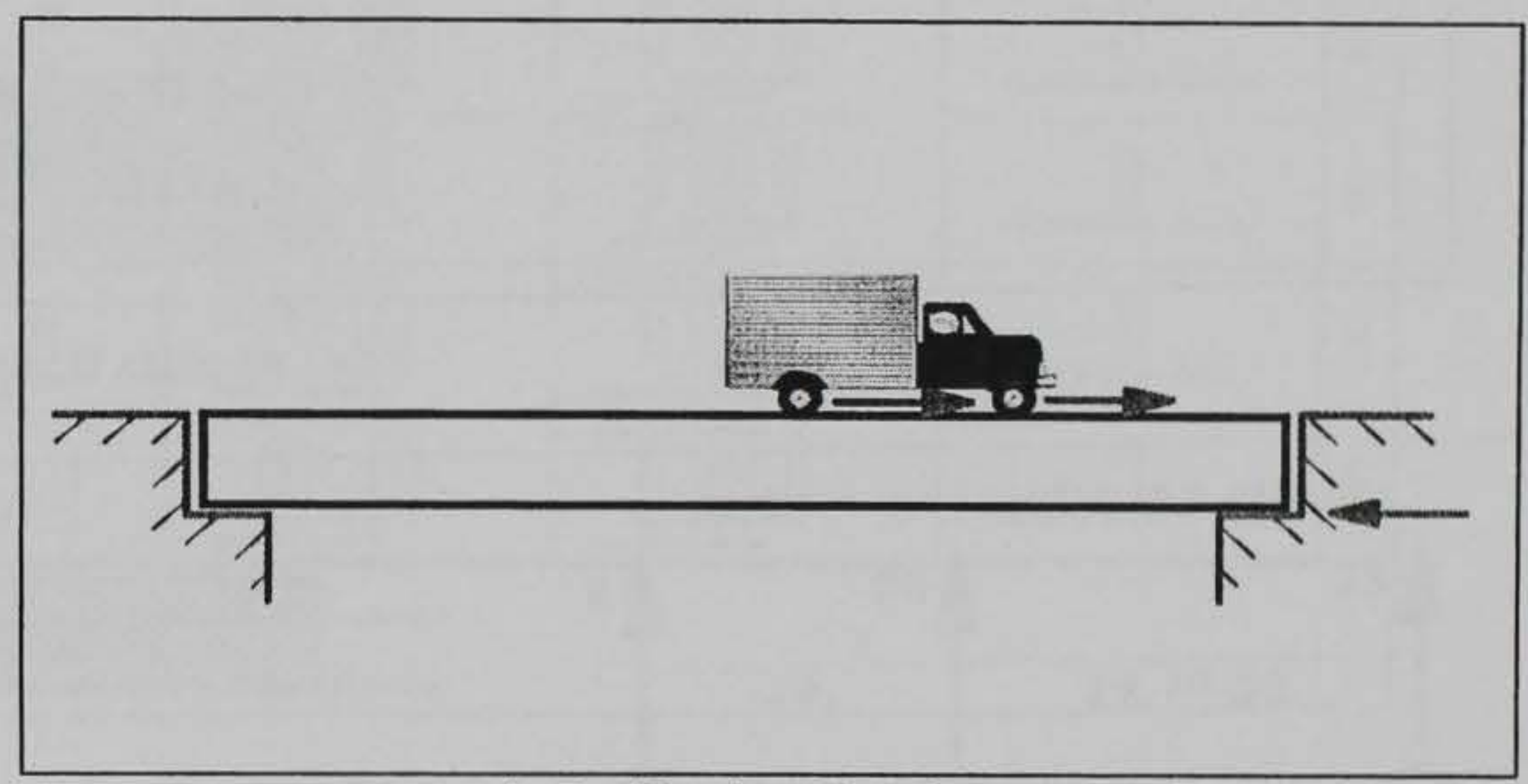

d. Braking / traction forces

Figure 21. Secondary loads on bridges 


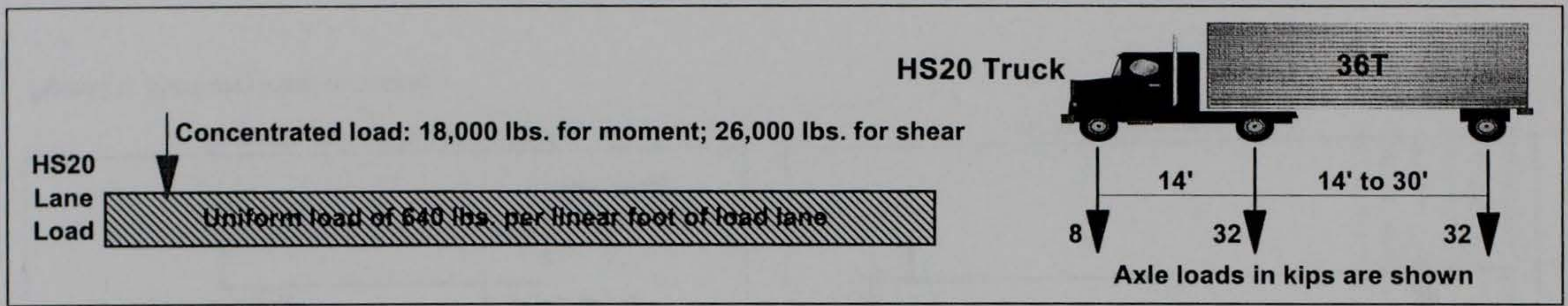

a. Rating vehicles

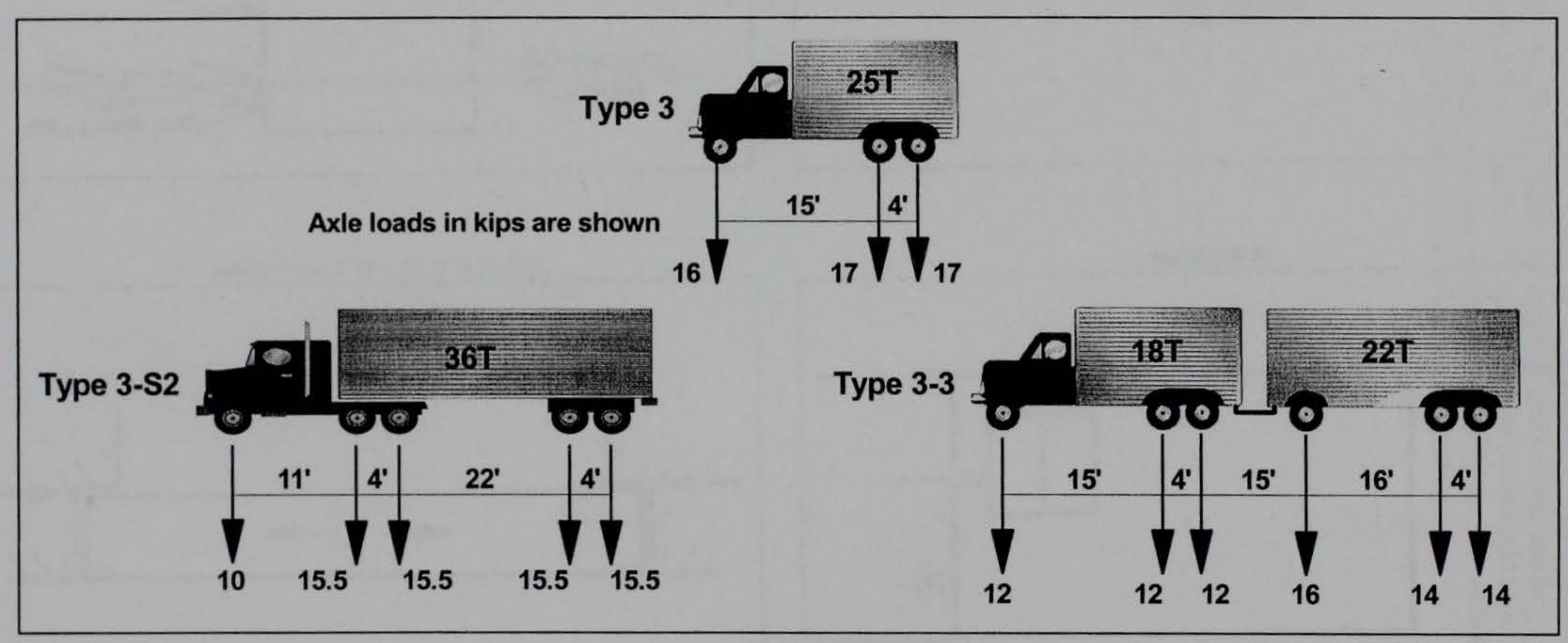

b. Posting vehicles

Figure 22. Civilian live loads (reference [1]) 


\begin{tabular}{|c|c|c|c|c|c|c|c|c|}
\hline \multicolumn{9}{|c|}{ Hypothetical Vehicles for Classification of Actual Vehicles and Bridges } \\
\hline 1 & 2 & 3 & 4 & 5 & 6 & 7 & 8 & 9 \\
\hline$\frac{\Omega}{\Phi^{\circ}}$ & Tracked Vehicles & \multicolumn{5}{|c|}{ Wheoled Vobicles } & & $\frac{2}{6}$ \\
\hline+ & $\sum_{-r+1}^{\infty r+\infty}$ & $\frac{9.96}{1.79}$ & $\prod_{i=1}$ & 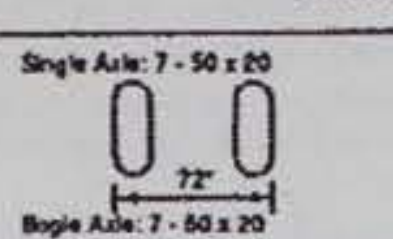 & "and & $\begin{array}{l}\text { NOTE: Spacing between } \\
\text { canter thres } x^{*} \\
\text { equals tite width. }\end{array}$ & $\bigcap_{2,500 \text { in on } 7 \cdot 50 \times 20}^{\text {Minimum Tile Size }}$ & ه \\
\hline$\infty$ & $\sum_{-\rightarrow-1}$ & $\int_{1}^{0}+9$ & $\Phi$ & $\int_{\infty}^{600}$ & 年 & & $\bigcap_{0.000 \text { in on } 12.00 \times 20}$ & $\infty$ \\
\hline$\vec{N}$ & & $\int_{10}^{1500} \frac{9}{5} \times ?$ & q & & 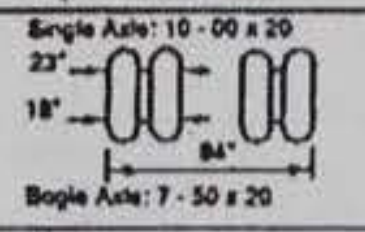 & & $\bigcup_{8.000 \text { on } 14-00 \times 20}$ & $\vec{N}$ \\
\hline के & & 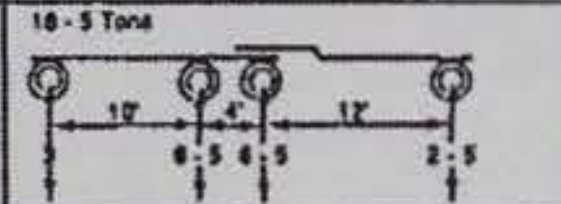 & p & 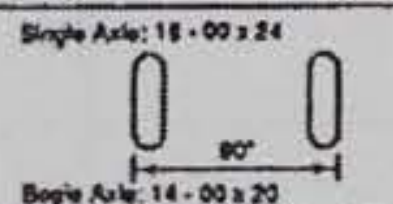 & $=00_{-\infty}^{20}$ & 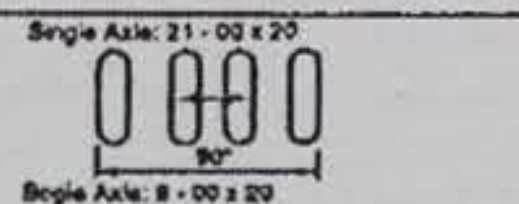 & $0_{10.001}$ on is $-00 \times 24$ & के \\
\hline \% & E्र & 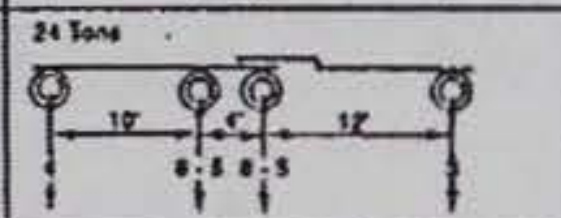 & 9 & $\bigcap_{-\infty}^{\infty}$ & $x-100-100$ & 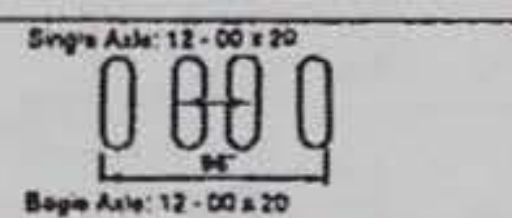 & $0_{11,00010 \text { on } 18 \cdot 00 \times 24}$ & 8 \\
\hline 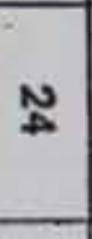 & एक & 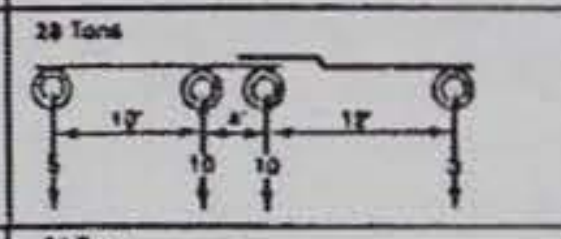 & 9 & $\int_{\infty}^{5 \sin 20} 0$ & (2) & 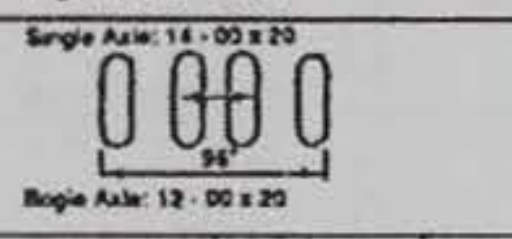 & $\bigcup_{12000 \text { to on } 18-00 \times 24}$ & ₹ \\
\hline$\omega$ & $\int_{-11-1}^{\infty 01000+1}$ & $9+9.9 \times 9$ & $\Phi$ & $\int_{-\infty}^{\infty}$ & "-201- & $\bigcap_{n=1}^{\infty} \bigcap_{n=1}^{\infty}$ & $\bigcup_{13.500 \text { it on } 18.00 x}$ & \% \\
\hline ô & $\sum_{-12-1}^{\infty}$ & 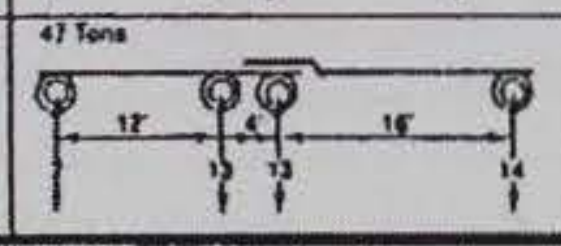 & p & $\bigcap_{-\infty}^{20} 0$ & 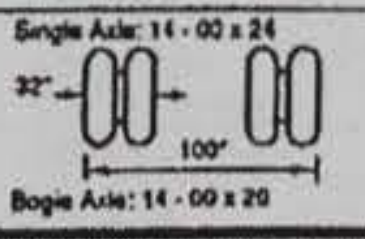 & 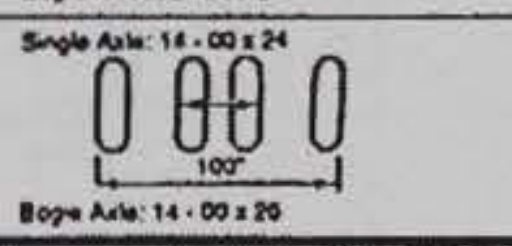 & $\bigcap_{17,000160021-00 \times 24}$ & ô \\
\hline & Short Tons & 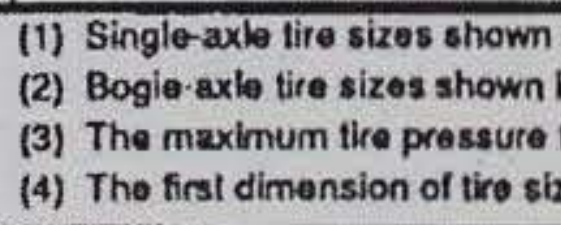 & 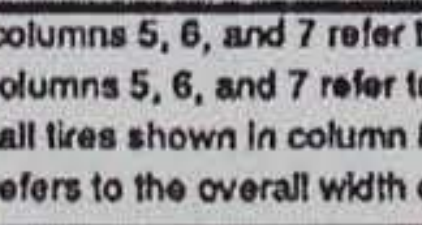 & 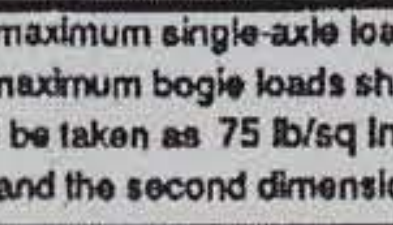 & $\begin{array}{l}\text { ncolumn } 4 \text {. } \\
\text { ofiagram in column } 3 \\
\text { m diamoler of the tire. }\end{array}$ & & & \\
\hline
\end{tabular}

Figure 23. Military live loads (reference [4]) 


\begin{tabular}{|c|c|c|c|c|c|c|c|c|}
\hline \multicolumn{9}{|c|}{ Hypothetical Vehicles for Classiflcation of Actual Vehicles and Bridges } \\
\hline 1 & 2 & & 4 & 5 & 6 & 7 & 8 & 5 \\
\hline 恶 & Tracked Vehleles & axito Lodda end specting & 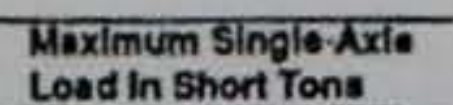 & Munlmum & of Spacing end Troo Sizos & fillest axios & $\begin{array}{l}\text { Maximum Tire Logd and } \\
\text { Minimum Intro Size }\end{array}$ & 摛 \\
\hline 照 & & $q-q$ q & 9 & 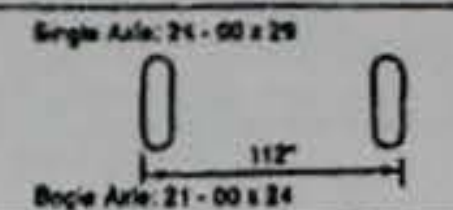 & $=00=-1,00$ & $0^{-1000} 0$ & 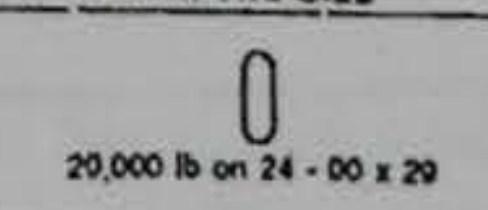 & \% \\
\hline 8 & & 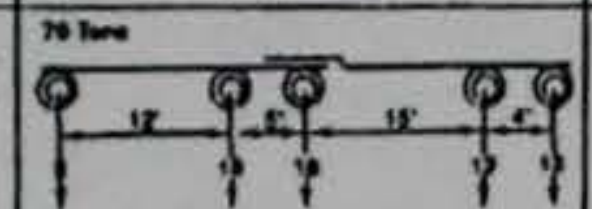 & $\$$ & & $=00=-1.00$ & $0_{-\infty}^{\infty}$ & $\bigcap_{20,000 \sin 24 \cdot-\infty \times x}$ & 8 \\
\hline d & $\sum^{6 r m}$ & 909 9.9 & $\Phi_{i}$ & & 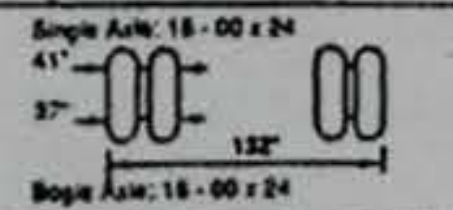 & 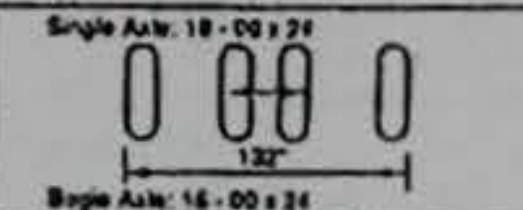 & $\bigcap_{20,00010 \text { on } 24.00 \times 20}$ & d \\
\hline : & & $9 \times 9, \quad 9,9$ & $\Phi$ & & 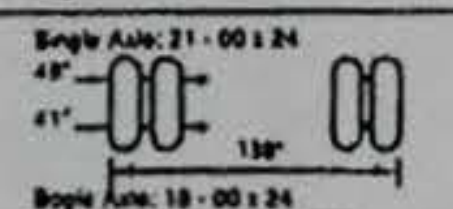 & 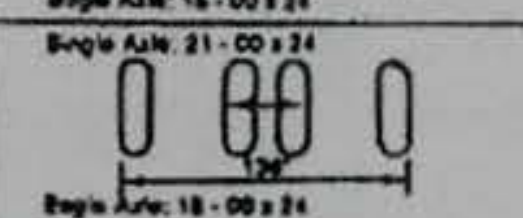 & $\bigcap_{20,000 \sin 24 \cdot \infty \times 20}$ & : \\
\hline 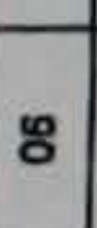 & $\frac{\mathrm{m}}{\cos }$ & $9.99 \%=96$ & $\Rightarrow 9$ & & $=00^{2}$ & $\bigcap_{n=\infty}^{\infty} \bigcap_{\infty}^{\infty}$ & $0_{20,00010 \text { o t } 24-\infty \times x \times 20}$ & 8 \\
\hline $\overrightarrow{8}$ & 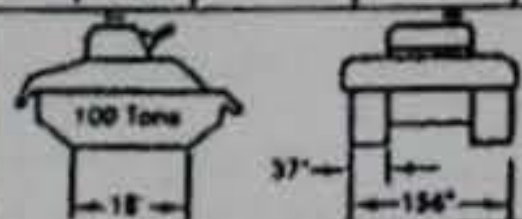 & $q_{p}^{9}=9,9 ?$ & $p$ & & $-200 \ldots$ & $0_{n=n=\infty}^{\infty} \theta_{n=12}^{\infty}$ & $\bigcap_{20,000 \sin 20 \text { 24 }}$ & $\overrightarrow{8}$ \\
\hline $\overrightarrow{\widetilde{\Omega}}$ & $\stackrel{5}{1108 m 0}$ & $9 \times 9.9=9.9$ & $\Phi$ & & & $0_{1}^{-\infty} \theta_{1}^{-\infty}$ & $0_{20.00010 \text { o } 24 .-00 \times 20}$ & $\overrightarrow{\mathrm{D}}$ \\
\hline $\overrightarrow{\mathrm{g}}$ & $\sum_{n=1}^{5}$ & 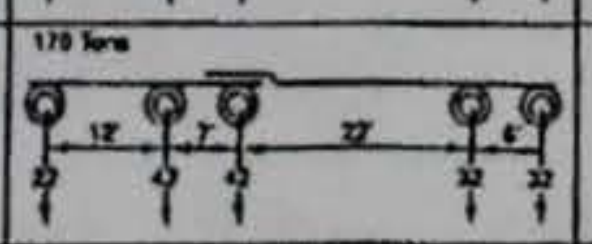 & q & & & $0_{100}^{\infty+\infty}$ & $0_{21,000 \operatorname{son} 24 \cdot-\infty \times 0 \times 0}$ & $\vec{\delta}$ \\
\hline & I Tons & 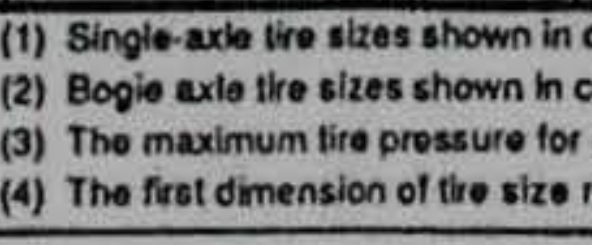 & 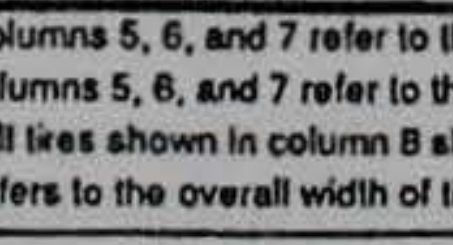 & 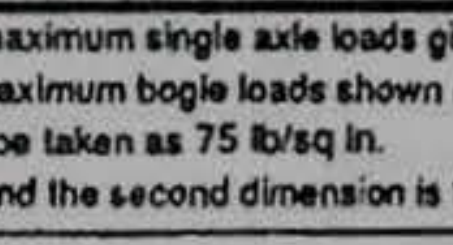 & 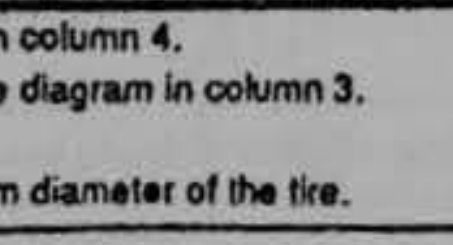 & & & \\
\hline
\end{tabular}

Figure 23 (cont'd). Military live loads 


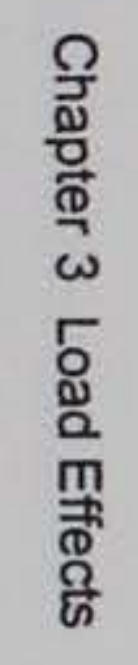
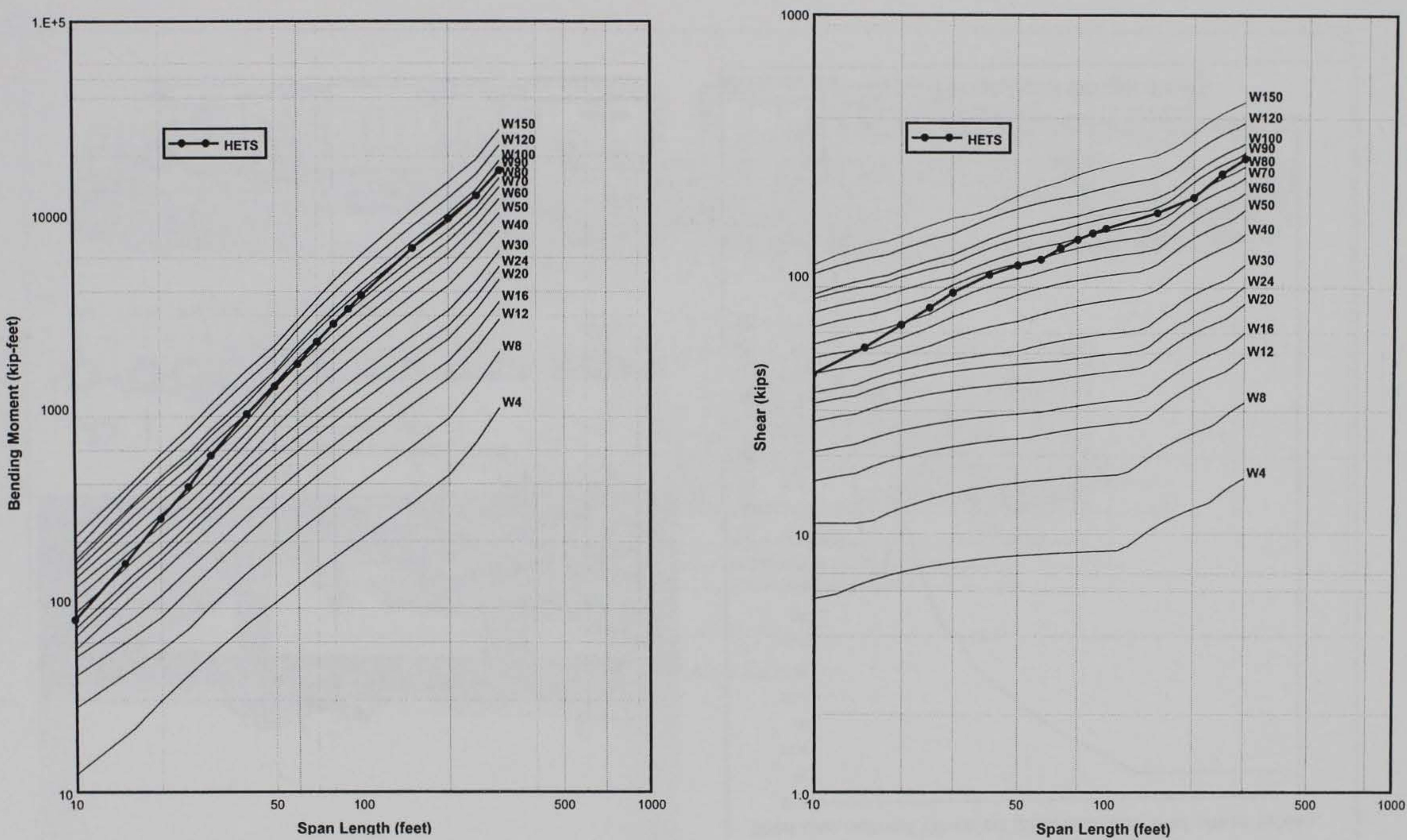

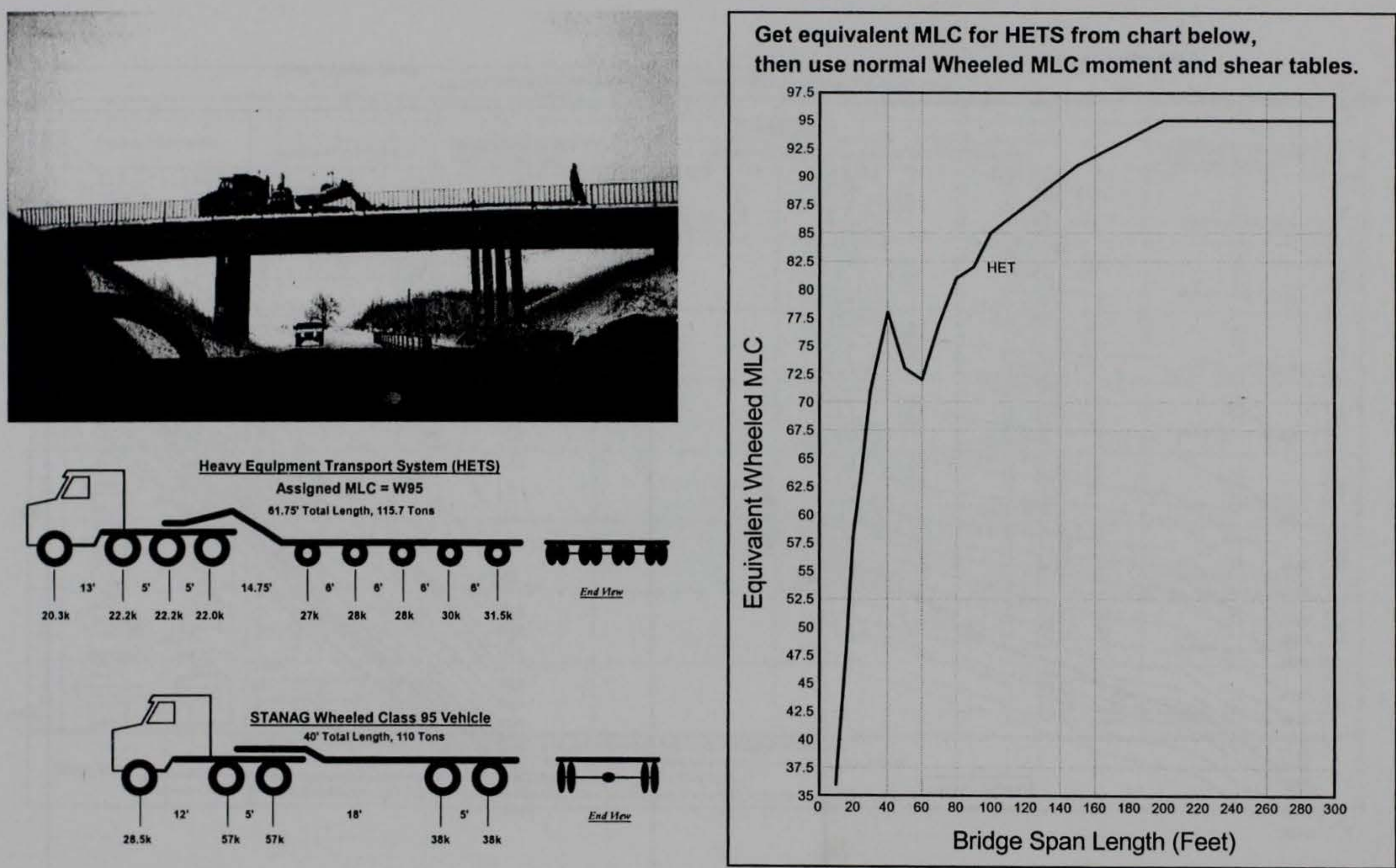

Figure 25. Heavy Equipment Transport System (HETS) 


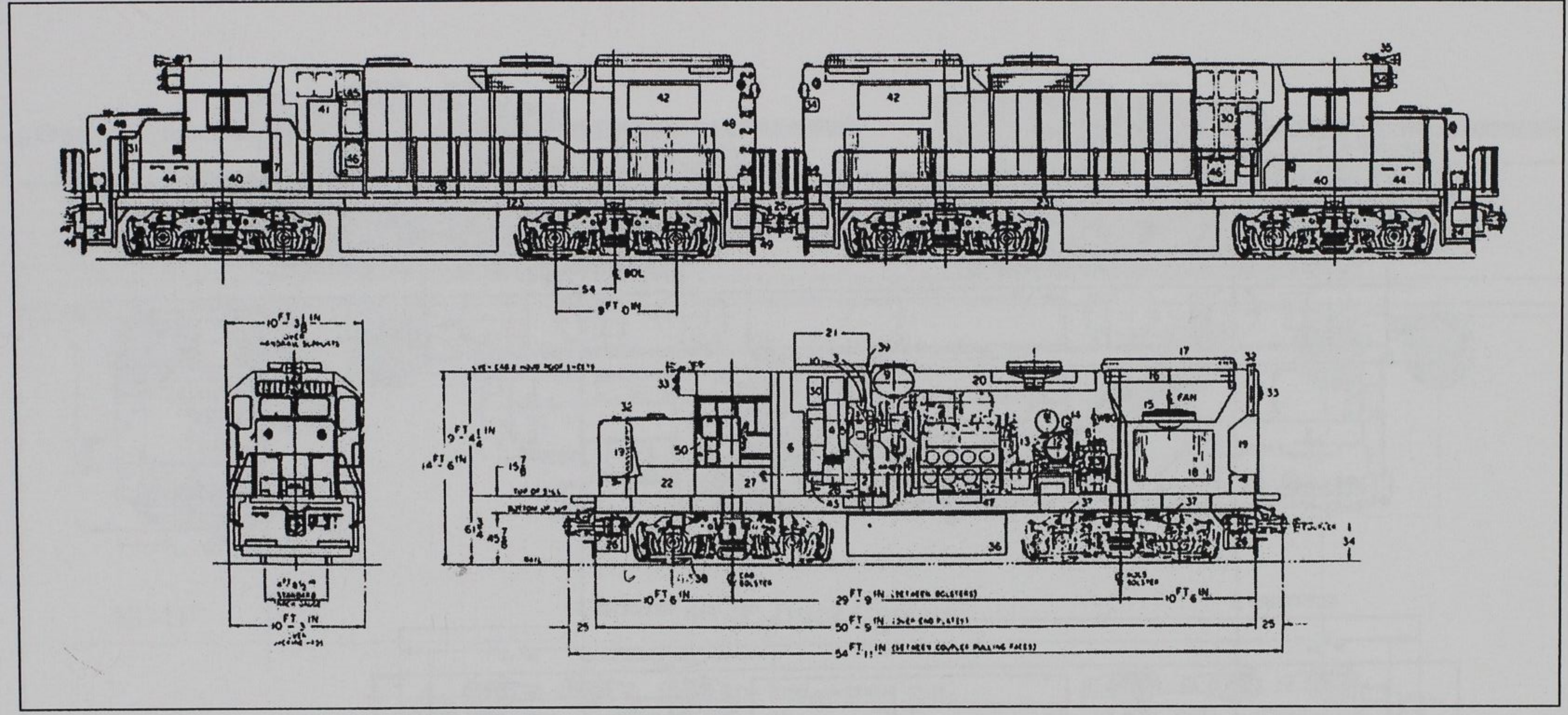

Figure 26. Model G515T-1500 general-purpose army locomotive, 120 tons each 


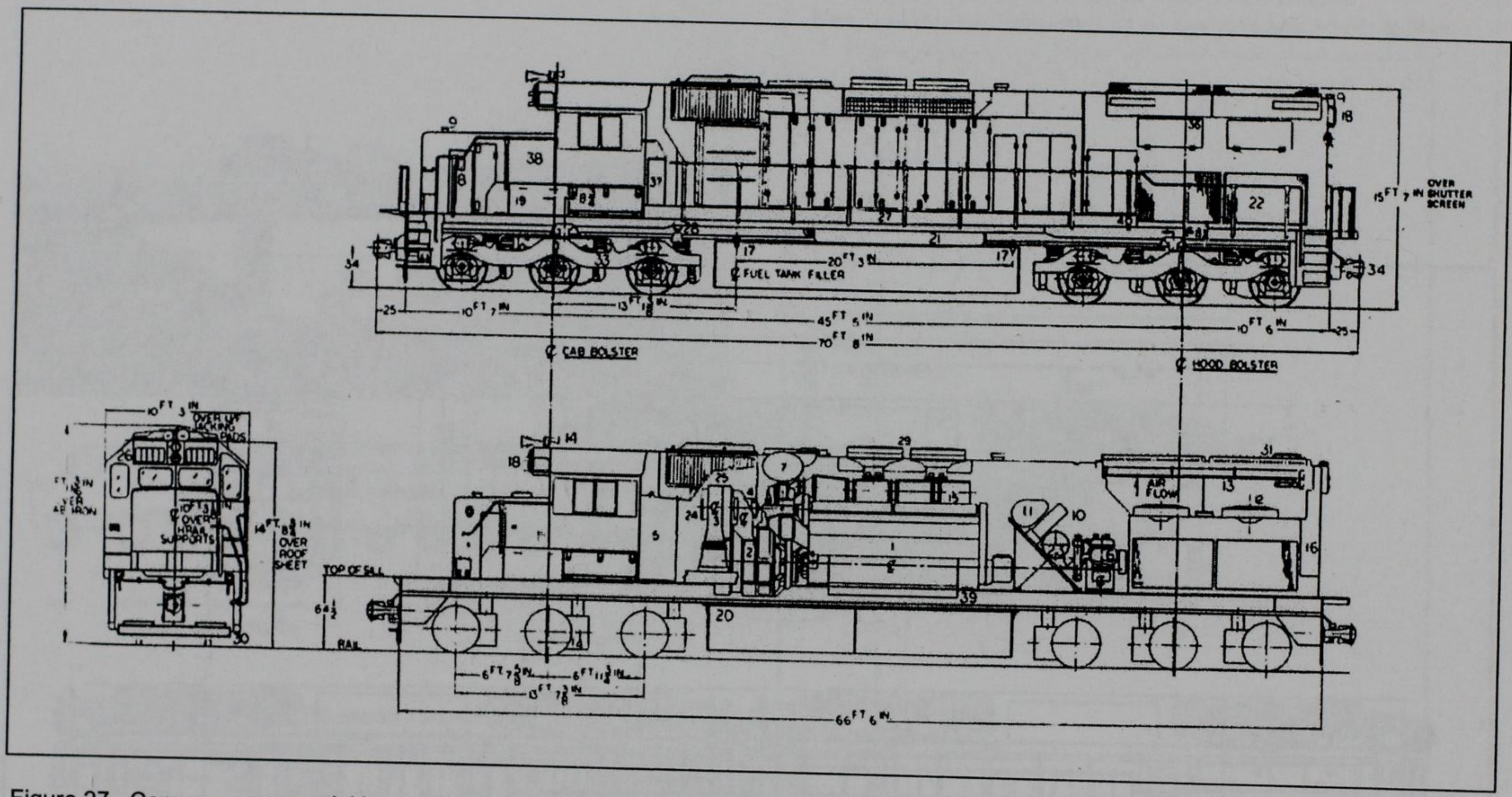

Figure 27. Common commercial locomotive, Model SD40-2, 184 tons each 


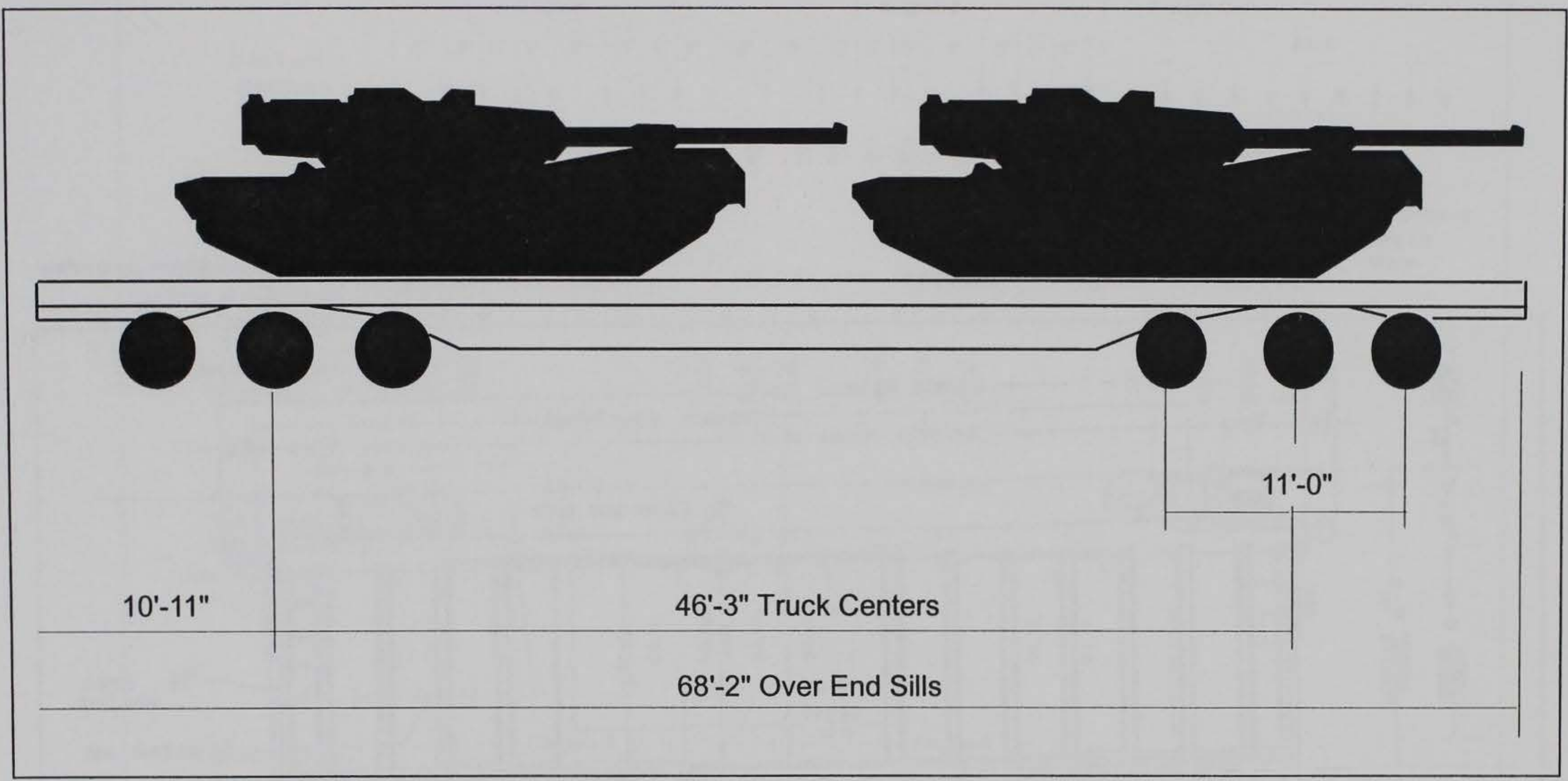

Figure 28. 140 ton special purpose flat car; 188 tons with $2 \mathrm{M} 1 \mathrm{~A} 1$ tanks 


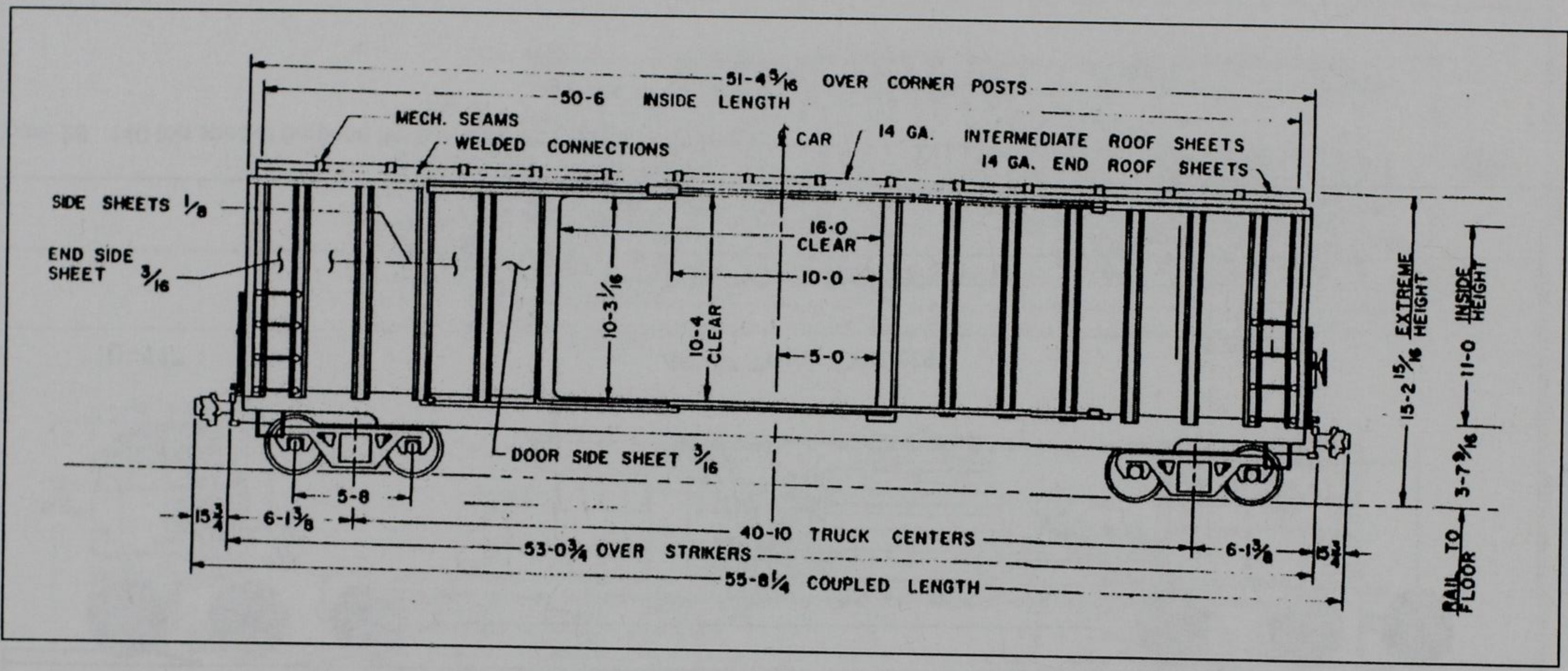

Figure 29. AMC ammo box car, 130 tons each 


\section{E 80 Train}

(284 Ton \begin{tabular}{l|l|l|l|l|l|l|l|l|l|l|l|l|l|l|l|l|l|l|}
$8^{\prime}$ & $5^{\prime}$ & $5^{\prime}$ & $5^{\prime}$ & $9^{\prime}$ & $5^{\prime}$ & $6^{\prime}$ & $5^{\prime}$ & $1^{\prime}$ & $8^{\prime}$ & $5^{\prime}$ & $5^{\prime}$ & $5^{\prime}$ & $9^{\prime}$ & $5^{\prime}$ & $6^{\prime}$ & $5^{\prime}$ & $5^{\prime}$ & \\
\hline
\end{tabular}

Engines)

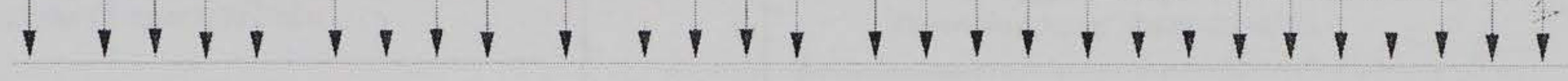

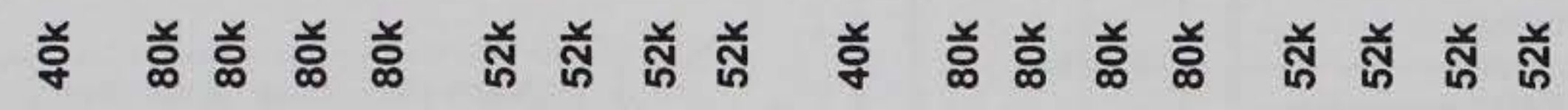

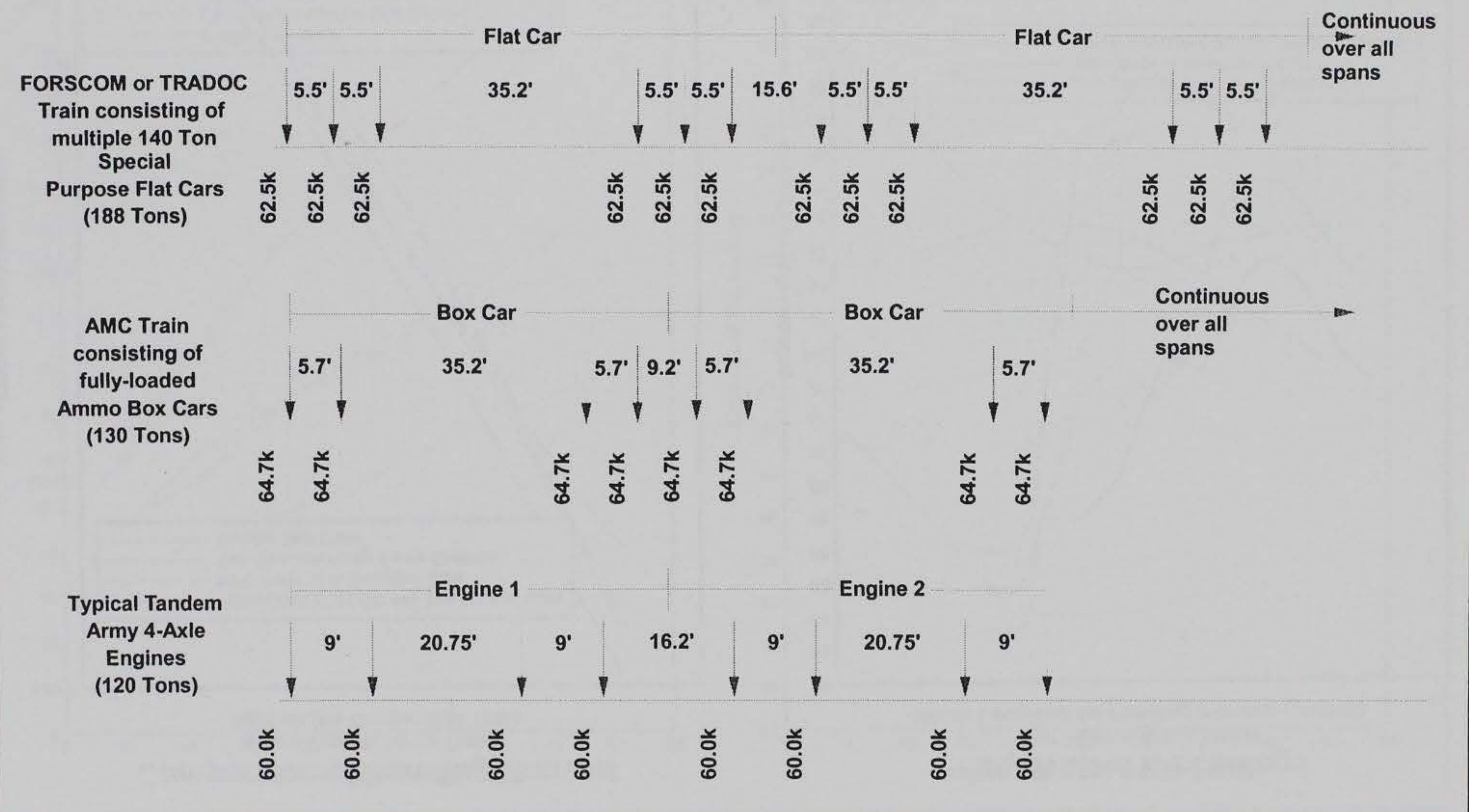




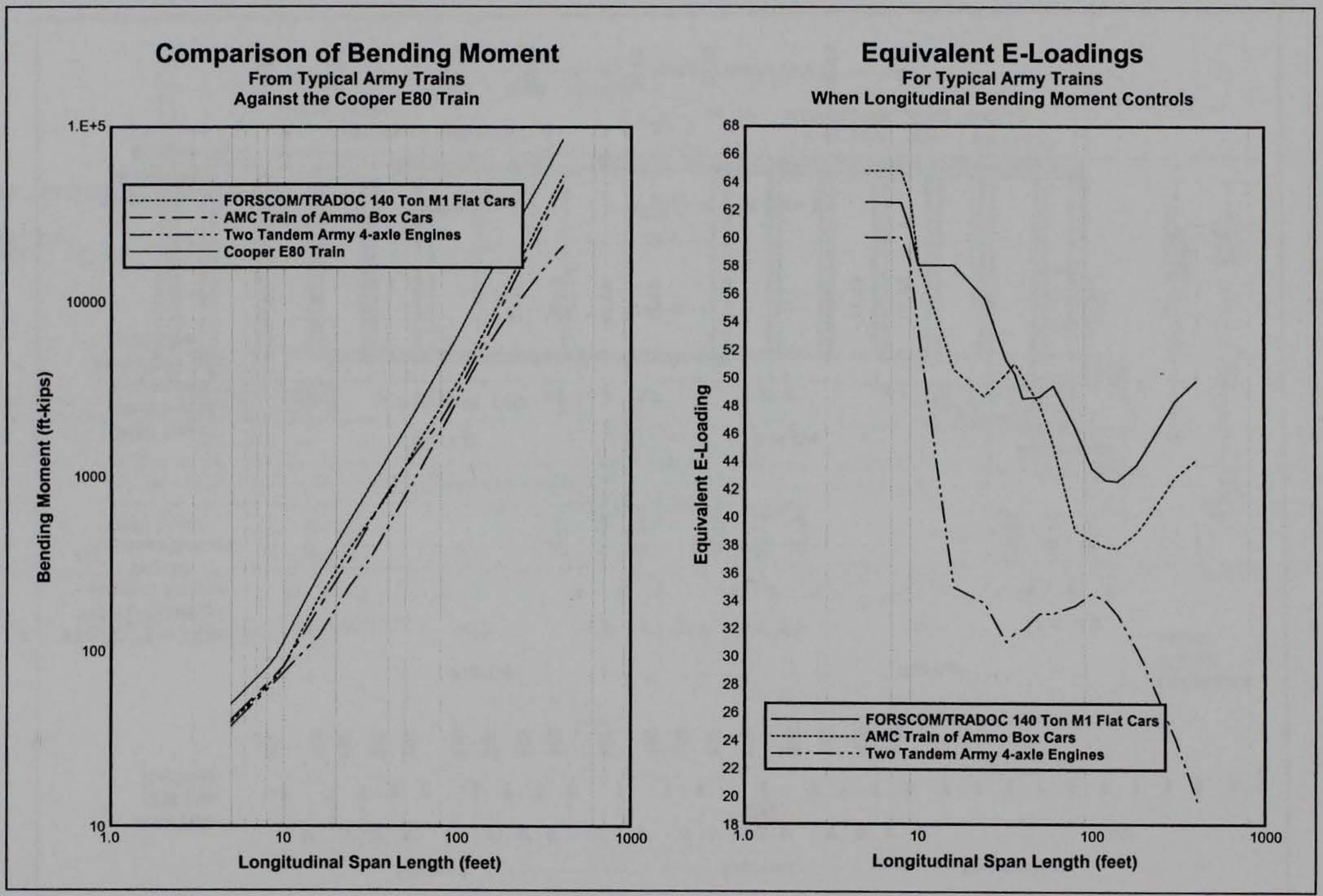

Figure 31. Equivalent E-loadings for typical army trains, based on bending moment 


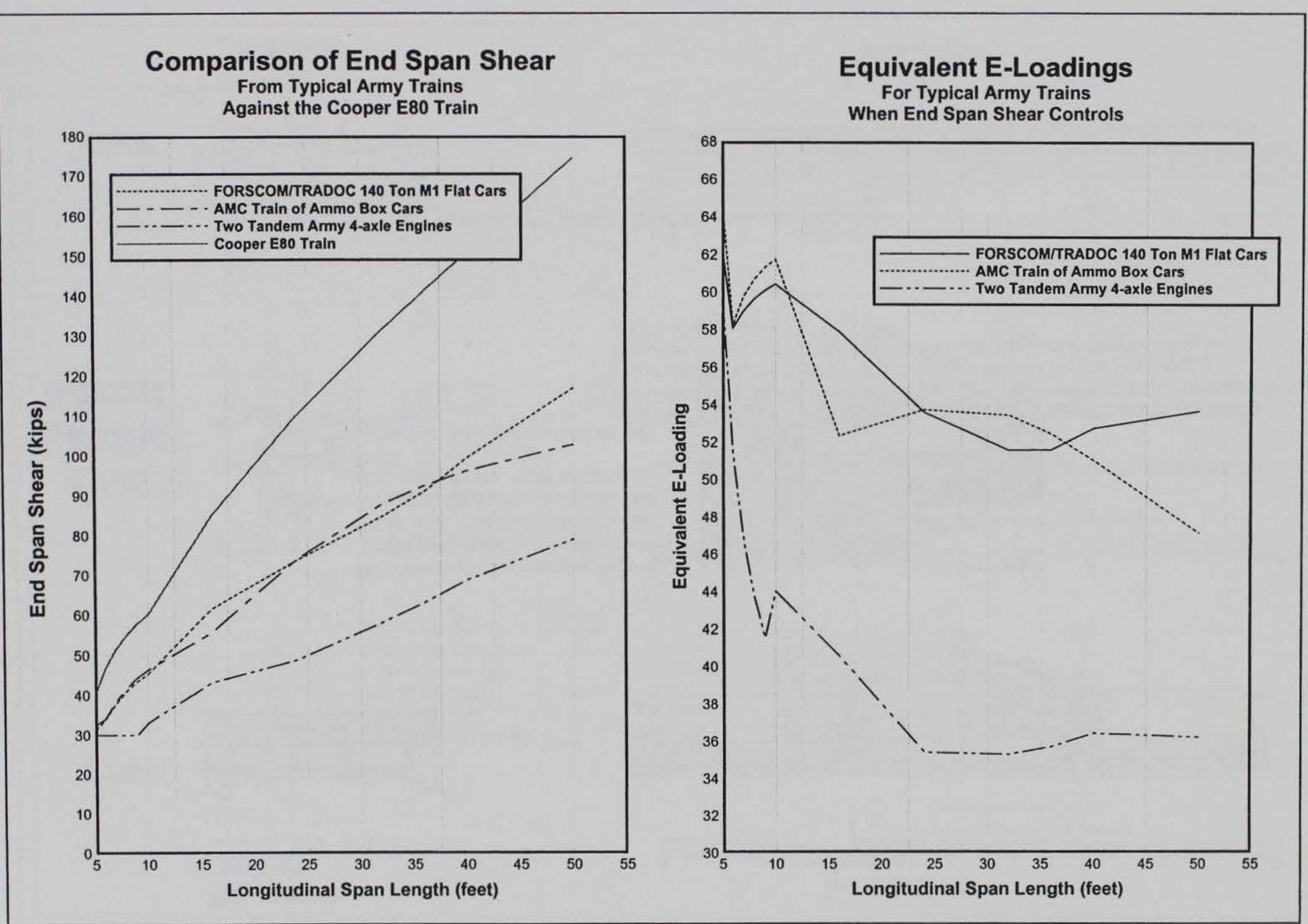




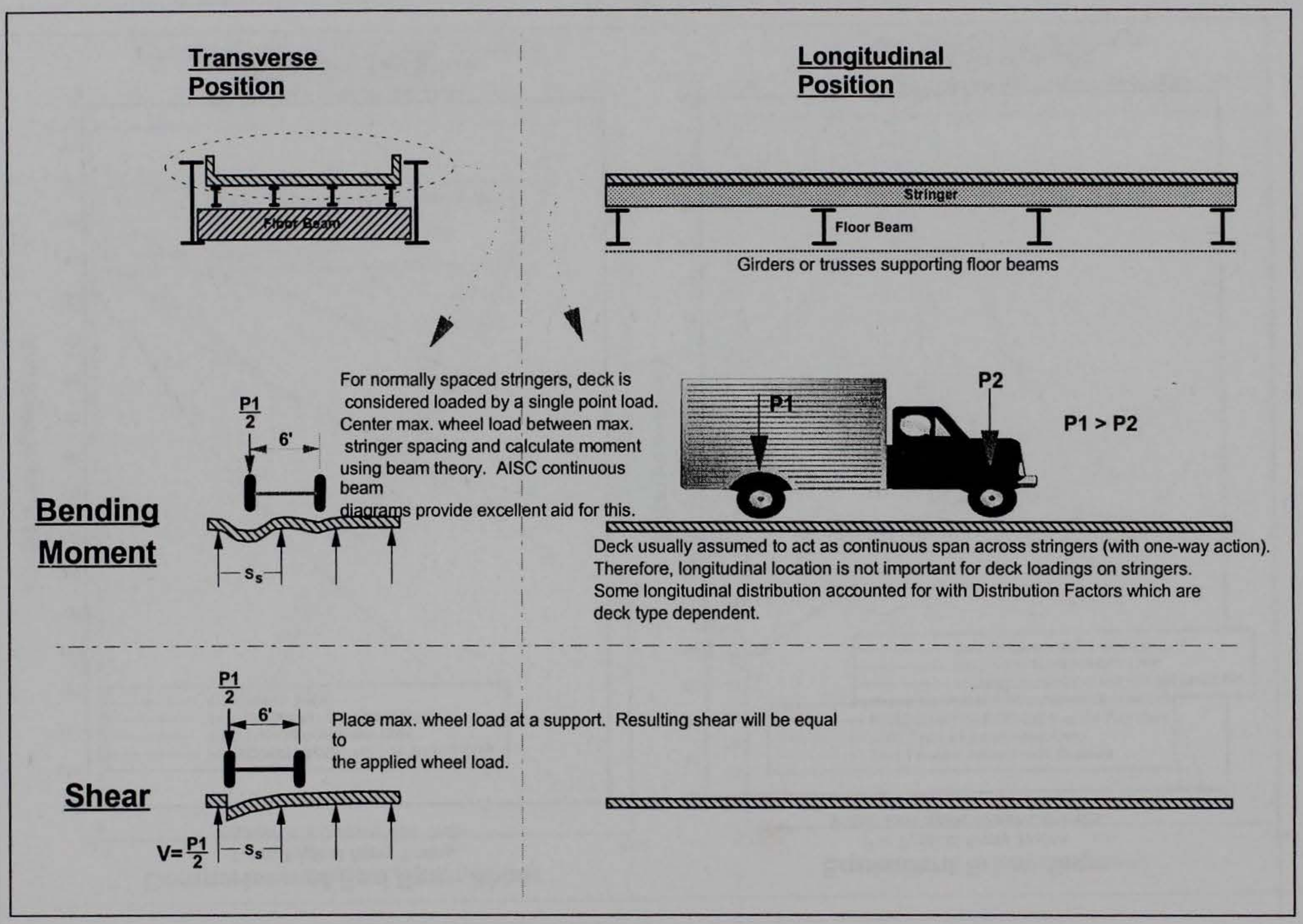

Figure 33. Maximum deck loadings 
Transverse

Position

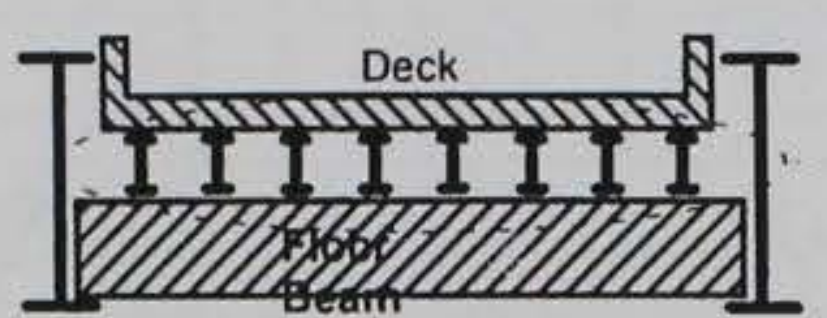

Longitudinal

Position

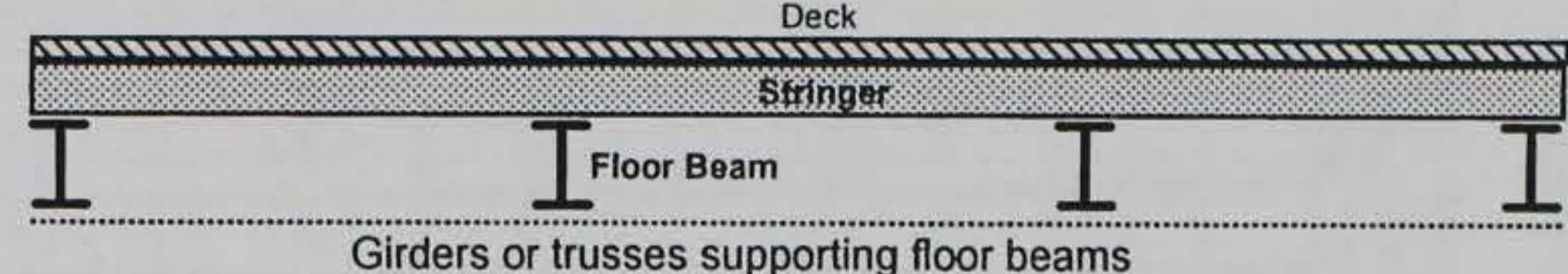

Girders or trusses supporting floor beams

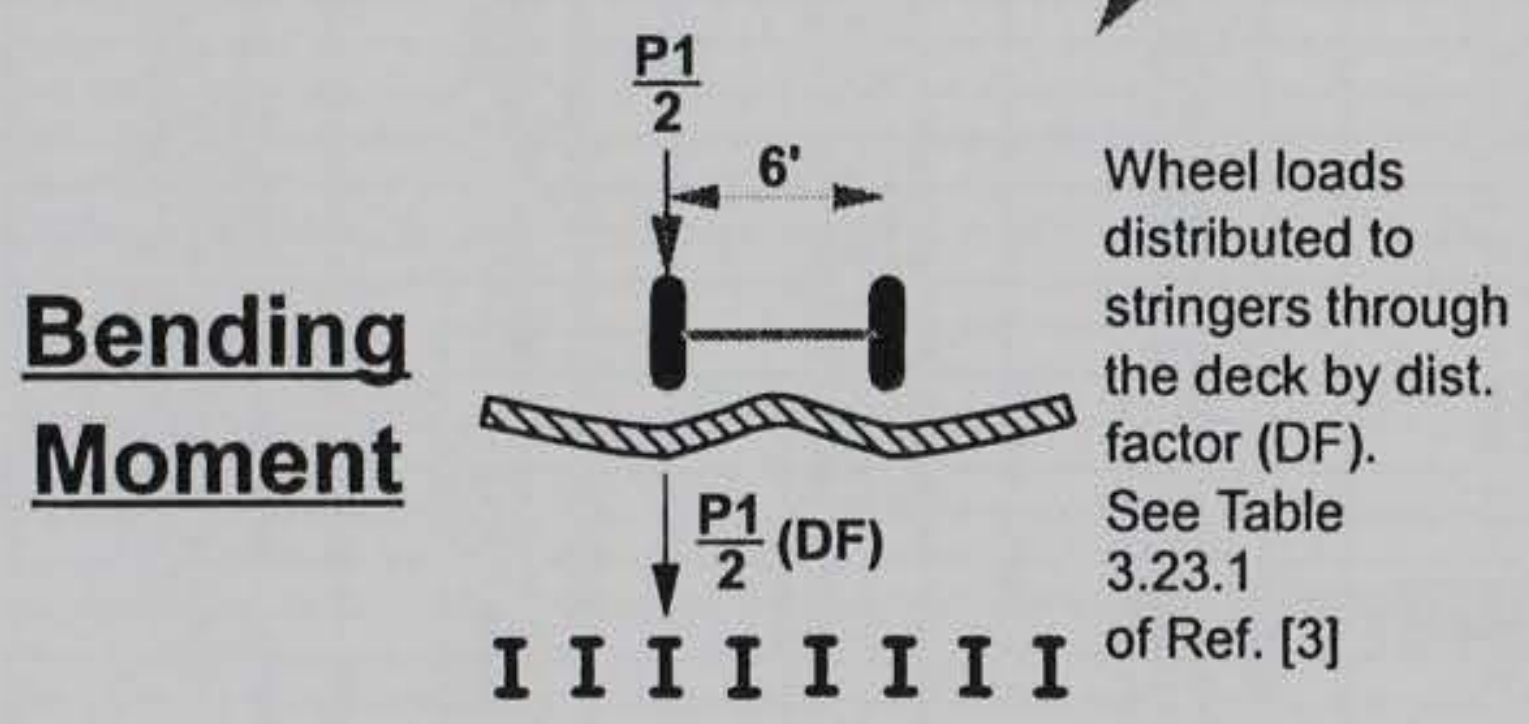

Shear

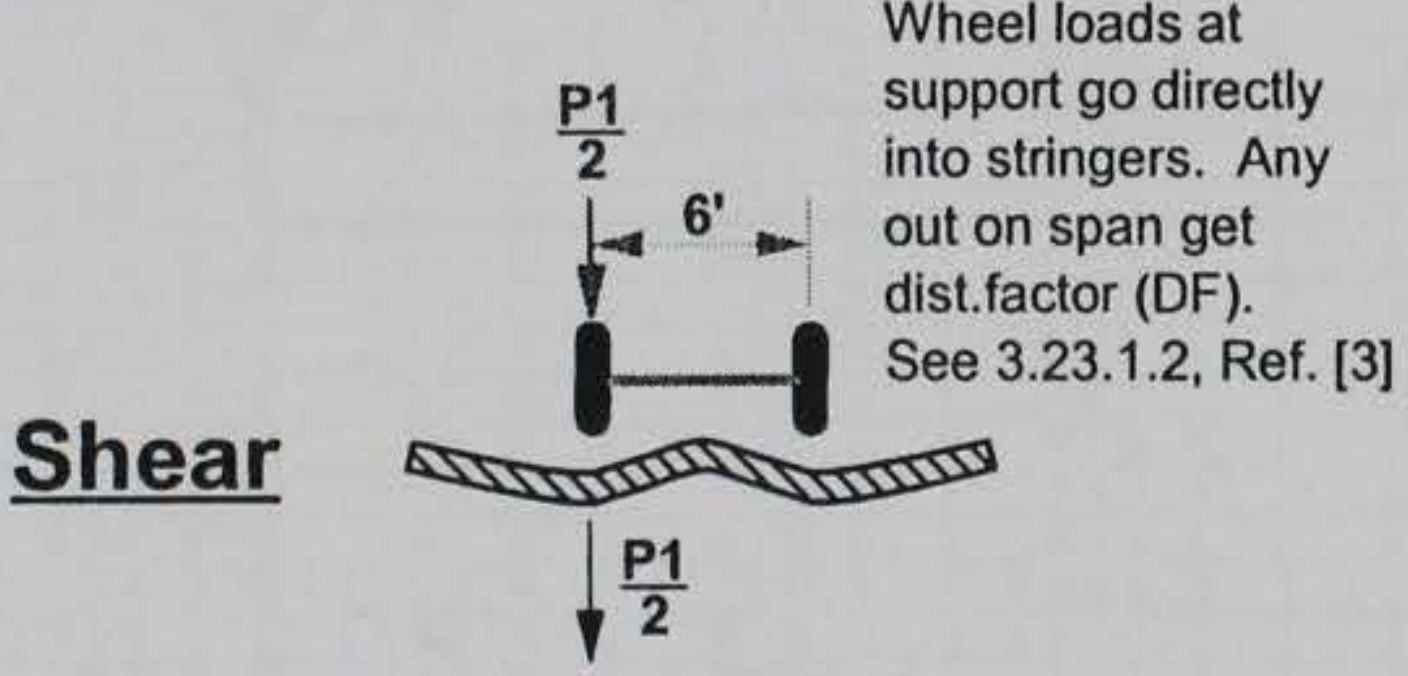

I I I I I I I I
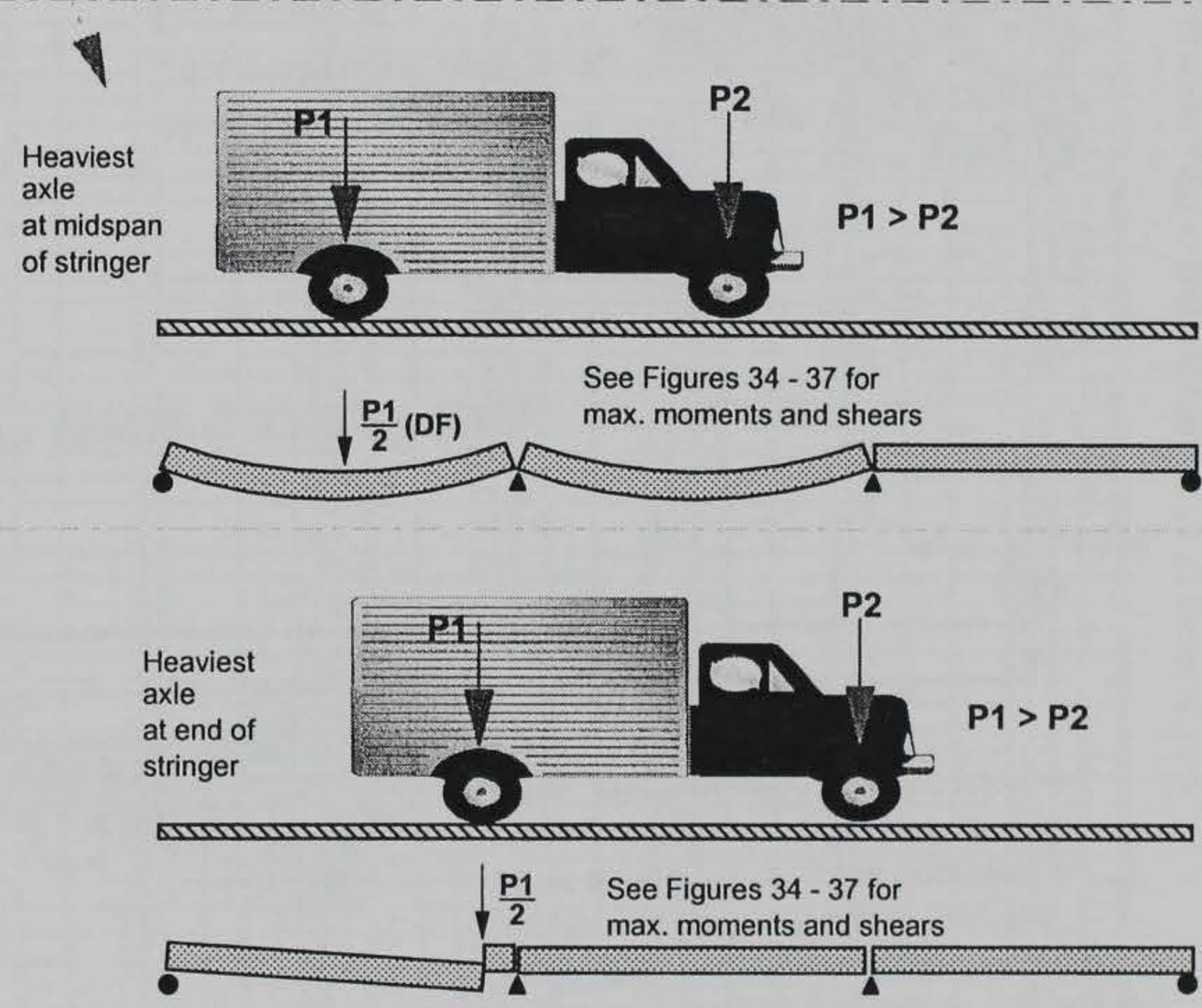


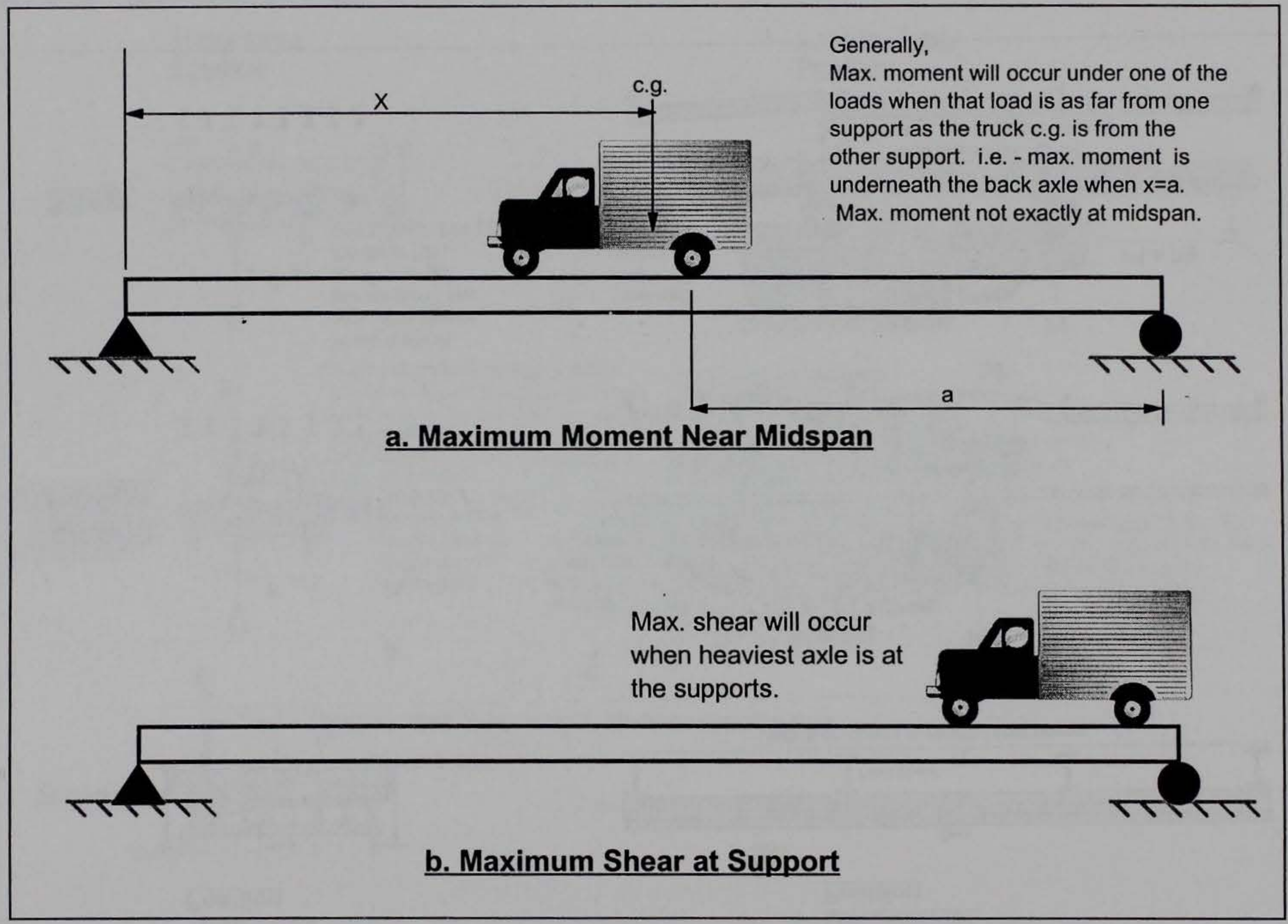

Figure 35. Vehicle placement for maximum load effects on elements 
LIVE LOAD MOMENTSONANDIX A3

\begin{tabular}{|c|c|c|c|c|c|c|c|c|c|c|c|}
\hline & Type of Lof & conse ens & our ming & & Span & & Type of $L$ & rading & th Impac & & \\
\hline $\mathrm{H}-15$ & ES-20 & 3 & $3-52$ & $3-3$ & Feet $c / c$ & $\mathrm{H}-15$ & $\frac{1}{S-20}$ & 3 & $3-52$ & & \\
\hline$\frac{15.0}{180}$ & 20.0 & $\frac{10.6}{128}$ & & 10.0 & 5 & 19.5 & 26.0 & 13.8 & 12.6 & 13.0 & \\
\hline & & & $\frac{11.6}{13.8}$ & $\frac{12.0}{14.0}$ & & & $\frac{31.2}{36.4}$ & $\frac{16.6}{19.7}$ & $\frac{15.1}{18.0}$ & & \\
\hline 24.0 & 32.0 & 19.1 & 17.4 & 16.0 & 8 & 31.2 & 41.6 & 24.9 & 22.7 & $\frac{10.2}{20.8}$ & 1 \\
\hline & & & & & $\frac{20}{10}$ & 39.0 & & 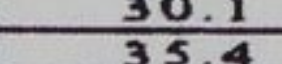 & & & $\geq$ \\
\hline 33.0 & 44.0 & 31.3 & 28.5 & 25.8 & 11 & 42.9 & & $\frac{3.7}{40.7}$ & & & \\
\hline & & & 32.2 & & & & & & & & \\
\hline 39.0 & 52.0 & 39.6 & 36.1 & 32.6 & 13 & 50.7 & & 51.4 & 46.9 & 42.3 & \\
\hline$\frac{42.0}{14.0}$ & 36.0 & 年3. & $\frac{39.9}{14.7}$ & & 14 & 34.6 & & 56.8 & $s_{1}$. & & \\
\hline & 64.0 & $\frac{47.9}{52.1}$ & $\frac{43}{47}$ & $\frac{39.4}{42.9}$ & $\frac{13}{1-6}$ & 62.4 & & $\frac{62.2}{67.7}$ & $\frac{360}{61}$ & $\frac{1.3}{55.7}$ & \\
\hline 51.0 & 68.0 & 56.3 & 51.3 & 46.3 & 17 & 66.3 & 88.4 & 73.1 & 66.7 & & \\
\hline $\begin{array}{l}\frac{34.0}{57.0} \\
5\end{array}$ & 72.0 & 60.4 & 55.1 & 49.8 & 18 & 70.2 & & & 71.6 & & \\
\hline & 16.0 & 64.6 & 58.9 & 53.2 & 19 & 74.1 & 98.8 & 84.0 & 76.6 & & \\
\hline 630 & $\frac{80.0}{84.0}$ & $\frac{\frac{08 . y}{7}}{73}$ & $\frac{62.8}{6.65}$ & 56.7 & 20 & $\frac{78.0}{78}$ & 104. & 89.5 & 81.6 & & \\
\hline 66.0 & 88.0 & 77.3 & $\frac{00.0}{70.5}$ & $\frac{60.2}{63.6}$ & $\frac{\frac{11}{22}}{22}+1$ & 81.8 & $\frac{109.2}{114.4}$ & $\frac{93.0}{100.5}$ & 86.6 & & \\
\hline 69.0 & 92 & 81.5 & 75.2 & 67.1 & 23 & & & 105.9 & & & \\
\hline & 96.3 & 85.7 & 80.3 & 70.6 & 24 & 93.6 & & 111.4 & 104.4 & & \\
\hline & & & & $\cdots$ & & 97.5 & 134.8 & 116.9 & & & \\
\hline$8 \longdiv { 3 }$ & 18.5 & 98.4 & 0.5 & & 20 & 101.4 & 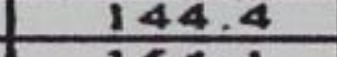 & 122.4 & 17.7 & & \\
\hline & & & 8007 & $\frac{01.0}{0.5}$ & & $\frac{103.7}{10.6}$ & 134. & $\frac{127.9}{13.1}$ & $\frac{124.3}{34}$ & & \\
\hline 88.8 & 133.5 & 106.8 & 105.9 & 88.0 & & & & 8.9 & & & \\
\hline 92.3 & 141.0 & 112.9 & 111.0 & 91.5 & 30 & 120.2 & 183.3 & 146.8 & 144.3 & & \\
\hline & & & 121.2 & 101.5 & 32 & 130.0 & $203 \pi$ & 162.9 & 157.6 & 1320 & \\
\hline 1.4 & 171.8 & 137.6 & 131.3 & 112.3 & 34 & 2.6 & & 118.8 & 170.9 & -0 & \\
\hline$\frac{4.8}{13}$ & $\frac{189.4}{307.3}$ & & & $\frac{123.1}{124}$ & $\frac{36}{38}$ & $\frac{149.2}{150}$ & & $\frac{195.0}{31}$ & $\frac{184.2}{107}$ & & \\
\hline$\frac{5}{0.7}$ & $\frac{254.9}{224.9}$ & 174.8 & 162.2 & 144.8 & $\frac{30}{40}$ & 8.6 & & 27 & & & \\
\hline 137.2 & 242.7 & 187.2 & 172.4 & 155.7 & $\overline{42}$ & 8 & 315 & & 224.0 & & \\
\hline 144.7 & 260.4 & 199.7 & 182.7 & 166.6 & 44 & 187.5 & 337.5 & 258.7 & 236.7 & 2,58 & \\
\hline 132.1 & 278.3 & 212 & 192.9 & 177.4 & 46 & 6.6 & 359.6 & 274.1 & 249.3 & & \\
\hline$\frac{139.6}{159.4}$ & $\frac{296.1}{394}$ & $\frac{224.5}{3.19}$ & 203.2 & 188.3 & 48 & 21 & 381 & 289.4 & 261.9 & & \\
\hline 174.6 & $\frac{31.8}{331.8}$ & $\frac{249.4}{249.4}$ & $\frac{2.38 .4}{238.4}$ & $\frac{193}{214.3}$ & 52 & & & 319.9 & $\frac{263.8}{305.8}$ & 574 & \\
\hline 182.0 & 349.7 & & 256.1 & 231.3 & 54 & 232.8 & 447.3 & 335.0 & 327.6 & & \\
\hline 189.5 & 3676 & 274.3 & 273.8 & 3002 & & $20 \%$ & & 350, & 3404 & $=$ & \\
\hline 198.8 & 385.4 & 286.8 & 291.4 & 265 & 58 & 25 & 5.6 & 365 . & 371.1 & & \\
\hline $20 s$ & 403.3 & 299.2 & 309.2 & 282.3 & 60 & $265.8^{\circ}$ & 512.2 & 380. & 392.7 & 358 & \\
\hline & & & & & & & & & & & \\
\hline & 582.4 & 423.9 & 487.1 & 471.8 & 80 & 40 & 72 & $52^{\circ}$ & 5.9 & & \\
\hline 394.90 & 672.2 & 486.3 & 576.4 & 571.7 & 90 & $486.7^{\circ}$ & 828.8 & 599.4 & 710.5 & 704.6 & \\
\hline 634.50 & 941.6 & 673.6 & 845.1 & 871.3 & $\frac{120}{120}$ & $764.0^{\circ}$ & $\frac{931.2}{1133.7}$ & 811.1 & 1017.5 & 1049.1 & \\
\hline $824.2^{\circ}$ & 1121.4 & 798.5 & 1024.5 & 1071.1 & 140 & $979.8^{-}$ & 1333.3 & 949.2 & 1217.8 & 1273.2 & \\
\hline $10^{-2}$ & $1384.0^{-}$ & 923.5 & 1204.1 & 1270.9 & 160 & 1220.10 & $1626.2^{\circ}$ & 1085.5 & 1415.3 & & \\
\hline $1537.5^{\circ}$ & $2050.0^{\circ}$ & $\frac{1173.4}{1173}$ & 1563.5 & 1670.8 & $\frac{180}{200}$ & $\frac{1484.0^{\circ}}{1774.0^{\circ}}$ & $\frac{1980.0}{2365.70}$ & 1353.9 & 1804.0 & 1927.8 & \\
\hline & $3062.5^{\circ}$ & 1485.8 & 2013.0 & 2170.6 & 250 & $2603.1^{\circ}$ & $13469.88^{\circ}$ & 1683.9 & $\begin{array}{r}2281.4 \\
\end{array}$ & \begin{tabular}{|l|l|}
2460.0 \\
40.0
\end{tabular} & \\
\hline 2500 & $\frac{1}{1} 4275.0^{\circ}$ & 1798.2 & $\frac{2462.6}{\text { All othe }}$ & $\frac{2670.5}{\text { values bas }}$ & $\frac{300}{0 n \operatorname{stan}}$ & $\frac{1}{1} 3583.5-100$ & $\begin{array}{l}\frac{1}{1} 4779.4- \\
\text { ding. }\end{array}$ & 2009.8 & 2752.4 & $\mid 2984.7$ & \\
\hline
\end{tabular}




\section{APPFNDIXA8}

\section{FORMULAE FOR MAXIMUM SHEAR \\ AT ANY POINT ON SPAN \\ (No impact included) \\ (Simple Spans Only)}

\begin{tabular}{|c|c|c|c|c|c|}
\hline \multirow[b]{2}{*}{$\begin{array}{l}\text { Type } \\
\text { Load }\end{array}$} & \multirow[b]{2}{*}{$\frac{L-X}{L}$} & \multirow{2}{*}{$\begin{array}{l}\text { Use for } \\
\text { Girder } \\
\text { Lengths }\end{array}$} & \multirow[b]{2}{*}{$\begin{array}{l}\text { Formula for } \\
\text { Maximum Shear (1) }\end{array}$} & \multicolumn{2}{|c|}{ Minimum } \\
\hline & & & & L-X & $x$ \\
\hline HS-20 & $0-0.500$ & Under $42^{\prime}$ & $V=\frac{36(X-4.67)}{L}-4$ & 14 & 14 \\
\hline & & $42^{\prime}$ to $120^{\prime}$ & $V=\frac{36(X-9.33)}{L}$ & 0 & 28 \\
\hline HS- 15 & $0-0.500$ & Under $42^{\prime}$ & $V=\frac{27(x-4.67)}{L}-3$ & 14 & 14 \\
\hline & & $42^{\prime}$ to $120^{\prime}$ & $V=\frac{27(X-9.33)}{L}$ & 0 & 28 \\
\hline I-20 & $0-0.500$ & to $35^{1 *}$ & $V=\frac{20(x-2.8)}{L}$ & 0 & 14 \\
\hline H-15 & $0-0.500$ & to $35^{\text {* }}$ & $V=\frac{15(X-2.8)}{L}$ & 0 & 14 \\
\hline
\end{tabular}

(1) All values based on standard truck loadings.

- Truck loading does not govem shear beyond the lengths specified. Use lane loading.

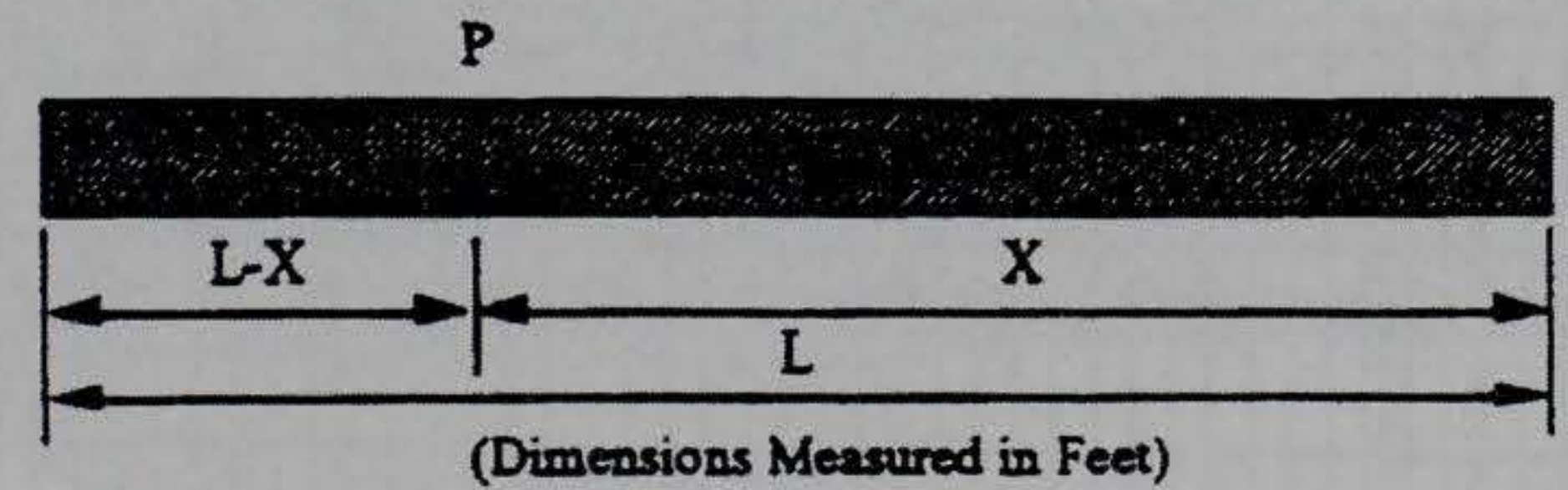

$V$ - Shear to Left of point "P" in kips per wheel line.

Figure 37. Maximum stringer or girder shears for live loads (reference [1]) 


\section{APPENDIXA8}

FORMULAE FOR MAXIMUM SHEAR

AT ANY POINT ON SPAN

(No impact included)

(Simple Spans Only)

\begin{tabular}{|c|c|c|c|c|c|}
\hline \multirow[b]{2}{*}{$\begin{array}{l}\text { Type } \\
\text { Load }\end{array}$} & \multirow[b]{2}{*}{$\frac{L-X}{L}$} & \multirow{2}{*}{$\begin{array}{l}\text { Use for } \\
\text { Girder } \\
\text { Lengths }\end{array}$} & \multirow[b]{2}{*}{$\begin{array}{l}\text { Formula for } \\
\text { Maximum Shear (1) }\end{array}$} & \multicolumn{2}{|c|}{ Minimum } \\
\hline & & & & L-X & $\mathrm{x}$ \\
\hline ES-20 & $0-0.500$ & $\begin{array}{l}\text { Under } 42^{\prime} \\
42^{\prime} \text { to } 120^{\prime \prime}\end{array}$ & $\begin{array}{c}V=\frac{36(X-4.67)}{L}-4 \\
V=\frac{36(X-9.33)}{L}\end{array}$ & 14 & $\begin{array}{r}14 \\
28 \\
\end{array}$ \\
\hline HS- 15 & $0-0.500$ & $\begin{array}{l}\text { Under } 42^{\prime} \\
42^{\prime} \text { to } 120^{\prime *}\end{array}$ & $\begin{array}{c}V=\frac{27(X-4.67)}{L}-3 \\
V=\frac{27(X-9.33)}{L}\end{array}$ & 14 & $\begin{array}{l}14 \\
28 \\
\end{array}$ \\
\hline H-20 & $0-0.500$ & to $35^{\prime *}$ & $V=\frac{20(X-2.8)}{L}$ & 0 & 14 \\
\hline H-15 & $0-0.500$ & $\cos 35^{\prime \prime}$ & $V=\frac{15(X-2.8)}{L}$ & 0 & 14 \\
\hline
\end{tabular}

(1) All values based on standard truck loadings.

- Truck loading does not govern shear beyond the lengths specified. Use lane loading.

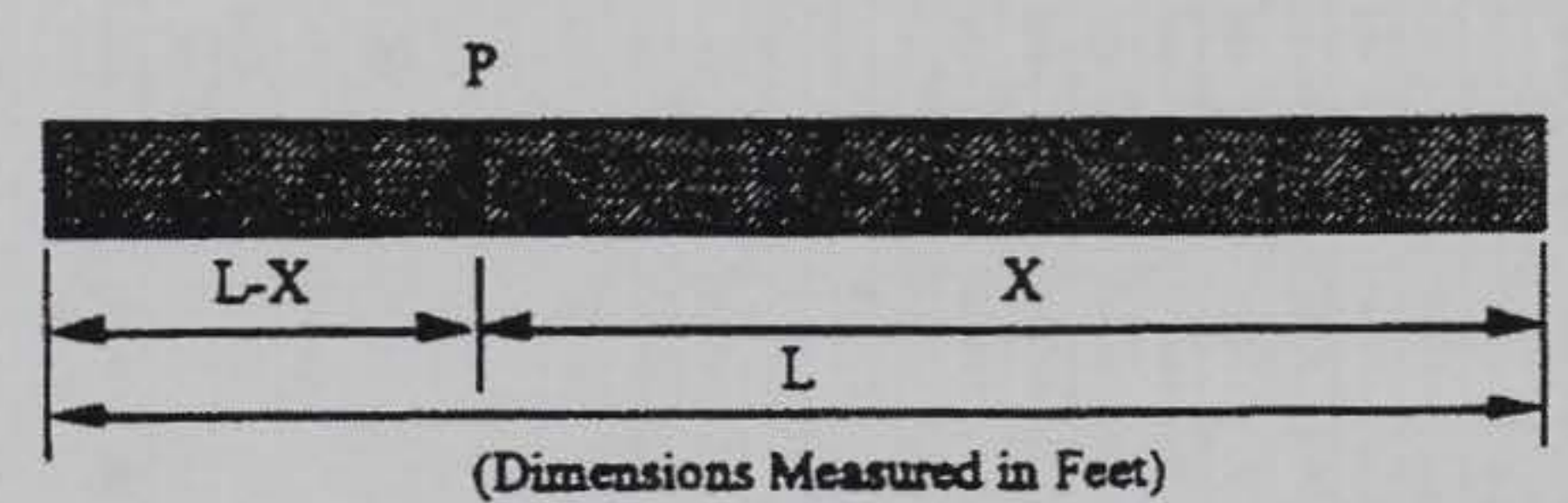

$V$ = Shear to Left of point "Pn in kips per wheel line.

Figure 37 (cont'd). Maximum stringer or girder shears for live loads (reference [1] 
Table C-2. Wheeled-and Tracked-Vehicle Moment (4- to 100-Foot Spans)

\begin{tabular}{|c|c|c|c|c|c|c|c|c|c|c|c|c|c|c|c|c|c|c|c|c|c|c|c|}
\hline \multirow{2}{*}{\multicolumn{3}{|c|}{ S. }} & \multicolumn{21}{|c|}{$\frac{0}{-1}$} \\
\hline & & & 4 & 6 & 8 & 10 & 12 & 14 & 16 & 18 & 20 & 25 & 30 & 35 & 40 & 45 & 50 & 55 & 60 & 70 & 80 & 90 & 100 \\
\hline \multirow{32}{*}{$\begin{array}{l}\mathscr{8} \\
\mathbb{0} \\
\frac{\mathbb{J}}{0}\end{array}$} & \multirow{2}{*}{4} & $w$ & 4.96 & 7.44 & 9.92 & 12.40 & 14.88 & 17.92 & 21.40 & 25.60 & 30.001 & 41.00 & 52.20 & 63.70 & 75.20 & 86.40 & 97.00 & 108.90 & 120.00 & 142.80 & 164.80 & 187.20 & 210.00 \\
\hline & & $\mathbf{T}$ & 2.64 & 6.00 & 9.92 & 14,00 & 18.00 & 22.10 & 25.90 & 29.90 & 34.00 & 44.00 & 54.00 & 63.70 & 73.80 & 83.70 & 94.00 & 103.40 & 114.00 & 134.40 & 153.60 & 174.60 & 194.00 \\
\hline & \multirow{2}{*}{8} & $w$ & 10.96 & 16.44 & 21.90 & 27.40 & 32.90 & 38.30 & 43.60 & 49.30 & 54.80 & 71.00 & 93.60 & 116.20 & 138.40 & 161.10 & 183.00 & 206.00 & 228.00 & 273.00 & 318.00 & 364.00 & 408.00 \\
\hline & & $T$ & 4.88 & 11.04 & 19.04 & 27.00 & 35.00 & 43.10 & 50.90 & 59.00 & 66.80 & 87.00 & 106.80 & 126.70 & 147.20 & 167.40 & 187.00 & 207.00 & 227.00 & 287.00 & 307.00 & 347.00 & 386.00 \\
\hline & \multirow{2}{*}{12} & $w$ & 16.00 & 24.00 & 32.00 & 40.00 & 48.00 & 56.00 & 64.00 & 72.00 & 80.80 & 112.50 & 145.20 & 180.60 & 218.00 & 256.00 & 293.00 & 331.00 & 368.00 & 444.00 & 518.00 & 592.00 & 668.00 \\
\hline & & $T$ & 5.44 & 12.00 & 21.30 & 33.00 & 44.90 & 57.10 & 69.10 & 81.00 & 92.80 & 123.00 & 153.00 & 182.70 & 213.00 & 243.00 & 273.00 & 303.00 & 332.00 & 393.00 & 453.00 & 513.00 & 572.00 \\
\hline & \multirow{2}{*}{16} & $w$ & 20.00 & 30.00 & 40.00 & 50.00 & 60.00 & 70.00 & 80.00 & 92.50 & 105.20 & 144.00 & 184.20 & 229.00 & 275.00 & 321.00 & 367.00 & 414.00 & 460.00 & 552.00 & 645.00 & 736.00 & 830.00 \\
\hline & & $\mathrm{T}$ & 7.12 & 15.96 & 28.50 & 44.00 & 60.00 & 75.90 & 91.80 & 108.00 & 124.00 & 164.00 & 204.00 & 244.00 & 284.00 & 324.00 & 364.00 & 404.00 & 444.00 & 524.00 & 603.00 & 684.00 & 764.00 \\
\hline & \multirow{2}{*}{20} & $w$ & 22.00 & 33.00 & 44.00 & 55.00 & 70.80 & 87.40 & 104.00 & 121.00 & 137.60 & 188.50 & 241.00 & 299.00 & 359.00 & 419.00 & 479.00 & 539.00 & 599.00 & 718.00 & 838.00 & 958.00 & $1,078.00$ \\
\hline & & $T$ & 8.88 & 20.00 & 35.50 & 55.00 & 74.90 & 94.90 & 114.90 & 135.00 & 154.80 & 205.00 & 255.00 & 305.00 & 355.00 & 405.00 & 455.00 & 505.00 & 554.00 & 655.00 & 755.00 & 855.00 & 954.00 \\
\hline & \multirow{2}{*}{24} & $w$ & 24.00 & 36.00 & 48.00 & 64.90 & $83.30 \mid$ & 102.80 & 122.60 & 142.20 & 162.00 & 223.00 & 285.00 & 353.00 & 422.00 & 492.00 & 562.00 & 633.00 & 702.00 & 843.00 & 982.00 & $1,121.00$ & $1,262.00$ \\
\hline & & $T$ & 10.64 & 24.00 & 42.70 & 66.00 & 90.00 & 114.00 & 137.90 & 162.00 & 186.00 & 246.00 & 306.00 & 366.00 & 426.00 & 486.00 & 546.00 & 606.00 & 666.00 & 785.00 & 906.00 & $1,026.00$ & $1,146.00$ \\
\hline & \multirow{2}{*}{30} & w & 26.70 & 40.40 & 53.90 & 70.40 & 91.70 & 113.10 & 134.70 & 156.60 & 178.00 & 246.00 & 316.00 & 398.00 & 482.00 & 567.00 & 652.00 & 737.00 & 822.00 & 991.00 & $1,162.00$ & $7+\infty 0^{\infty}$ & $1,500.00$ \\
\hline & & $T$ & 10.88 & 24.50 & 43.70 & 68.20 & 97.40 & 127.40 & 157.40 & 187.60 & 218.00 & 293.00 & 367.00 & 442.00 & 518.00 & 592.00 & 667.00 & 743.00 & 817.00 & 987.00 & $1,117.00$ & $1,287.00$ & $1,418.00$ \\
\hline & \multirow{2}{*}{40} & $\bar{w}$ & 34.00 & 51.00 & 68.00 & 85.00 & 108.30 & 133.80 & 159.40 & 185.00 & 210.00 & 277.00 & 359.00 & 442.00 & 553.00 & 671.00 & 788.00 & $905.00 \mid 1$ & $1,022.00$ & $1,257.00$ & $1,493.00$ & $1,728.00$ & $1,962.00$ \\
\hline & & $T$ & 13.36 & 30.00 & 53.30 & 83.40 & 120.00 & 158.90 & 200.00 & 240.00 & 280.00 & 380.00 & 480.00 & 580.00 & 680.00 & 780.00 & 880.00 & 980.001 & 1.080 .001 & $1,280.00$ & $1,480.00$ & $1,679.00$ & $1,880.00$ \\
\hline & \multirow{2}{*}{50} & $w$ & 40.00 & 60.00 & 80.00 & 100.00 & 125.00 & 154.30 & 183.70 & 213.00 & 243.00 & 320.00 & 415.00 & 511.00 & 656.00 & 800.00 & 945.00 & $1,090.0011$ & $1,235.00$ & $1,525.00$ & $1,814.00$ & $2,100.00$ & $2,390.00$ \\
\hline & & $T$ & 15.36 & 34.60 & 61.60 & 96.20 & 138.50 & 187.60 & 237.00 & 288.00 & 338.00 & 463.00 & 587.00 & 713.00 & 838.00 & 962.00 & $1,087.00$ & $1,212.00$ & $1,338.00$ & $1,588.00$ & $1,837.00$ & $2,090.00$ & $2,340.00$ \\
\hline & \multirow{2}{*}{60} & $w$ & 46.00 & 69.00 & 92.00 & 115.00 & 138.00 & 170.00 & 205.00 & 240.00 & 276.00 & 365.00 & 474.00 & 584.00 & 740.00 & 914.00 & 1.089 .00 & 1.263 .00 & \begin{tabular}{|l|l|l|l}
1.438 .00 & 1 \\
\end{tabular} & $1,786.00$ & 2.140 .00 & $2,490.00$ & $2,840.00$ \\
\hline & & $T$ & 17.12 & 38.50 & 68.60 & 107.20 & 154.30 & 210.00 & 270.00 & 330.00 & 390.00 & 540.00 & 690.00 & 840.00 & 990.00 & $1,140.00$ & $1,290.00$ & $1,440.00$ & $1,590.00$ & $1,690.00$ & $2,190.00$ & $2,490.00$ & $2,790.00$ \\
\hline & \multirow{2}{*}{70} & $w$ & 51.00 & 76.40 & 101.90 & 127.40 & 157.90 & 198.20 & 239.00 & 280.00 & 322.00 & 426.00 & 557.00 & 688.00 & 856.00 & $1,057.00$ & $1,257.00$ & $1,458.00$ & $1,658.00$ & 2.060 .00 & $2,460.00$ & $2,870.00$ & $3,270.00$ \\
\hline & & $T$ & 18.64 & 42.00 & 74.70 & 116.60 & 168.00 & 229.00 & 298.00 & 368.00 & 438.00 & 613.00 & 787.00 & 963.00 & $1,138.00$ & $1,312.00$ & $1,487.00$ & $1,662.00$ & $1,837.00$ & $2,190.00$ & $2,540.00$ & $2,890.00$ & $3,240.00$ \\
\hline & \multirow{2}{*}{80} & $w$ & 56.00 & 84.00 & 112.00 & 140.00 & 180.50 & 227.00 & 273.00 & 320.00 & 368.00 & 486.00 & 636.00 & 786.00 & 936.00 & $1,103.00$ & $1,332.00$ & $1,561.00$ & $1,790.00$ & $2,250.00$ & $2,710.00$ & 3.170 .00 & $3,630.00$ \\
\hline & & $T$ & 20.00 & 45.00 & 80.00 & 125.00 & 180.00 & 245.00 & 320.00 & 400.00 & 480.00 & 680.00 & 880.00 & $1,080.00$ & $1,280.00$ & $1,480.00$ & 1.680 .00 & $1,880.00$ & $2,000.00$ & $2,480.00$ & $2,880.00$ & $3,280.00$ & $3,680.00$ \\
\hline & \multirow{2}{*}{90} & w & 60.00 & 90.00 & 120.00 & 151.80 & 203.00 & 225.00 & 308.00 & 360.00 & 414.00 & 547.00 & 716.00 & \begin{tabular}{|l|}
884.00 \\
\end{tabular} & 1.053 .00 & $1,242.00$ & 1.499 .00 & 1.757 .00 & $2,010.00$ & $2,530.00$ & $3,050.00$ & $3,560.00$ & $4,080.00$ \\
\hline & & $T$ & 21.20 & 47.60 & 84.60 & 132.40 & 190.60 & 259.00 & 339.00 & 427.00 & 518.00 & 743.00 & 967.00 & $1,193.00$ & $1,418.00$ & $1,643.00$ & $1,867.00$ & 2.090 .00 & $2,320.00$ & $2,770.00$ & $3,220.00$ & $3,670.00$ & $4,120.00$ \\
\hline & \multirow{2}{*}{100} & $w$ & 64.00 & 96.00 & 128.00 & 160.00 & 203.00 & 259.00 & 317.00 & 375.00 & 434.00 & 581.00 & 765.00 & 953.00 & $1,140.00$ & $1,328.00$ & $1,543.00$ & $1,828.00$ & $2,110.00$ & $2,690.00$ & $3,260.00$ & $3,830.00$ & $4,410.00$ \\
\hline & & $T$ & 22.20 & 50.00 & 89.00 & 138.80 & 199.90 & 272.00 & 356.00 & 450.00 & 550.00 & 800.00 & $1,050.00$ & $1,300.00$ & $1,550.00$ & $1,800.00$ & $2,050.00$ & $2,300.00$ & $2,550.00$ & $3,050.00$ & $3,550.00$ & $4,050.00$ & $4,550.00$ \\
\hline & \multirow{2}{*}{120} & w & 72.00 & 108.00 & 144.00 & 180.00 & 243.00 & 311.00 & 380.00 & 450.00 & 520.00 & 697.00 & 918.00 & $1,143.00$ & $1,368.00$ & $1,593.00$ & $1,851.00$ & $2,195.00$ & $2,540.00$ & 3.230 .00 & $3,910.00$ & $4,600.00$ & $5,290.00$ \\
\hline & & $T$ & 24.00 & 54.00 & 96.00 & 150.00 & 216.00 & 294.00 & 384.00 & 486.00 & 600.00 & 900.00 & $1,200.00$ & $1,500.00$ & $1,800.00$ & $2,100.00$ & $2,400.00$ & $2,700.00$ & 3.000 .00 & $3,600,00$ & $4,200.00$ & $4,800.00$ & $5,400.00$ \\
\hline & \multirow{2}{*}{150} & $w$ & 84.00 & 126.00 & 168.00 & 210.00 & 253.00 & 331.00 & 410.00 & 491.00 & 572.00 & 777.00 & 1.032 .00 & $1,297.00$ & $1,562.00$ & $1,827.00$ & $2,092.00$ & $2,405.00$ & 2.830 .00 & 3.670 .00 & $4,520.00$ & $5,560.00$ & $8,210.00$ \\
\hline & & $T$ & 25.00 & 56.30 & 100.00 & 156.20 & 225.00 & 306.00 & 400.00 & 506.00 & 625.00 & 975.00 & $1,350.00$ & $1,725.00$ & 2.100 .00 & $2,478.00$ & $2,850.00$ & 3.230 .00 & $3,600.00$ & $4,350.00 \mid$ & $5,100.00$ & $5,850.00$ & $6,600.00$ \\
\hline
\end{tabular}

Figure 38. Maximum longitudinal bending moments for military live loads 
Table C-3. Wheeled- and Tracked-Vehicle Moment (110- to 300-Foot Spans) (Foot-Kips)

\begin{tabular}{|c|c|c|c|c|c|c|c|c|c|c|c|c|c|c|c|c|c|c|c|c|c|c|}
\hline \multirow{2}{*}{ (x) } & & & \multicolumn{20}{|c|}{ Span Length (Feet) } \\
\hline & & & 110 & 120 & 130 & 140 & 150 & 160 & 170 & 180 & 190 & 200 & 210 & 220 & 230 & 240 & 250 & 260 & 270 & 280 & 290 & 300 \\
\hline \multirow{32}{*}{$\frac{\mathscr{d}}{\mathrm{d}}$} & \multirow{2}{*}{4} & $w$ & 233 & 254 & 278 & 270 & 321 & 346 & 367 & 389 & 414 & 448 & 491 & 532 & 579 & 619 & 665 & 733 & 799 & 868 & 934 & 1,002 \\
\hline & & $T$ & 213 & 233 & 255 & 274 & 294 & 314 & 333 & 353 & 391 & 428 & 466 & 502 & 538 & 586 & 645 & 707 & 767 & 823 & 887 & 948 \\
\hline & \multirow{2}{*}{8} & $w$ & 453 & 499 & 543 & 588 & 633 & 678 & 724 & 767 & 813 & 880 & 966 & 1.052 & 1,136 & 1,224 & 1,310 & 1,414 & 1,550 & 1,686 & 1,821 & 1.956 \\
\hline & & $T$ & 427 & 468 & 507 & 546 & 588 & 627 & 666 & 706 & 775 & 852 & 924 & 1,003 & 1,078 & 1,162 & 1,285 & 1,404 & 1,523 & 1,641 & 1,763 & 1,884 \\
\hline & \multirow{2}{*}{12} & $w$ & 744 & 818 & 892 & 969 & 1.044 & 1.117 & 1193 & 1,287 & 1,341 & 1,416 & 1,491 & 1.593 & 1.734 & 1.877 & 2,020 & 2,160 & 2,310 & 2,450 & 2,660 & 2,890 \\
\hline & & $\mathbf{T}$ & 634 & 694 & 754 & 812 & 873 & 934 & 993 & 1.051 & 1,136 & 1,248 & 1,361 & 1,474 & 1,587 & 1,704 & 1,855 & 2,040 & 2,220 & 2,400 & 2,580 & 2,750 \\
\hline & \multirow{2}{*}{16} & $w$ & 922 & 1.015 & 1,108 & 1.198 & 1,293 & 1,386 & 1,476 & 1,570 & 1,661 & 1,752 & 1,848 & 1,958 & 2,130 & 2,390 & 2,490 & 2,660 & 2,840 & 3.020 & 3.290 & 3.570 \\
\hline & & $\mathbf{T}$ & 845 & 924 & 1,004 & 1.084 & 1,164 & 1.245 & 1,323 & 1,404 & 1,516 & 1,664 & 1.814 & 1,967 & 2.120 & 2,270 & 2,480 & 2,710 & 2,950 & 3,200 & 3,430 & 3,680 \\
\hline & \multirow{2}{*}{20} & $w$ & 1,199 & 1,318 & 1,438 & 1.557 & 1,677 & 1,798 & 1,918 & 2.040 & 2.160 & 2,280 & 2,400 & 2,540 & 2,770 & 3,000 & 3,230 & 3,460 & 3,690 & 3,920 & 4,270 & 4.630 \\
\hline & & $T$ & 1,054 & 1.154 & 1,256 & 1,355 & 1,455 & 1,555 & 1,656 & 1,753 & 1,896 & 2,080 & 2,270 & 2,460 & 2,650 & 2,840 & 3,100 & 3,400 & 3,690 & 3,990 & 4,290 & 4,600 \\
\hline & \multirow{2}{*}{24} & $w$ & 1,401 & 1.543 & 1.682 & 1,823 & 1,962 & 2,100 & 2,240 & 2,380 & 2,520 & 2,660 & 2.800 & 2,970 & 3,240 & 3,500 & 3.770 & 4,040 & 4,310 & 4,580 & 4,990 & 5,410 \\
\hline & & $T$ & 1,265 & 1,385 & 1,505 & 1,627 & 1,746 & 1,866 & 1,986 & 2,110 & 2,280 & 2,500 & 2,720 & 2,950 & 3,170 & 3,400 & 3,720 & 4,070 & 4,430 & 4,790 & 5,160 & 5,510 \\
\hline & \multirow{2}{*}{30} & w & 1,670 & 1.841 & 2,010 & 2,180 & 2,350 & 2,520 & 2,690 & 2,860 & 3,030 & 3,200 & 3,370 & 3,590 & 3,910 & 4,240 & 4.570 & 4,890 & 5,220 & 5,550 & 6,020 & 6.530 \\
\hline & & $T$ & 1,566 & 1,718 & 1,867 & 2,020 & 2,170 & 2,310 & 2,470 & 2,620 & 2,790 & 3,070 & 3,350 & 3,630 & 3,910 & 4.200 & 4,510 & 4,960 & 5,410 & 5,860 & 6,310 & 6,760 \\
\hline & \multirow{2}{*}{40} & $w$ & 2,200 & 2,430 & 2,670 & 2,900 & 3,140 & 3,370 & 3,610 & 3,840 & 4,080 & 4.310 & 4,550 & 4,780 & 5,140 & 5,590 & 6,040 & 6,490 & 6.940 & 7,400 & 7,850 & 8,310 \\
\hline & & $T$ & 2,080 & 2.280 & 2,480 & 2,680 & 2,880 & 3,080 & 3,280 & 3,480 & 3,680 & 4.050 & 4,430 & 4,800 & 5,180 & 5,560 & 5,940 & 6,520 & 7,120 & 7,720 & 8,320 & 8,920 \\
\hline & \multirow{2}{*}{50} & $w$ & 2,680 & 2,970 & 3,260 & 3.550 & 3,840 & 4,130 & 4,420 & 4,710 & 5,000 & 5,290 & 5,580 & 5,870 & 6,370 & 6,930 & 7,480 & 8.030 & 8,590 & 9.150 & 9,710 & 10,270 \\
\hline & & $T$ & 2,590 & 2,840 & 3,090 & 3,340 & 3,590 & 3,840 & 4,090 & 4,340 & 4,590 & 5,020 & 5,490 & 5,950 & 6,430 & 6,900 & 7.380 & 8,040 & 8,790 & 9,540 & 10,290 & 11,040 \\
\hline & \multirow{2}{*}{60} & $w$ & 3.190 & 3,540 & 3,880 & 4,230 & 4,580 & 4,930 & 5,280 & 5.630 & 5,990 & 6,330 & 6,680 & 7.030 & 7,410 & 8.070 & 8,740 & 9,410 & 10,050 & 10,760 & 11,430 & 12.110 \\
\hline & & $T$ & 3.090 & 3,390 & 3,690 & 4.000 & 4,290 & 4,590 & 4,890 & 5,190 & 5,490 & 5,970 & 6.530 & 7,090 & 7.650 & 8.220 & 8,800 & 9,510 & 10,410 & 11,310 & 12,210 & 13.110 \\
\hline & \multirow{2}{*}{70} & $w$ & 3.670 & 4,070 & 4.470 & 4,880 & 5,280 & 5,680 & 6,080 & 6.490 & 6,890 & 7,290 & 7,690 & 8,100 & 8.500 & 9,260 & 10,030 & 10,800 & 11,570 & 12,350 & 13,130 & 13,910 \\
\hline & & $T$ & 3,590 & 3,940 & 4,290 & 4,640 & 4,990 & 5,340 & 5.690 & 6,040 & 6,390 & 8.900 & 7,550 & 8,200 & 8,860 & 9,530 & 10,200 & 10,940 & 11,990 & 13,040 & 14,090 & 15,140 \\
\hline & \multirow{2}{*}{80} & $w$ & 4,090 & 4,550 & 5,010 & 5,460 & 5.930 & 6,380 & 6,840 & 7,300 & 7,780 & 8.820 & 8,680 & 9,140 & 9,600 & 10,180 & 11,060 & 11,940 & 12,830 & 13,720 & 14,610 & 15,500 \\
\hline & & $T$ & 4,080 & 4,480 & 4,880 & 5,280 & 5.680 & 6,080 & 6.480 & 6,880 & 7,280 & 7,810 & 8.550 & 9.300 & 10,060 & 10,810 & 11,580 & 12,340 & 13,520 & 14,720 & 15,920 & 17,120 \\
\hline & \multirow{2}{*}{90} & $w$ & 4,600 & 5,110 & 5,630 & 6.150 & 6,670 & 7,180 & 7.700 & 8,220 & 8,730 & 9,250 & 9,770 & 10,290 & 10,810 & 11,450 & 12,450 & 13,440 & 14,430 & 15,440 & 16,440 & 17,440 \\
\hline & & $T$ & 4570 & 5,020 & 5,470 & 5,920 & 8,370 & 6,820 & 7,270 & 7,720 & 8,170 & 8,700 & 9,530 & 10,380 & 11,220 & 12,080 & 12,940 & 13,800 & 15,010 & 16,360 & 17,710 & 19,060 \\
\hline & \multirow{2}{*}{100} & $w$ & 4,980 & 5,560 & 6,130 & 6,710 & 7,280 & 7,860 & 8.430 & 9.000 & 9,580 & 10,160 & 10,730 & 11,300 & 11,880 & 12,450 & 13,480 & 14.580 & 15,690 & 16,800 & 17,910 & 19,030 \\
\hline & & $T$ & 5,050 & 5,550 & 6.050 & 6,550 & 7,050 & 7,550 & 8.050 & 8.550 & 9,050 & 9,570 & 10,500 & 11,440 & 12,380 & 13,330 & 14,280 & 15,230 & 16,450 & 17,950 & 19,450 & 21,000 \\
\hline & \multirow{2}{*}{120} & $w$ & 5,980 & 6.670 & 7,360 & 8.050 & 8,740 & 9,430 & 10,120 & 10.810 & 11,500 & 12,180 & 12,870 & 13.570 & 14,260 & 14,940 & 16.170 & 17,490 & 18,820 & 20,200 & 21,500 & 22,800 \\
\hline & & $T$ & 6,000 & 6.600 & 7,200 & 7,800 & 8,400 & 9,000 & 9,600 & 10,200 & 10,800 & 11,400 & 12,380 & 13,500 & 14,630 & 15,760 & 16,910 & 18,050 & 19,200 & 21,000 & 22,800 & 24,600 \\
\hline & \multirow{2}{*}{150} & $w$ & 7.060 & 7,910 & 8,760 & 9.600 & 10,450 & 11,300 & 12,150 & 13,000 & 13,850 & 14,700 & 15,550 & 16,400 & 17,250 & 18,100 & 19,300 & 20,900 & 22,500 & 24,200 & 25,800 & 27,500 \\
\hline & & $T$ & 7,350 & 8,100 & 8,850 & 9.600 & 10.350 & 11,100 & 11,850 & 12,600 & 13,350 & 14,100 & 14.910 & 16,320 & 17.720 & 19,140 & 20,600 & 22,000 & 23,400 & 24,700 & 27,200 & 29,400 \\
\hline
\end{tabular}

W = Wheeled Vehicle Moment T I Tracked Vehicte Moment 


\begin{tabular}{|c|c|c|c|c|c|c|c|c|c|c|c|c|c|c|c|c|c|c|c|c|c|c|c|}
\hline \multirow{2}{*}{\multicolumn{3}{|c|}{$3^{3}$}} & \multicolumn{21}{|c|}{ Span Length (Feet) } \\
\hline & & & 4 & 6 & 8 & 10 & 12 & 14 & 16 & 18 & 20 & 25 & 30 & 35 & 40 & 45 & 50 & 55 & 60 & 70 & 80 & 90 & 100 \\
\hline \multirow{32}{*}{$\begin{array}{l}\frac{8}{0} \\
\frac{\pi}{0}\end{array}$} & & w & 2.50 & 2.50 & 2.63 & 2.80 & 2.92 & 3.14 & 3.31 & 3.44 & 3.55 & 3.74 & 3.87 & 3.96 & 4.03 & 4.08 & 4.12 & 4.15 & 4.18 & 4.23 & 4.26 & 4.29 & 4.31 \\
\hline & & $T$ & 1.33 & 2.00 & 2.50 & 2.80 & 3.00 & 3.14 & 3.25 & 3.33 & 3.40 & 3.52 & 3.60 & 3.66 & 3.70 & 3.73 & 3.76 & 3.78 & 3.80 & 3.83 & 3.85 & 3.87 & 3.88 \\
\hline & \multirow{2}{*}{8} & w & 5.50 & 5.50 & 5.50 & 5.50 & 5.50 & 5.50 & 5.63 & 8.00 & 6.30 & 6.84 & 7.20 & 7.46 & 7.65 & 7.80 & 7.92 & 8.02 & 8.10 & 8.23 & 8.33 & 8.40 & 8.46 \\
\hline & & $T$ & 2.46 & 3.69 & 4.75 & 5.40 & 5.83 & 6.14 & 6.38 & 6.56 & 6.70 & 8.96 & 7.13 & 7.26 & 7.35 & 7.42 & 7.48 & 7.53 & 7.57 & 7.63 & 7.68 & 7.71 & 7.74 \\
\hline & \multirow{2}{*}{12} & $\bar{w}$ & 8.00 & 8.00 & 8.00 & 8.00 & 8.33 & 8.57 & 9.13 & 9.56 & 9.90 & 10.52 & 10.93 & 11.23 & 11.45 & 11.62 & 11.76 & 11.87 & 12.13 & 12.54 & 12.85 & 13.09 & 13.28 \\
\hline & & $T$ & 2.87 & 4.00 & 5.33 & 6.60 & 7.50 & 8.14 & 8.62 & 9.00 & 9.30 & 9.84 & 10.20 & 10.46 & 10.65 & 10.80 & 10.92 & 11.02 & 11.10 & 11.23 & 11.32 & 11.40 & 11.46 \\
\hline & \multirow{2}{*}{16} & $w$ & 10.00 & 10.00 & 10.00 & 10.40 & 10.83 & 11.14 & 11.75 & 12.22 & 12.60 & 13.28 & 13.73 & 14.06 & 14.30 & 14.49 & 14.84 & 14.78 & 14.87 & 15.34 & 15.74 & 16.04 & 16.29 \\
\hline & & $T$ & 3.56 & 5.33 & 7.11 & 8.80 & 10.00 & 10.86 & 11.50 & 12.00 & 12.40 & 13.12 & 13.60 & 13.94 & 14.20 & 14.40 & 14.56 & 14.69 & 14.80 & 14.97 & 15.10 & 15.22 & 15.28 \\
\hline & \multirow{2}{*}{20} & $w$ & 11.00 & 11.33 & 12.75 & 13.60 & 14.17 & 14.57 & 15.38 & 16.00 & 16.50 & 17.40 & 18.00 & 18.43 & 18.75 & 19.00 & 19.20 & 19.36 & 19.50 & 19.97 & 20.48 & 20.87 & 21.18 \\
\hline & & $T$ & 4.44 & 6.67 & 8.89 & 11.00 & 12.50 & 13.57 & 14.38 & 15.00 & 15.50 & 18.40 & 17.00 & 17.43 & 17.75 & 18.00 & 18.20 & 18.36 & 18.50 & 18.72 & 18.88 & 19.00 & 19.10 \\
\hline & \multirow{2}{*}{24} & $w$ & 12.00 & 13.33 & 15.00 & 16.00 & 16.67 & 17.14 & 18.13 & 18.89 & 19.50 & 20.60 & 21.33 & 21.86 & 22.25 & 22.56 & 22.80 & 23.00 & 23.17 & 23.48 & 24.03 & 24.47 & 24.82 \\
\hline & & $T$ & 5.53 & 8.00 & 10.67 & 13.20 & 15.00 & 16.28 & 17.25 & 18.00 & 18.60 & 19.68 & 20.40 & 20.92 & 21.30 & 21.60 & 21.84 & 22.04 & 22.20 & 22.46 & 22.65 & 22.80 & 22.92 \\
\hline & \multirow{2}{*}{30} & $w$ & 13.50 & 14.67 & 16.50 & 17.60 & 18.33 & 18.86 & 20.00 & 20.89 & 21.60 & 22.88 & 23.73 & 24.34 & 24.80 & 25.16 & 25.60 & 26.38 & 27.00 & 28.00 & 28.75 & 29.33 & 29.80 \\
\hline & & $T$ & 5.46 & 8.18 & 10.91 & 13.64 & 16.25 & 18.22 & 19.69 & 20.83 & 21.75 & 23.40 & 24.50 & 25.28 & 25.88 & 28.33 & 26.70 & 27.00 & 27.25 & 27.64 & 27.94 & 28.17 & 28.35 \\
\hline & \multirow{2}{*}{40} & $w$ & 17.00 & 17.33 & 19.50 & 20.80 & 21.67 & 22.29 & 22.75 & 23.89 & 24.80 & 26.72 & 28.93 & 30.51 & 31.70 & 32.62 & 33.36 & 34.42 & 35.47 & 37.11 & 38.35 & 39.31 & 40.08 \\
\hline & & $T$ & 6.67 & 10.00 & 13.33 & 16.67 & 20.00 & 22.86 & 25.00 & 26.67 & 28.00 & 30.40 & 32.00 & 33.14 & 34.00 & 34.67 & 35.20 & 35.64 & 36.00 & 36.57 & 37.00 & 37.33 & 37.60 \\
\hline & \multirow{2}{*}{50} & $w$ & 20.00 & 20.00 & 22.50 & 24.00 & 25.00 & 25.71 & 26.25 & 27.56 & 28.60 & 31.60 & 34.67 & 36.86 & 38.50 & 40.31 & 42.08 & 43.53 & 44.73 & 46.63 & 48.05 & 49.16 & 50.04 \\
\hline & & $T$ & 7.69 & 11.54 & 15.38 & 19.23 & 23.08 & 26.78 & 29.69 & 31.94 & 33.75 & 37.00 & 39.17 & 40.72 & 41.88 & 42.78 & 43.50 & 44.09 & 44.58 & 45.36 & 45.94 & 46.39 & 46.75 \\
\hline & \multirow{2}{*}{60} & $\bar{w}$ & 23.00 & 23.00 & 24.75 & 27.00 & 28.50 & 29.57 & 30.38 & 38.44 & 32.70 & 35.52 & 39.93 & 43.09 & 45.45 & 47.29 & 48.76 & 49.96 & 51.43 & 54.09 & 56.08 & 57.62 & 58.86 \\
\hline & & $T$ & 8.57 & 12.86 & 17.14 & 21,43 & 25.72 & 30.00 & 33.75 & 36.67 & 39.00 & 43.20 & 46.00 & 48.00 & 49.50 & 50.07 & 51.60 & 52.36 & 53.00 & 54.00 & 54.75 & 55.33 & 55.60 \\
\hline & \multirow{2}{*}{70} & $w$ & 25.50 & 25.50 & 28.68 & 31.50 & 33.25 & 34.50 & 35.44 & 36.75 & 38.33 & 41.16 & 45.97 & 49.40 & 51.98 & 53.98 & 55.58 & 56.89 & 58.22 & 61.40 & 63.7 & 65.64 & 67.13 \\
\hline & & $T$ & 9.33 & 14.00 & 18.67 & 23.33 & 28.00 & 32.67 & 37.19 & 40.83 & 43.75 & 49.00 & 52.50 & 55.00 & 56.88 & 58.33 & 59.50 & 60.46 & 61.25 & 62.50 & 63.44 & 64.17 & 64.75 \\
\hline & \multirow{2}{*}{80} & $w$ & 28.00 & 28.00 & 33.00 & 36.00 & 38.00 & 39.43 & 40.50 & 42.00 & 43.80 & 47.04 & 49.20 & 53.26 & 56.60 & 59.20 & 61.28 & 62.98 & 84.40 & 66.63 & 69.70 & 72.18 & 74.16 \\
\hline & & $T$ & 10.00 & 15.00 & 20.00 & 25.00 & 30.00 & 35.00 & 40.00 & 44.44 & 48.00 & 54.40 & 58.67 & 61.72 & 64.00 & 65.78 & 67.20 & 68.36 & 69.33 & 70.86 & 72.00 & 72.89 & 73.60 \\
\hline & \multirow{2}{*}{90} & $w$ & 30.00 & 31.50 & 37.13 & 40.50 & 42.75 & 44.36 & 45.56 & 47.25 & 49.28 & 52.92 & 55.35 & 59.91 & 63.68 & 66.60 & 68.94 & 70.85 & 72.45 & 74.96 & 78.41 & 81.20 & 83.43 \\
\hline & & $T$ & 10.59 & 15.88 & 21.18 & 26.47 & 31.76 & 37.08 & 42.35 & 47.50 & 51.75 & 59.40 & 64.50 & 68.14 & 70.88 & 73.00 & 74.70 & 76.09 & 77.25 & 79.07 & 80.44 & 81.50 & 82.35 \\
\hline & \multirow{2}{*}{100} & $w$ & 32.00 & 32.00 & 37.50 & 42.00 & 45.00 & 47.14 & 48.75 & 50.00 & 52.50 & 57.00 & 60.02 & 64.57 & 69.00 & 72.44 & 75.20 & 77.45 & 7 & 82.29 & 84.69 & 88.06 & 90.75 \\
\hline & & $T$ & 11.11 & 16.67 & 22.22 & 27.78 & 33.33 & 38.89 & 44,44 & 50.00 & 55.00 & 64.00 & 70.00 & 74.28 & 77.50 & 80.00 & 82.00 & 83.64 & 85.00 & 87.14 & 88.75 & 90.00 & 91.00 \\
\hline & \multirow{2}{*}{120} & $w$ & 36.00 & 36.00 & 45.00 & 50.40 & 54.00 & 56.57 & 38.50 & 60.00 & 63.00 & 68.40 & 72.02 & 77.49 & 82.80 & 86.93 & 90.24 & 92.94 & 95.20 & 98.74 & 101.60 & 105.70 & 108.90 \\
\hline & & $T$ & 12.00 & 18.00 & 24.00 & 30.00 & 36.00 & 42.00 & 48.00 & 54.00 & 60.00 & 72.00 & 80.00 & 85.71 & 90.00 & 93.33 & 96.00 & 98.18 & 100.00 & 102.90 & 105.00 & 108.70 & 108.00 \\
\hline & \multirow{2}{*}{150} & $w$ & 42.00 & 42.00 & 47.25 & 54.60 & 59.50 & 63.00 & 65.63 & 67.67 & 70.40 & 77.52 & 82.98 & 85.66 & 89.45 & 95.76 & 101.20 & 105.40 & 109.00 & 114.70 & 121.60 & 127.00 & 131.30 \\
\hline & & $T$ & 12.50 & 18.75 & 25.00 & 31.25 & 37.50 & 43.75 & 50.00 & 56.25 & 62.50 & 78.00 & 90.00 & 98.57 & 105.00 & 110.00 & 114.00 & 117.30 & 120.00 & 124.30 & 127.50 & 130.00 & 132.00 \\
\hline
\end{tabular}

W - Wheeled Vehicle Shear T - Tracked Vehicle Shear

Figure 39. Maximum endspan shears for military live loads 
Table C-5. Wheeled- and Tracked Vehicle Shear (110- to 300-Foot Spans)

Note: in units of U.S. Tons

\begin{tabular}{|c|c|c|c|c|c|c|c|c|c|c|c|c|c|c|c|c|c|c|c|c|c|c|}
\hline \multirow{2}{*}{\multicolumn{3}{|c|}{ (6) }} & \multicolumn{20}{|c|}{ Span Length (Feet) } \\
\hline & & & 110 & 120 & 130 & 140 & 150 & 160 & 170 & 180 & 190 & 200 & 210 & 220 & 230 & 240 & 250 & 260 & 270 & 280 & 290 & 300 \\
\hline \multirow{32}{*}{$\frac{g}{8}$} & \multirow{2}{*}{4} & $w$ & 4.33 & 4.52 & 4.83 & 5.13 & 5.39 & 5.61 & 5.81 & 5.99 & 6.15 & 6.29 & 8.42 & 6.54 & 6.70 & 6.96 & 7.22 & 7.47 & 7.69 & 7.90 & 8.09 & 8.27 \\
\hline & & $T$ & 3.94 & 4.27 & 4.56 & 4.80 & 5.01 & 5.20 & 5.36 & 5.51 & 5.64 & 5.78 & 5.87 & 6.05 & 6.31 & 6.55 & 6.77 & 6.97 & 7.16 & 7.33 & 7.49 & 7.64 \\
\hline & \multirow{2}{*}{8} & $w$ & 8.51 & 8.75 & 9.28 & 9.90 & 10.44 & 10.91 & 11.33 & 11.70 & 12.03 & 12.33 & 12.60 & 12.84 & 13.10 & 13.53 & 14.04 & 14.54 & 15.00 & 15.43 & 15.83 & 16.20 \\
\hline & & $\mathbf{T}$ & 7.83 & 8.47 & 9.05 & 9.54 & 9.97 & 10.35 & 10.68 & 10.98 & 11.24 & 11.48 & 11.70 & 12.03 & 12.55 & 13.02 & 13.46 & 13.87 & 14.24 & 14.59 & 14.92 & 15.22 \\
\hline & \multirow{2}{*}{12} & $w$ & 13.44 & 13.57 & 13.77 & 14.21 & 15.13 & 16.04 & 16.86 & 17.59 & 18.24 & 18.83 & 19.36 & 19.85 & 20.29 & 20.69 & 21.06 & 21.50 & 22.15 & 22.91 & 23.67 & 24.38 \\
\hline & & $T$ & 11.52 & 12.20 & 13.10 & 13.89 & 14.58 & 15.15 & 15.67 & 16.13 & 16.55 & 18.92 & 17.26 & 17.58 & 18.23 & 18.97 & 19.66 & 20.28 & 20.87 & 21.41 & 21.91 & 22.38 \\
\hline & \multirow{2}{*}{16} & $w$ & 16.50 & 16.65 & 16.89 & 17.41 & 18.55 & 19.67 & 20.69 & 21.59 & 22.41 & 23.14 & 23.00 & 24.40 & 24.94 & 25.45 & 25.91 & 26.43 & 27.22 & 28.16 & 29.10 & 29.98 \\
\hline & & $T$ & 15.35 & 16.27 & 17.48 & 18.51 & 19.41 & 20.20 & 20.89 & 21.51 & 22.08 & 22.56 & 23.01 & 23.43 & 24.31 & 25.30 & 26.21 & 27.05 & 27.82 & 28.54 & 29.21 & 29.84 \\
\hline & \multirow{2}{*}{20} & $w$ & 21.44 & 21.65 & 21.95 & 22.63 & 24.12 & 25.58 & 26.89 & 28.07 & 29.12 & 30.06 & 30.91 & 31.69 & 32.40 & 33.05 & 33.65 & 34.32 & 35.36 & 36.58 & 37.80 & 38.94 \\
\hline & & $\mathbf{T}$ & 19.19 & 20.33 & 21.85 & 23.14 & 24.27 & 25.25 & 26.12 & 26.89 & 27.58 & 28.20 & 28.76 & 29.29 & 30.39 & 31.62 & 32.76 & 33.81 & 34.78 & 35.68 & 36.52 & 37.30 \\
\hline & \multirow{2}{*}{24} & w & 25.11 & 25.35 & 25.71 & 26.51 & 28.28 & 29.98 & 31.51 & 32.87 & 33.67 & 35.18 & 36.17 & 37.07 & 37.90 & 38.65 & 39.34 & 40.14 & 41.38 & 42.79 & 44.21 & 45.54 \\
\hline & & $T$ & 23.03 & 24.40 & 26.22 & 27.77 & 29.12 & 30.30 & 31.34 & 32.27 & 33.09 & 33.84 & 34.51 & 35.15 & 36.47 & 37.95 & 39.31 & 40.57 & 41.73 & 42.81 & 43.82 & 44.76 \\
\hline & \multirow{2}{*}{30} & $w$ & 30.18 & 30.50 & 30.95 & 31.91 & 33.92 & 35.98 & 37.36 & 39.53 & 41.03 & 42.38 & 43.60 & 44.71 & 45.72 & 46.65 & 47.50 & 48.48 & 49.91 & 51.60 & 53.34 & 54.96 \\
\hline & & $T$ & 28.50 & 29.55 & 31.85 & 33.80 & 35.60 & 37.13 & 38.47 & 39.67 & 40.74 & 41.70 & 42.57 & 43.38 & 44.47 & 46.31 & 48.06 & 49.67 & 51.17 & 52.55 & 53.84 & 55.05 \\
\hline & \multirow{2}{*}{40} & $\bar{w}$ & 40.71 & 41.23 & 41.68 & 42.86 & 44.24 & 48.75 & 49.36 & 51.84 & 54.06 & 56.06 & 57.87 & 59.51 & 61.01 & 62.38 & 63.65 & 64.82 & 66.21 & 67.70 & 69.81 & 72.04 \\
\hline & & $T$ & 37.82 & 38.89 & 41.85 & 44.57 & 46.93 & 49.00 & 50.82 & 52.44 & 53.89 & 55.20 & 56.38 & 57.45 & 58.70 & 61.00 & 63.36 & 65.54 & 67.58 & 69.43 & 71.17 & 72.80 \\
\hline & \multirow{2}{*}{50} & $\bar{w}$ & 50.76 & 51.37 & 51.88 & 53.46 & 55.29 & 58.40 & 61.60 & 64.62 & 67.33 & 69.78 & 71.96 & 73.96 & 75.79 & 77.47 & 79.01 & 80.43 & 82.19 & 84.11 & 86.73 & 89.48 \\
\hline & & $T$ & 47.04 & 48.08 & 51.54 & 55.00 & 58.00 & 60.63 & 62.94 & 65.00 & 66.84 & 68.50 & 70.00 & 71.36 & 72.74 & 75.31 & 78.30 & 81.06 & 83.61 & 85.98 & 88.19 & 90.25 \\
\hline & \multirow{2}{*}{60} & $w$ & 59.87 & 60.71 & 61.43 & 62.41 & 63.57 & 67.18 & 70.99 & 74.74 & 78.17 & 81.26 & 84.06 & 86.60 & 88.92 & 91.05 & 93.01 & 94.62 & 96.49 & 98.60 & 100.92 & 103.87 \\
\hline & & $T$ & 56.18 & 57.14 & 60.92 & 65.14 & 68.80 & 72.00 & 74.82 & 77.33 & 79.58 & 81.60 & 83.43 & 85.09 & 88.65 & 89.29 & 92.88 & 96.23 & 99.33 & 102.20 & 104.90 & 107.40 \\
\hline & \multirow{2}{*}{70} & $w$ & 68.35 & 69.36 & 70.22 & 71.35 & 73.88 & 76.65 & 80.99 & 85.31 & 89.31 & 92.89 & 96.13 & 99.08 & 101.80 & 104.20 & 106.50 & 108.60 & 110.60 & 113.00 & 115.60 & 118.90 \\
\hline & & $T$ & 65.23 & 66.11 & 70.00 & 75.00 & 79.33 & 83.13 & 86.47 & 89.44 & 92.10 & 94.50 & 96.67 & 98.64 & 100.40 & 103.10 & 107.10 & 111.10 & 114.70 & 118.10 & 121.30 & 124.30 \\
\hline & \multirow{2}{*}{80} & $w$ & 75.78 & 77.13 & 78.28 & 79.26 & 81.71 & 84.35 & 87.95 & 92.62 & 97.43 & 101.80 & 105.70 & 109.20 & 112.50 & 115.50 & 118.20 & 120.70 & 123.10 & 125.30 & 128.10 & 131.00 \\
\hline & & $T$ & 74.18 & 75.00 & 78.85 & 84.57 & 89.60 & 93.89 & 97.77 & 101.20 & 104.30 & 107.10 & 109.60 & 112.00 & 114.10 & 116.70 & 121.00 & 125.50 & 129.80 & 133.70 & 137.40 & 140.80 \\
\hline & \multirow{2}{*}{90} & $w$ & 85.25 & 86.77 & 88.06 & 89.16 & 91.92 & 94.89 & 98.95 & 104.20 & 109.60 & 114.50 & 118.90 & 122.90 & 126.60 & 129.90 & 133.00 & 135.80 & 138.50 & 140.90 & 144.10 & 147.40 \\
\hline & & $T$ & 83.04 & 83.82 & 87.56 & 93.86 & 99.60 & 104.60 & 109.10 & 113.00 & 116.50 & 119.70 & 122.60 & 125.20 & 127.60 & 130.10 & 134.50 & 139.70 & 144.50 & 149.00 & 153.20 & 157.10 \\
\hline & \multirow{2}{*}{100} & $w$ & 92.95 & 94.79 & 96.35 & 97.68 & 100.00 & 103.50 & 106.90 & 112.20 & 117.90 & 123.50 & 128.60 & 133.20 & 137.40 & 141.30 & 144.80 & 148.10 & 151.10 & 153.90 & 156.80 & 160.60 \\
\hline & & $T$ & 91.82 & 92.59 & 96.15 & 102.90 & 109.30 & 115.00 & 120.00 & 124.40 & 128.40 & 132.00 & 135.20 & 138.20 & 140.90 & 143.50 & 147.70 & 153.50 & 158.90 & 163.90 & 168.60 & 173.00 \\
\hline & \multirow{2}{*}{120} & $w$ & 111.50 & 113.80 & 115.60 & 117.20 & 120.00 & 124.20 & 128.20 & 134.60 & 141.50 & 148.20 & 154.30 & 159.80 & 164.90 & 169.50 & 173.80 & 177.70 & 181.40 & 184.70 & 188.20 & 192.70 \\
\hline & & $T$ & 109.10 & 110.00 & 113.10 & 120.00 & 128.00 & 135.00 & 141.20 & 148.70 & 151.60 & 156.00 & 160.00 & 163.60 & 167.00 & 170.00 & 174.00 & 180.00 & 186.70 & 192.90 & 198.60 & 204.00 \\
\hline & \multirow{2}{*}{150} & $w$ & 134.80 & 137.70 & 140.20 & 142.30 & 144.80 & 149.80 & 154.80 & 160.30 & 168.20 & 176.30 & 184.10 & 191.20 & 197.77 & 203.60 & 209.10 & 214.10 & 218.80 & 223.10 & 227.10 & 231.50 \\
\hline & & $T$ & 133.60 & 135.00 & 137.00 & 142.90 & 152.00 & 161.30 & 169.40 & 176.70 & 183.20 & 189.00 & 194.30 & 199.10 & 203.50 & 207.50 & 211.30 & 216.30 & 223.40 & 231.40 & 239.00 & 246.00 \\
\hline
\end{tabular}

W - Wheoled Vehicle Shear $T$ - Tracked Vehicle Shear

Figure 39 (cont'd). Maximum endspan shears for military live loads 
Transverse

Position

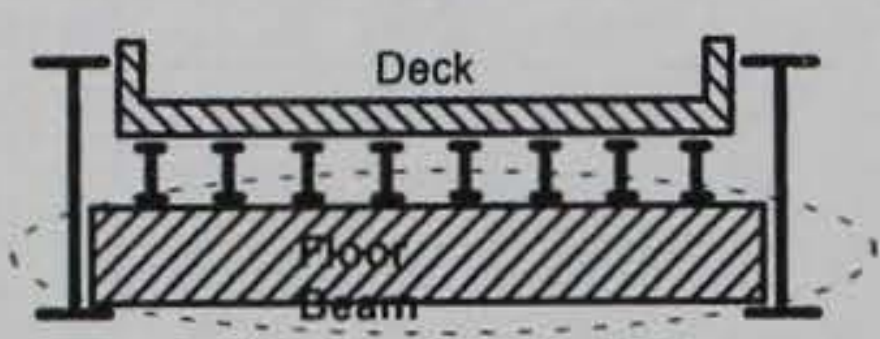

Bending Moment
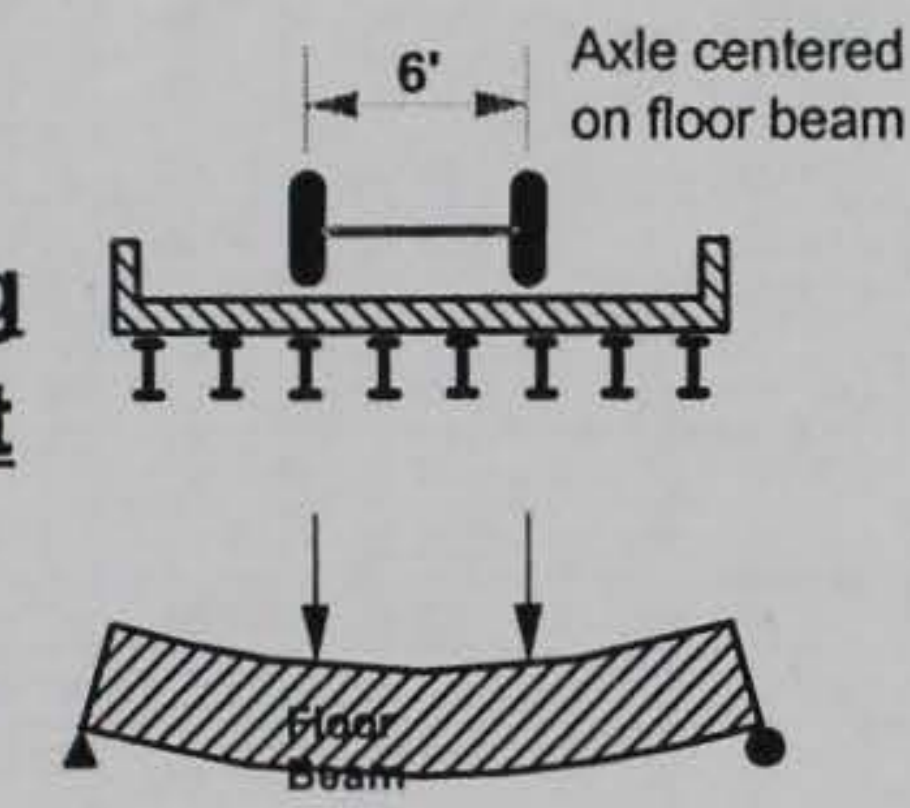

Edge of

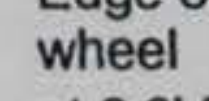

at $2.0^{\prime}$ from

curb

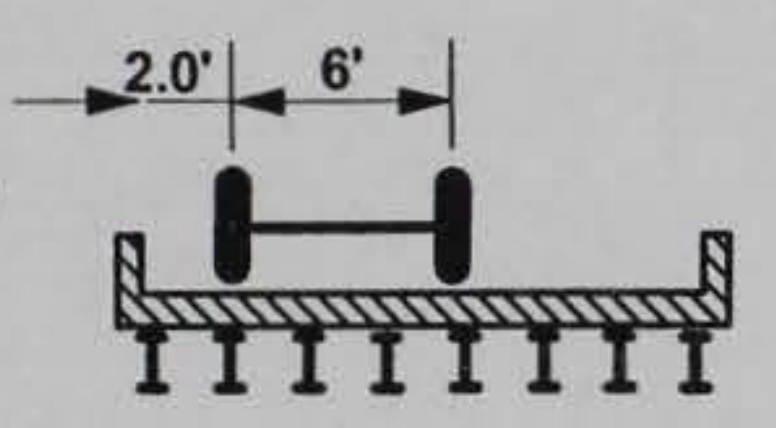

Shear

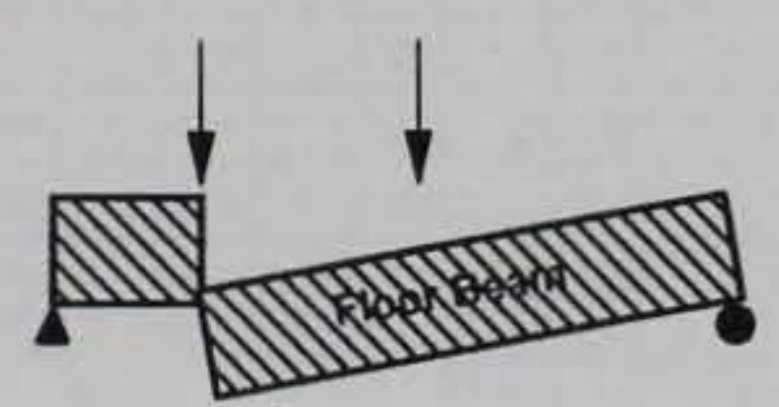

\section{Longitudinal}

Position

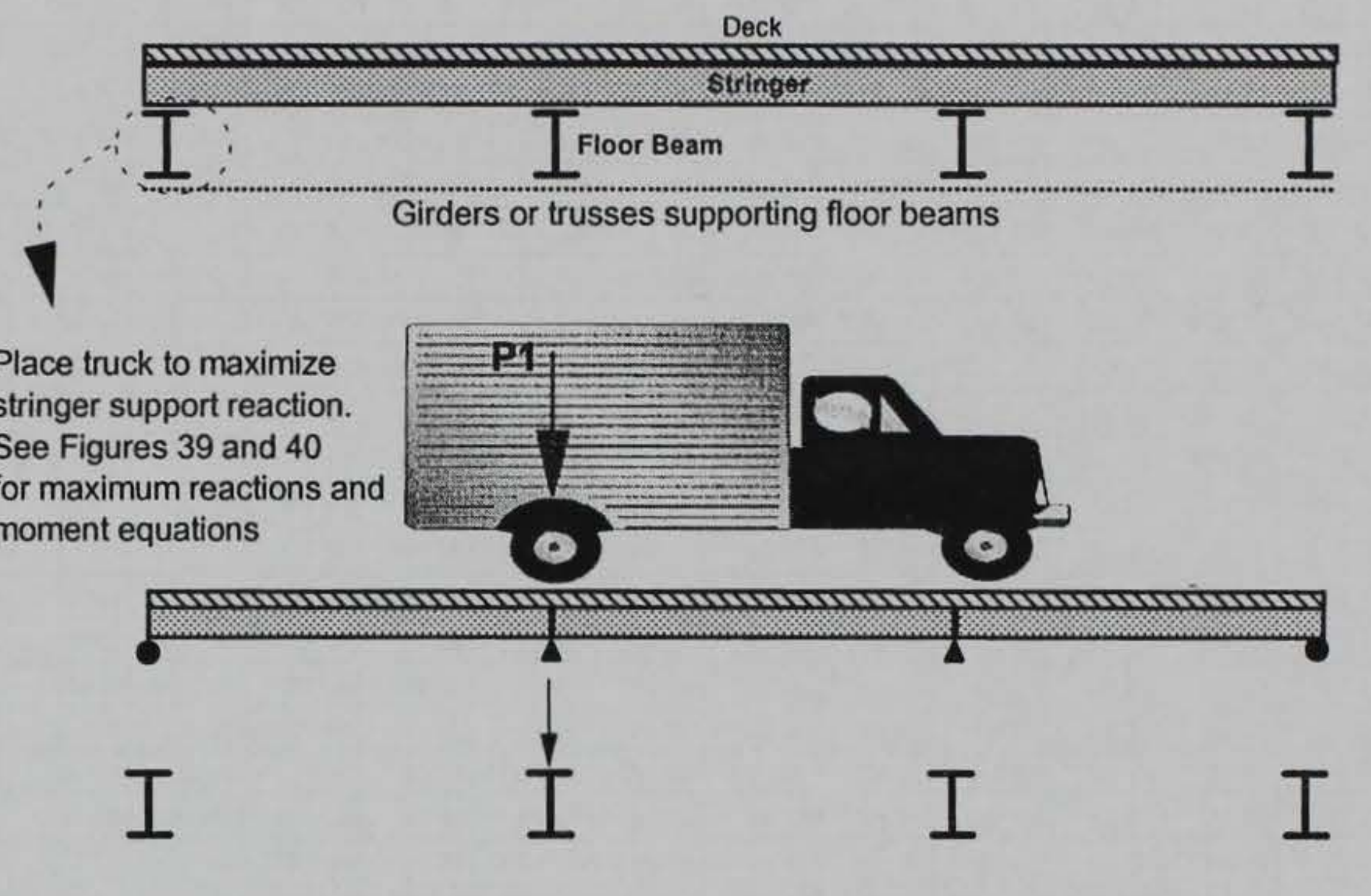

As with Moment above, place truck to maximize

stringer support reaction. See Figures 39 and 40 for maximum reactions and shear equations

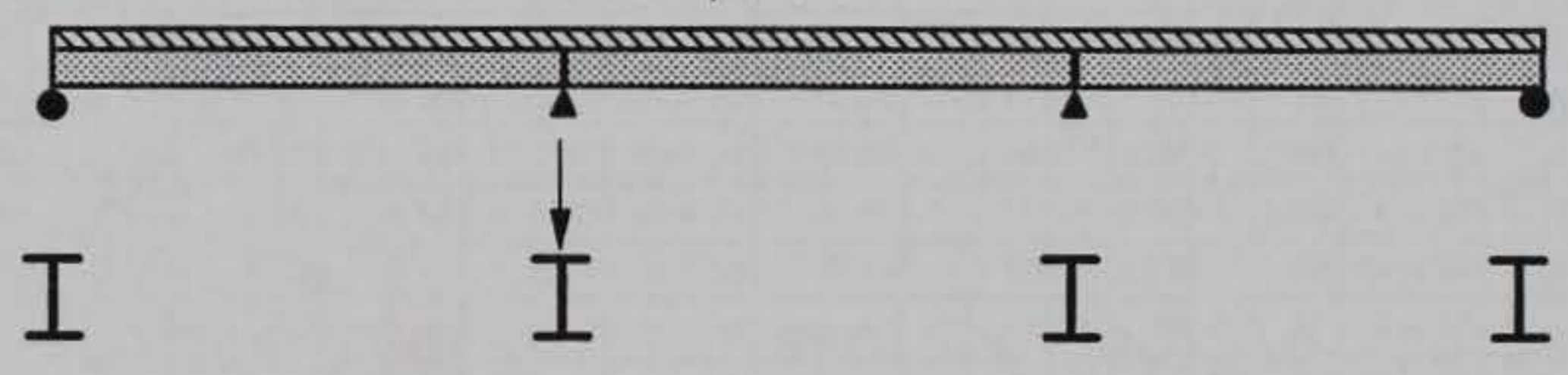

Figure 40. Maximum floor beam loadings 
ARPENDIXA4

STRINGER LIVE LOAD REACTIONS ON

TRANSVERSE FLOOR BEAMS \& CAPS

(INTERMEDIATE TRANSVERSE BEAMS)

(Simple Span Oniy)

\begin{tabular}{|c|c|c|c|c|c|}
\hline \multirow{3}{*}{$\begin{array}{c}\text { STRNGER } \\
\text { SPAN }\end{array}$} & \multicolumn{5}{|c|}{ LIVE LOAD REACTONS (R) IN KIPS PER WHEEL LINE } \\
\cline { 2 - 6 } FEET & \multicolumn{5}{|c|}{ NY IMPACT } \\
\cline { 2 - 6 } & TYPE 3 & TYPE 3-S2 & TYPE 3-3 & H-15 & HS-20 \\
\hline 10 & 13.6 & 12.4 & 11.2 & 12.0 & 16.0 \\
\hline 11 & 13.9 & 12.7 & 11.5 & 12.0 & 16.0 \\
\hline 12 & 14.2 & 13.1 & 11.7 & 12.0 & 16.0 \\
\hline 13 & 14.4 & 13.7 & 11.9 & 12.0 & 16.0 \\
\hline 14 & 14.6 & 14.2 & 12.0 & 12.0 & 16.0 \\
\hline 15 & 14.8 & 14.6 & 12.2 & 12.2 & 17.3 \\
\hline 16 & 15.3 & 15.0 & 12.3 & 12.4 & 18.5 \\
\hline 17 & 15.8 & 15.4 & 12.7 & 12.5 & 19.5 \\
\hline 18 & 16.4 & 15.6 & 13.3 & 12.7 & 20.4 \\
\hline 19 & 16.8 & 15.9 & 13.7 & 12.8 & 21.3 \\
\hline 20 & 17.2 & 16.1 & 14.2 & 12.9 & 22.0 \\
\hline 21 & 17.6 & 16.3 & 14.5 & 13.0 & 22.7 \\
\hline 22 & 18.0 & 16.5 & 14.9 & 13.1 & 23.3 \\
\hline 23 & 18.3 & 16.7 & 15.2 & 13.2 & 23.8 \\
\hline 24 & 18.5 & 16.9 & 15.5 & 13.3 & 24.3 \\
\hline 25 & 18.8 & 17.0 & 15.7 & 13.4 & 24.8 \\
\hline 26 & 19.0 & 17.5 & 16.2 & 13.4 & 25.2 \\
\hline 27 & 19.3 & 18.2 & 16.8 & 13.5 & 25.6 \\
\hline 28 & 19.5 & 18.8 & 17.5 & 13.5 & 26.0 \\
\hline 29 & 19.7 & 19.4 & 18.0 & 13.6 & 26.3 \\
\hline 30 & 19.9 & 20.1 & 18.8 & 13.6 & 26.7 \\
\hline
\end{tabular}

ONE LANE LOADING

$M=\frac{(L-3)^{2} R}{2 L}$

"TWO LANE ROADWAY OVER 18 FEET___ $M=\left(L-9+\frac{2.25}{\mathrm{~L}}\right) \mathrm{R}$

*WHEEL LINES/TRUSS: $\left\{\begin{array}{l}\text { ONE LANE LOADING }=\left(1+\frac{\mathrm{W}-9}{\mathrm{C}}\right) \\ \text { TWO LANE LOADING }=\left(1+\frac{\mathrm{W}-18}{\mathrm{C}}\right)^{2}\end{array}\right.$

Where:

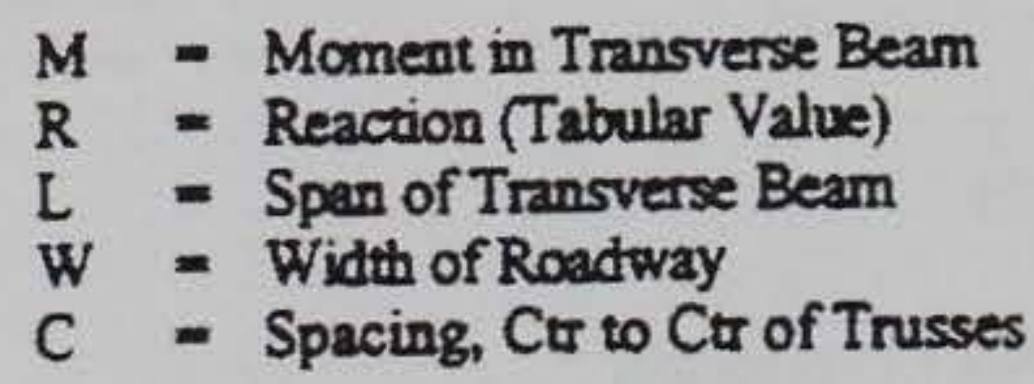

All vahues based on standard truck loadings.

- Based on $9 \mathrm{ft}$. lane width.

a. Intermediate beams

Figure 41. Maximum floor beam loadings for civilian live loads (reference [1]) 


\begin{tabular}{|c|c|c|c|c|c|}
\hline \multicolumn{6}{|c|}{$\begin{array}{l}\text { STRINGER LIVE LOAD REACTIONS ON } \\
\text { TRANSVERSE FLOOR BEAMS \& CAPS } \\
\text { (END TRANSVERSE BEAMS) } \\
\text { (Simple Span Only) }\end{array}$} \\
\hline \multirow{3}{*}{$\begin{array}{c}\text { STRINGER } \\
\text { SPAN } \\
\text { FEET }\end{array}$} & LIV] & DAD REACT & $\begin{array}{l}\text { NS (R) IN K } \\
\text { VO IMPACI }\end{array}$ & ER W & INE \\
\hline & \multicolumn{5}{|c|}{ TYPE OF LOADING } \\
\hline & TYPE 3 & TYPE 3-S2 & TYPE 3-3 & $\mathrm{H}-15$ & HS-20 \\
\hline 10 & 13.6 & 12.4 & 11.2 & 12.0 & 16.0 \\
\hline 11 & 13.9 & 12.7 & 11.5 & 12.0 & 16.0 \\
\hline 12 & 14.2 & 12.9 & 11.7 & 12.0 & 16.0 \\
\hline 13 & 14.4 & 13.1 & 11.9 & 12.0 & 16.0 \\
\hline 14 & 14.6 & 13.3 & 12.0 & 12.0 & 16.0 \\
\hline 15 & 14.7 & 13.4 & 12.1 & 12.2 & 17.1 \\
\hline 16 & 14.9 & 13.9 & 12.3 & 12.4 & 18.0 \\
\hline 17 & 15.0 & 14.3 & 12.4 & 12.5 & 18.9 \\
\hline 18 & 15.1 & 14.6 & 12.4 & 12.7 & 19.6 \\
\hline 19 & 15.2 & 14.9 & 12.5 & 12.8 & 20.2 \\
\hline 20 & 15.7 & 15.2 & 12.6 & 12.9 & 20.8 \\
\hline 21 & 16.1 & 15.5 & 13.1 & 13.0 & 21.3 \\
\hline 22 & 16.6 & 15.7 & 13.5 & 13.1 & 21.8 \\
\hline 23 & 16.9 & 15.9 & 13.8 & 13.2 & 22.2 \\
\hline 24 & 17.3 & 16.1 & 14.2 & 13.3 & 22.6 \\
\hline 25 & 17.6 & 16.3 & 14.5 & 13.4 & 23.0 \\
\hline 26 & 17.9 & 16.4 & 14.8 & 13.4 & 23.4 \\
\hline 27 & 18.1 & 16.6 & 15.0 & 13.5 & 23.7 \\
\hline 28 & 18.4 & 16.7 & 15.3 & 13.5 & 24.0 \\
\hline 29 & 18.6 & 16.8 & 15.5 & 13.6 & 24.4 \\
\hline 30 & 18.8 & 17.0 & 15.7 & 13.6 & 24.8 \\
\hline
\end{tabular}

\section{b. End beams}

Figure 41 (cont'd). Maximum floor beam loadings for civilian live loads 

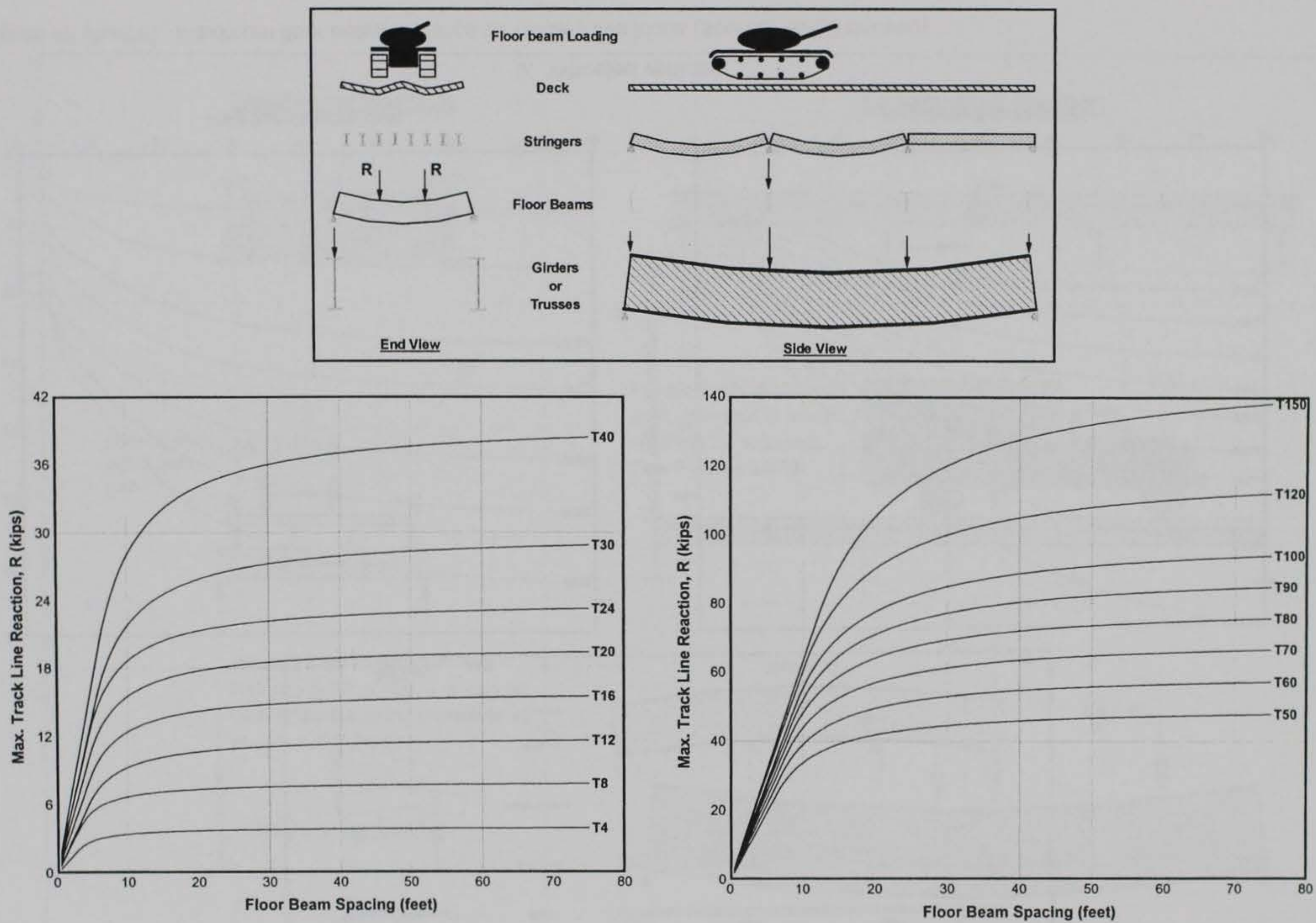

a. Tracked vehicles

Figure 42. Maximum floor beam loadings for military live loads (source: WES derived) 

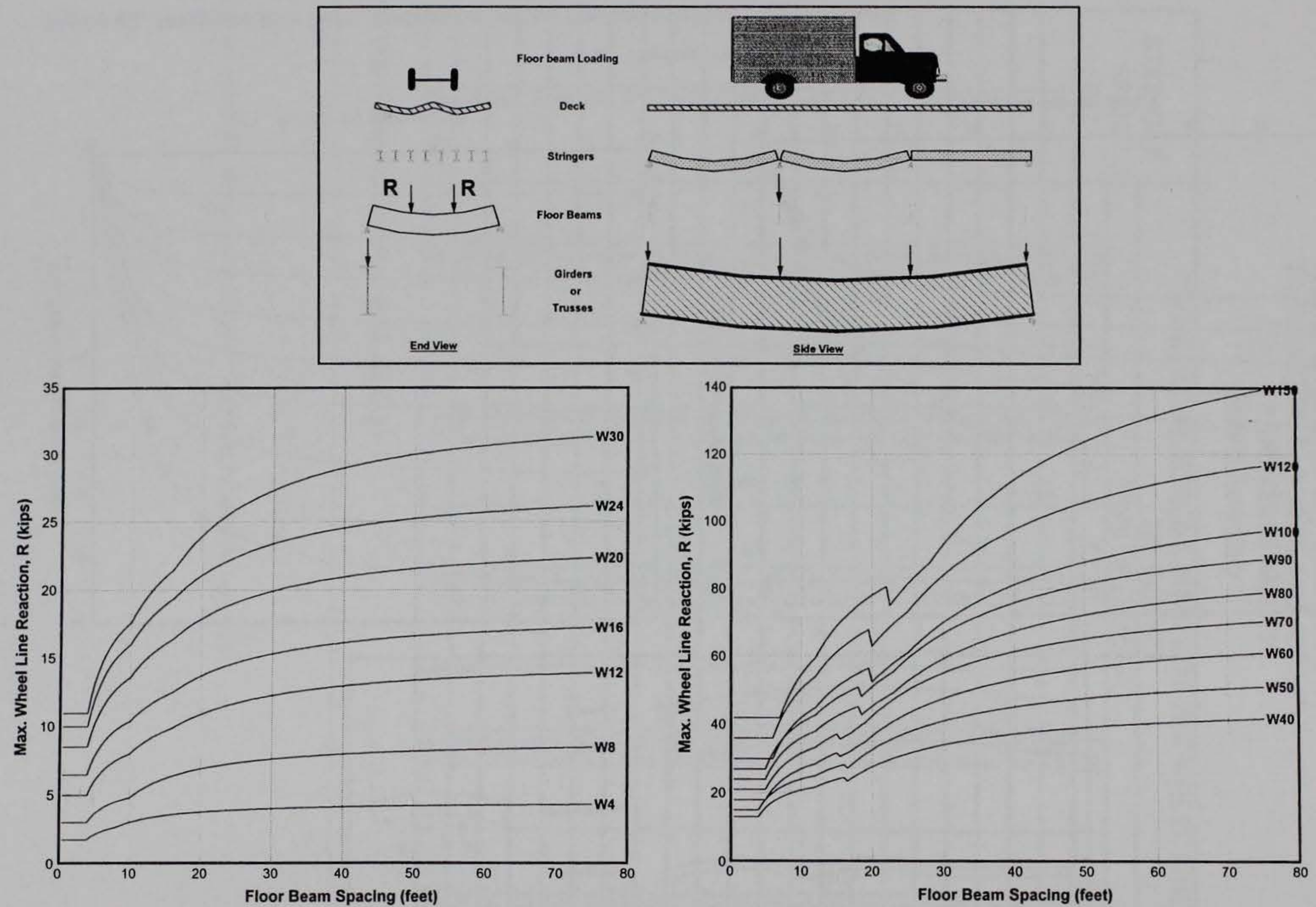

b. Wheeled vehicles

Figure 42 (cont'd). Maximum floor beam loadings for military live loads (source: WES derived) 


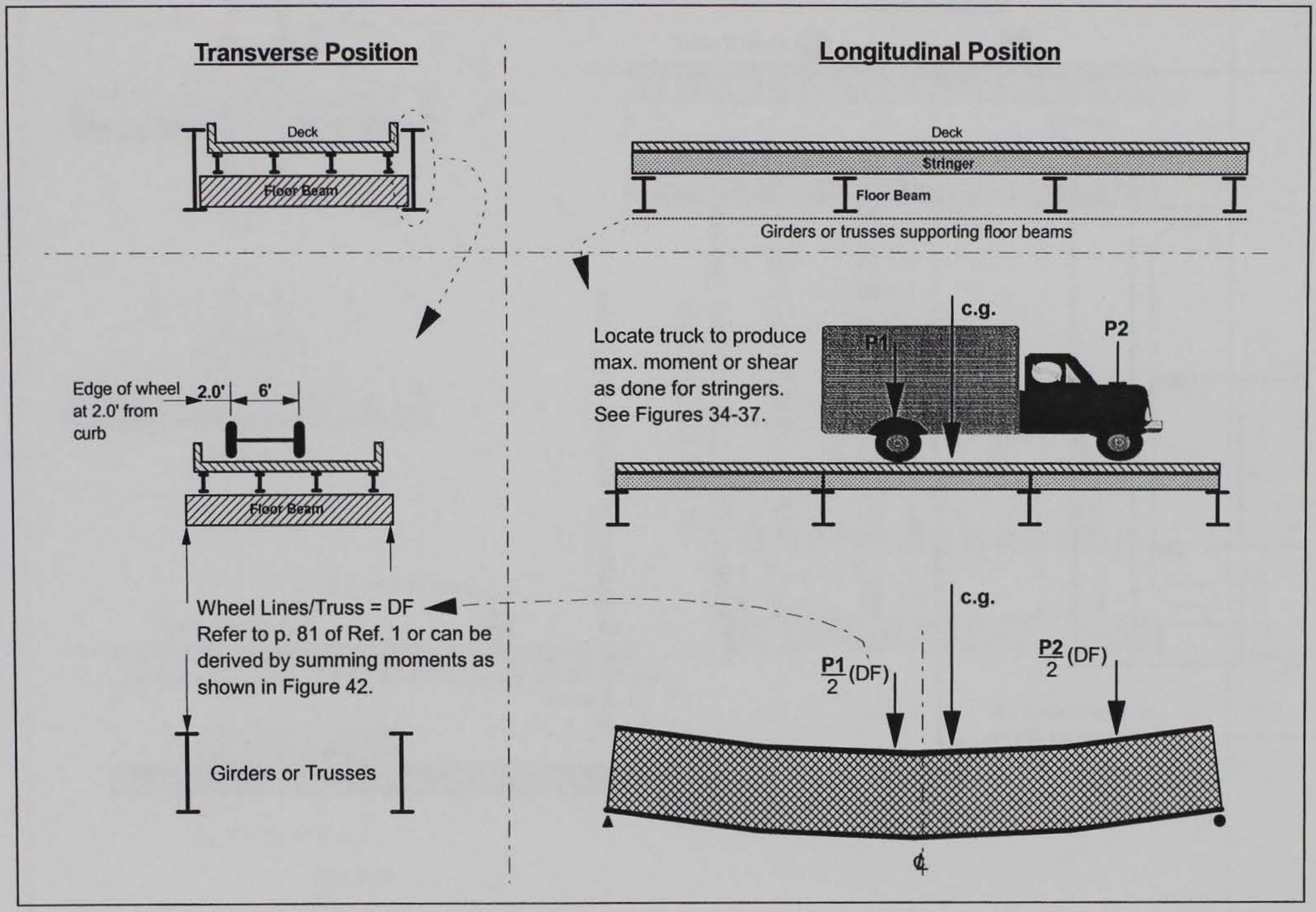




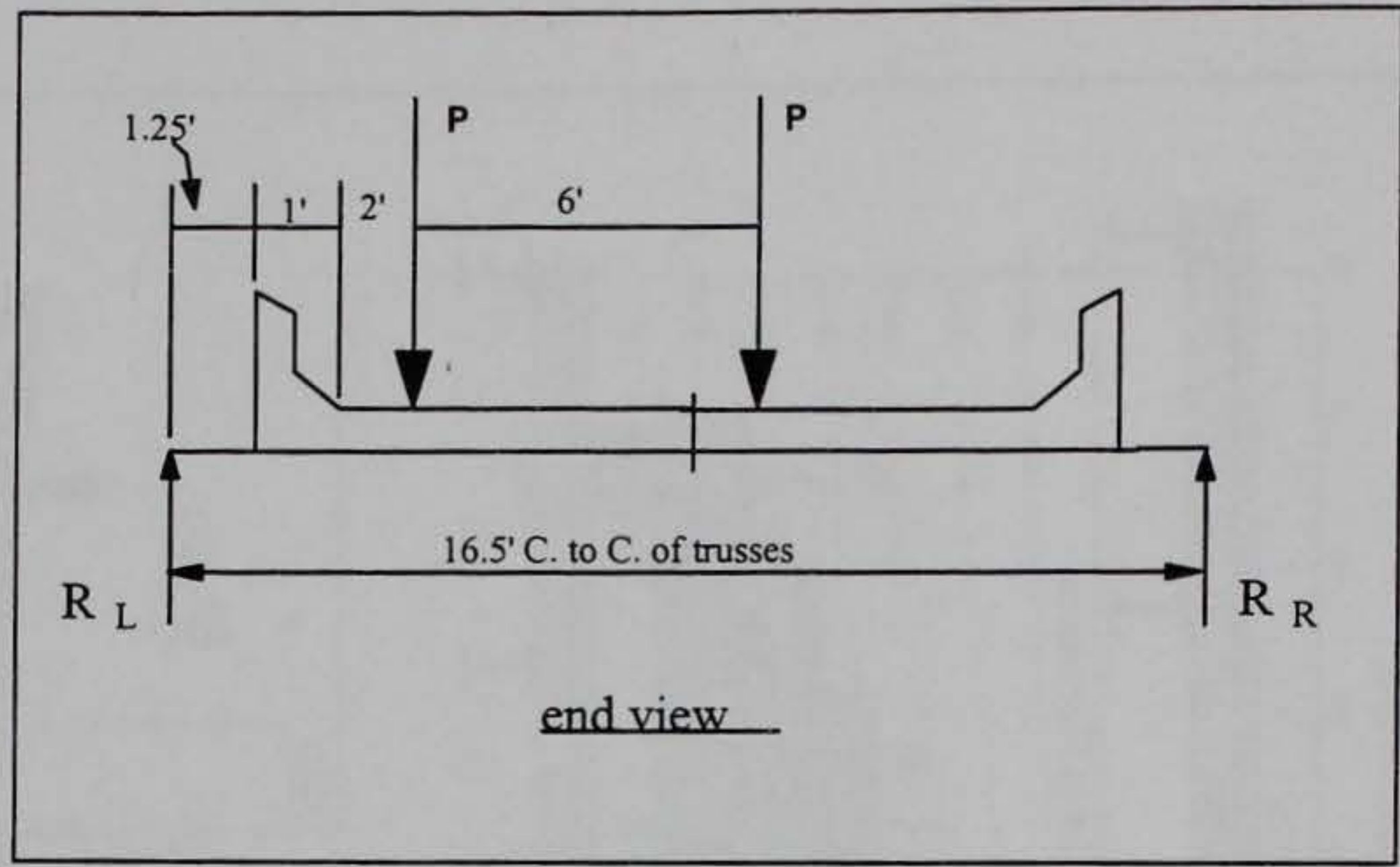

$$
\begin{gathered}
\Sigma \mathrm{M}_{\mathrm{RL}}=0=P(3.25+9.25)-R_{R}(16.5) \\
R_{R}=0.88 P \\
R_{L}=2 P-.88 P=1.12 P \Rightarrow \text { Max } .
\end{gathered}
$$

Therefore, $D F=\underline{1.12}$ for wheel line loads or 0.56 for axle loads

Figure 44. Calculation of wheel lines per truss 


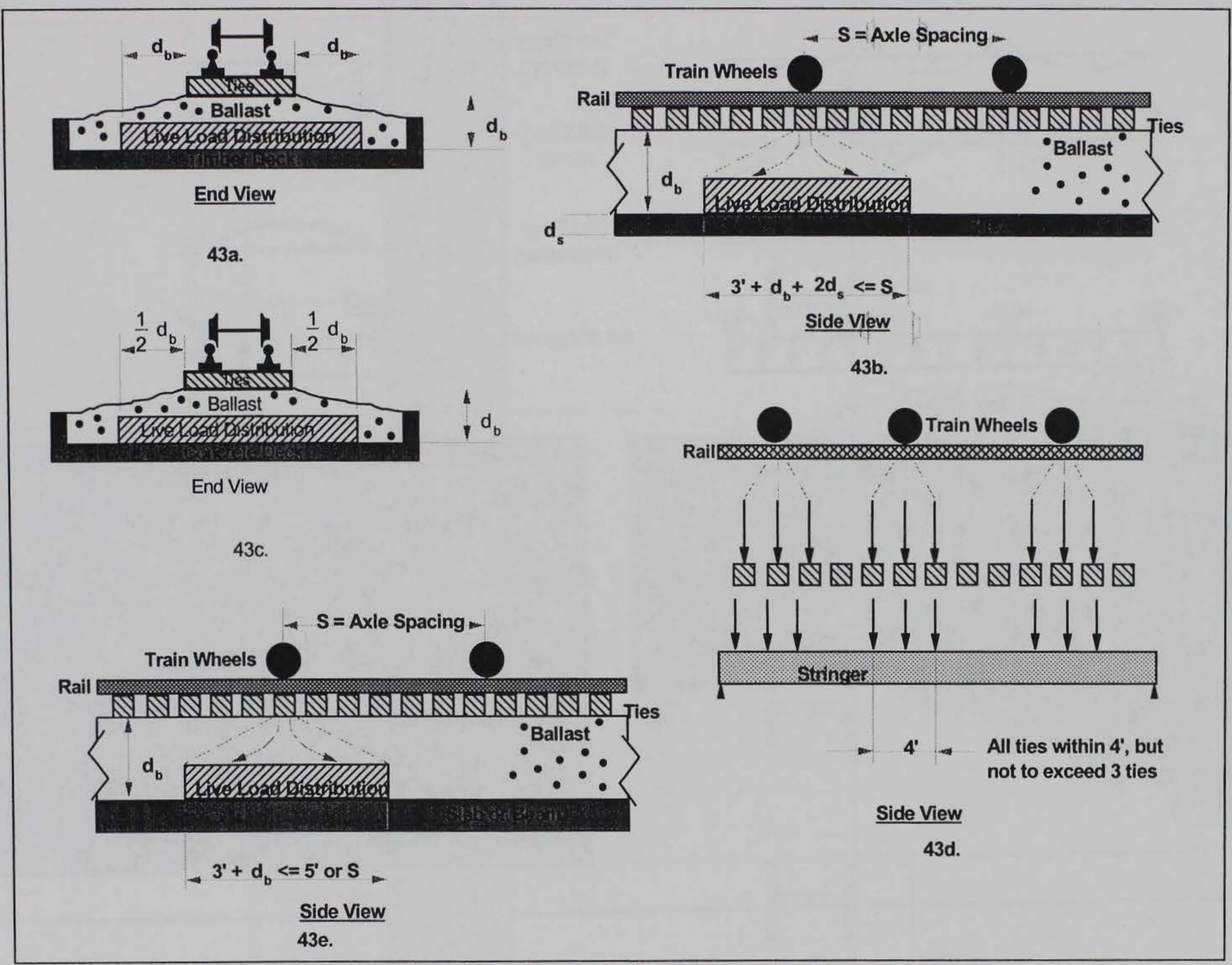




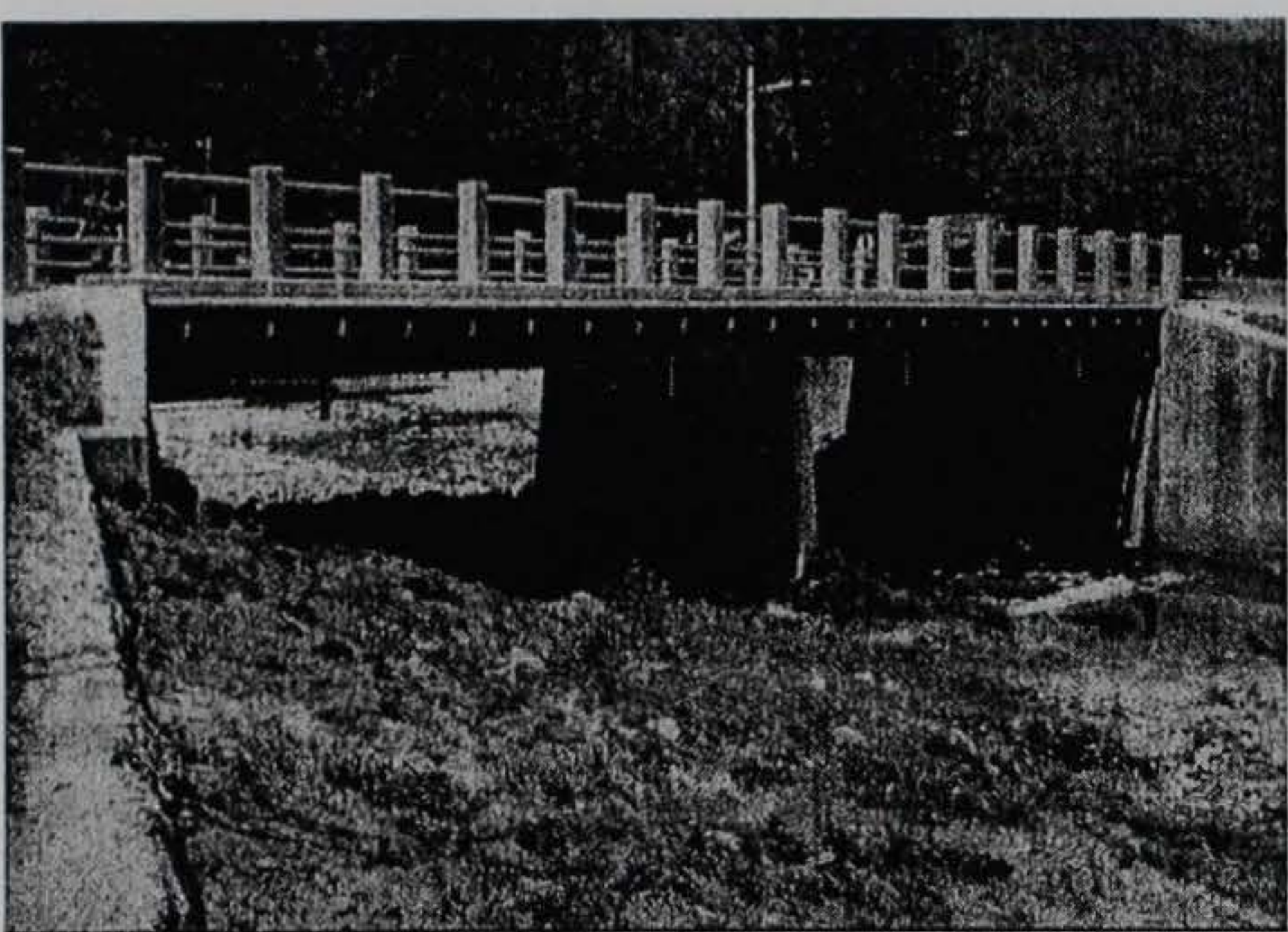

Simple Spans
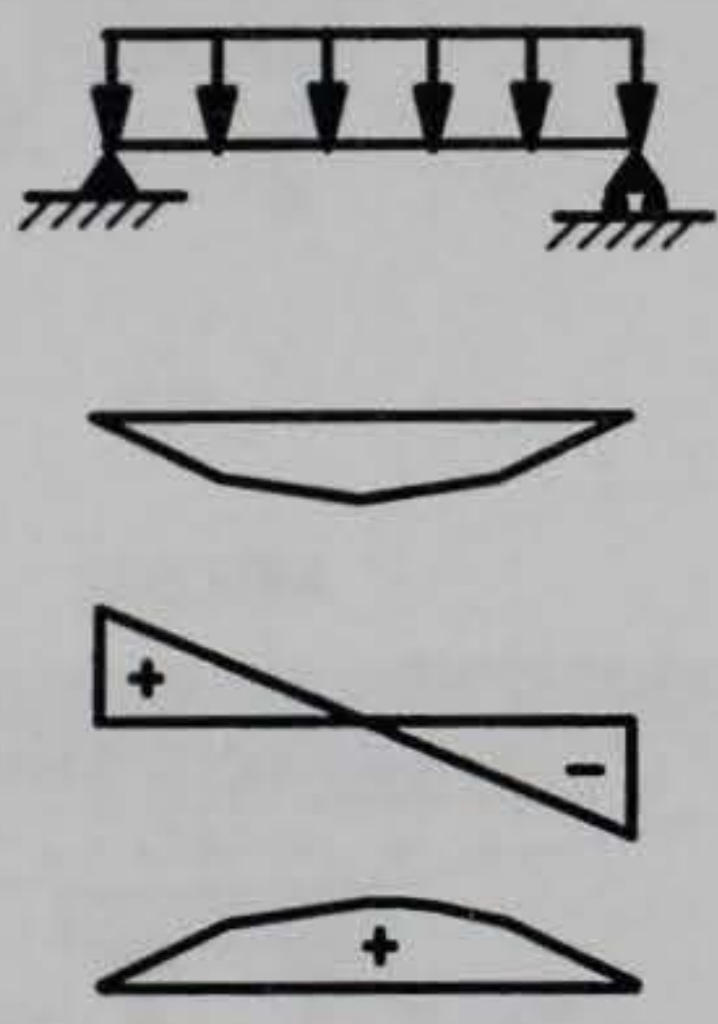

Beam Diagram

Deflection

Diagram

Shear

Diagram

Moment

Diagram

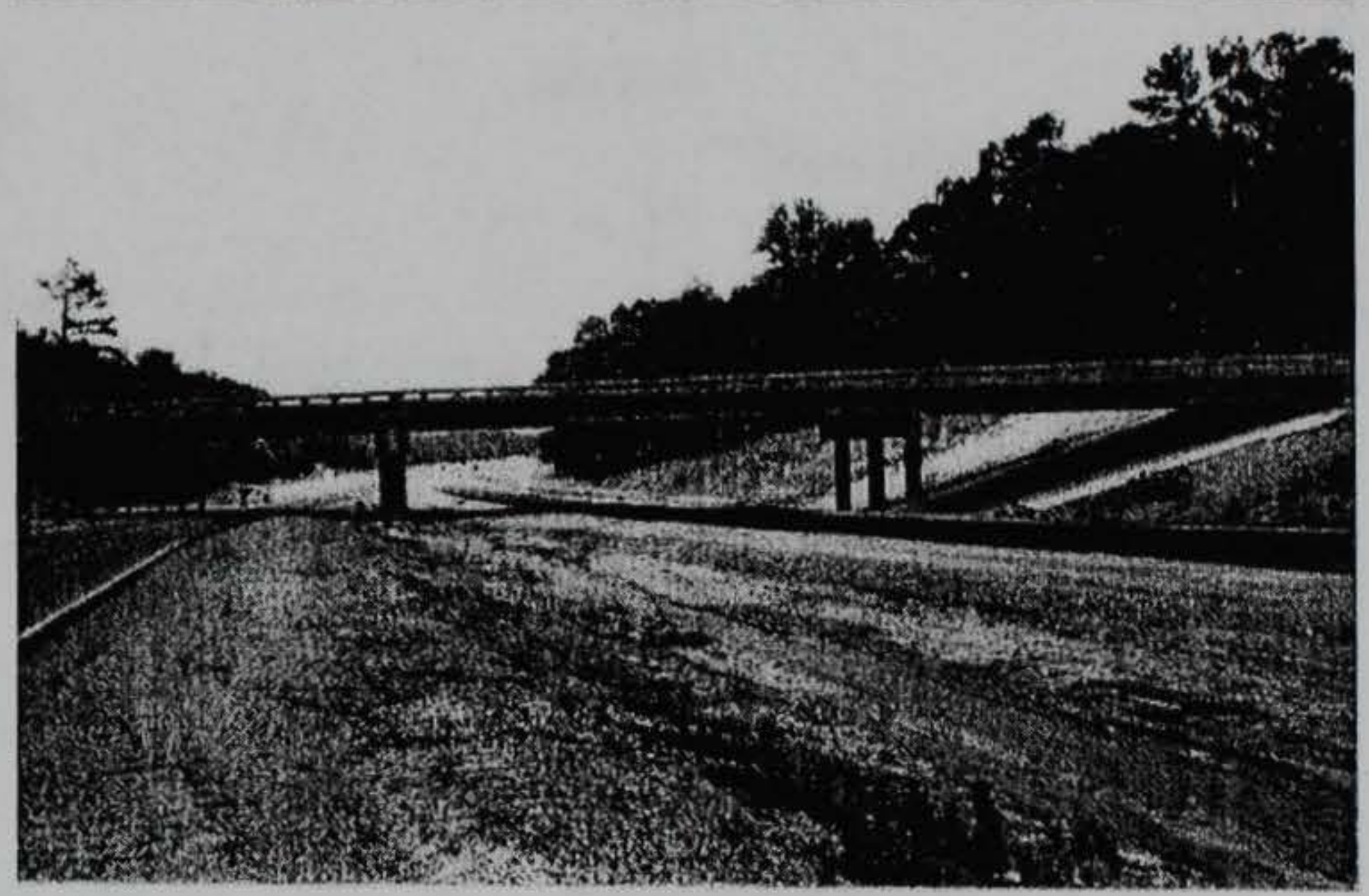

Continuous Spans 


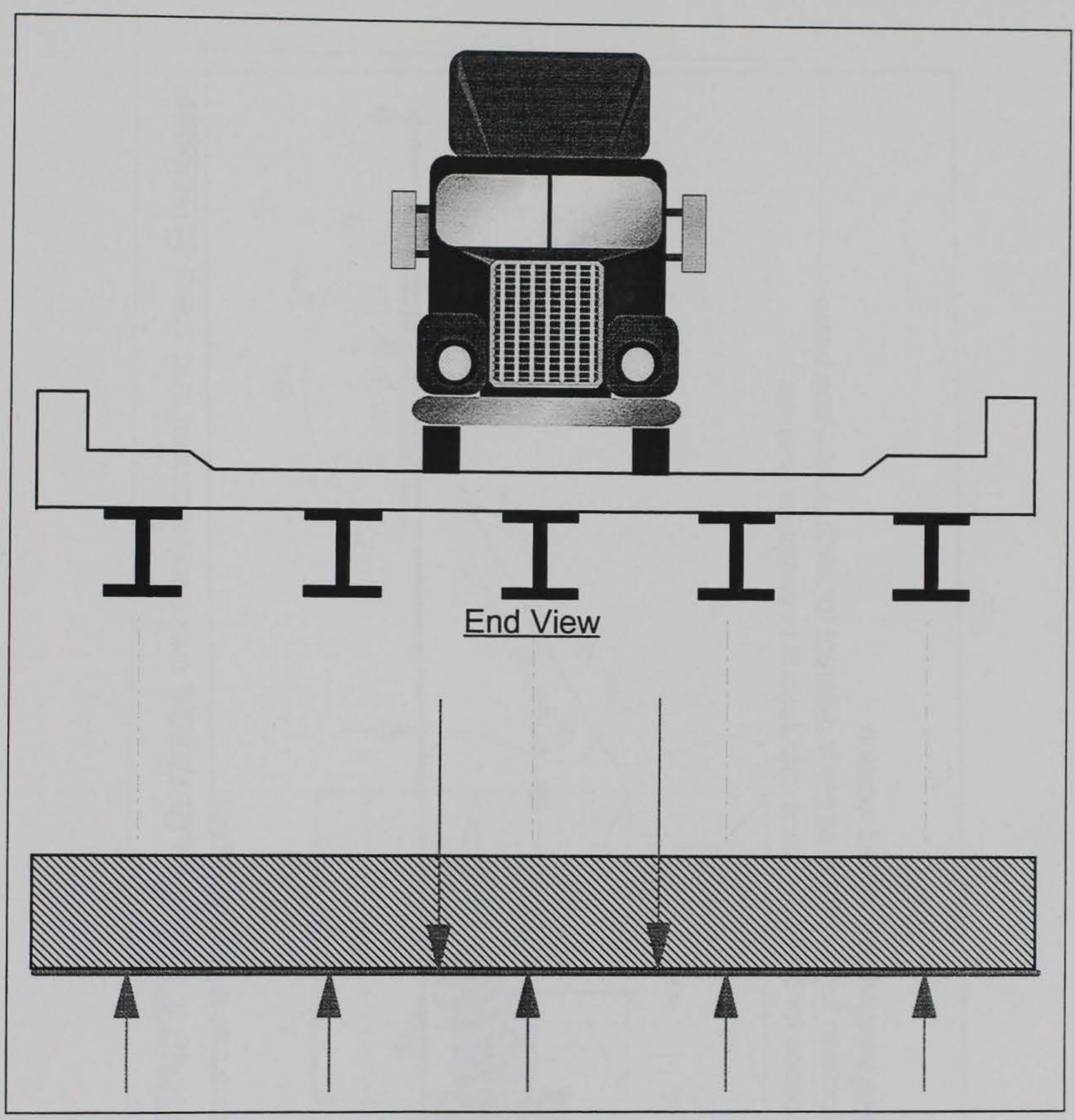

Figure 47. Bridge decks are often continuous in the transverse direction 
- Stresses vary with each load location

- Load location for maximum stress is different for each point along beam

- Two options for analysis: hand calculations or computer analysis

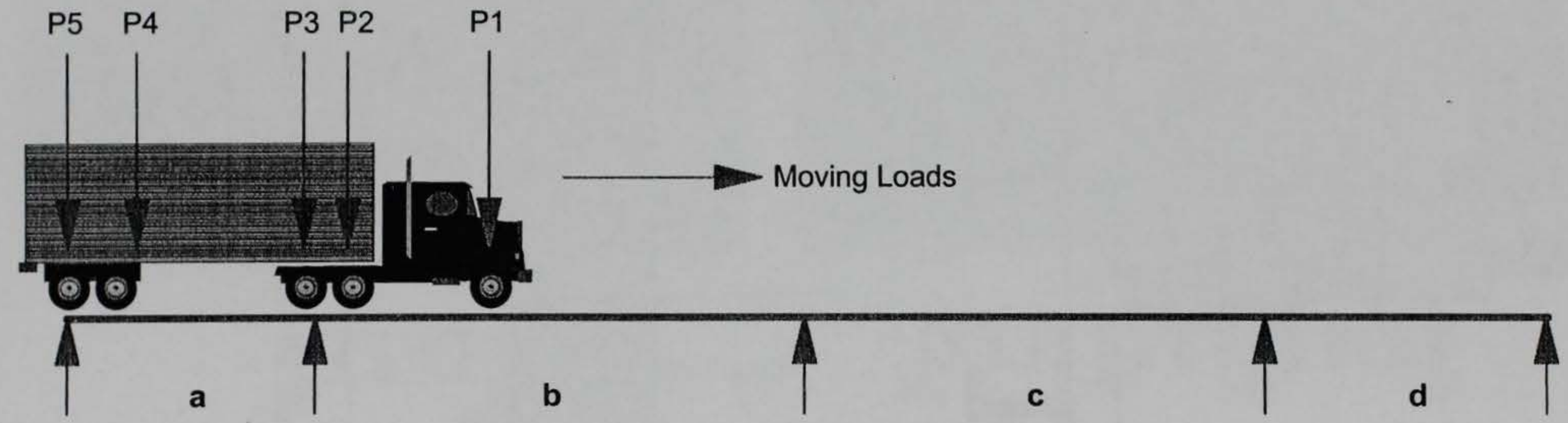

Figure 48. Moving load analysis on continuous spans 
- Hand calculations result in Influence Diagrams and max. moment and shear Envelopes.

- As an example, consider a simple beam:

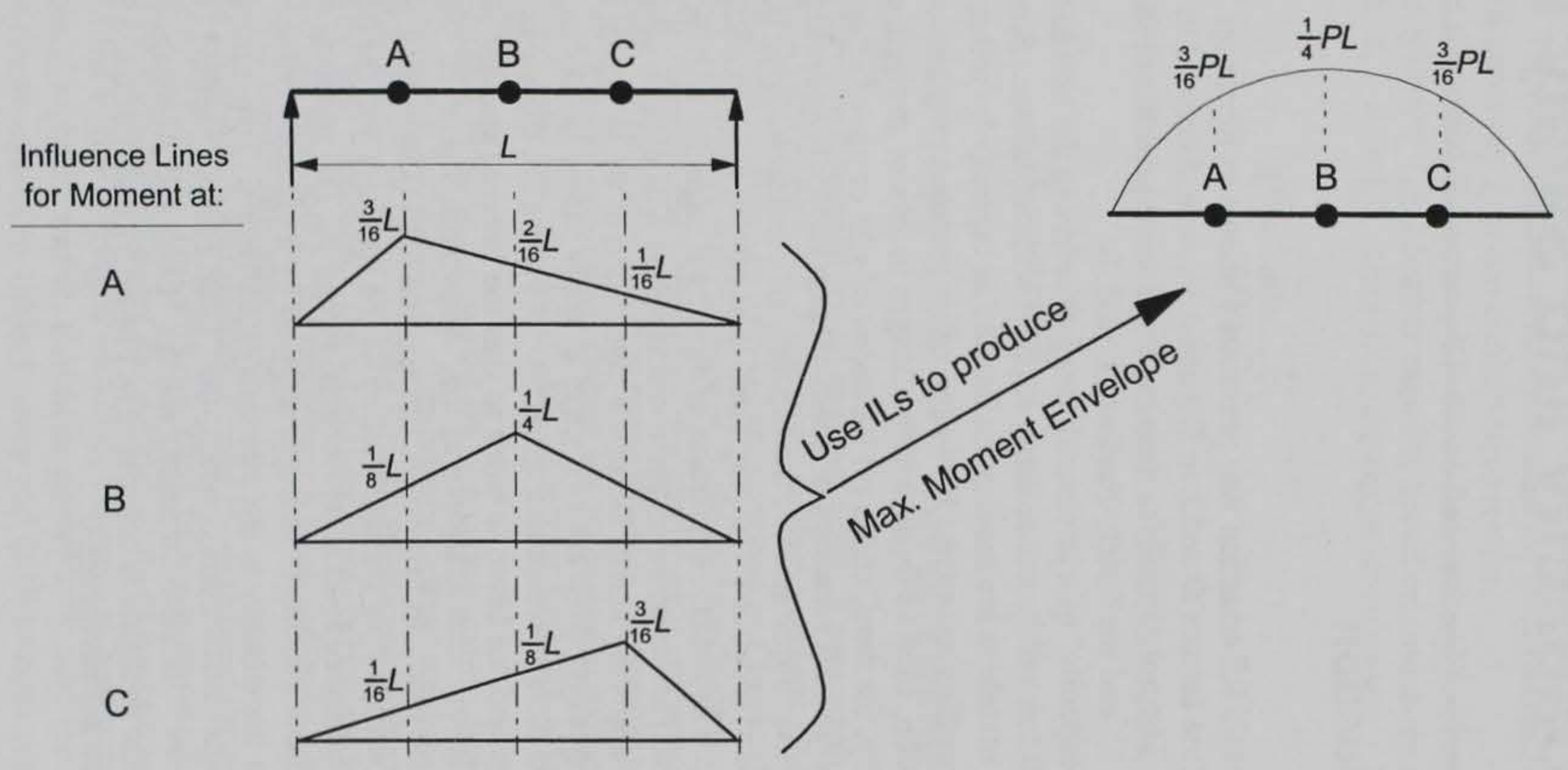

Figure 49. Moving load analysis by hand 


\section{Capacity and Safety Factors}

\section{Introduction}

The basic RF equation was previously shown in Equation 1. Dead and live loadings (the factors $D$ and $L$ in Equation 1) were discussed in the previous chapters. The only variables missing from this equation are the Nominal Capacity, $C$, and the Safety Factors, $A_{1}$ and $A_{2}$.

The "capacity" of a structural member refers to the maximum amount of load that it can safely and reliably support without failure. Simple span structural members are most often limited in capacity by either endspan shear or midspan bending moment. However, other sections may also require consideration, such as those where changes in size or strength occur. Specifically, for steel, check all locations of size or cover plate changes. For concrete, check all locations of cross-section and/or reinforcing changes (i.e., bar cutoff points). Additionally, the capacity of continuous span members must also be checked at locations where applied load effects are maximum, as discussed in Chapter 3. The actual calculation of structural capacity will be discussed in later paragraphs. However, since these calculations will depend upon the chosen method of applying safety factors, a discussion of these is first required.

Conceptually, there are two ways to apply safety factors in a structural analysis, as demonstrated in Figure 50. In Figure 50, the actual load is applied to the beam and the beam is sized so that the internal stresses never exceed some allowable level. This is known as the "Allowable Stress" or "Working Stress" analytical method. In Figure 50, the applied load is increased by some safe amount to account for the uncertainty of the loadings and the beam is sized to carry this increased load at its nominal strength. The nominal strength is based on the member's ultimate strength reduced by a capacity reduction factor to account for uncertainty in the strength calculations. Two analytical methodologies utilize this concept, the "Load Factor" method (sometimes referred to as "Ultimate Strength) and the "Load and Resistance Factor" method. Each of these methods is compared in Figure 51 and discussed in greater detail in the following paragraphs. 


\section{Allowable Stress Method}

As previously stated, the Allowable Stress method utilizes actual loadings combined to produce maximum stress in a member, which is not to exceed the "allowable" or "working" stress of the member. Thus, safety factors are applied to the allowable stress only. This is the only method currently allowable for timber bridges [1]. This method is not recommended for steel or concrete bridges since it will generally give too conservative results.

This method is discussed in paragraph 6.4 .1 of Reference [1]. The values for Equation [1] are as follows: $C=$ Member capacity based on Inventory and Operating Stresses; $A_{1}=A_{2}=1.0$. Therefore, the equation becomes:

$$
R F=\frac{C_{\text {Allow }}-D}{L(1+I)}
$$

Member capacity is determined from basic strength of materials equations, such as:

$$
M_{\text {allow }}=\frac{\sigma_{\text {allow }}}{S}
$$

where: $M_{\text {allow }}=$ allowable bending moment; $\sigma_{\text {allow }}=$ allowable bending stress; and $S=$ section modulus.

Allowable stresses are discussed for all material types in paragraph 6.6 .2 of Ref. [1]. Specifically, paragraph 6.6.2.7 addresses timber members. All timber strength requirements not provided in Ref. [1] are provided in Chapter 13 of Ref. [7]. Paragraph 6.6.2.1 addresses steel members. Note that the "date built" of the bridge can be used to estimate steel strength if the steel type is unknown. Part C, Chapter 10, Reference [3] provides all other requirements. Allowable stresses for reinforced and prestressed concrete members are discussed in paragraphs 6.6.2.3 through 6.6.2.5, Ref. [1]. Paragraph 8.15, Chapter 8 of Ref. [3] provides all other requirements.

Note that the capacity must be calculated for two rating levels: Inventory and Operating (paragraph 6.3 of Ref. [1]). The Inventory level corresponds closely to the original design level of stresses for a conventional highway bridge, but also reflects its current condition. The Operating level defines the maximum permissible live load that may utilize the structure on a limited basis. Extended usage of this level may shorten the structure's life.

The responsible engineer should post the bridge at some level between the Inventory and Operating ratings. This decision must be made on a case-by-case basis, depending upon such factors as traffic volume, level of load enforcement, and the condition of the bridge. Bridges with high volumes of heavy trucks, similar to conventional highway traffic, should be posted at or near the Inventory level. However, as demonstrated in Table 1, army and COE bridges generally have much lower truck volumes than conventional highway bridges while often being well maintained. These bridges may be posted closer to the Operating level. 


\section{Load Factor (Ultimate Strength) Method}

For this method, it is assumed that the capacity of the member is just reached when the factored (i.e., increased) loads are all applied. Different factors are applied to each type of load to reflect the uncertainty of the loadings. Since dead loads are more predictable than live loads, a smaller increase factor is applied to dead loads. The nominal capacity of the member is based on its ultimate capacity (i.e., failure limit) and is reduced by a capacity reduction factor $(\phi)$ to account for uncertainty in the strength calculations. To utilize this method, use Equation [1] along with the following values: $C=\phi C_{\text {ultimate }} ; A_{1}=1.3 ; A_{2}=$ 2.17 for Inventory Level and 1.30 for Operating Level.

Nominal capacity is discussed for all material types in paragraph 6.6 .3 of Ref. [1]. Specifically, paragraph 6.6.3.1 addresses steel members. Note that the "date built" of the bridge can be used to estimate steel strength if the steel type is unknown. Part D, Chapter 10, Reference [3] provides all other requirements. Reinforced and prestressed concrete members are discussed in paragraphs 6.6.3.2 through 6.6.3.3, Ref. [1]. Paragraph 8.16, Chapter 8 of Ref. [3] provides all other requirements. Appendix C, Ref. [1] also provides a summary of all formulas used for the capacity of typical bridge components based on the Load Factor method.

\section{Load and Resistance Factor Rating (LRFR) Method}

The LRFR method is the most recently developed method and is an extrapolation of the Load Factor method to make it more applicable for bridge rating as opposed to bridge design. With the LRFR method, the safety factors can be varied within limits to more accurately address a specific bridge and its specific condition, usage, and level of maintenance/inspection. As demonstrated in Table 1, this type of latitude in a load rating is very important for rating Army and the $\mathrm{COE}$ bridges since they are often very different from civilian highway bridges in terms of these factors. Because of this flexibility, this is the preferred method of rating for the Army and the COE.

Paragraph 6.1, Ref. [1] refers to Ref. [2] for all LRFR considerations. Note that Ref. [2] is currently only applicable to steel and concrete bridges. Ref. [2] provides the exact same rating equation as Ref. [1] (equation 15), but defines its variables slightly differently as follows:

$$
R F=\frac{\phi R_{n}-\gamma_{D} D}{\gamma_{L} L(1+I)},
$$

where: $\phi=$ Resistance factor

$R_{n}=$ Ultimate member capacity, with no safety factor

$D=$ Dead load effect on the member

$L=$ Live load effect on the member

$I=$ Impact factor for live load

$\gamma_{D}=$ Factor for dead loads

$\gamma_{L}=$ Factor for live loads 
A very useful step-by-step flowchart is provided in Figure 1 of Ref. [2] for completing this equation. The ultimate capacity, $R_{n}$, is determined using the same methods and formulas as discussed above for the Load Factor method. However, do not apply the $\phi$ factors given in the Load Factor equations. Instead, apply the LRFR-specific $\phi$ factors discussed in Section 3.3.2.4, Ref. [2].

Figure 4 of Ref. [2], provides a useful flowchart for determining the appropriate $\phi$ factor. Note that it is very dependent upon the condition of the bridge and its level of inspection and maintenance. These factors thus reflect the fact that well maintained bridges will be more reliable than those that are neglected will. Additional guidance for accounting for deterioration, inspection, and maintenance is provided in Table $3 \mathrm{a}$ of Ref. [2].

The dead and live load factors, $\gamma_{D}$ and $\gamma_{L}$, respectively, are most easily obtained from Table 2, Ref. [2]. The live load factor is dependent upon the ADTT (average daily truck traffic) and the level of control against overloads. For example, a small military installation with controlled vehicle access may be able to use a live load factor of 1.30 due to its low truck volume and easily enforced truck loadings. However, a bridge in a training area, where load enforcement is difficult, may require a larger live load factor of 1.65.

Note that the LRFR method does not differentiate between Inventory and Operating levels of service. Reference [2] states that, "With the LRFR factors properly applied, bridges may reach or even exceed their previous operating rating when they receive frequent, qualified inspections with proper maintenance and load enforcement. Conversely, those without these conditions or with nonredundant critical components will find their ratings fall to, or even lower than the inventory rating." From this it can be seen that proper inspection and maintenance of the bridge will likely be rewarded by higher load ratings. Special Permit loads should still be considered separately.

\section{Railroad Bridges}

The AREA (Reference 5) is somewhat behind the highway community in providing up-to-date criteria for the rating of bridges. They have yet to adopt the LRFR method and except for concrete bridges, have yet to adopt even the Ultimate Strength method. Therefore, the RF equation 16, as discussed above, should also be used for railroad bridges, but with the following guidelines from Reference 5: For concrete bridges, use Chapter 8, Article 19.4.1.2 for the Allowable Stress method or Article 19.4.1.3 for the Ultimate Strength method. For steel bridges, use Chapter 15, Article 7.3.4.3 for the Allowable Stress method. For timber bridges, use Chapter 7, Article 2.10.13 for the Allowable Stress method. 


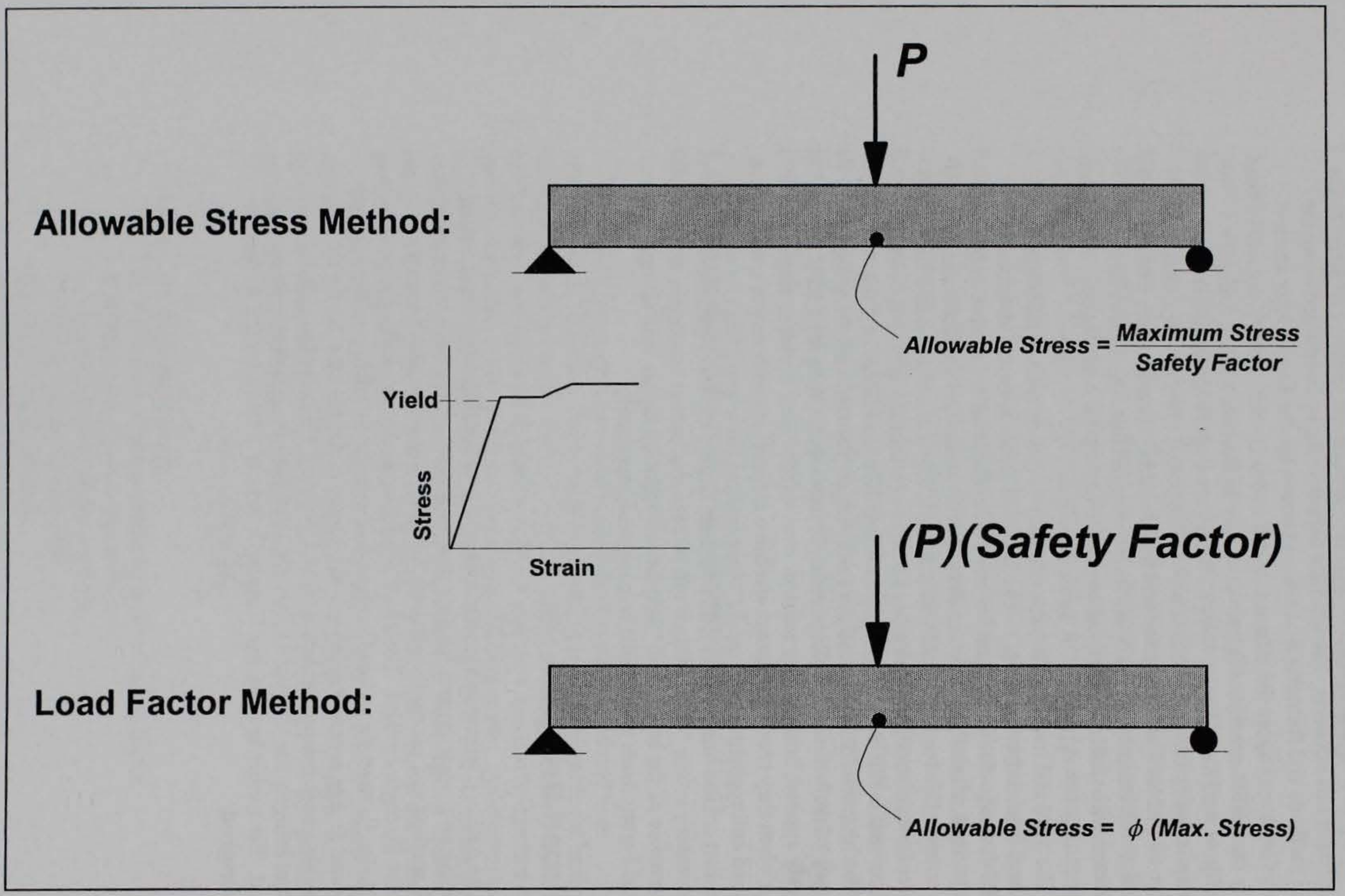

Figure 50. Allowable stress compared to load factor method 
Basic Equation:

(Ref. 1, Par. 6.5)

\section{Rating Factor $=$ RF $=$ Capacity - Dead Load Applied Live Load}

$=\frac{C-A_{1} D}{A_{2} \perp(1+I)}$
$C=$ Nominal Capacity of the member (Par 6.6) $D=$ Dead Load effect on the member (6.7.1) $L=$ Live Load effect on the member (6.7.2) I = Impact factor for live load (6.7.4) Af Factor for dead loads $(6.5 .2 \& 6.5 .3)$ $A_{Z}=$ Factor for live loads (6.5.2 \& 6.5.3)

Allowable Stress Method: - Actual loadings combined to produce max. stress in a member, which is not to exceed the (6.4.1\&6.5.2)

"allowable" or "working" stress. Safety factors applled to allowable stress only.

- only method available for timber

- Use basic equation with: $C$ = Allowable $C$ based on Inventory and Operating Stresses (6.6.2 Ref. 1)

$$
A F=C-D \quad A_{1}=A_{2}=1.0
$$

$R F=\frac{C-D}{L(1+1)}$, where $C$ based on allowable stress

Load Factor (Ultimate Strength) Method: - Based on analyzing a structure subject to multiples of the actual load (factored

$(6.4 .2 \& 6.5 .3)$

loads). Different factors are applied to each type of load to reflect the

uncertainty inherent in the load calculations. The Nominal Capacity of the

member is based on its ultimate capacity and is reduced by a safety factor

$(\phi)$ to account for uncertainty in these calculations.

- Use basic equation with: $C=\not C$ utt (6.6.3 Ref. 1)

$$
\begin{aligned}
& A_{1}=1.3 \\
& A_{2}=2.17 \text { for Inventory level } \\
& A_{2}=1.30 \text { for Operating level }
\end{aligned}
$$

Load and Resistance Factor Rating (LRFR) Method: - Very simllar to Load Factor method, but more applicable to existing bridges (6.1 of Ref. 1 refers to Ref. 2)

because it better allows for varied bridge conditions and maintenance

practices. Each varlable in the RF equation can be addressed separately,

analyzed in-depth if need, and proportlonally weighed in the overall rating.

- Only applicable to steel and concrete

- Use basic equation with; $C=\phi(C F) C_{\text {utt }}$ where: $\phi$ from Fig. 4, Ref. 2, reflects inspection

level, deterioration, level of maint.,. \& redundancy. CF from Tab.1, Ref. 2, reflects level of analysis.

$A_{1}=1.2 \quad$ (Table 2, Ref. 2)

$A_{2}$ from Table 2, Ref. 2, reflects traffic volume and level of enforcement of loads on bridges.

Figure 51. Rating factor equation for three different load rating methods (vehicular bridges only) 


\section{Summary}

\section{Basic Rating Procedure}

Based upon all of the previous chapters, the basic procedure for load rating a bridge may be summarized as follows: For each bridge element in the load path, perform the following procedure using Reference [1] as the overall guideline (all "Article" references below are from Reference [1]):

1. Calculate the required nominal member capacities (Article 6.6) using either the Allowable Stress method (Article 6.6.2), Load Factor method (Article 6.6.3), or the LRFR method (Reference [2]). Deterioration of elements is accounted for in this step.

2. Calculate load effects. For Dead Load, use Article 6.7.1. For Live Load, the Rating Vehicle is the HS20 (Article 6.7.2). The Posting Vehicles are the Type 3, $3 \mathrm{~S} 2$, and 3-3 vehicles or any desired state legal loads.

3. Calculate the RF (Article 6.5). Post the bridge only if the RF is less than 1.0 for any of the Posting Vehicles. Refer to Chapter 1 of this report for a discussion on bridge posting.

4. Calculate the Military Load Classes as described in the following paragraph.

\section{Military Load Classification (MLC)}

Once the RFs are determined for the civilian truck loadings, the same RF equation may be used to solve for the allowable MLCs for the bridge. Since it is known that a RF greater than or equal to 1.0 is acceptable, the RF equation may be set equal to 1.0 and the allowable live loading solved for as follows:

$$
\begin{aligned}
& R F=1.0=\frac{C-A_{1} D}{A_{2} L(1+I)} \\
& \therefore L=\frac{C-A_{1} D}{A_{2}(1+I)}
\end{aligned}
$$


Once the live load effect is obtained, the MLC moment and shear curves in Figures 39 and 40, respectively, may be used to find the military wheel and tracked vehicles that produce this magnitude or less. Be very careful however, the live load effect, $L$, from the equation above will be for a vehicular line load, and the values in Figures 39 and 40 are for axle loads. Therefore, the value $L$ must be multiplied by 2.0 prior to utilizing Figures 39 and 40 . The MLC process is demonstrated in the Rating Examples of the Appendices.

\section{Rating Examples}

Load rating examples are provided in Appendices A - D for the most common bridge types. Because it is the preferred method by the Army and COE, the LRFR method is used throughout. Each of the examples follows the basic rating procedure described above. Note that the Reference numbers used in the examples are the same as those used in the main body of this report. 


\section{References}

[1] Condition Evaluation Manual

[2] GSSE Manual

[3] AASHTO Design Manual, "sixteenth edition", 1996

[4] FM5-446 or TM5-312

[5] AREA Manual

[6] Steel Manual

[7] Timber Bridge Manual

[8] ACI Code 


\section{Appendix A Timber Bridge Example}

\section{Timber Deck, Timber Stringer Bridge}

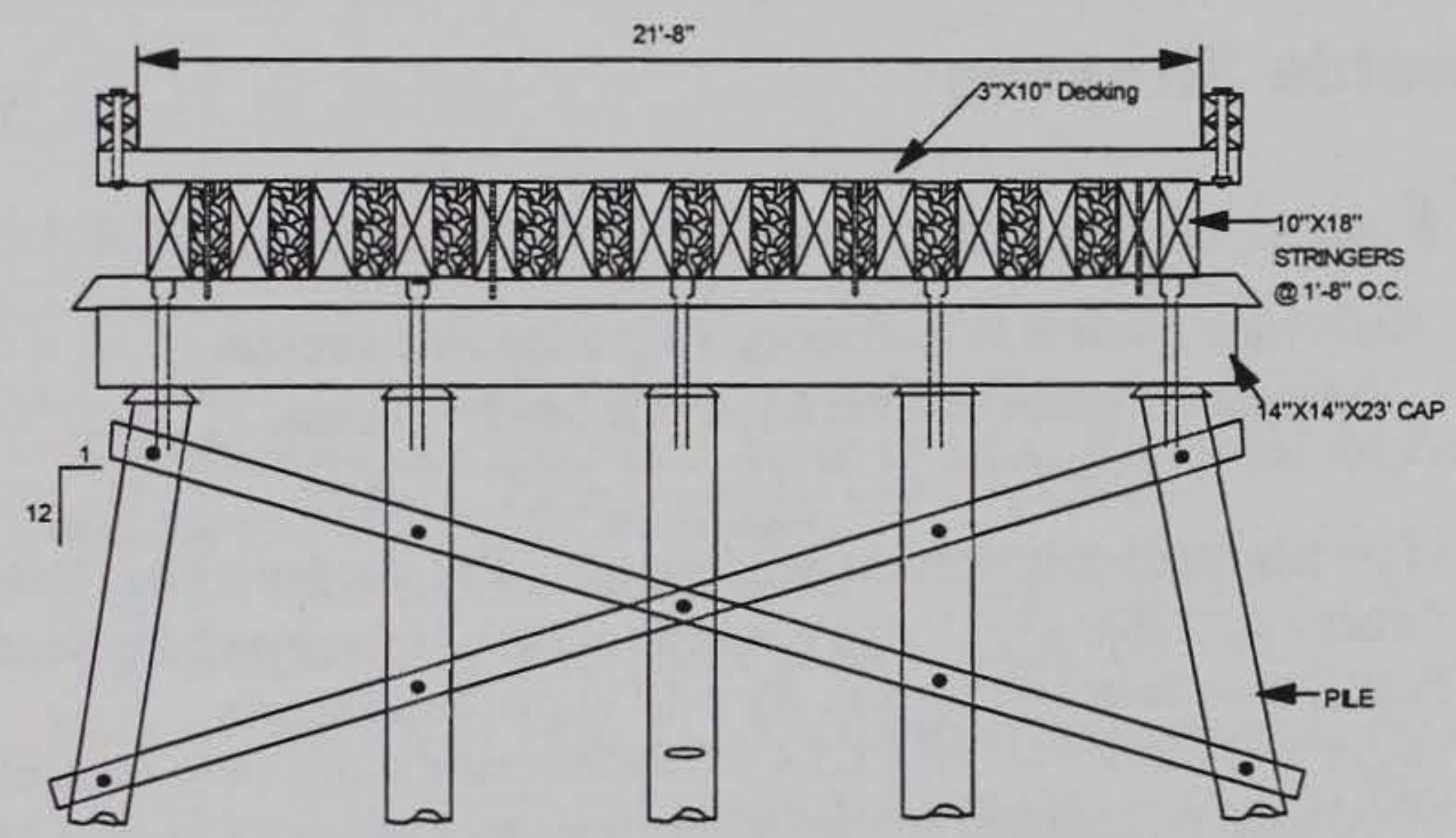

MPICAL BRDGE TRANSVERSE SECTION

- The span length is 14'

- The deck is Southern Pine Select Structural. The Stringers are Southern Pine Dense Select Structural.

*Note that unless design drawings are available, timber species will not generally be known and extreme conservatism should be exercised in determining species and allowable stresses. 
Sited References:

1. Manual For Condition Evaluation of Bridges, AASHTO, 1994.

2. Guide Specifications for Strength Evaluation of Existing Steel and Concrete Bridges, AASHTO, 1989.

3. Standard Specifications for Highway Bridges, AASHTO, fifteenth edition, 1992.

4. Manual for Maintenance Inspection of Bridges, AASHTO, 1983.

5. Military Nonstandard Fixed Bridging, FM5-446 or TM5-312.

6. Manual of Steel Construction, American Institute of Steel and Concrete (AISC), Edition.

7. Timber Bridges; Design, Construction, Inspection, and Maintenance. US Dept. of Agriculture, 1992.

\section{Allowable Stresses}

\section{Bending}

-6.6.2.7, Reference 1 refers to Reference 3 for allowable stresses

-13.6.2.1, Reference 3 states that the allowable bending stress, $F_{b}^{\prime}$, is:

$$
F_{b}^{\prime}=F_{b} C_{M} C_{D} C_{F} C_{V} C_{L} C_{f} C_{f u} C_{r} \text {, where }
$$

$-F_{b}=$ tabulated unit stress in bending (psi); For Southern Pine, Select Structural, Table 13.5.1.A; $F_{b}=2050 \mathrm{psi}$ for decking and for Southern Pine Dense Select Structural, $F_{b}=1750$ psi for stringers $-C_{M}=$ wet service factor 13.5.4.1.3 states that the moisture content of wood used on exposed bridge applications will normally exceed $19 \%$ and tabulated values shall be reduced by the wet service factor unless an analysis of regional, geographic and climatological conditions that affect moisture content indicate that the in-service moisture content will not exceed $19 \%$. Reference 7 states that in most applications, bridge members are exposed to the weather and should be adjusted for wet service conditions. In cases where beams are protected by waterproof deck, design for dry conditions may be appropriate. For southern pine use tabulated values for wet service condition and $C_{M}=1.0$

$-C_{D}=$ load duration factor from 13.5.4.2.1 Tabulated values for sawn lumber are based on an assumed normal load duration. In this case, normal duration of load is based on the expectation that members will be stresses to the maximum stress level either continuously or cumulatively, for a period of approximately 10 years, and/or stressed $90 \%$ of the maximum design level continuously for the remainder of the life of the structure. Since bridges generally are not at their maximum stress level, $C_{D}=1.0$ will be conservative.

$-C_{F}=$ bending size factor for sawn lumber. From 13.6.4.2: $C_{F}=1.0$ for decking

$$
\text { for stringers, 13.6.4.2.2 applies and } C_{F}=\left(\frac{12}{d}\right)^{\frac{1}{9}}=\left(\frac{12}{18}\right)^{\frac{1}{9}}=0.96
$$


$-C_{V}=$ volume factor for glued laminated timber. $C_{V}=1.0$

$-C_{L}=$ beam stability factor from 13.6.4.4: In this example, assume

adequate bracing supplied by decking, $C_{L}=1.0$

$-C_{f}=$ form factor from 13.6.4.5: $C_{f}=1.0$

$-C_{f u}=$ flat use factor for sawn lumber from footnotes of Table 13.5.1A.

For the decking, $C_{f u}=1.2$

$-C_{r}=$ repetitive member factor for sawn lumber from footnotes of Table

13.5.1A:

For decking, $C_{r}=1.15$

For stringers, $C_{r}=1.00$

-Therefore:

for decking, $F_{b}^{\prime}=2050(1.0)(1.0)(1.0)(1.0)(1.0)(1.0)(1.2)(1.15)=2829 \mathrm{psi}$

for stringers, $F_{b}^{\prime}=1750(1.0)(1.0)(0.96)(1.0)(1.0)(1.0)(1.0)(1.0)=1680 \mathrm{psi}$

\section{Shear}

-13.6 .5 .3 , Reference 3 states that allowable unit stress in shear parallel to grain, $F_{v}^{\prime}$, is:

$$
F_{v}^{\prime}=F_{v} C_{M} C_{D}, \text { where }
$$

$-F_{v}=$ tabulated unit stress from Table 13.5.1A; $F_{v}=90$ psi for the

decking and $110 \mathrm{psi}$ for the stringers

$-C_{M}=$ wet service factor, same as for bending. $C_{M}=1.0$

$-C_{D}=$ load duration factor, same as for bending. $C_{D}=1.0$

Note: Footnote 6 of Table 13.5.1A allows an increase in $F_{v}^{\prime}$ by a factor, $C_{H}$, if the degree of splitting and checking is known. This factor should only be used under carefully-controlled conditions. For this example, $C_{H}=1.0$

- Therefore: for decking, $F^{\prime}{ }_{V}=90 p s i(1.0)(1.0)=90 p s i$

for stringers, $F^{\prime}{ }_{v}=110 p \operatorname{si}(1.0)(1.0)=110 p s i$

\section{Deck Rating}

\section{Nominal Moment Capacity, $M_{n}$}

-From previous pages: $\quad$ Inventory: $\quad F_{b}^{\prime}=2829 \mathrm{psi}$

As per 6.6.2.7, Reference 1, Operating: $\quad F_{b}^{\prime}=1.33(2829)=3763$ psi -13.2 .1 .2 .1 , Reference 3: Use actual dimensions for sawed lumber. $b=10$ in., $d=3$ in.

$-M_{n}=F_{b}^{\prime} S$, where $S=$ section modulus

Inventory: $M_{n I}=(2829 \mathrm{psi})\left(15 \sin ^{3}\right)\left(\frac{f t}{12 i n}\right)=3536 \mathrm{ft} \cdot \mathrm{lb}$

Operating: $M_{n O}=(3763 p s i)\left(15 \sin ^{3}\right)\left(\frac{f t}{12 i n}\right)=4704 \mathrm{ft} \cdot 1 \mathrm{~b}$ 


\section{Nominal Shear Capacity}

Inventory: $F^{\prime}{ }_{v}=90 \mathrm{psi}$

Operating: $F^{\prime}{ }_{v}=90 \mathrm{psi}(1.33)=120 \mathrm{psi}$

-From 13.6.5.2, Reference 3, $F_{v}^{\prime}=\frac{3 V n}{2 b d}, F_{v}^{\prime}=\frac{3 V n}{2 b d}$, or $V_{n}=\frac{2}{3} F^{\prime}{ }_{v} b d$

Inventory: $V_{n I}=\frac{2}{3}(110 \mathrm{psi})(10 \mathrm{in})(3 \mathrm{in})=2200 \mathrm{lb}$

Operating: $V_{n O}=\frac{2}{3}(146 \mathrm{psi})(10 \mathrm{in})(3 \mathrm{in})=2926 \mathrm{lb}$

\section{Load Effects on Deck}

Dead Load:

-3.25.1.2, Reference 3: $S p a n=S=20 i n-10 i n+3 i n=13 i n=1.1 f t$

-3.3 .6 , Reference 3: Unit weight of timber $=50 \mathrm{pcf}$

-Dead load will be computed for one plank width since live load is only applied to one plank width:

$$
\begin{aligned}
& \omega_{D}=(50 p c f)(3 i n)(10 i n)\left(\frac{f t^{2}}{144 i^{2}}\right)=10.4 \frac{l b}{f t} \\
& M_{D}=\frac{\omega_{D} S^{2}}{8}=\frac{10.4 \frac{l b}{f t}(1.1 f t)^{2}}{8}=1.53 f t \cdot l b
\end{aligned}
$$

-13.6.5.2, Reference 3: Dead load shear is computed at a distance, $t$, from the support and the load within a distance $t$ from the support is neglected ( $t=$ deck thickness):

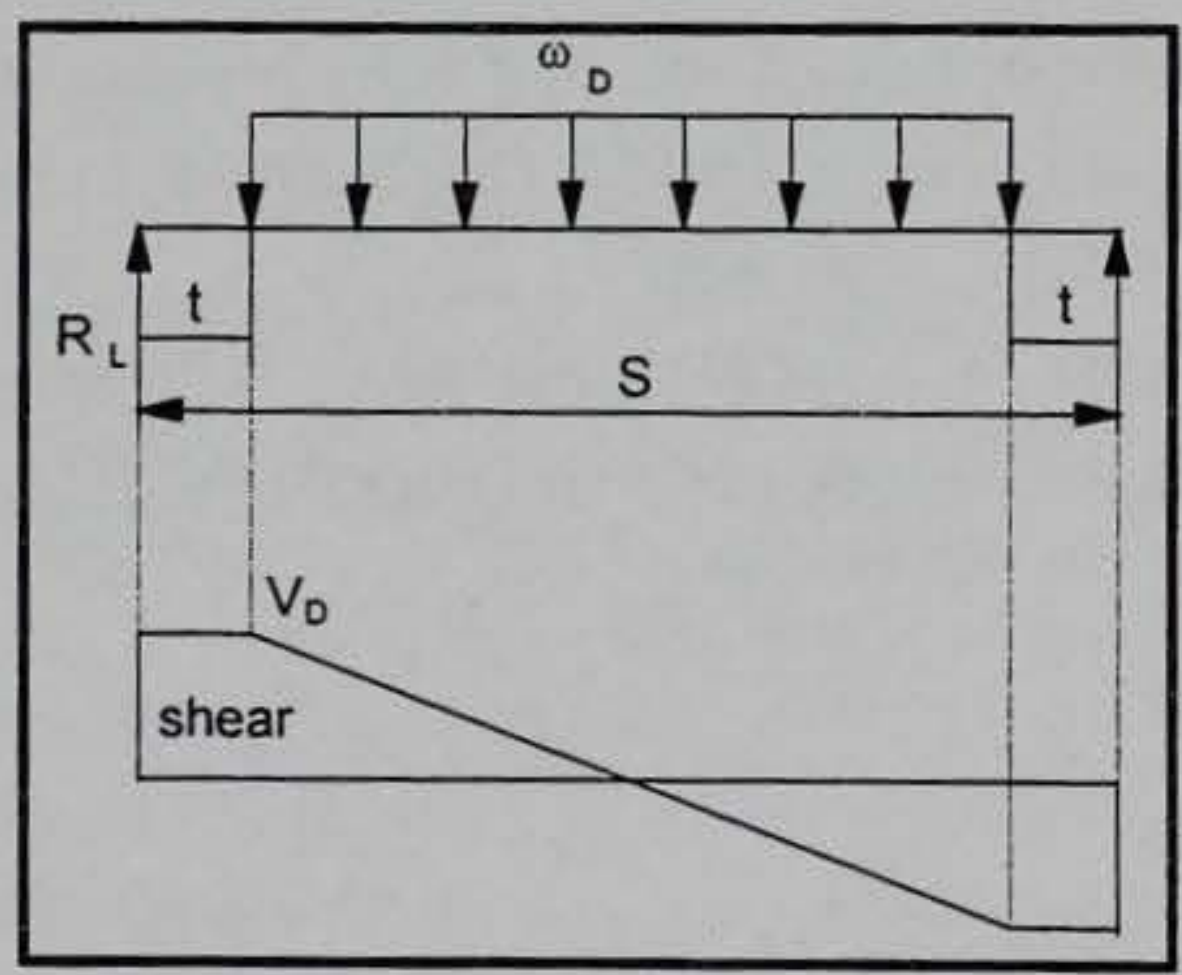

$$
\begin{aligned}
V_{D} & =R_{L}=\frac{1}{2} \omega_{D}(S-2 t) \\
& =\omega_{D}\left(\frac{S}{2}-t\right) \\
& =10.4 \frac{l b}{f t}\left(\frac{f t}{12 i n}\right)\left(\frac{13 i n}{2}-3 i n\right)=3.0 l b
\end{aligned}
$$


Live Load:

-3.25.1.1 and 3.30, Reference 3: Wheel loadings are distributed longitudinally over one plank width and over a tire contact area $=0.01 \mathrm{P}$, where $\mathrm{P}=$ wheel load in pounds. Thus, transverse distribution width, $W$, is:

$$
W=\frac{0.01 P}{\text { plankwidth }}=\frac{0.01 P}{10 \text { in }}
$$

\begin{tabular}{|c|c|c|}
\hline Vehicle & $\begin{array}{c}\text { Wheel } \\
\text { Load (lb) }\end{array}$ & $\begin{array}{c}W \\
\text { (in) }\end{array}$ \\
\hline Type 3 & 8,500 & 8.5 \\
\hline Type 3S2 & 7,750 & 7.75 \\
\hline Type 3-3 & 8,000 & 8.0 \\
\hline HS20 & 16,000 & 16.0 \\
\hline
\end{tabular}

-For a Type 3 vehicle with wheel load $=8,500 \mathrm{lb}$ (Refer to Figure below):

$$
\begin{aligned}
\omega_{L} & =\frac{8,500}{8.5 i n\left(\frac{f t}{12 i n}\right)}=12,000 \frac{\mathrm{lb}}{f t} \\
M_{L} & =(4250 \mathrm{lb})(6.5 \mathrm{in})-(4250 \mathrm{lb})(2.125 \mathrm{in}) \\
& =18,594 \mathrm{in} \cdot \mathrm{lb}\left(\frac{\mathrm{ft}}{12 \mathrm{in}}\right)=1550 \mathrm{ft} \cdot \mathrm{lb}
\end{aligned}
$$

For Type 3 Wheel loading,

laterally over 8.5 in :

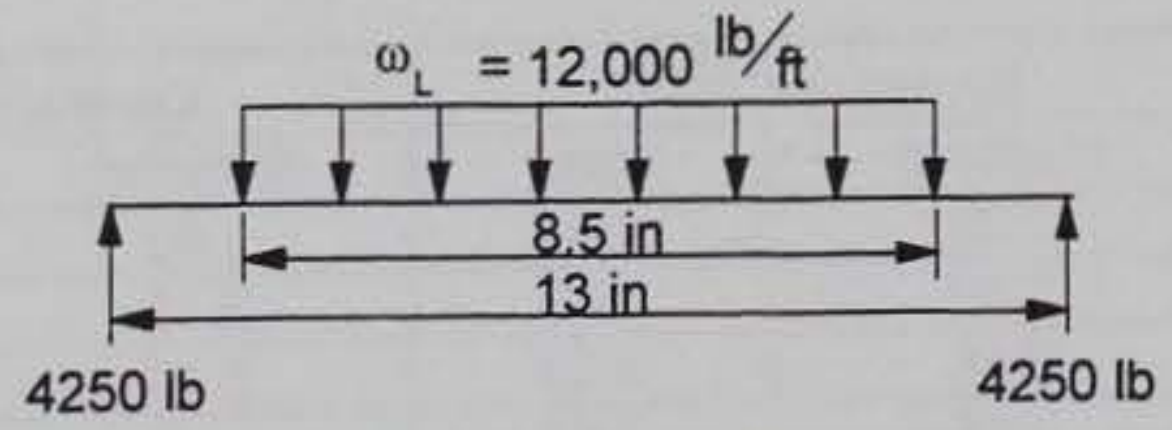

-Since the wheel load appears as a uniform load between stringers, Par. 13.6.5.2 applies where it stipulates to calculate the maximum shear occurring at a distance, $t$, from the support (Refer to Figure below):

$$
\begin{aligned}
& \Sigma M=0=R_{L}\left(\frac{13 i n}{12 i / / / h}\right)-12,000 \frac{l b}{f t}\left(\frac{8.5 i n}{12}\right)\left(\frac{8.5}{2}+1.5\right)\left(\frac{1}{12}\right) \\
& R_{L}=V_{L_{3}}=3760 l b
\end{aligned}
$$




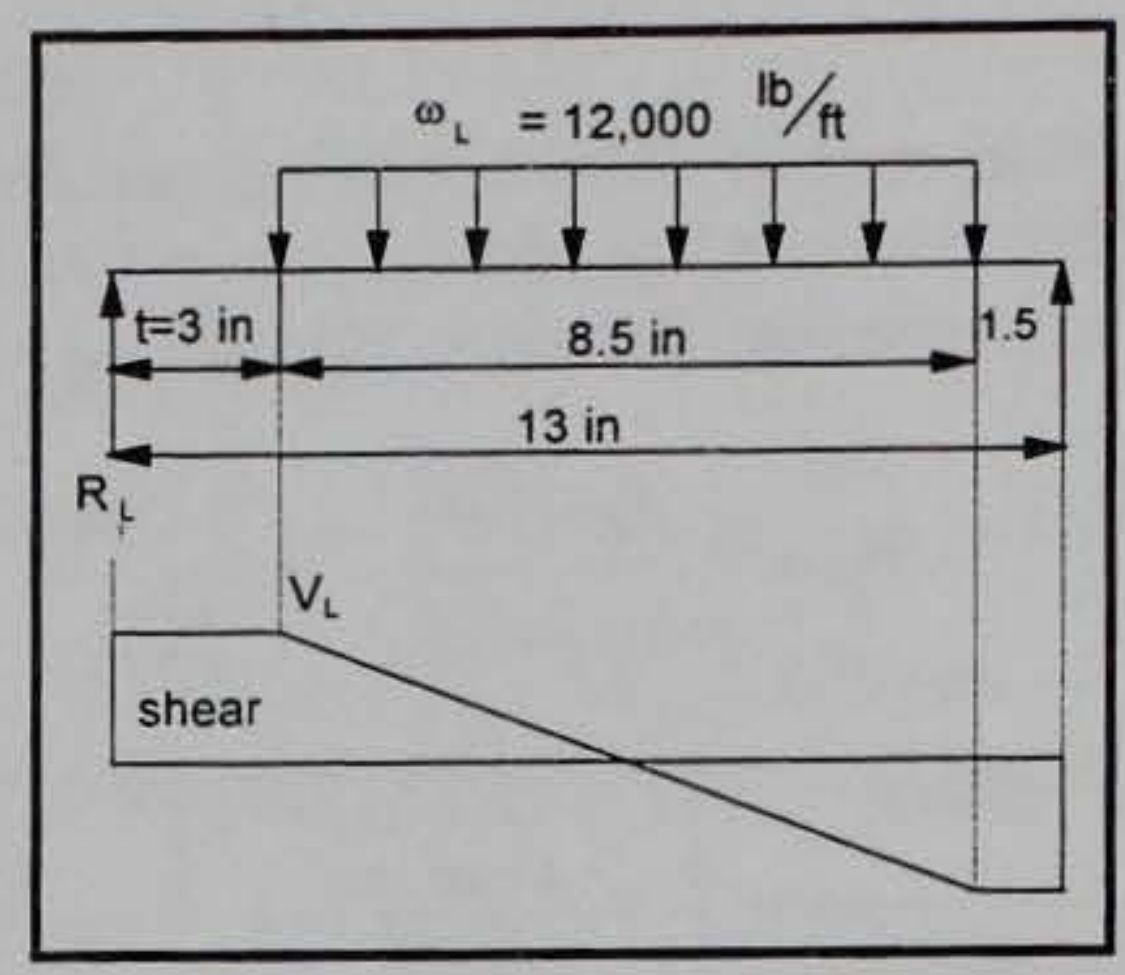

-All other moments and shears are calculated similarly and summarized as follows:

\begin{tabular}{|c|c|c|}
\hline Vehicle & $\begin{array}{c}M_{L} \\
(f t \cdot l b)\end{array}$ & $\begin{array}{c}V_{L} \\
(l b)\end{array}$ \\
\hline Type 3 & 1550 & 3760 \\
\hline Type3S2 & 1473 & 3651 \\
\hline Type 3-3 & 1500 & 3692 \\
\hline HS20 & 1760 & 3846 \\
\hline
\end{tabular}

\section{Deck Rating Factors}

Moment: $R F_{M}=\frac{M_{n}-M_{D L}}{M_{L}}$; Shear: $R F_{V}=\frac{V_{n}-V_{D}}{V_{L}}$

$$
R F_{M}=\frac{3536-1.53}{1550}=2.28 \quad R F_{V}=\frac{1800-3}{3760}=0.48
$$

\begin{tabular}{|c|c|c|c|c|}
\hline \multirow{2}{*}{ Vehicle } & \multicolumn{2}{|c|}{ Inventory $R F$} & \multicolumn{2}{c|}{ Operating $R F$} \\
\cline { 2 - 5 } & Moment & Shear & Moment & Shear \\
\hline Type 3 & 2.28 & 0.48 & 3.03 & 0.64 \\
\hline Type 3S2 & 2.40 & 0.49 & 3.19 & 0.66 \\
\hline Type 3-3 & 2.36 & 0.49 & 3.13 & 0.65 \\
\hline HS20 & 2.01 & 0.47 & 2.67 & 0.62 \\
\hline
\end{tabular}

\section{Military Load Class (MLC) of Deck}

- As per Chapter 6 of Reference 5, the tire load of wheeled vehicles will always control the deck rating since tire loading is much more concentrated than track loading. While this rating procedure would at first seem simple, it is actually quite complex. As a simpler and yet still conservative alternative, Figure 6-9 of Reference 5 may be used to obtain MLCs of timber decks. For this example; Figure 6-9 indicates a MLC of 8 for both wheeled and tracked vehicles. However, if a less conservative rating is desired, the following procedure may be utilized:

- Note that shear controlled the civilian vehicle deck rating. Thus, only shear will be considered for the MLC determination. In addition, only the Operating Rating will be considered for MLC since military loading frequencies are generally low. These decisions must be made on a case-by-case basis. 
Wheeled Vehicle Rating:

-Since a Rating Factor greater than 1.0 is satisfactory, the MLC can be obtained by setting RF equation equal to 1.0 and solving for $\mathrm{V}_{\mathrm{L}}$ as follows :

$$
\begin{aligned}
R F_{V} & =1.0=\frac{V_{n}-V_{D}}{V_{L}} \\
V_{L} & =V_{n}-V_{D}
\end{aligned}
$$

Operating : $V_{L}=2400 \mathrm{lb}-3.0 \mathrm{lb}=2397 \mathrm{lb}$

-Assuming a wheel load appears as a uniform load on a deck span between stringers, $V_{L}$ represents the maximum vertical shear that can be "allowed" at a distance, $t$, from the support (13.6.5.2, Reference 3 ). Therefore, the value, $\omega_{L}$, which causes this shear must be solve for as follows (Refer to Figure below):

$$
\begin{aligned}
& U \operatorname{sing} R_{L}=V_{L}: \\
\sum M= & 0=V_{L}(13)-\omega_{L}(10)(5) \\
\omega_{L}= & 0.26 V_{L}=0.26(2397) \\
\omega_{L}= & 623 \frac{\mathrm{lb}}{\mathrm{in}}
\end{aligned}
$$

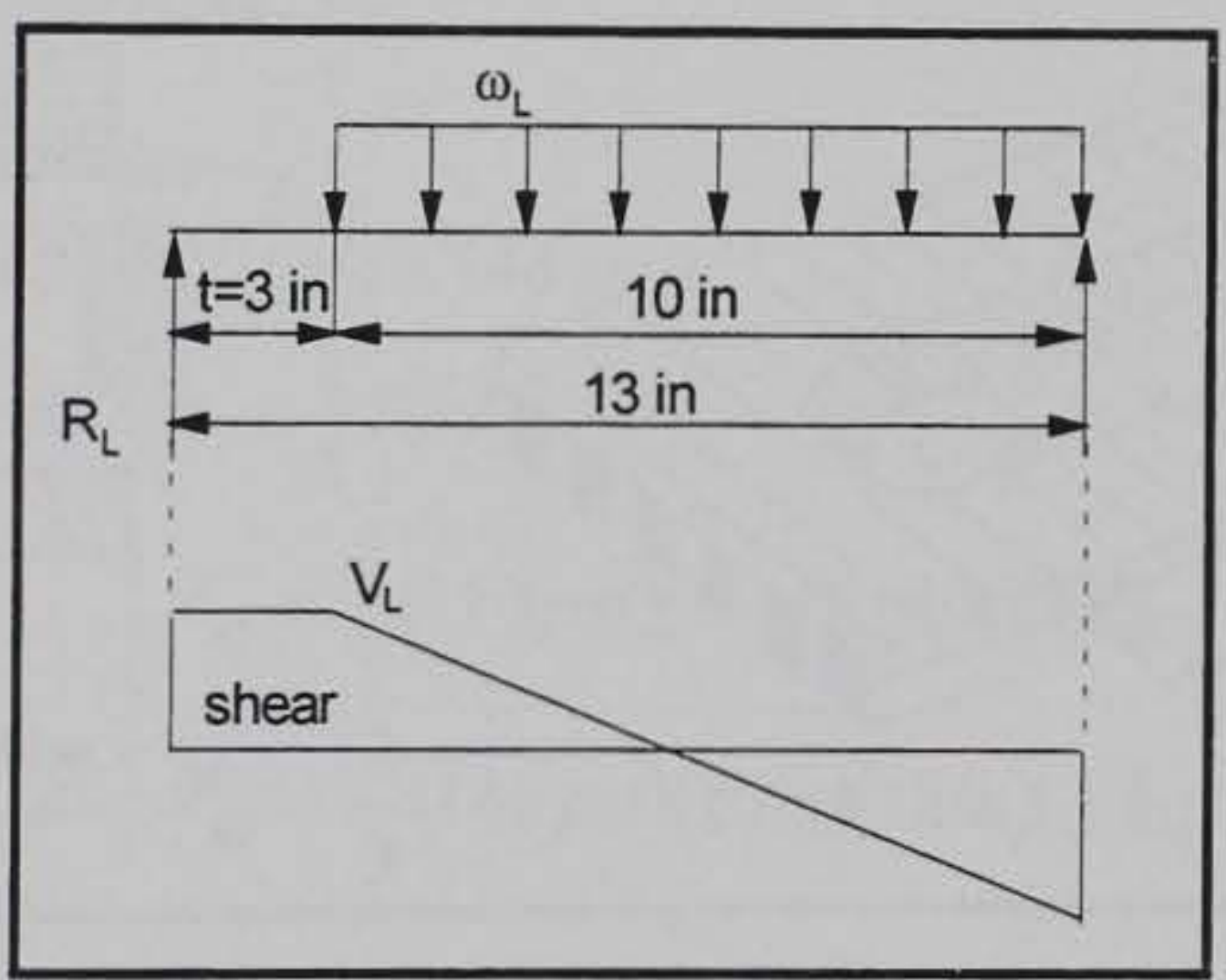

$-\omega_{L}$ represents the allowable distributed wheel load. Therefore, multiply $\omega_{L}$ by a typical tire width* to get allowable wheel load:

$$
-P_{\text {allow }}=\omega_{L}(\text { tire width })=\left(623 \frac{\mathrm{lb}}{\mathrm{in}}\right)(14 \mathrm{in})=8,722 \mathrm{lb}
$$

-Convert to tons and axle load for use in vehicle data table of Reference 5:

$$
8,722 \mathrm{lbs}\left(\frac{\text { ton }}{2000 \mathrm{lb}}\right)\left(\frac{2 \text { wheels }}{\text { axle }}\right)=8.72 \frac{\text { ton }}{\text { axle }}
$$

-From Column 4 of Reference 5 vehicle data, $M L C=W 12$, and its tire width is $14 "$, therefore, the initial assumption of tire width was good $\Rightarrow M L C=W 12$

*Tire widths for military vehicles vary considerably (as seen in Reference 5 Veh. data). Therefore, use a width from the expected class for which the bridge will be rated. This may require an iteration process. 
For this example, the expected class is somewhere around 20 , so use a width $=14$ in from column 5 .

\section{Tracked Vehicle Rating:}

- In most cases, tracked vehicles will not cause critical loadings on decks since tracks distribute their loads longitudinally over much of the length of the bridge. The wheeled vehicle rating will always be less than the tracked rating and if desired, the wheeled MLC may be conservatively used for the tracked MLC. However, if a higher tracked MLC is desired, the following procedure may be used:

- As seen in the Vehicle Data of Reference 5, the track lengths and widths vary considerably between load classes. Therefore, for rating purposes, make a conservative assumption based on the expected load class. For this example, use the data from the class 12 tracked vehicle which has a track length of 9 feet and width of 12 inches.

- As done for the wheel MLC, setting the RF equation equal to 1.0 and solving for $V_{L}$ gives an allowable shear per plank, $V_{L}=2397 \mathrm{lb}$.

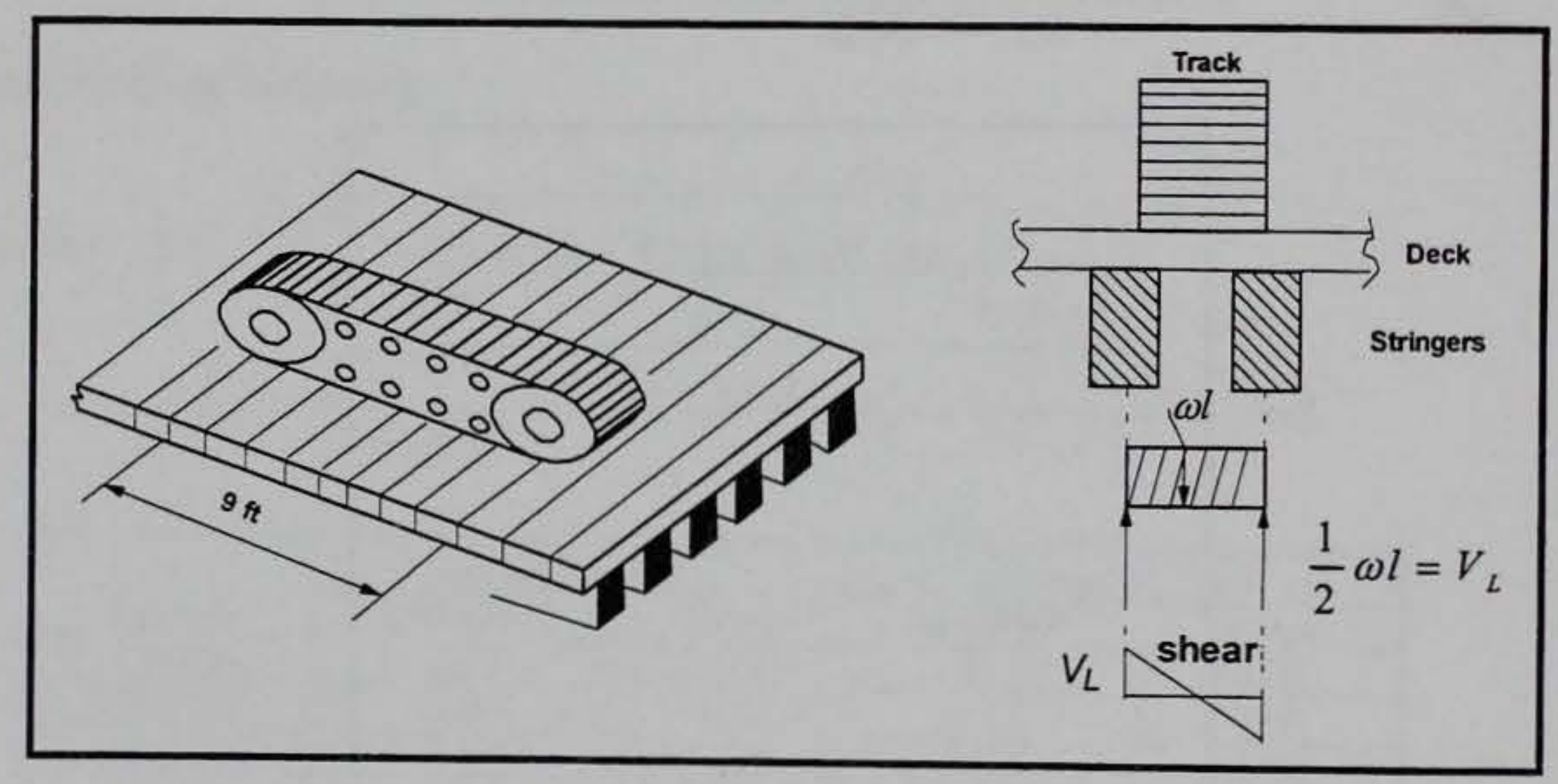

- As seen in the Figure above, a 12 in wide track will spread the load laterally almost evenly across the 13 in deck span. Assuming this to be the case, the total load per plank will be: $2 V_{L}=2(2397 l b)=4794 \mathrm{lb} /$ plank .

- Since $\frac{(9 f t)\left(\frac{12 i n}{n}\right)}{10 \text { in. plank width }}=10.8$ planks will be beneath a track at any given time sharing in the load, the total allowable track load is thus $\left(10.8 \frac{\text { planks }}{\text { track }}\right)(4794 \mathrm{lb})\left(\frac{\mathrm{kip}}{1000 \mathrm{lb}}\right)=51.8 \mathrm{kip} / \mathrm{track}$.

- Therefore, the total allowable tank weight is $\left(2 \frac{\text { tracks }}{\text { tank }}\right)\left(51.8 \frac{\text { kip }}{\text { track }}\right)=103 \frac{\text { kip }}{\text { tank }}\left(\frac{1 \text { ton }}{2 k i p}\right)=51 \frac{\text { ton }}{\text { tank }}$.

- From Reference 5 Vehicle Data, this corresponds to $\underline{M L C=T 50}$. 


\section{Stringer Rating}

\section{Nominal Moment Capacity, $M_{n}$}

-From previous pages: $\quad$ Inventory: $\quad F_{b}^{\prime}=1680 p s i$

As per 6.6.2.7, Reference 1, Operating: $\quad F_{b}^{\prime}=1.33(1680 \mathrm{psi})=2234 \mathrm{psi}$

-13.2.1.2.1, Reference $3:$ Use actual dimensions for sawn lumber:

$b=10 \mathrm{in}, d=18 \mathrm{in}$

$-M_{n}=F^{\prime} S$, where $S=\frac{I}{c}$

$$
=\frac{b h^{3}}{12 c}=\frac{(10)(18)^{3}}{12(9)}=540.0 \mathrm{in}^{3}
$$

Inventory : $\quad M_{n I}=(1680 p s i)\left(540 \mathrm{in}^{3}\right)\left(\frac{f t}{12 i n}\right)\left(\frac{k i p}{10001 b}\right)=75.6 f t \cdot k i p$

Operating: $\quad M_{n O}=(2234 p s i)\left(540 i^{3}\right)\left(\frac{f t}{12 i n}\right)\left(\frac{k i p}{10001 b}\right)=100 f t \cdot k i p$

\section{Nominal Shear Capacity, $V_{n}$}

Inventory: $F^{\prime}{ }_{v}=110 \mathrm{psi}$

Operating: $F^{\prime}{ }_{v}=1.33(110 \mathrm{psi})=146 \mathrm{psi}$

-13.6.5.2, Reference 3: $V_{n}=\frac{2}{3} F_{v} b d$

Inventory : $\quad V_{n I}=\frac{2}{3}(110 p s i)(10 \mathrm{in})(18 \mathrm{in})\left(\frac{\mathrm{kip}}{1000 \mathrm{lb}}\right)=13.2 \mathrm{kip}$

Operating: $\quad V_{n O}=\frac{2}{3}(146 p s i)(10 i n)(18 i n)\left(\frac{k i p}{10001 b}\right)=17.6 k i p$

\section{Load Effects on Stringers}

Dead Load $\left(\omega_{D}\right)$ :

- Stringer Spacing $=\mathrm{S}=20 \mathrm{in}$; Bearing area sufficient as per 13.6.6.3, Reference 3.

- 13.6.1.2; Reference 3: $\operatorname{Span}=14 \mathrm{ft}-14 \mathrm{in}\left(\frac{\mathrm{ft}}{12 i n}\right)+\frac{1}{2}(14 \mathrm{in})\left(\frac{\mathrm{ft}}{12 i n}\right)=13.4 \mathrm{ft}$

- 3.3.6; Reference 3 : Unit weight of timber $=50 \mathrm{pcf}$

- Compute dead load applied to one stringer: 
Deck: $\omega_{D}=$ thickness $* S *$ timber unit wt.

$$
=(3 i n)(20 i n)(50 p c f)\left(\frac{f^{2}}{144 i^{2}}\right)\left(\frac{k i p}{10001 b}\right)=0.021 \frac{k i p}{f t}
$$

Stringer: $\omega_{D}=$ stringer area $*$ timber unit wt.

$$
=(10 i n)(18 i n)(50 p c f)\left(\frac{f^{2}}{144 i^{2}}\right)\left(\frac{k i p}{1000 i b}\right)=0.063 \frac{k i p}{f t}
$$

Misc.:

$$
\text { Total } \omega_{D}=0.284 \frac{k i p}{f t}
$$

Dead Load Moment $\left(M_{D}\right)$ : For a simple beam:

$$
M_{D}=\frac{\omega l^{2}}{8}=\frac{\left(0.284 \frac{k i p}{f t}\right)(13.4 f t)^{2}}{8}=6.37 f t \cdot k i p
$$

Dead Load Shear $\left(V_{D}\right)$ :

- 13.6.5.2, Reference 3 : Dead load shear is computed at a distance ,d, from the support and the load within a distance, d, from the support is neglected (refer to deck calculations for demonstration):

$$
\begin{aligned}
V_{D} & =\omega_{D}\left(\frac{l}{2}-d\right) \\
& =\left(0.284 \frac{k i p}{f t}\right)\left(\frac{13.4 f t}{2}-1.5 f t\right)=1.48 k i p
\end{aligned}
$$

Live Load:

- Due to its width, the bridge is assumed to have two traffic lanes for civilian loadings as per 3.6.3

- Stringer Distribution Factor (DF): From 3.23.2.2, Reference 3 for timber plank:

$$
\text { Two-Way Traffic: } D F=\frac{S}{3.75}=\frac{1.67 f t}{3.75}=0.44
$$

- Live load moments and shears are those produced from the wheel lines of the rating vehicles on a $13.4 \mathrm{ft}$ simple span. These can be obtained through basic structural analysis by placing the vehicle to produce maximum moments and shears, or more simply from Appendix A of Reference 1 (Refs. 3 and 4 also contain these values). Note in Table A3 that interpolation between a 13 and $14 \mathrm{ft}$ span is required.

$$
\begin{array}{ll}
M_{L 3} & =(\text { max. moment per wheel line }) * D F \\
M_{L 3 S 2} & =41.7 \mathrm{ft} \cdot \mathrm{kip} \text { per wheel line } * 0.44=18.3 \mathrm{ft} \cdot \mathrm{kip} \\
M_{L 3-3} & =38.0 \mathrm{ft} \cdot \mathrm{kip} \text { per wheel line } * 0.44=16.7 \mathrm{ft} \cdot \mathrm{kip} \\
M_{L H S 20} & =54.0 \mathrm{ft} \cdot \mathrm{kip} \text { per wheel line } * 0.44=15.0 \mathrm{ft} \cdot \mathrm{kip} \\
&
\end{array}
$$

- For live load shear, Par. 13.6.5.2, Reference 1 applies. It states that the vehicle live loads shall be placed to produce the max. vertical shear at a distance from 
the support equal to the lesser of $3 \mathrm{~d}$ or $\mathrm{L} / 4$. The distributed live load shear is determined by:

$$
V_{L}=0.50\left[\left(0.60 V_{L U}\right)+V_{L D}\right]
$$

where: $\quad V_{L U}=$ Max. undistributed vertical shear at $3 \mathrm{~d}$ or $\mathrm{L} / 4$

$V_{L D}=V_{L U} * D F$ as described for moment in 3.23.2.2, Reference 1.

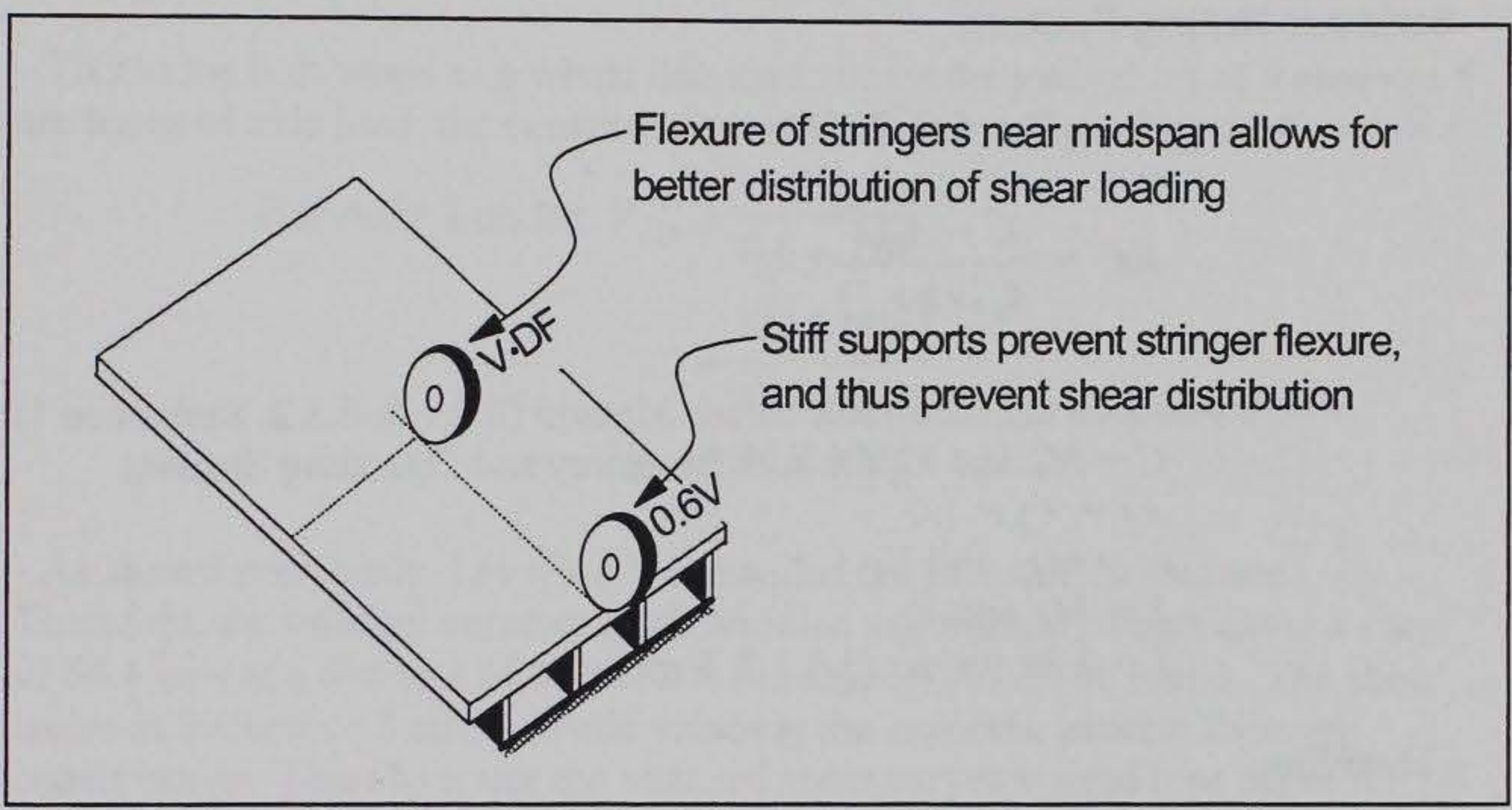

- Check: $3 d=3(1.5 f t)=4.5 f t>L / 4=13.4 / 4=3.4 f t \Rightarrow$ Use $3.4 f t$

- Therefore, place wheel loads for max. shear at $3.4 \mathrm{ft}$. from the support:

For Type 3 Vehicle:

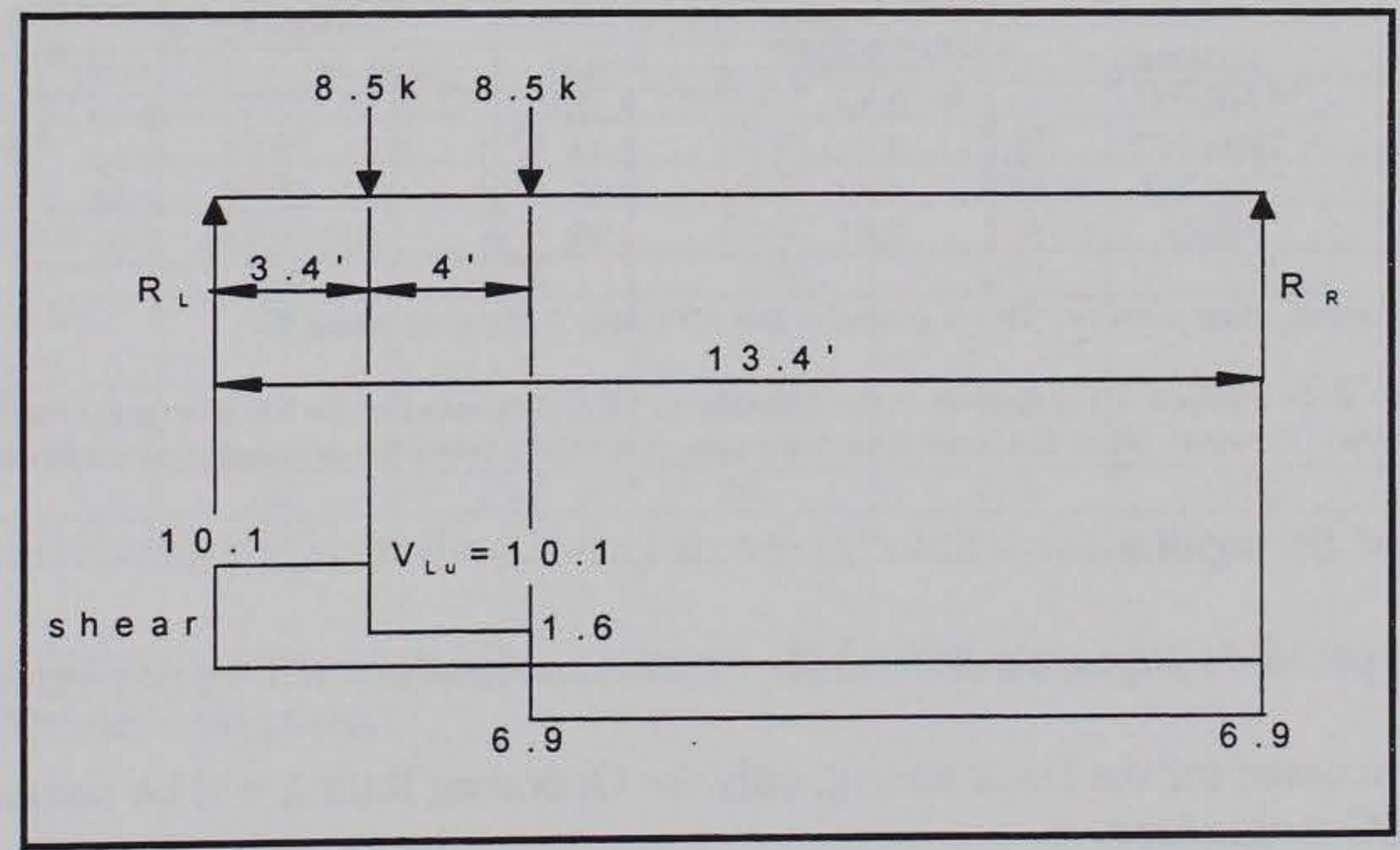

$$
\begin{aligned}
\sum M_{R} & =0=R_{L}(13.4)-8.5(10)-8.5(6.0) \\
R_{L} & =10.1 \mathrm{kip}=V_{L U}
\end{aligned}
$$




$$
V_{L_{3}}=0.50[(0.60)(10.1)+(0.44)(10.1)]=5.2 k i p
$$

All other shears calculated similarly and summarized as follows:

\begin{tabular}{|c|c|}
\hline Vehicle & $\mathbf{V}_{\mathbf{I}}$ (kip) \\
\hline Type 3 & 5.2 \\
Type 3S2 & 4.8 \\
Type 3-3 & 4.5 \\
HS20 & 6.2 \\
\hline
\end{tabular}

\section{Stringer Rating Factors}

- Basic equation from Par. 6.5, Reference 1:

$$
R F=\frac{C-A_{1} D}{A_{2} L(1+I)},
$$

where based on the Allowable Stress Method (6.4.1 \& 6.5.2, Reference 1):

$C=M_{n}$ and $V_{n}$ for both Inventory and Operating Stresses

$A_{1}=A_{2}=1.0$

$D=M_{D}$ and $V_{D}$

$L=M_{L}$ and $V_{L}$

$I=0$ for timber (3.8.1.2, Reference 3)

- Therefore:

Moment: $R F_{m}=\frac{M_{n}-M_{D}}{M_{L}}$

Shear: $R F_{V}=\frac{V_{n}-V_{D}}{V_{L}}$

$$
R F_{M}=\frac{75.6-6.37}{18.3}=3.78
$$

$$
R F_{V}=\frac{13.2-1.48}{5.2}=2.25
$$

\begin{tabular}{|c|c|c|c|c|}
\hline \multirow{2}{*}{ Vehicle } & \multicolumn{2}{|c|}{ Inventory RF } & \multicolumn{2}{c|}{ Operating RF } \\
\cline { 2 - 5 } & Moment & Shear & Moment & Shear \\
\hline Type 3 & 3.78 & 2.25 & 5.12 & 3.10 \\
Type 3S2 & 4.14 & 2.44 & 5.61 & 3.36 \\
Type 3-3 & 4.62 & 2.60 & 6.24 & 3.58 \\
HS20 & 2.91 & 1.89 & 3.93 & 2.60 \\
\hline
\end{tabular}

- As seen above, shear controls. This is generally true for timber flexural members.

- Note that since the deck rating controls in this example an MLC determination for the stringers is really not required. However, since this is not always the case, it is shown below for demonstration purposes.

\section{MLC of Stringers}

- From previous pages, shear controls. Therefore, moment will be neglected here.

- As discussed for the Deck Rating, only the Operating Rating will be considered for MLC in this case.

- As done for the deck, set RF equal to 1.0 and solve for $\mathrm{V}_{\mathrm{L}}$ :

$$
\begin{aligned}
R F_{V} & =1.0=\frac{V_{n}-V_{D}}{V_{L}} \\
V_{L} & =V_{n}-V_{D}=17.6 \mathrm{kip}-1.48 \mathrm{kip}=16.1 \mathrm{kips}
\end{aligned}
$$


- This value for $V_{L}$ represents the maximum shear that can be applied to a single stringer at a distance $3 \mathrm{~d}$ or $\mathrm{L} / 4$ (whichever is smaller). Therefore, to find the total vehicle loading that would cause this shear, solve for $V_{L U}$ out of the following equation:

$$
\begin{aligned}
V_{L} & =0.50\left[(0.60) V_{L U}+(D F) V_{L U}\right] \\
V_{L U} & =\frac{2 V_{L}}{0.6+D F}
\end{aligned}
$$

- This value is in terms of a wheel line load. Since the load tables of Reference 5 are terms of axle load, the equation above should be multiplied by 2.0 :

$$
\text { For Axle Loads: } \begin{aligned}
V_{L U} & =\frac{4 V_{L}}{0.6+D F} \\
& =\frac{4(16.1 \mathrm{kip})}{0.6+0.44} \\
V_{L U} & =61.9 \mathrm{kips}
\end{aligned}
$$

- As shown previously, $\mathrm{L} / 4=3.4 \mathrm{ft}$ controlled the shear check location.

Therefore, the military vehicles (both wheeled and tracked) which cause a shear of 64.4 kips at a distance of $3.4 \mathrm{ft}$ form the support should be found. The shear tables in Reference 5 only provide values at the supports, making them too

\begin{tabular}{|c|c|c|c|c|c|c|c|}
\hline \multirow{2}{*}{$\begin{array}{l}\text { Bridge } \\
\text { Element }\end{array}$} & \multicolumn{7}{|c|}{ Rating Vehicle } \\
\hline & Type 3 & Type 3S2 & Type 3-3 & HS20 & Mil. Wheel & Mil. Track & \\
\hline \multirow[t]{2}{*}{ Deck } & 0.48 & 0.49 & 0.49 & 0.47 & NA & NA & Inv. \\
\hline & 0.64 & 0.66 & 0.65 & 0.62 & 12 & 50 & Oper. \\
\hline \multirow[t]{2}{*}{ Stringers } & 2.25 & 2.44 & 2.6 & 1.89 & NA & NA & Inv. \\
\hline & 3.10 & 3.36 & 3.58 & 2.6 & 100 & 150 & Oper. \\
\hline $\begin{array}{l}\text { Vehicle Wt. } \\
\text { (tons) }\end{array}$ & 25 & 36 & 40 & 36 & - & - & \\
\hline \multirow{2}{*}{$\begin{array}{l}\text { Load Rating } \\
\text { (tons) }{ }^{* *}\end{array}$} & 12 & 17.6 & 19.6 & 16.9 & $\overline{N A}$ & NA & Inv. \\
\hline & 16 & 23.7 & 26 & 22.3 & $16 \mathrm{~W}$ & $60 \mathrm{~T}$ & Oper. \\
\hline
\end{tabular}
conservative. Therefore, use the attached shear curves instead (use curve for 14foot span):

$\therefore$ The MLC is $\underline{100 W}$ and $\underline{150 T}$ for 2 -Way traffic

\section{Rating Summary}

** Load Rating $=($ Controlling Rating shown in bold $)($ Vehicle Wt. $)$

- Note that only a two-way MLC is shown. If desired, a one-way MLC can also be calculated and posted. 


\section{NATO Standard Wheeled Vehicle Bending Moment (kip-feet)}

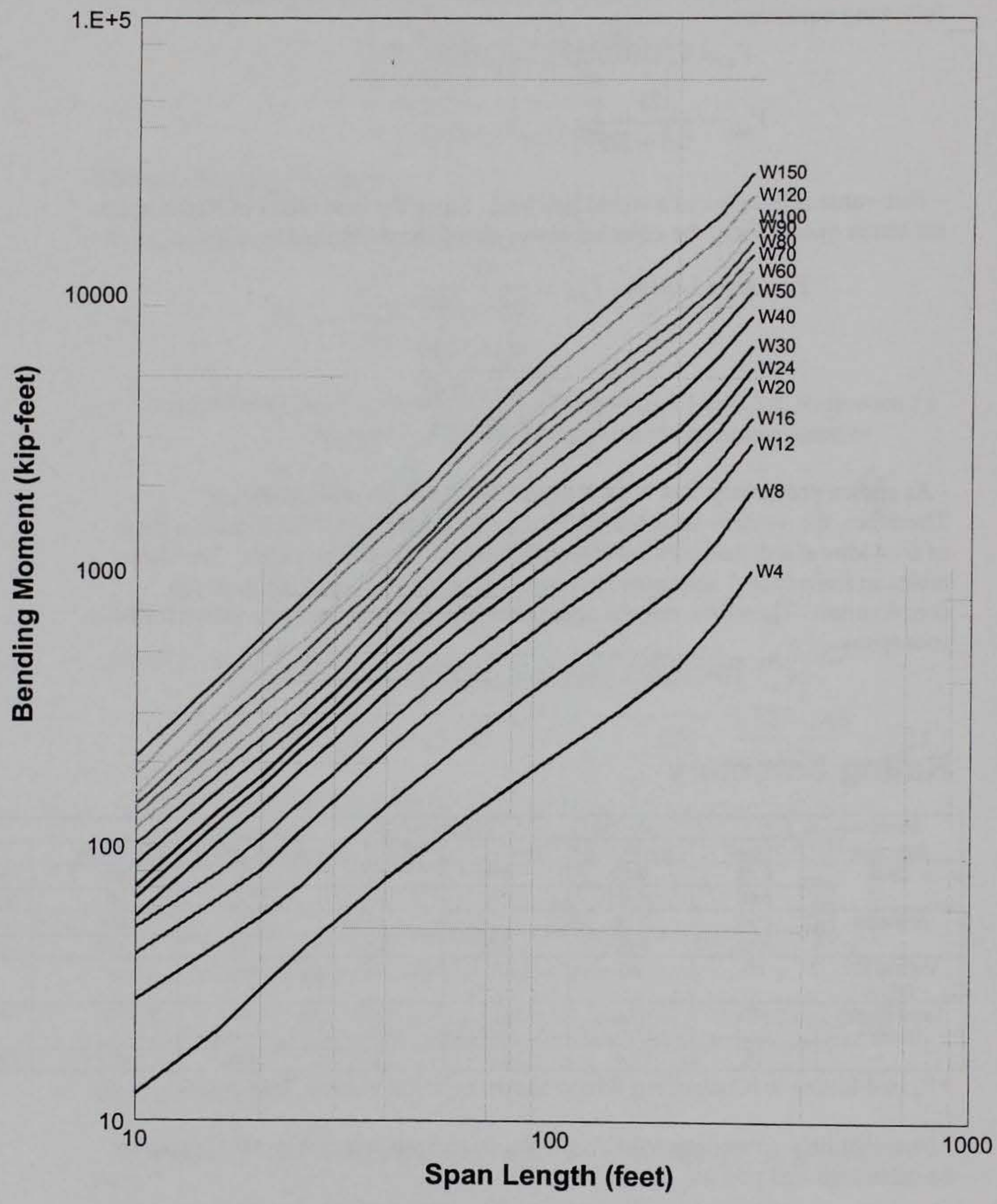




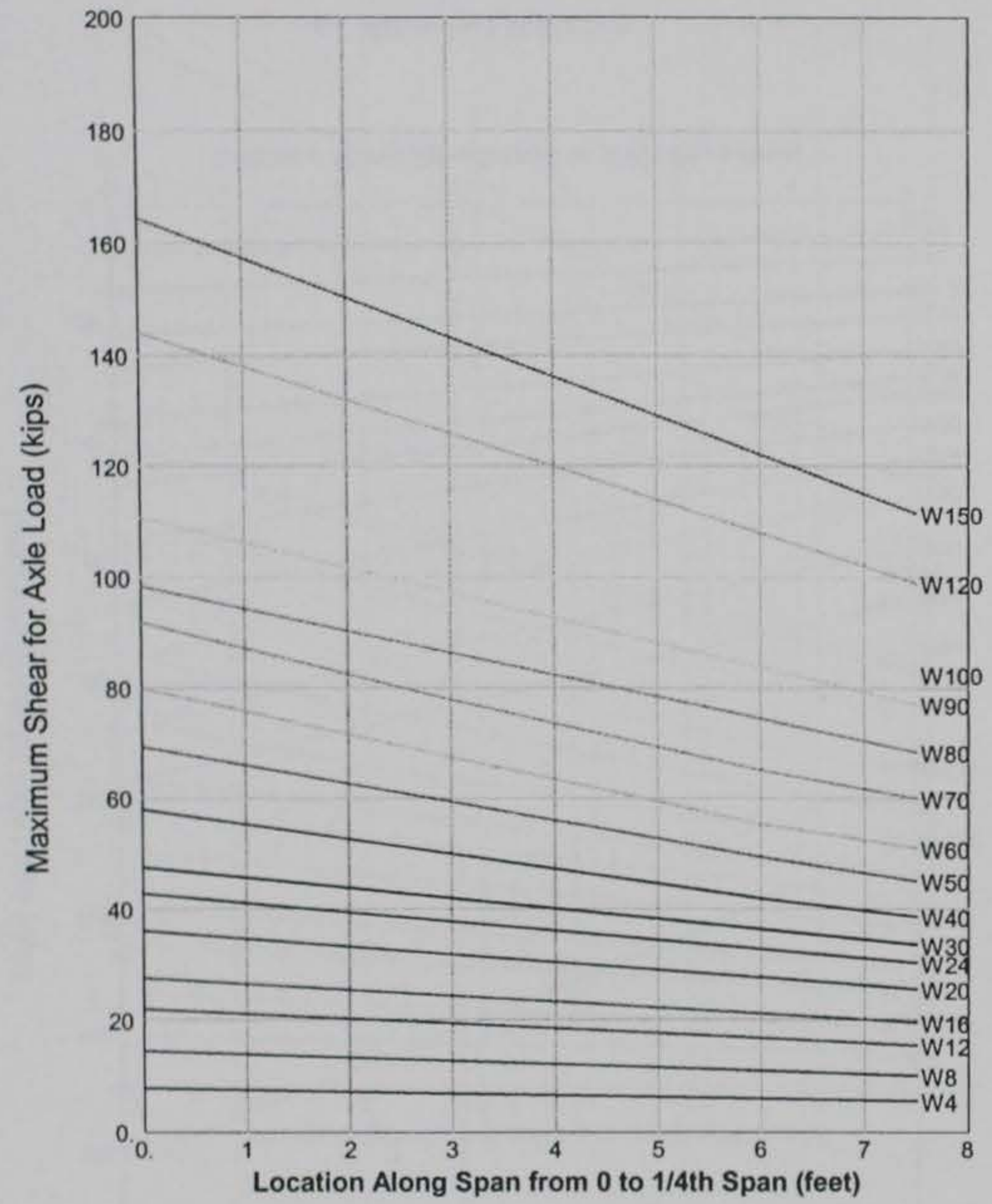

a. Wheeled Vehicles

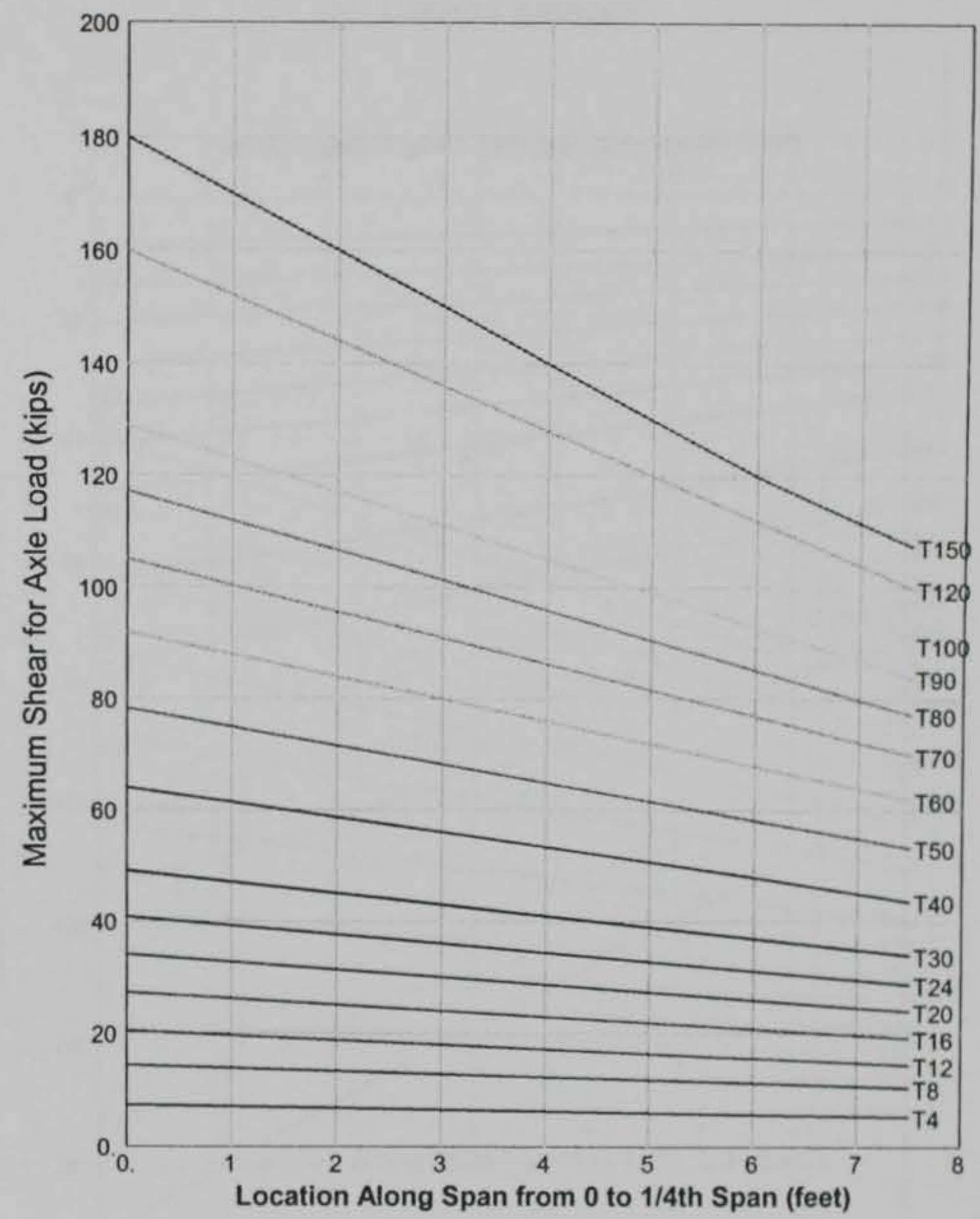

b. Tracked Vehicles 


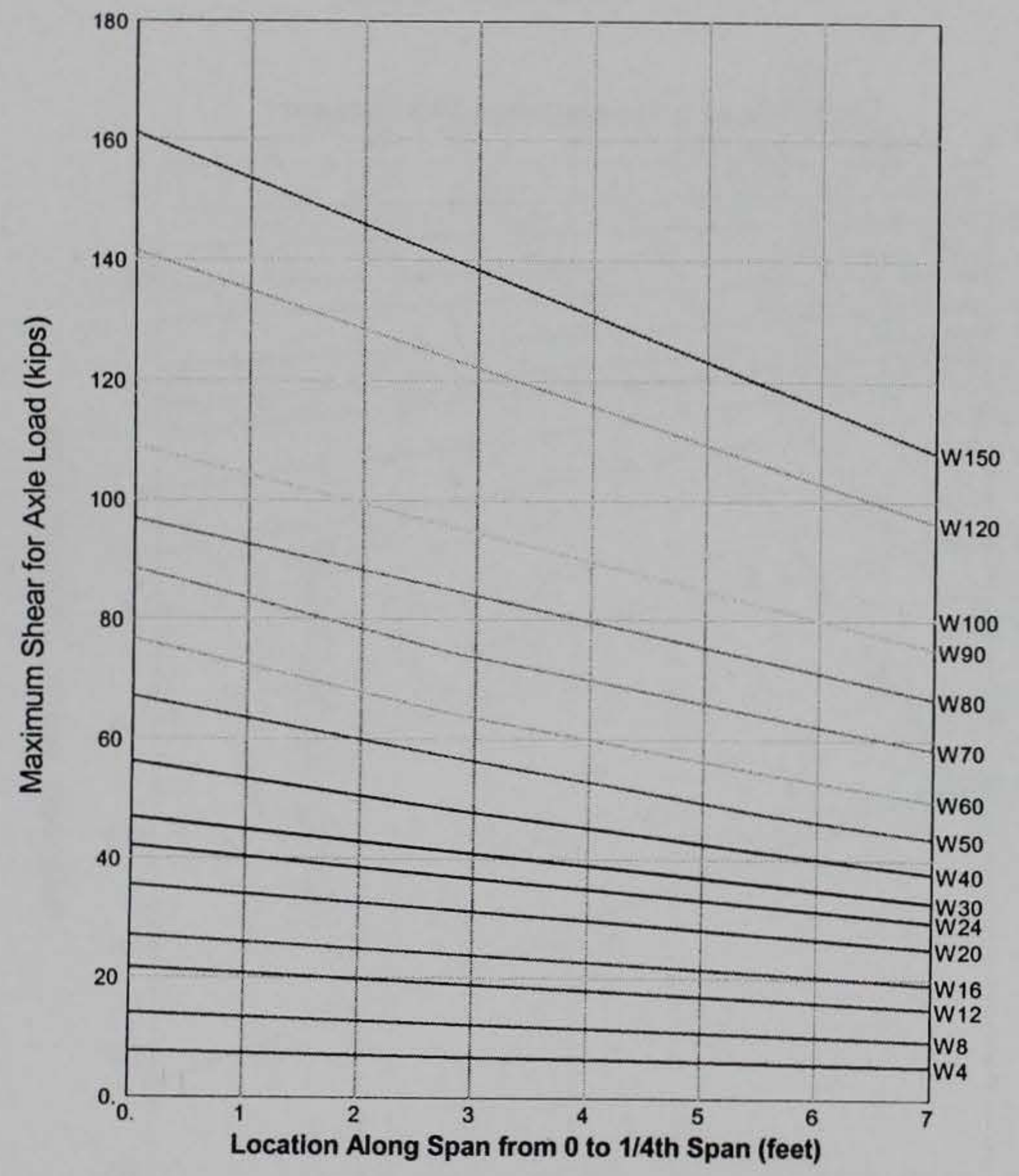

a. Wheeled Vehicles

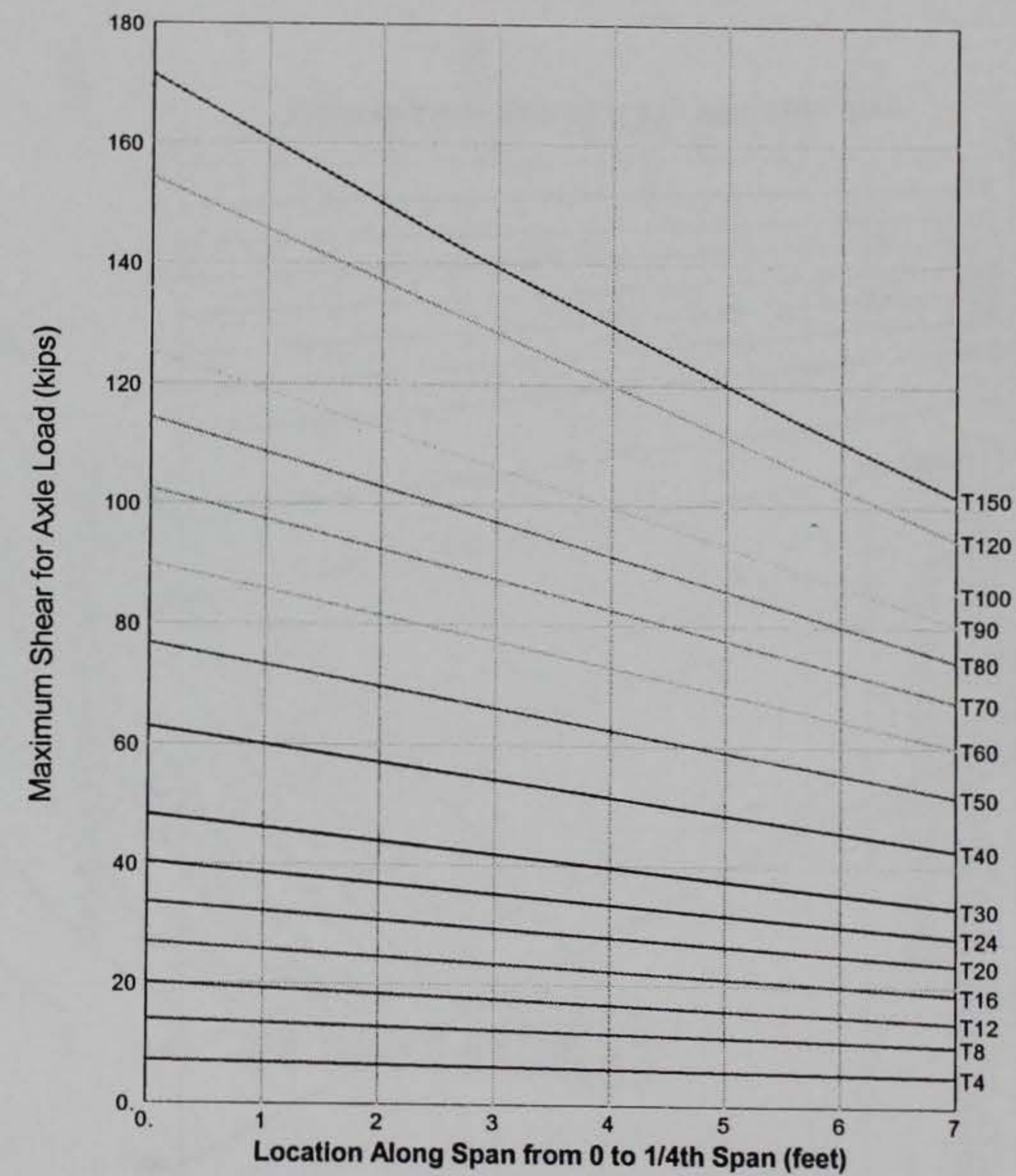

b. Tracked Vehicles

Maximum Shear, $V_{\mathrm{LU}}$, Along a 28.0-foot Span 


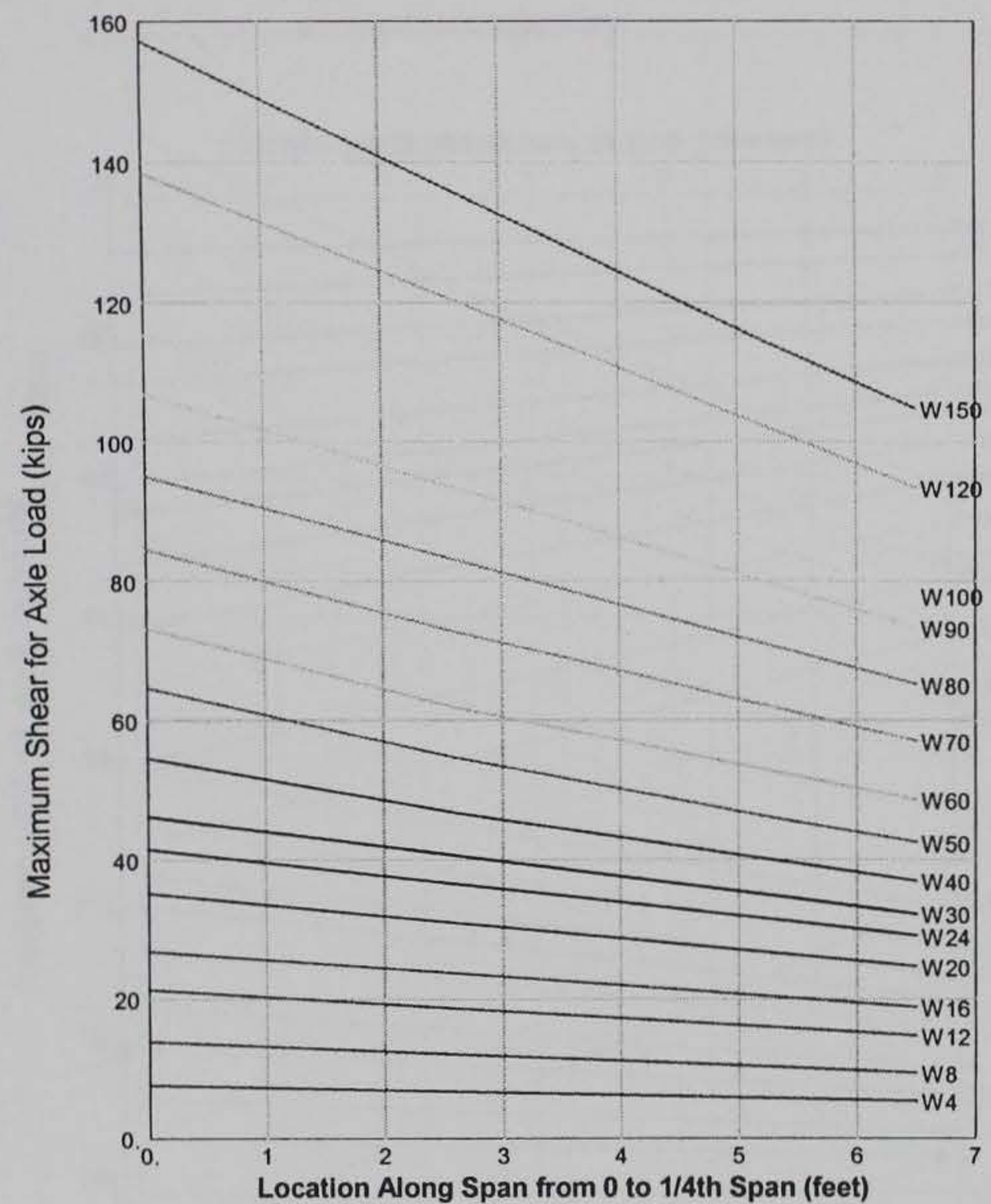

a. Wheeled Vehicles

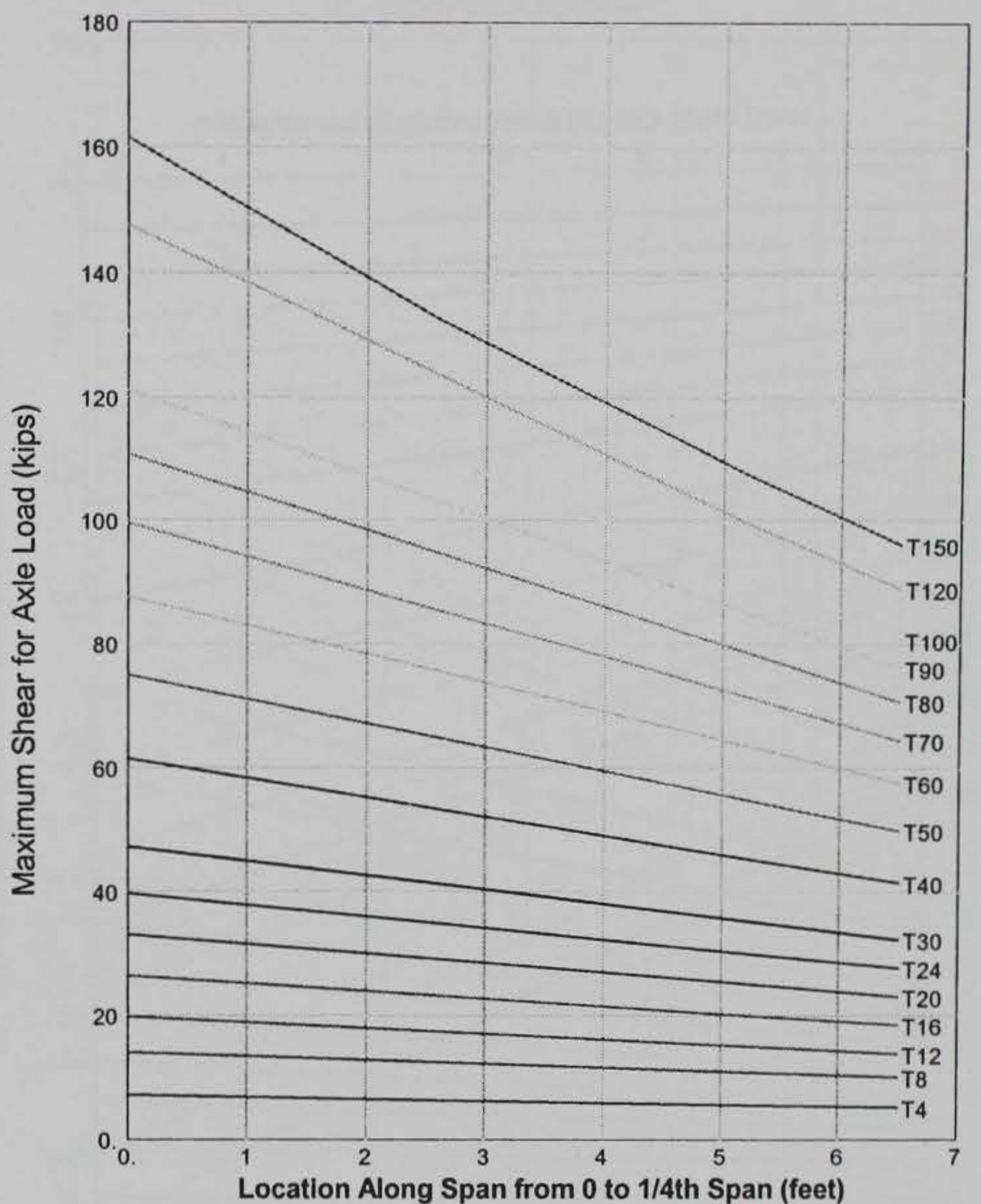

b. Tracked Vehicles 


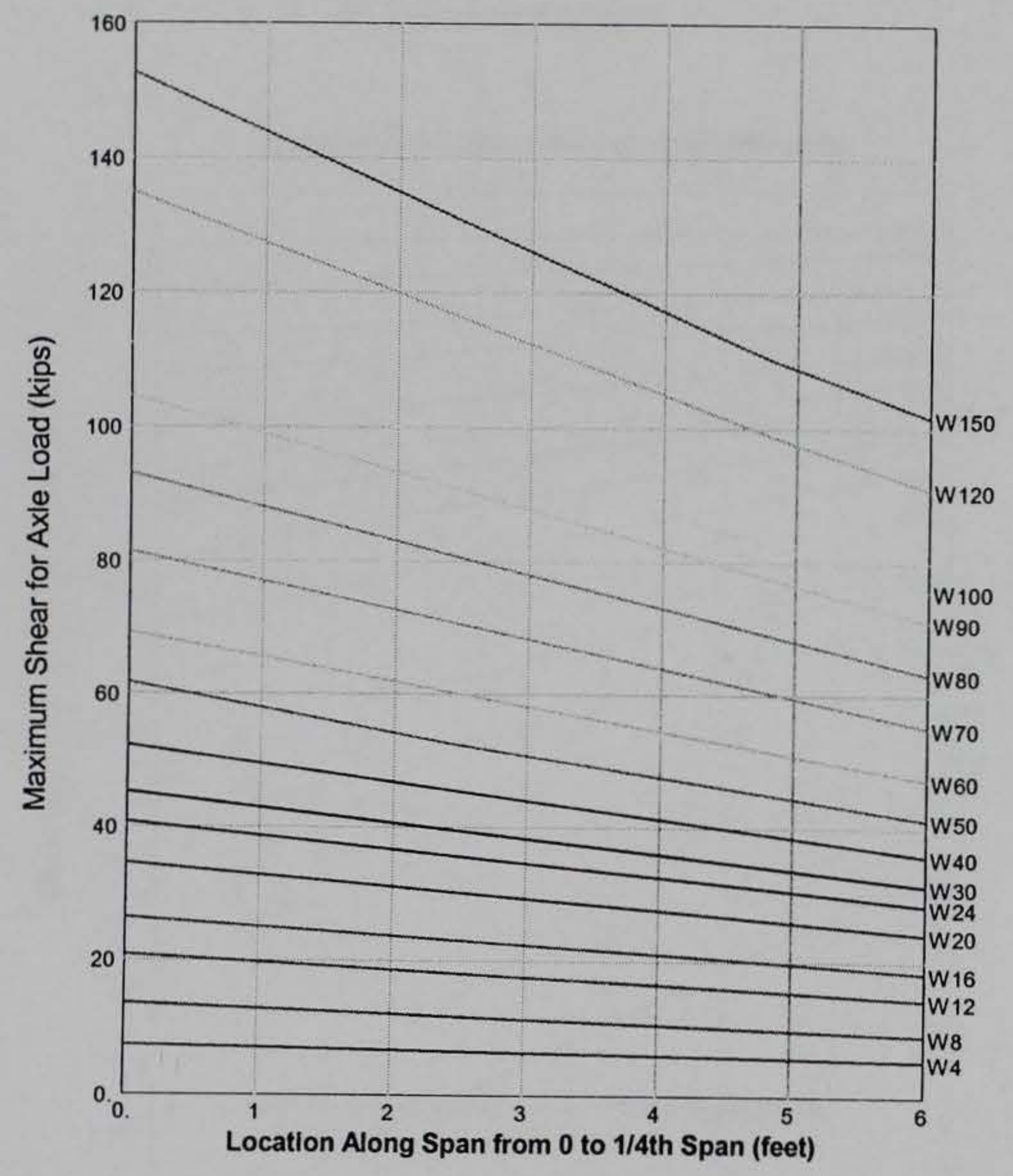

a. Wheeled Vehicles

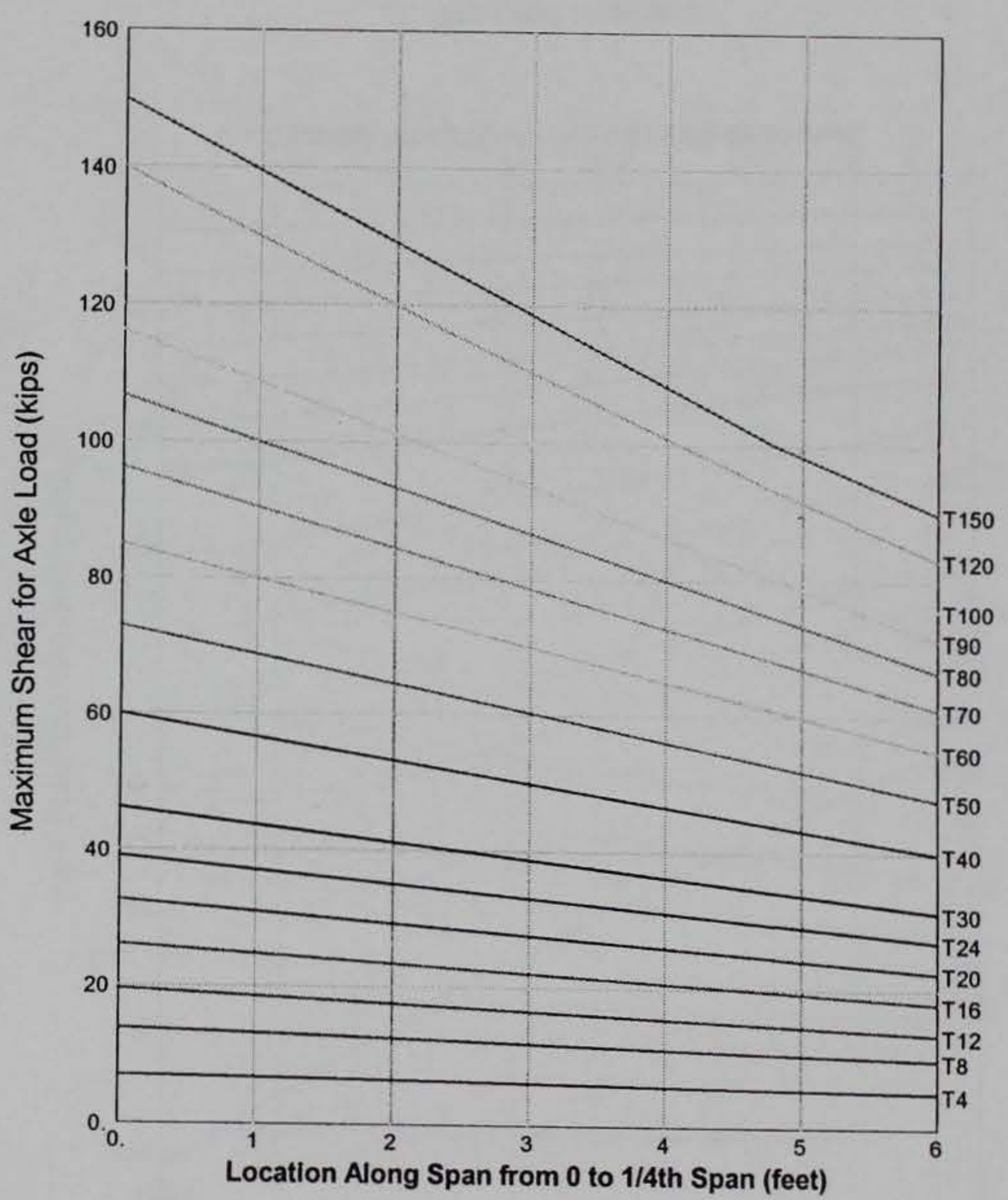

b. Tracked Vehicles

Maximum Shear, $\mathrm{V}_{\mathrm{LU}}$, Along a 24.0-foot Span 

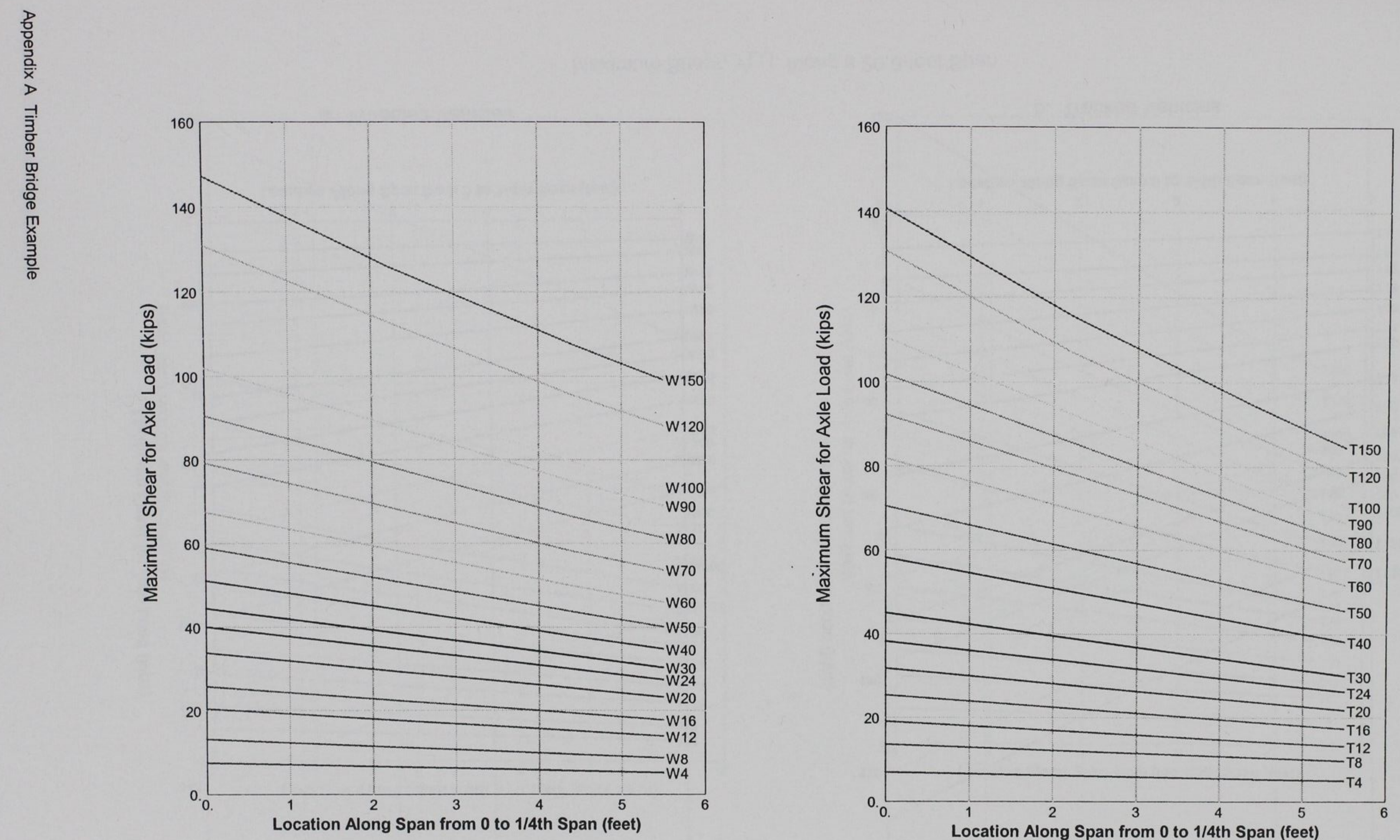

a. Wheeled Vehicles

b. Tracked Vehicles 


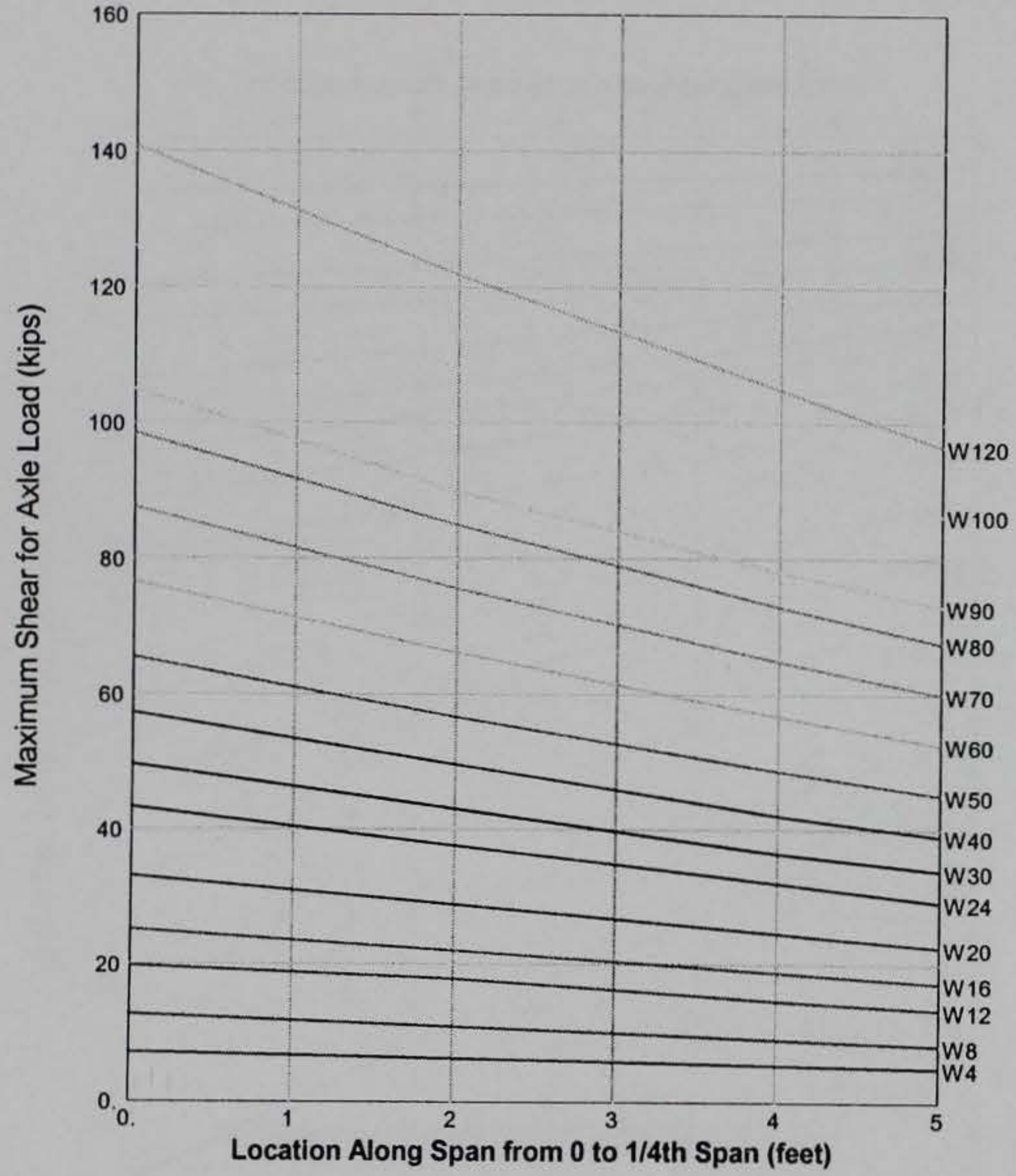

a. Wheeled Vehicles

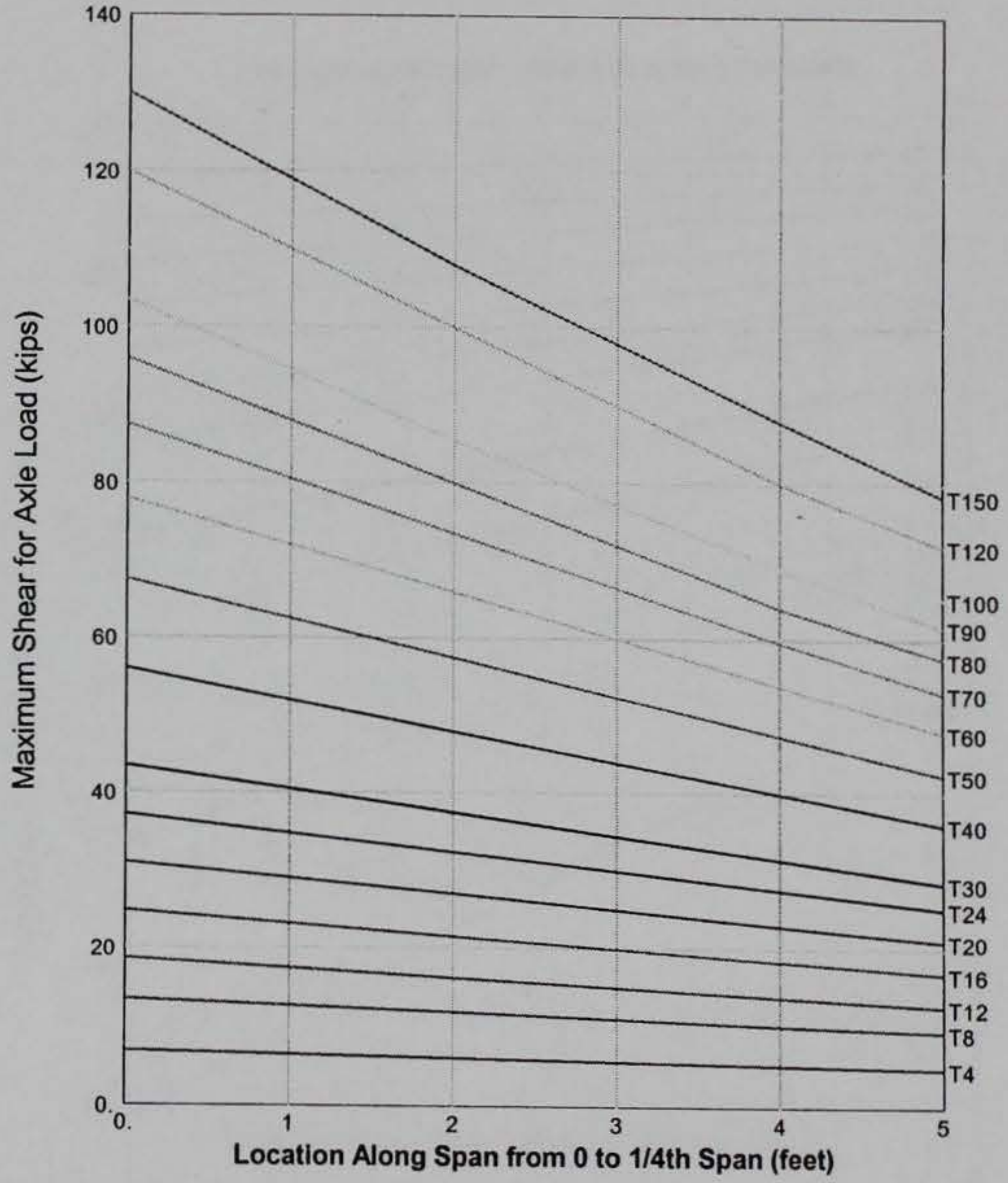

b. Tracked Vehicles

Maximum Shear, $V_{\mathrm{LU}}$, Along a 20.0-foot Span 


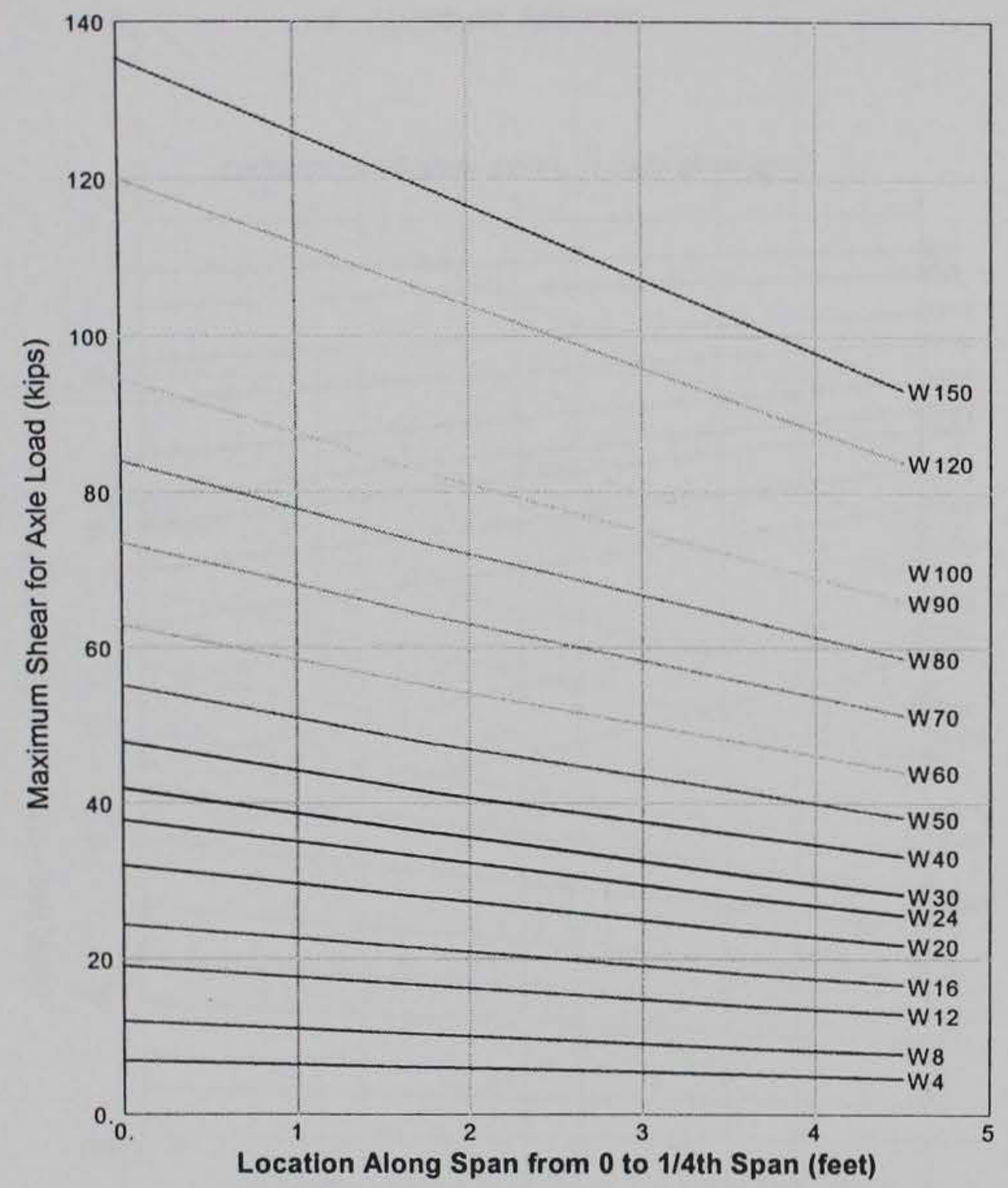

a. Wheeled Vehicles

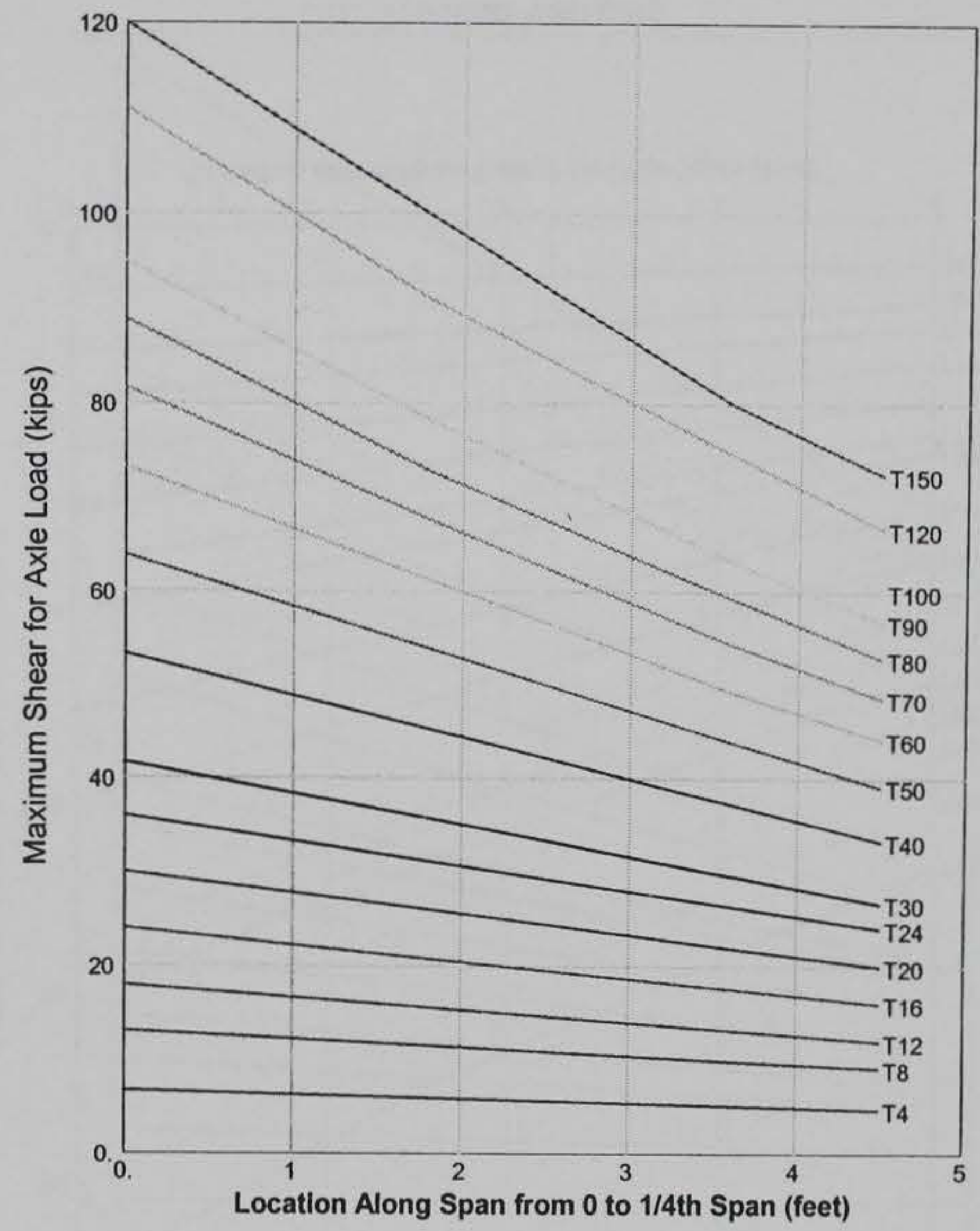

b. Tracked Vehicles

Maximum Shear, $V_{L U}$, Along a 18.0-foot Span 


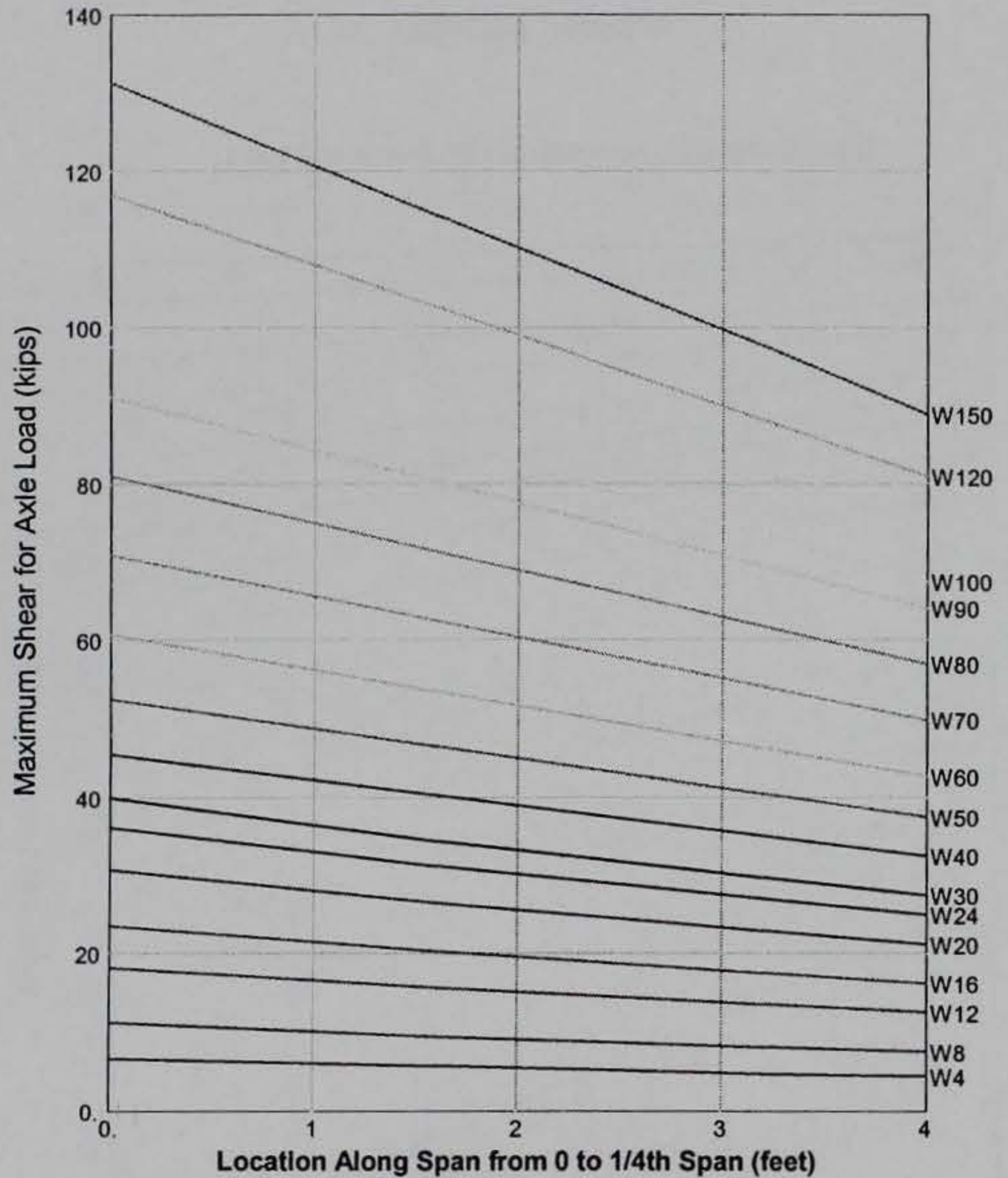

a. Wheeled Vehicles

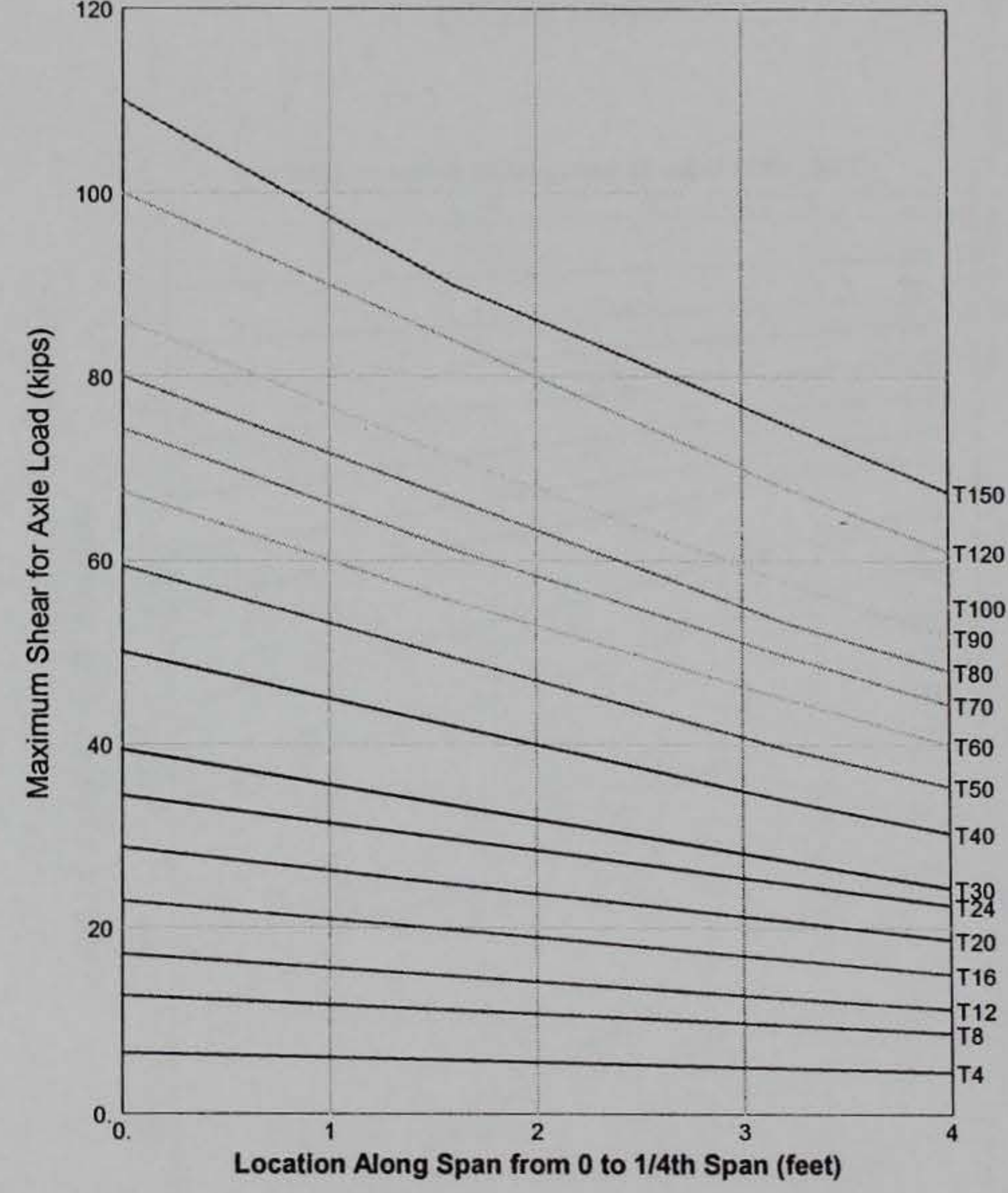

b. Tracked Vehicles

Maximum Shear, $V_{\mathrm{LU}}$, Along a 16.0-foot Span 


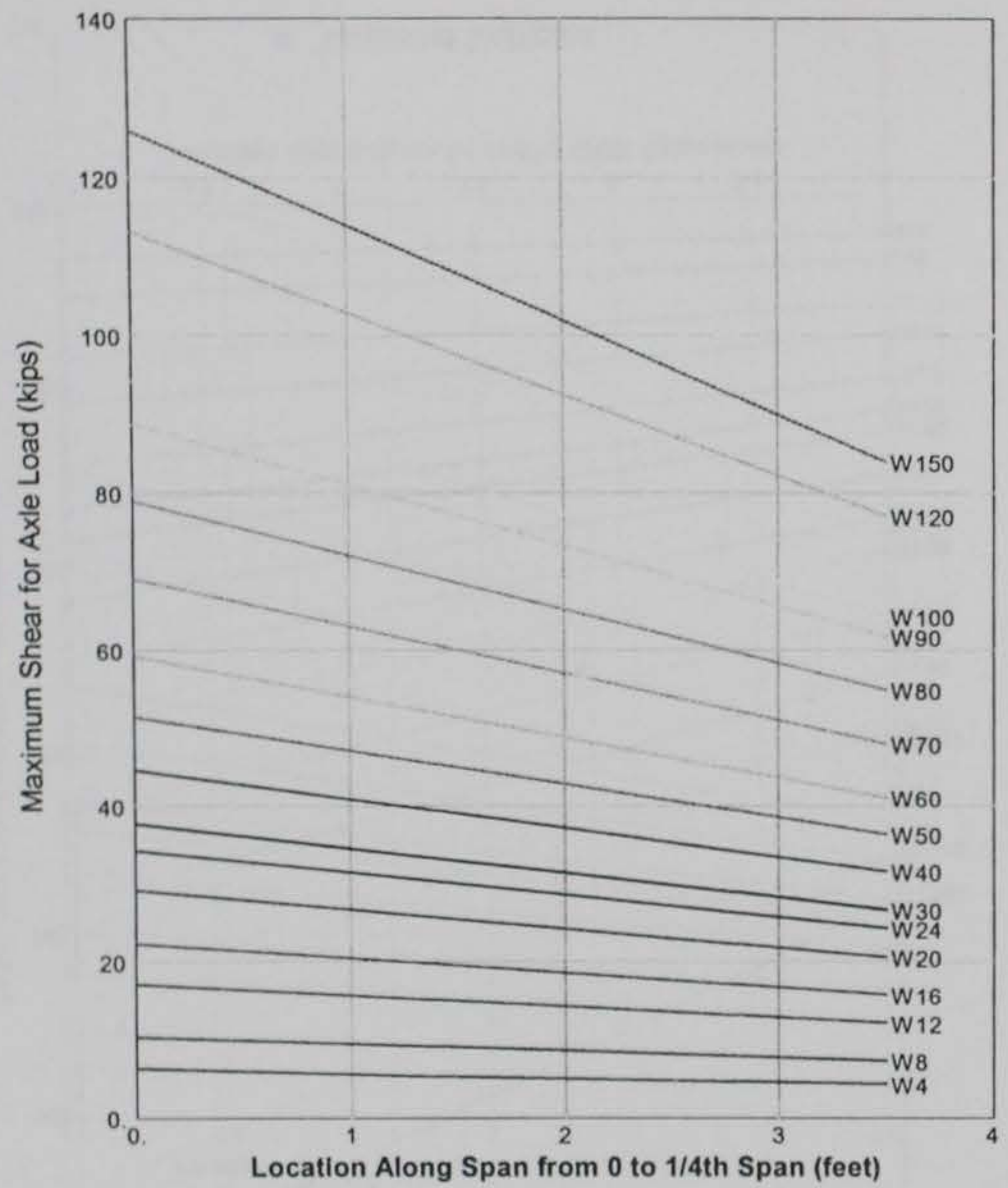

a. Wheeled Vehicles

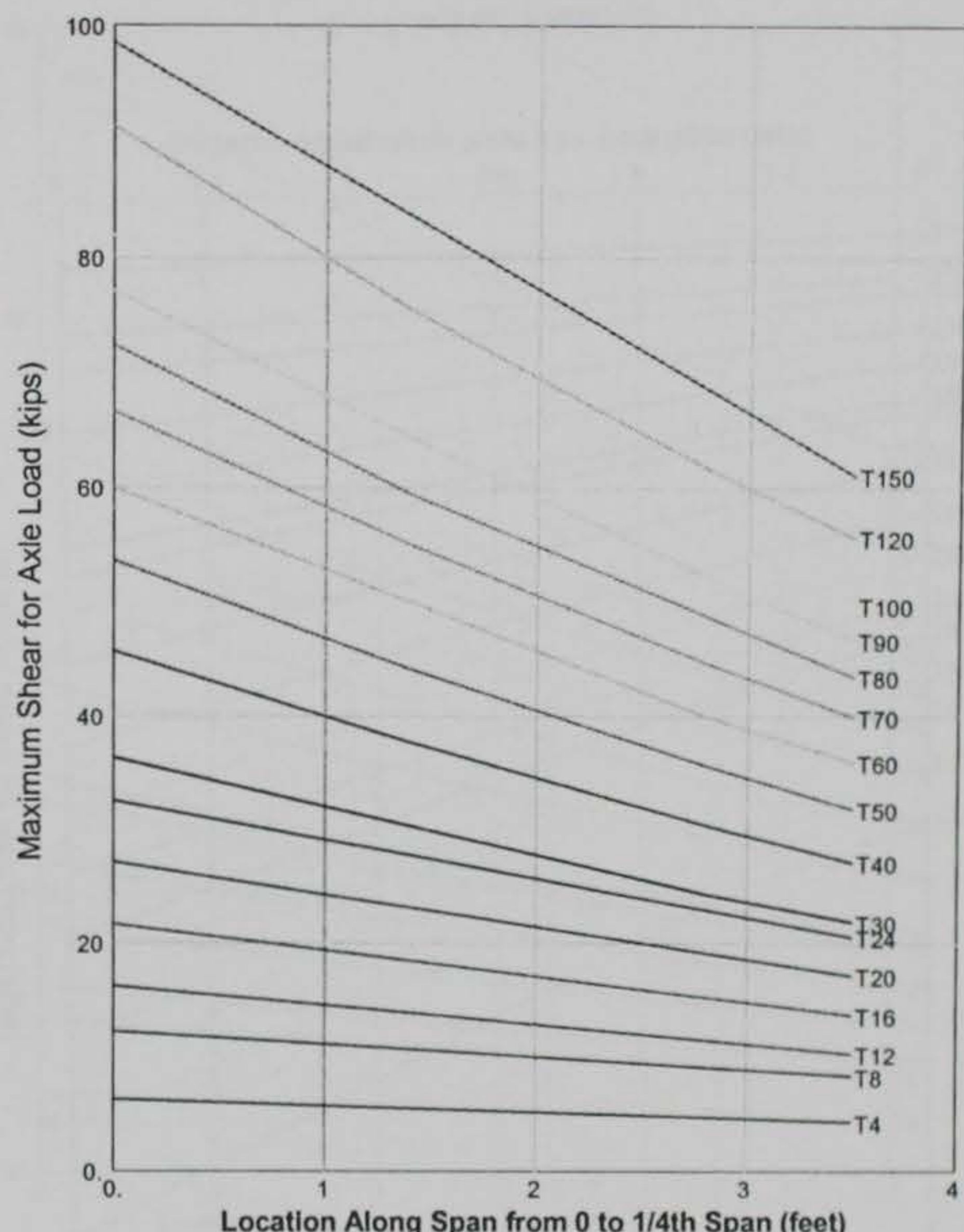

b. Tracked Vehicles 


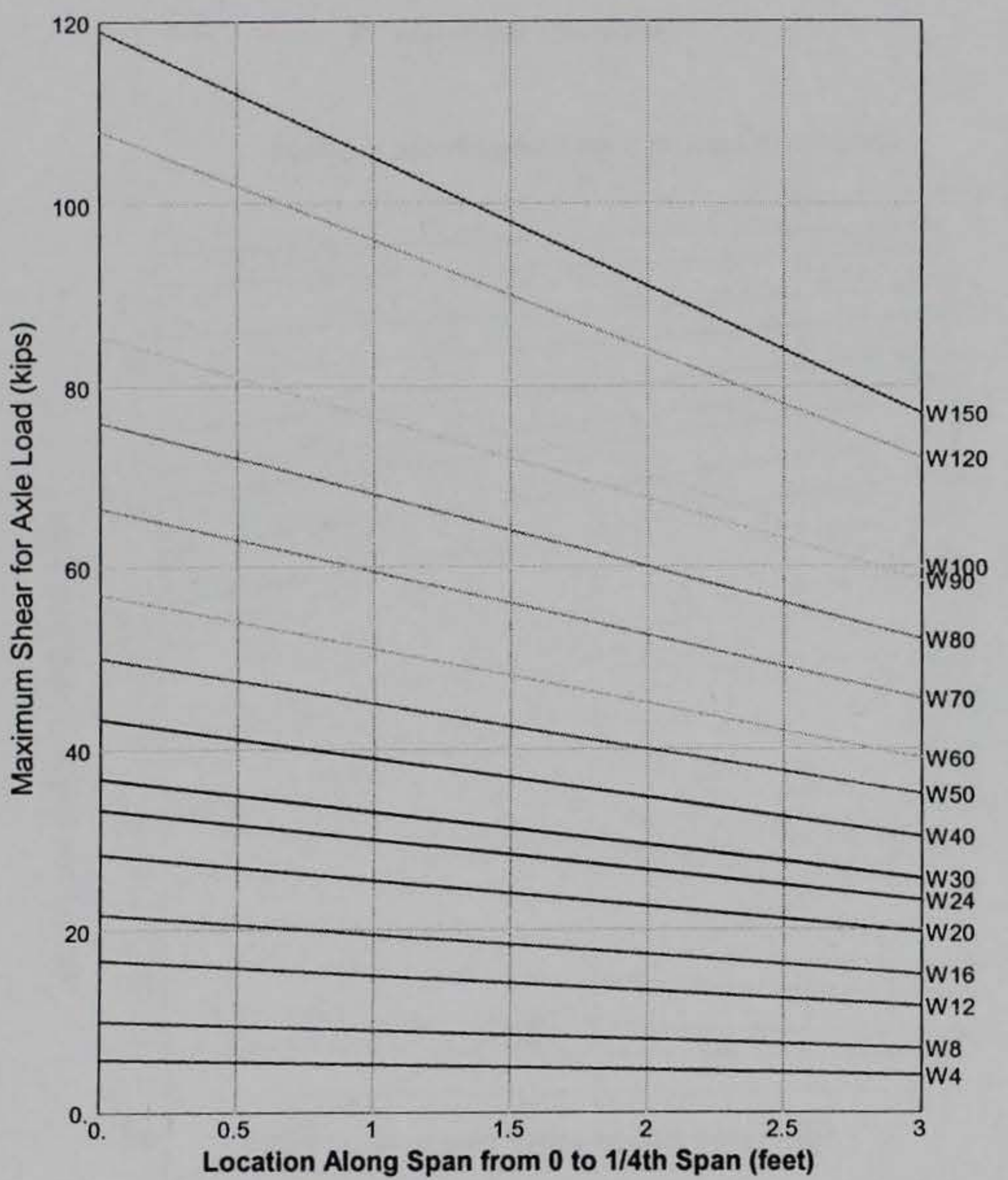

a. Wheeled Vehicles

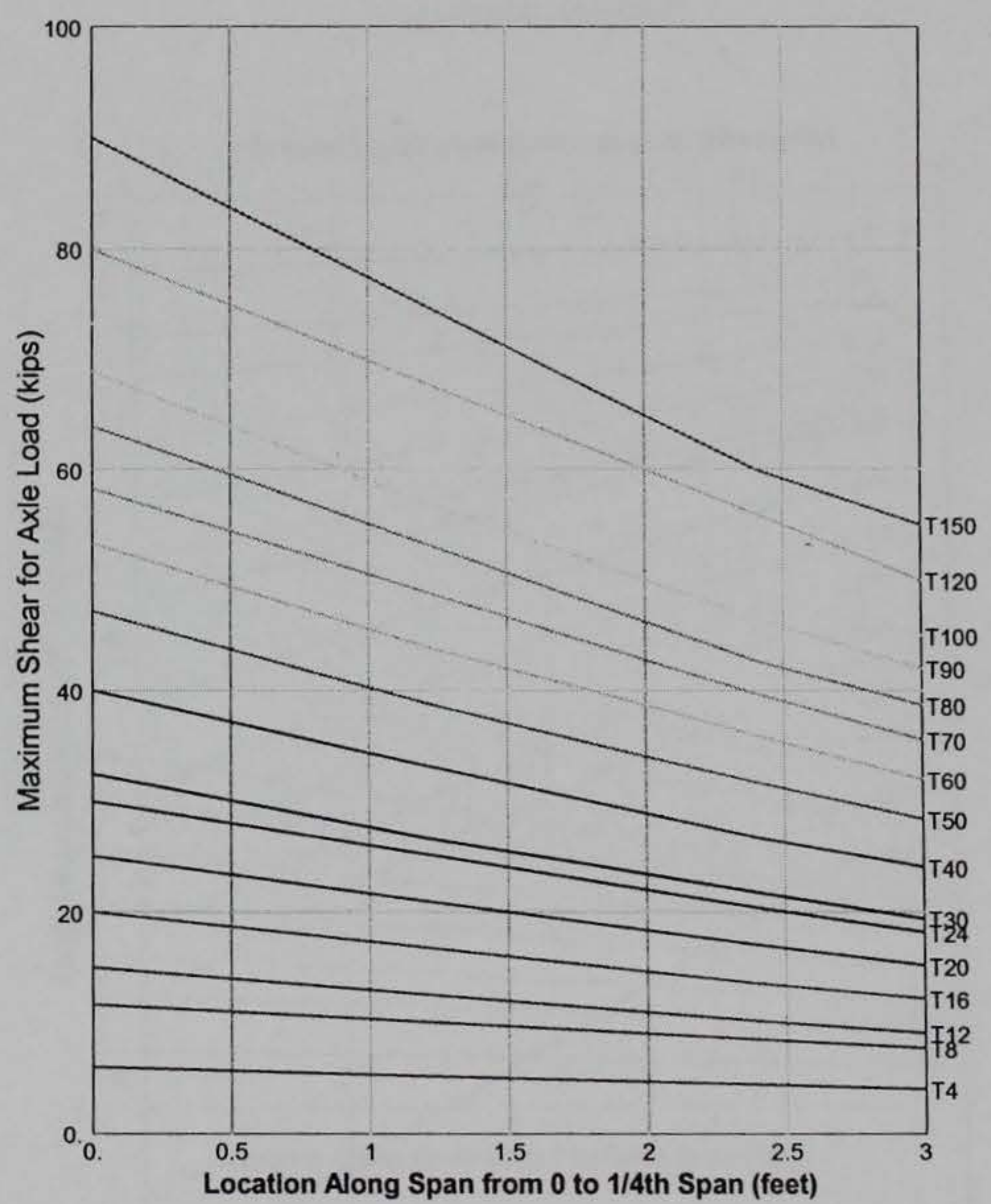

b. Tracked Vehicles

Maximum Shear, $V_{\mathrm{LU}}$, Along a 12.0-foot Span 


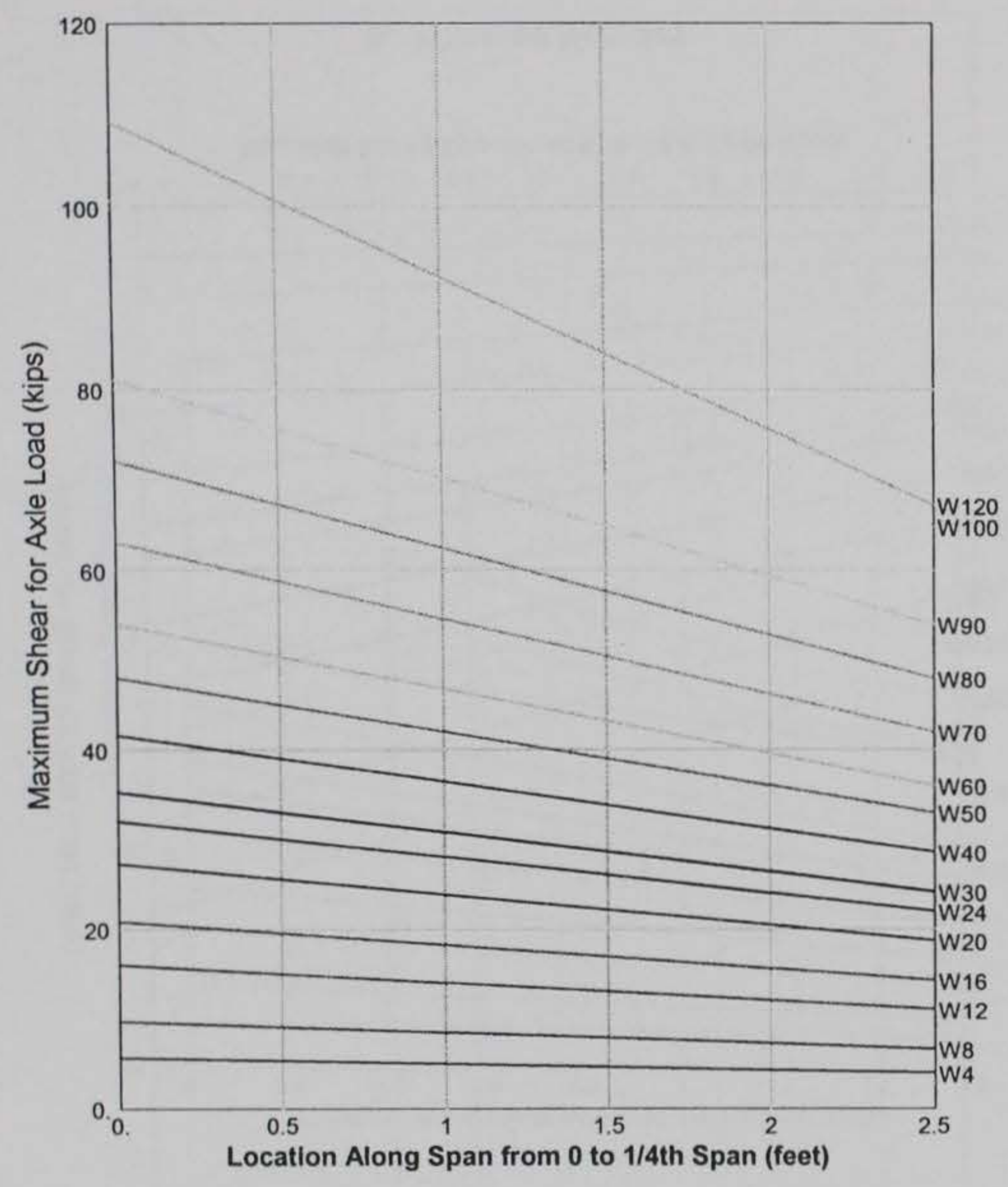

a. Wheeled Vehicles

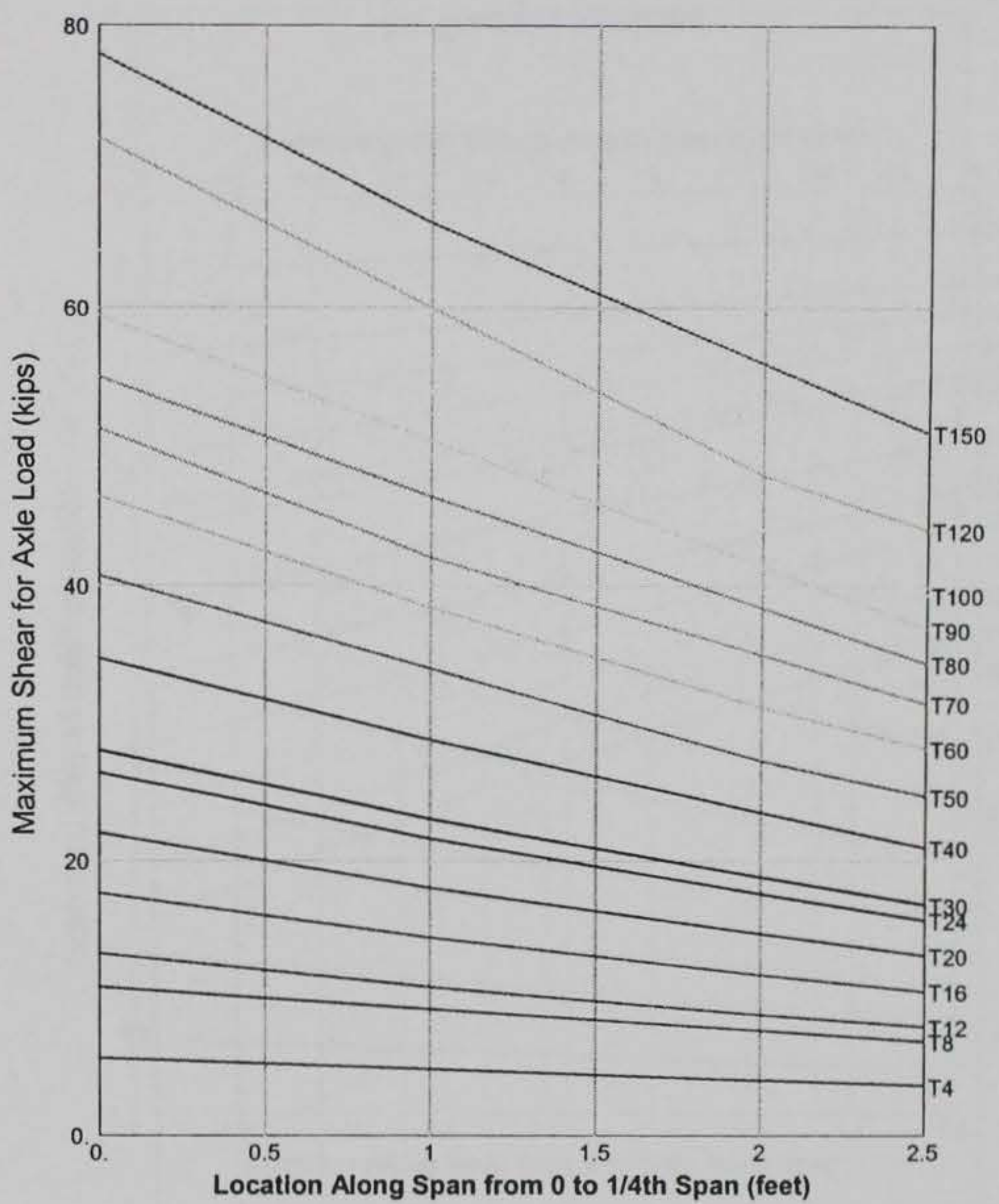

b. Tracked Vehicles 


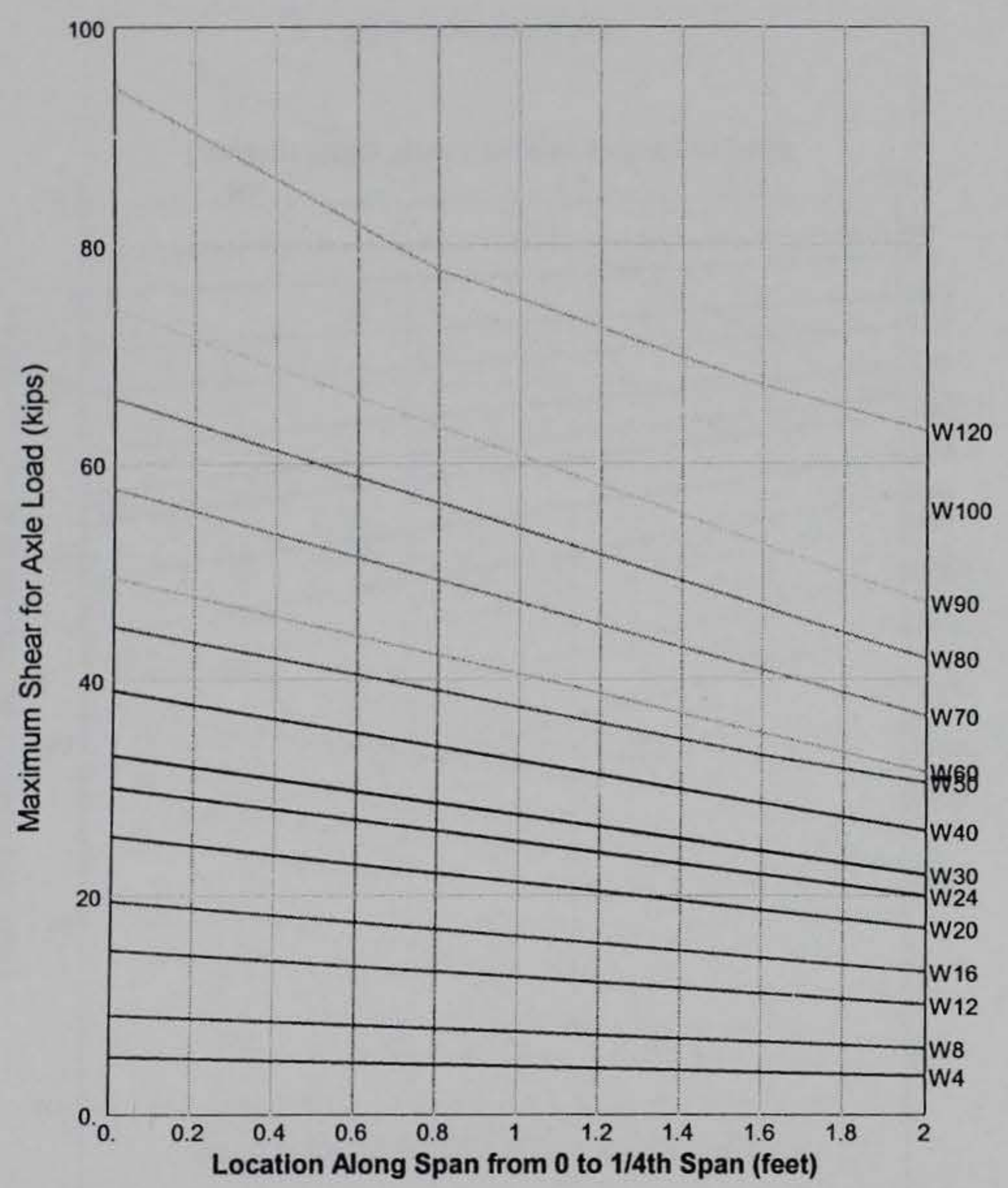

a. Wheeled Vehicles

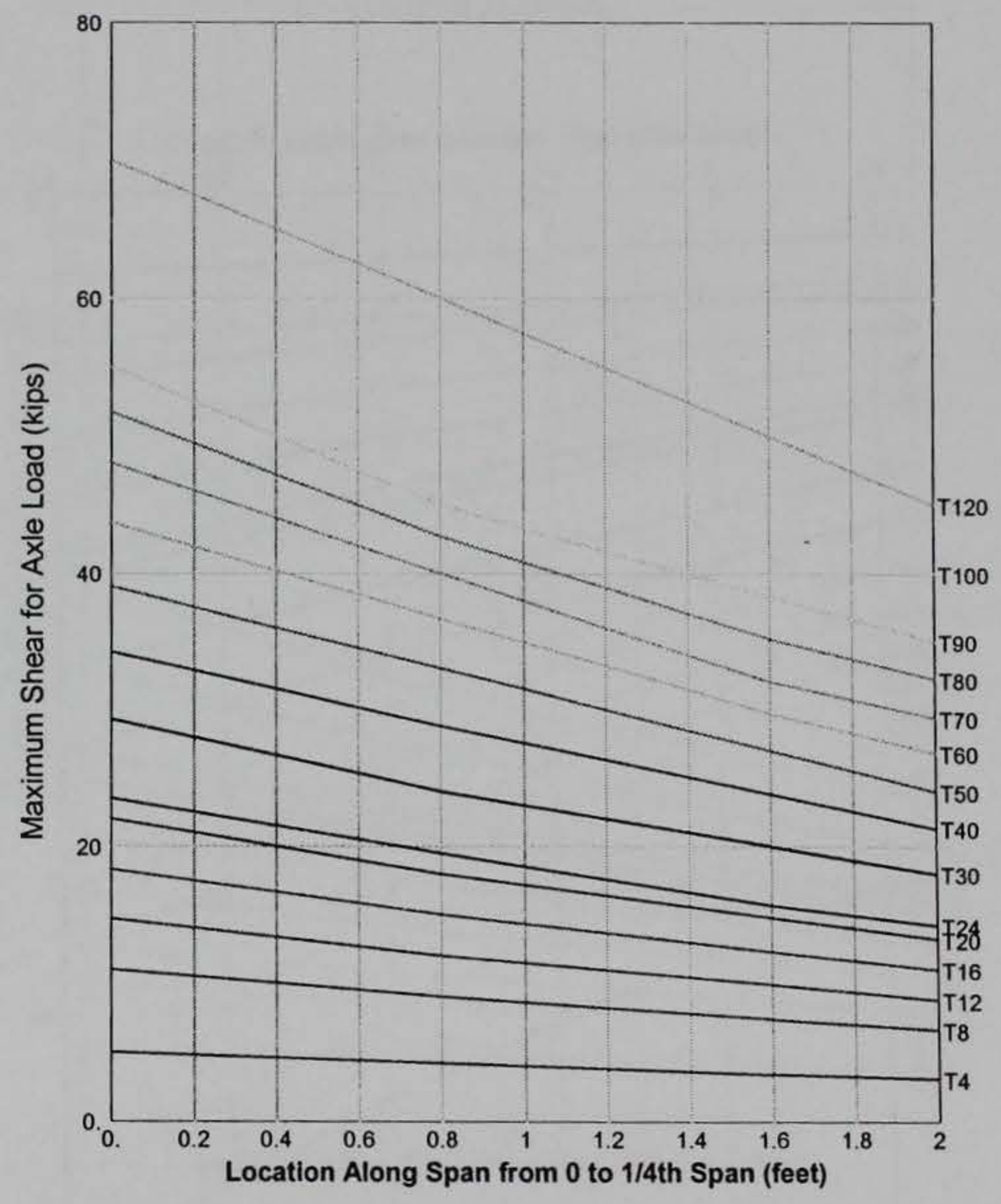

b. Tracked Vehicles

Maximum Shear, $V_{\mathrm{LU}}$, Along a 8.0-foot Span 


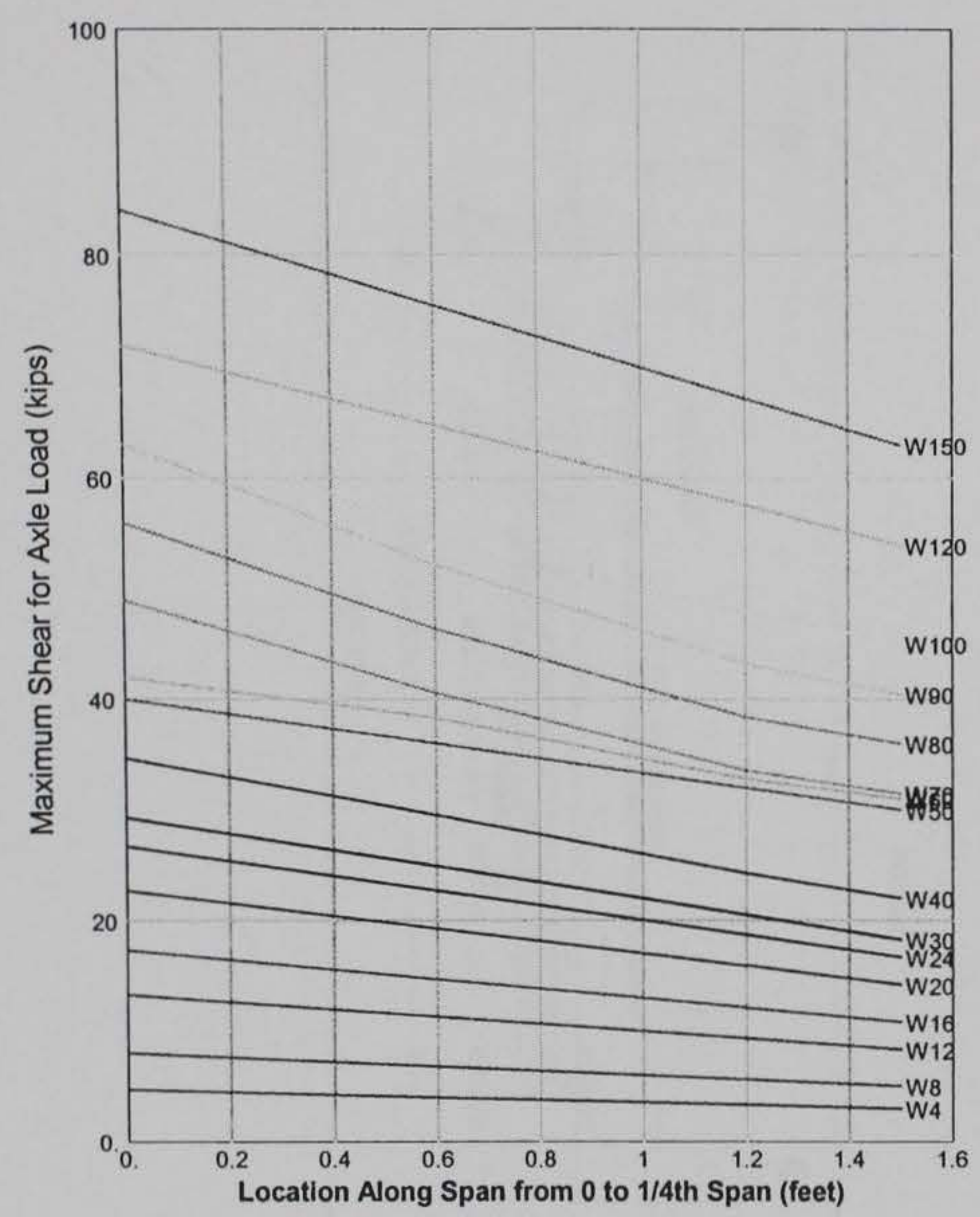

a. Wheeled Vehicles

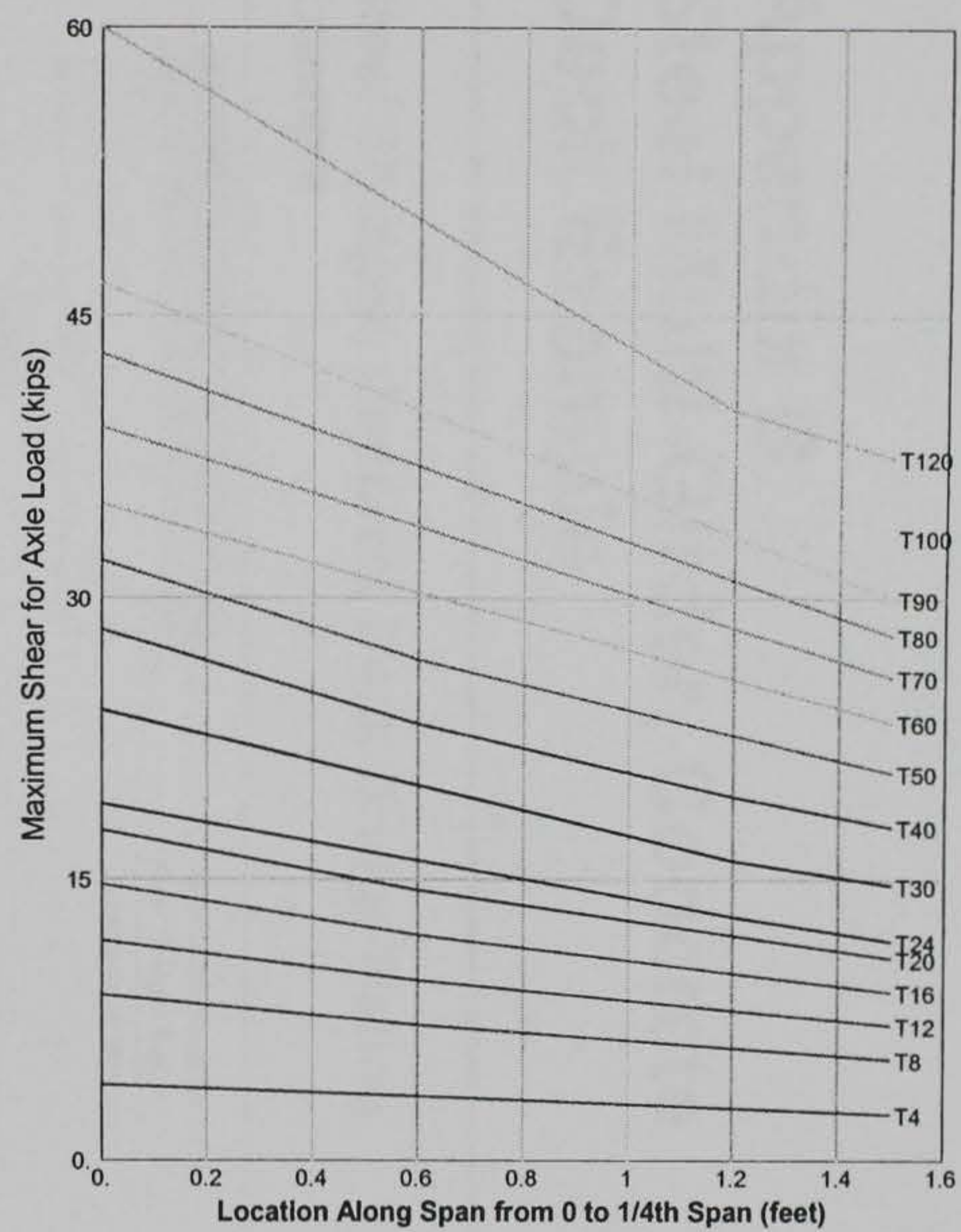

b. Tracked Vehicles

Maximum Shear, $\mathrm{V}_{\mathrm{LU}}$, Along a 6.0-foot Span 


\section{Appendix B \\ Steel Multi-Girder, Concrete \\ Deck Example}

Steel Stringer, Concrete Deck Bridge Rating Example

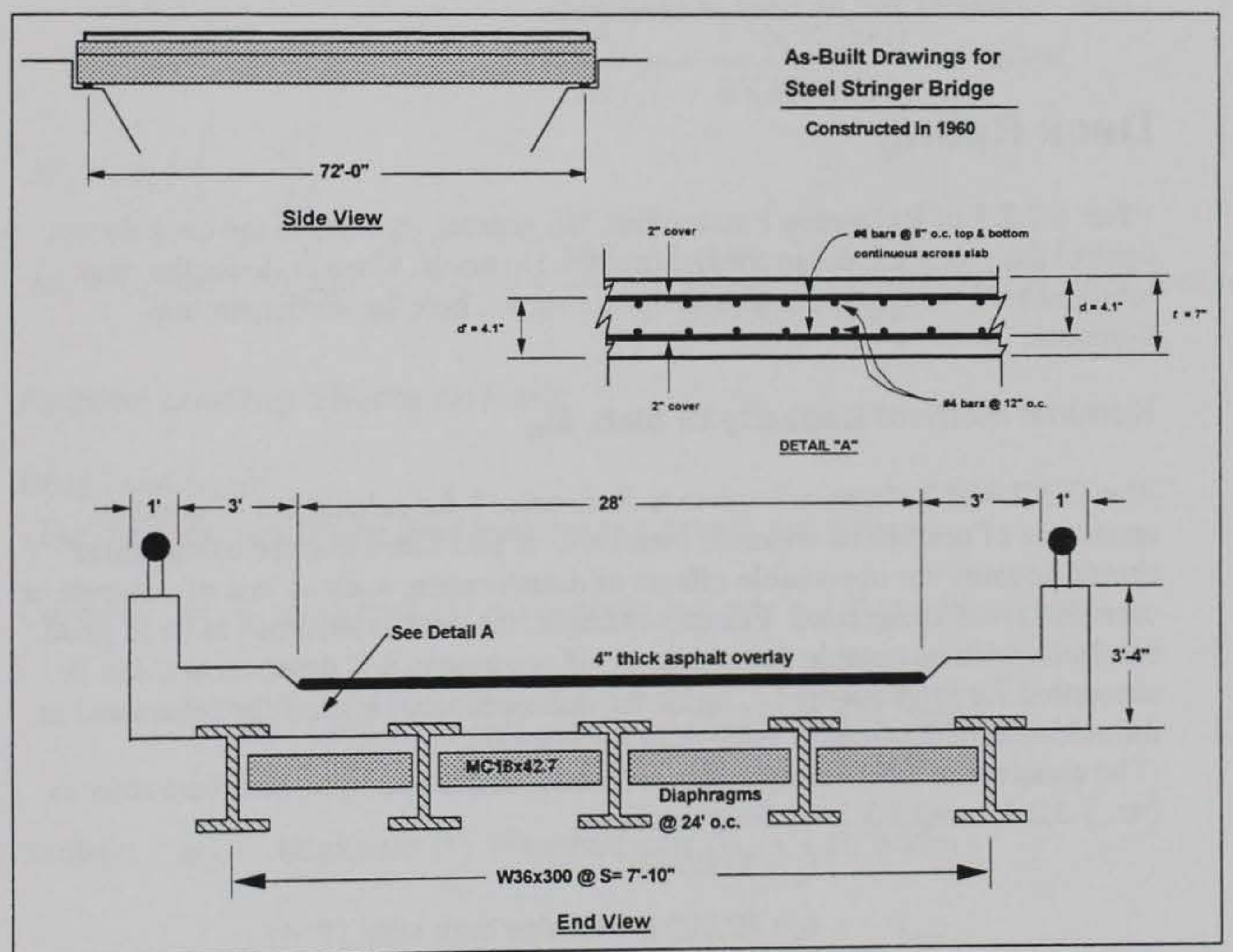


Sited References:

1. Manual For Condition Evaluation of Bridges, AASHTO, 1994.

2. Guide Specifications for Strength Evaluation of Existing Steel and Concrete Bridges, AASHTO, 1989.

3. Standard Specifications for Highway Bridges, AASHTO, fifteenth edition, 1992.

4. Manual for Maintenance Inspection of Bridges, AASHTO, 1983.

5. Military Nonstandard Fixed Bridging, FM5-446 or TM5-312.

6. Manual of Steel Construction, American Institute of Steel and Concrete (AISC), Eighth Edition.

Reference 1 is the primary source of guidelines for load rating existing bridges. It allows a choice of load rating methods. The load and resistance factor rating (LRFR) method outlined in Reference 2 was used herein since it more accurately reflects the current condition of the bridge and the degree of inspection and analysis. For this method, Paragraph 6.1 of Reference 1 refers all guidelines to Reference 2 . Thus, Reference 2 becomes the primary source for this example. Other references will be cited as applicable.

\section{Deck Rating}

- Par. 6.7.2.1 of Reference 1 states that, "In general, stresses in the deck do not control the rating except in special cases." However, when in doubt the deck rating should be checked and is therefore shown here for demonstration purposes.

\section{Nominal Moment Capacity of Slab, $\mathbf{M}_{\mathbf{n}}$}

-Par. 3.3.2.4 of Reference 2 refers to Reference 3 for calculation of nominal resistance of reinforced concrete members. It also states that the calculations should account for observable effects of deterioration, such as loss of concrete or corroded reinforcing steel. For this example, the deck is assumed to be in good condition with no notable deterioration. If necessary, $\mathrm{R} / \mathrm{C}$ deterioration can be accounted for by reducing $\mathrm{f}_{\mathrm{c}}$, $\mathrm{f}_{\mathrm{y}}$, or the cross-sectional area of the rebars and in the selection of Resistance Factors in Reference 2.

-The concrete or steel strengths are unknown in this example, therefore refer to Par. 3.3.2.4.1 and 3.3.2.4.2 for guidelines:

$$
\begin{aligned}
& \mathrm{f}_{\mathrm{c}}{ }^{\prime}=3,000 \text { psi } \\
& \mathrm{f}_{\mathrm{y}}=40,000 \text { psi (bridge built after 1954) }
\end{aligned}
$$

-Slab reinforcing as shown in Detail A on page 1.

- Tension Steel Area per foot of slab width $=$

$$
\begin{aligned}
A_{s} & =\frac{\text { area of one bar }\left(\mathrm{in}^{2}\right) * 12 \mathrm{in} / \mathrm{ft}}{\text { bar spacing (in) }} \\
& =\frac{\left(0.44 \mathrm{in}^{2}\right)(12 \mathrm{in} / \mathrm{ft})}{8 \mathrm{in}}=0.66 \mathrm{in}^{2} / \mathrm{ft}
\end{aligned}
$$


- Compression Steel Area per foot width $=A_{s}^{\prime}=A_{s}=0.66 \mathrm{in}^{2} / \mathrm{ft}$

- Par. 8.16.2.7, Reference 3: $\quad \beta=0.85$

- Check compression steel criteria of Sec. 8.16.3.4, Reference 3:

$$
\begin{gathered}
\frac{A_{s}-A_{s}^{\prime}}{b d} \leq 0.85 \beta_{1}\left(\frac{f_{c}^{\prime} d^{\prime}}{f_{y} d}\right)\left(\frac{87,000}{87,000-f_{y}}\right) \\
\frac{0.66-0.66}{(12)(4.1)}=0<0.85(0.85)\left(\frac{3000(4.1)}{40,000(4.1)}\right)\left(\frac{87,000}{87,000-40,000}\right)=0.10
\end{gathered}
$$

- Because the previous expression is true, the $\mathrm{R} / \mathrm{C}$ section can be treated as having tension reinforcing only (i.e. neglect compression reinforcing). Therefore, use Par. 8.16.3.2, Reference 3 to calculate moment capacity:

$$
\begin{gathered}
\qquad a=\frac{A_{s} f_{y}}{.85 f_{c}^{\prime} b}=\frac{0.66(40,000)}{.85(3000)(12)}=0.863 \mathrm{in} \\
M_{n}=A_{s} f_{y}\left(d-\frac{a}{2}\right) \\
M_{n}=0.66 \mathrm{in}^{2}\left(40,000 \frac{\mathrm{lb}}{\mathrm{in}^{2}}\right)\left(4.1 \mathrm{in}-\frac{.863 \mathrm{in}}{2}\right)\left(\frac{1 \mathrm{kip}}{1000 \mathrm{lb}}\right)\left(\frac{1 \mathrm{ft}}{12 \mathrm{in}}\right)=8.07 \mathrm{ft} \cdot \mathrm{kip} / \mathrm{foot} \text { width }
\end{gathered}
$$

\section{Applied Loading Effects on Deck}

Dead Load $\left(\omega_{D}\right)$ :

- For the deck, neglect the dead load due to sidewalk and railings).

Concrete: $\omega_{D}=$ thickness $(\mathrm{t}) *$ concrete unit wt. $* 1 \mathrm{ft}$. width

$$
=(7.0 \mathrm{in})\left(150 \frac{\mathrm{lb}}{\mathrm{ft}^{3}}\right)\left(\frac{1 \mathrm{ft}}{12 \mathrm{in}}\right)\left(\frac{1 \mathrm{kip}}{1000 \mathrm{lb}}\right)=0.088 \frac{\mathrm{kip}}{\mathrm{ft}}
$$

Asphalt: $\quad \omega_{D}=$ thickness $(\mathrm{t}) *$ asphalt unit wt. $* 1 \mathrm{ft}$. width

$$
\begin{aligned}
=(4.0 \mathrm{in})\left(150 \frac{\mathrm{lb}}{\mathrm{ft}^{3}}\right)\left(\frac{1 \mathrm{ft}}{12 \mathrm{in}}\right)\left(\frac{1 \mathrm{kip}}{1000 \mathrm{lb}}\right) & =\frac{0.050 \frac{\mathrm{kip}}{\mathrm{ft}}}{\text { Total } \omega_{\mathrm{D}}}=0.138 \frac{\mathrm{kip}}{\mathrm{ft}}
\end{aligned}
$$


Dead Load Moment $\left(\mathrm{M}_{D}\right)$ :

- Note: Only bending moment is considered for the R/C deck since Sec. 3.24.4, Reference 3 states that "Slabs designed for bending moment shall be considered satisfactory in bond and shear."

- For simplicity, neglect the effect of sidewalk overhang which would only serve to reduce the positive bending moment. Therefore, the deck is treated as a fourspan continuous beam (i.e. it spans five stringers) with equal span lengths and the bending moments can be obtained from the standard beam diagrams of Reference 6:

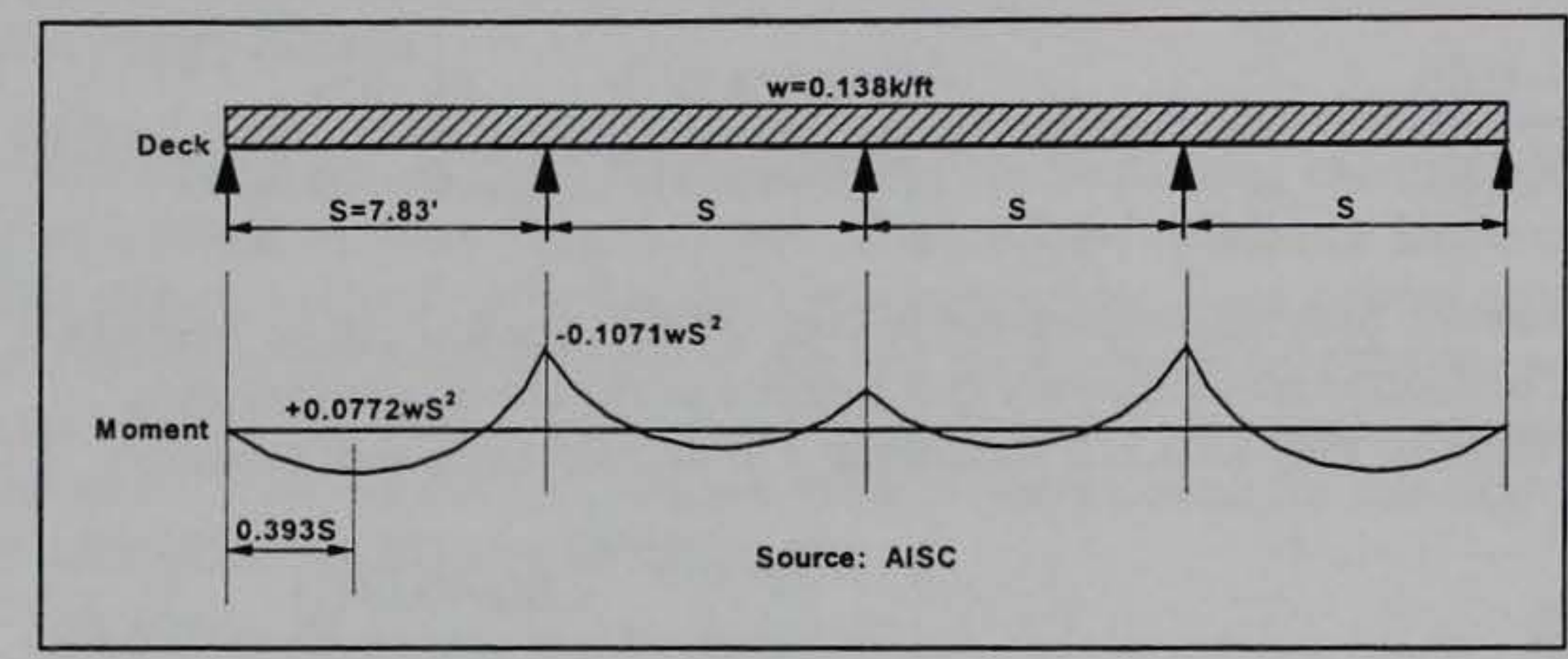

- Max. Positive DL Moment, $M_{D_{p}}=0.0772 \omega S^{2}$

$$
=0.0772\left(0.138 \frac{k i p}{f t}\right)(7.83 f t)^{2}=0.653 f t \cdot k i p
$$

- Max. Negativ DL Moment, $M_{D_{N}}=0.1071 \omega S^{2}$

$$
=0.1071\left(0.138 \frac{k i p}{f t}\right)(7.83 f t)^{2}=0.906 f t \cdot k i p
$$

Live Load Moment $\left(\mathrm{M}_{L}\right)$ :

- Several different live loadings must be considered: Par. 6.7.2 of Reference 1 states that the HS20 loading (Figure 6.7.2.2, Reference 1) should be used to compare with original design calculations and for input to the National Bridge Inventory (NBI). The three typical legal loads shown in Figure 7.4.3.1 (discussed in Par. 7.4.2, Reference 1) should be used for determination of allowable loadings (i.e. bridge postings). In addition, for bridges on military installations, the allowable Military Load Class (MLC) must also be obtained. These loadings are described in Reference 5.

- Recall from the drawing on page 1 that the deck is a one-way slab spanning transversely across the stringers and that slab capacity and dead loads were calculated for a 1-foot transverse width of slab. As seen in the figure below, the worst-case live loading for the 1 -foot width of slab will be caused by the heaviest wheel of any of the rating vehicles centered between two stringers. 


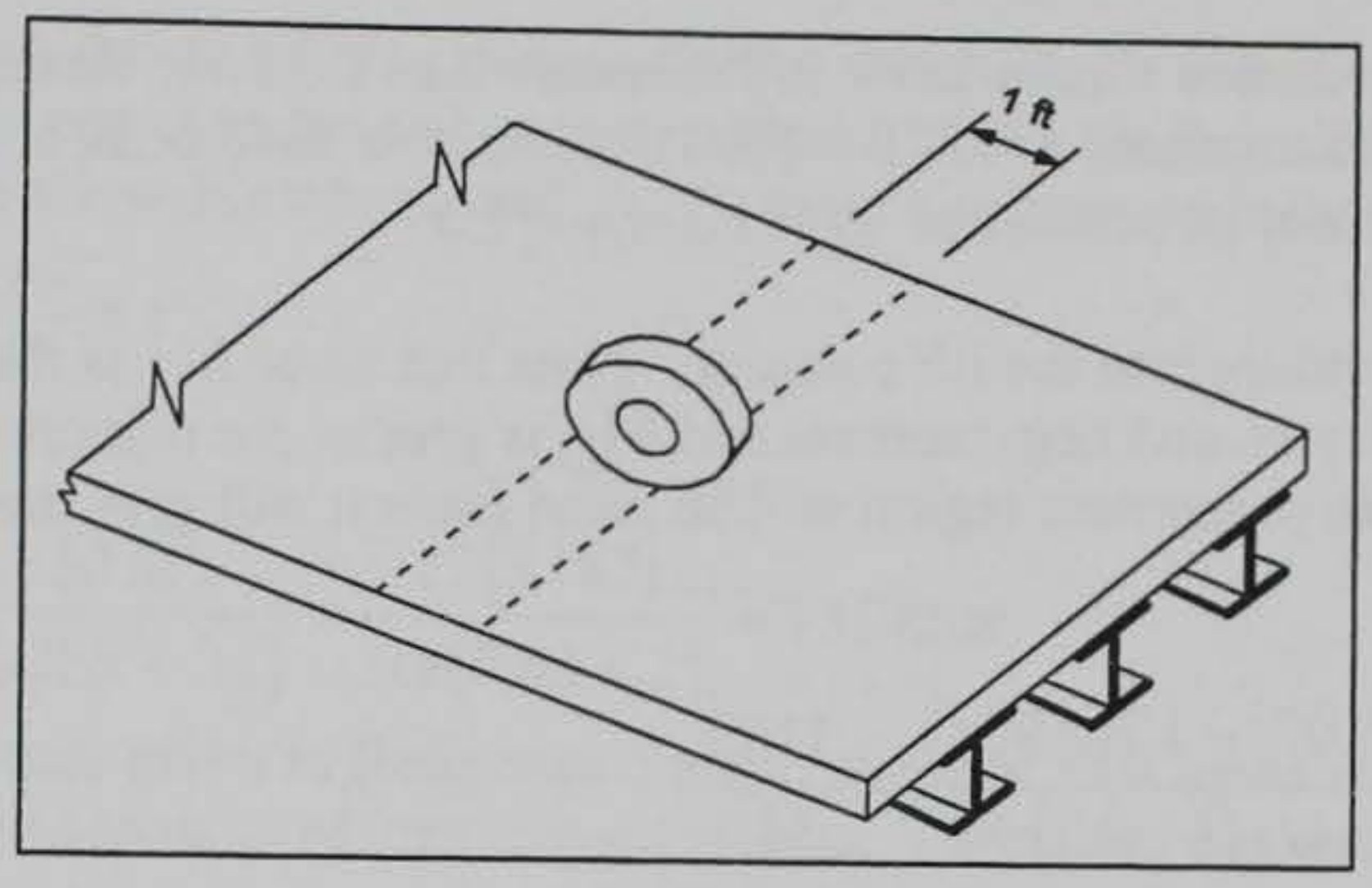

- It can also be seen from the previous figure that the wheel loading will actually be distributed to (shared by) more than a 1-foot width of slab. To account for this distribution, the following Equation is recommended in Par. 3.24.3.1 of Reference 3 for calculating live load moment (both positive and negative) on the deck:

Live Load Moment, $M_{L}=0.8 \frac{S+2}{32} * P$, where $P=$ heaviest wheel load in kips.

-Dividing the axle loads of the rating vehicles by 2 gives wheel loads in kips:

$$
P_{3}=8.5 ; P_{3 S 2}=7.8 ; P_{3-3}=8.0 ; P_{H S 20}=16.0
$$

$$
\therefore M_{L_{3}}=0.8 \frac{7.83+2}{32} * 8.5=2.09 \mathrm{ft} \cdot \mathrm{kip} / \text { foot } \text { width }
$$

Likewise:

$$
M_{L_{3 S 2}}=1.92 \mathrm{ft} \cdot \mathrm{kip} ; M_{L_{3-3}}=1.97 \mathrm{ft} \cdot \mathrm{kip} ; M_{L_{H S 20}}=3.93 \mathrm{ft} \cdot \mathrm{kip} ;
$$

\section{Deck Rating Factors}

- The Rating Factor Equation shows the ratio of available live load capacity (i.e. nominal capacity minus applied dead load) to applied live load. For the LRFR method (Reference 2) used herein, the Rating Factor Equation is defined in Par. 3.3 and when applied to bending moment becomes:

$$
R F=\frac{\phi M_{n}-\gamma_{D} M_{D}}{\gamma_{L} M_{L}(1+I)}
$$

- The Load and Resistance Factors are determined from Reference 2 as follows:

- Par. 3.3.2.3: I= Impact: Assume bumpy approach; $\mathrm{I}=0.2$

- Calculate $\phi$ from Figure 4, Reference 2 as follows:

- Slab redundant since failure of one slab span will not cause failure of bridge: $\phi=0.9$

- Some minor deterioration of the slab: $\phi=0.9-0.1=0.8$

- An intermittent maintenance program is used: $\phi=0.8-0.05=\underline{0.75}$ 
- Determine $\gamma$ from Table 2, Reference 2 as follows: Assuming low traffic volume (ADTT < 1000), reasonable enforcement and apparent control of overloads: $\gamma_{\mathrm{D}}=1.2, \gamma_{\mathrm{L}}=1.3$

- Now, plug values into the $R F$ equation. Note that since $M_{L}$ is the same on the deck for both pos. and neg. moment and $\mathrm{M}_{\mathrm{D}}$ is greater for negative moment, only the negative moment region will be rated since it will give the lowest the rating:

$$
\begin{aligned}
& R F=\frac{0.75(8.07)-1.2(0.906)}{1.3 M_{L}(1+0.2)}=\frac{3.183}{M_{L}} \\
& R F_{3}=\frac{3.183}{2.09}=1.5>1.0 \Rightarrow \text { Good } \\
& R F_{3 S 2}=\frac{3.183}{1.92}=1.7>1.0 \Rightarrow \text { Good } \\
& R F_{3-3}=\frac{3.183}{1.97}=1.6>1.0 \Rightarrow \text { Good } \\
& R F_{H S 20}=\frac{3.183}{3.93}=0.8<1.0 \Rightarrow \text { Too low, but not used for posting }
\end{aligned}
$$

\section{Military Load Class (MLC) for Deck}

- The figure below demonstrates that the deck will generally not be of concern for "Tracked" vehicles since the load is spread over the entire track length. Therefore, the MLC of the deck will only be obtained for "Wheeled" vehicles. The allowable Tracked class will be obtained in the Stringer Rating section.

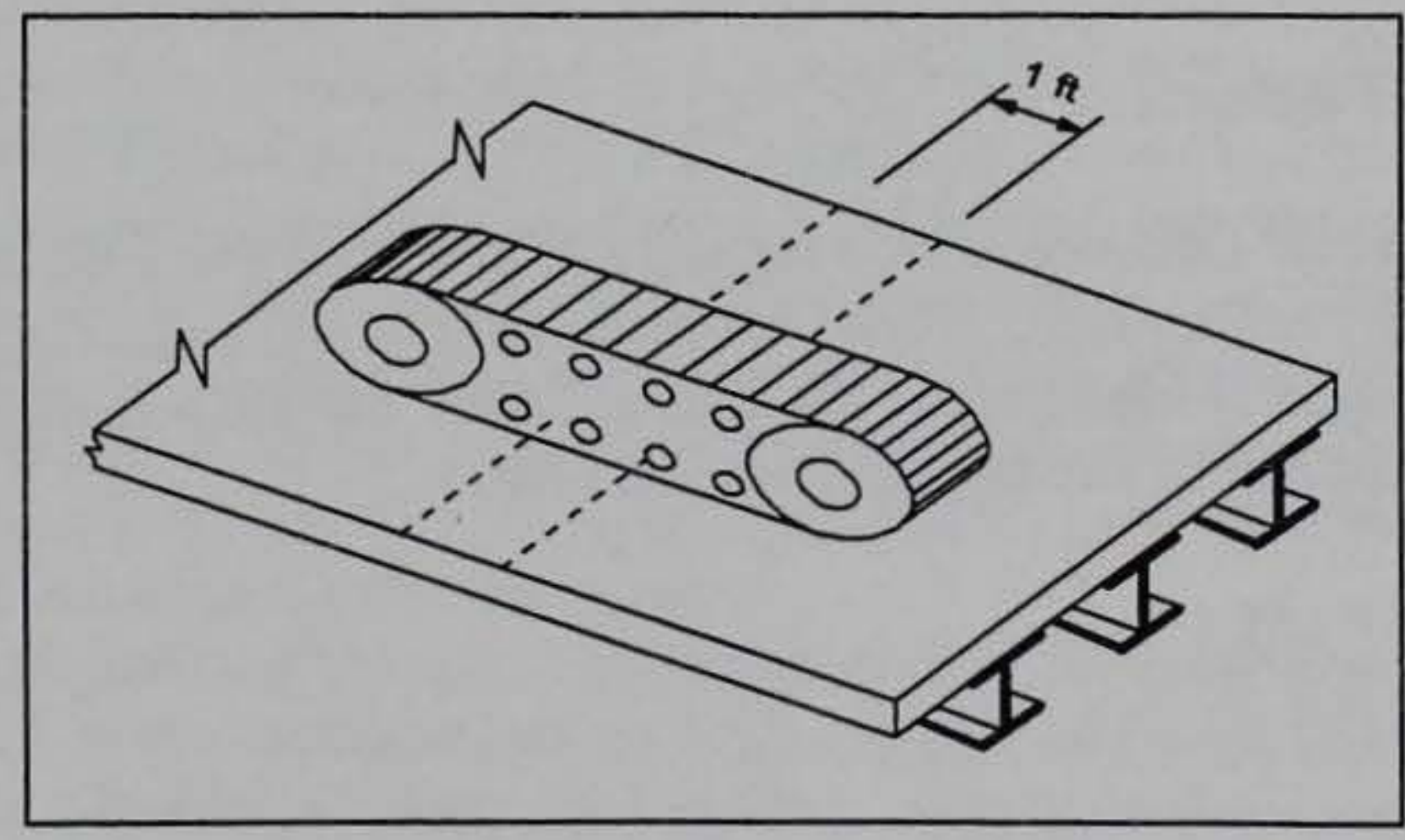

- Since with the LRFR method, a Rating Factor greater than 1.0 is satisfactory, the MLC can be obtained by setting the RF equation from the previous page equal to 1.0 and solving for $\mathrm{M}_{\mathrm{L}}$ as follows:

$$
\begin{aligned}
& R F=1.0=\frac{3.183}{M_{L}} \\
& M_{L}=3.183 \mathrm{ft} \cdot \mathrm{kips}
\end{aligned}
$$


- $M_{L}$ represents the distributed moment in the deck slab. It should now be used in the previous equation for slab moment (Par. 3.24.3.1, Reference 3) to solve for the maximum allowable wheel load, $\mathrm{P}_{\max }$, from a military vehicle as follows:

$$
M_{L}=0.8 \frac{S+2}{32} * P
$$

or

$$
P=P_{\max }=\frac{32 M_{L}}{0.8(S+32)}=\frac{32(3.183)}{0.8(7.83+2)}=13.0 \text { kips }
$$

- The vehicle data given in Reference 5 are in terms of axle loads instead of wheel loads, and in units of tons instead of kips. Therefore, convert $\mathrm{P}_{\max }$ :

$$
P_{\max }=13.0 \frac{\text { kips }}{\text { wheel }}\left(\frac{2 \text { wheels }}{\text { axle }}\right)\left(\frac{1 \text { ton }}{2 \text { kips }}\right)=13.0 \frac{\text { tons }}{\text { axle }}
$$

- Use Column $3^{*}$ of the Vehicle Data in Reference 5 to find the maximum allowable wheeled vehicle where any axle load does not exceed 13.0 tons.

Choose W30 with a heaviest axle of 11 tons, which is $<13.0$ tons

* Note that conservatively, Column 4 of the Vehicle Data in Reference 5 should be used since it lists the max. possible axle load for each particular load class. However, since we are using the LRFR method of rating, which accounts for possible overloads with the load factors $(\gamma)$, the use of Column 4 would be too conse4rvative in most cases. This decision must be made on an individual basis based on expected loadings at the particular installation. For example, Korean installations may have widely varied and unpredictable military loadings. They may choose to use the more conservative values in Column 4.

\section{Stringer Rating}

- Interior stringers generally control the rating and this will be assumed true herein. However, if in doubt, always check both interior and fascia stringers. - Sufficiency of connections and bearings are generally not considered in load ratings. However, if in doubt, check.

\section{Nominal Capacities of Stringer}

- Par. 3.3.2.4 of Reference 2 refers to Reference 3 for calculation of nominal resistance. It also states that the calculations should account for observable effects of deterioration, such as loss of steel cross-section area. For this example, the stringers are assumed to be in good condition with no notable deterioration. If necessary, stringer deterioration can be accounted for by reducing crosssectional area or $\mathrm{f}_{\mathrm{y}}$, and in the selection of Resistance Factors in Reference 2 . - The bridge drawing (page 1) does not show shear connectors on top of the stringers. Therefore, the deck is assumed non-composite with the stringers for this example. Design drawings are generally the only reliable means of determining whether a deck is composite. If drawings are unavailable, non- 
composite action must conservatively be assumed. In general, bridges built prior to 1940 were non-composite and those built after 1950 may be composite.

- The stringers are 36 WF 300 without cover plates or web stiffeners. From Reference 6:

$$
\begin{gathered}
\mathrm{A}=88.3 \text { in }^{2}, \mathrm{~d}=36.74 \text { in, } \mathrm{t}_{\mathrm{w}}=0.945 \text { in, } \mathrm{t}_{\mathrm{f}}=1.68 \text { in, } \mathrm{b}_{\mathrm{f}}=16.655 \text { in } \\
\mathrm{I}_{\mathrm{x}}=20,300 \text { in }^{4}, \mathrm{I}_{\mathrm{y}}=1300 \mathrm{in}^{4} \\
\mathrm{~S}_{\mathrm{x}}=1110 \text { in }^{3}, \mathrm{~S}_{\mathrm{y}}=156 \mathrm{in}^{3} \\
\mathrm{Z}_{\mathrm{x}}=1260 \text { in }^{3}, \mathrm{Z}_{\mathrm{y}}=241 \mathrm{in}^{3} \\
\mathrm{~T}_{\mathrm{x}}=15.2 \text { in, } \mathrm{r}_{\mathrm{y}}=3.83 \text { in }
\end{gathered}
$$

- The steel section described above comes from the current AISC manual where A36 steel has a $F_{y}=36 \mathrm{ksi}$. However, for this example, assume the yield strength is unknown. In that case, Par. 3.3.2.4, Reference 2 refers to Par. 5.5.2, Reference 4 (also in Reference 1, Par. 6.6.2.1) which allows determination of yield strength based on the date built of the bridge. Since this bridge was built in 1960, Table 5.4.2.A, Reference 4 specifies $f_{y}=33 k s i$.

\section{Nominal Moment, $M_{n}$ :}

- Check compact section criteria of Par. 10.48.1, Reference 3:

(a) Projecting compression flange element: Check that $\frac{b^{\prime}}{t_{f}} \leq \frac{2055}{\sqrt{F_{y}}}$

$$
\begin{gathered}
\text { where } b^{\prime}=\frac{b_{f}-t_{w}}{2}=\frac{16.655-0.945}{2}=7.86 \\
\frac{b^{\prime}}{t_{f}}=\frac{7.86}{1.68}=4.7 \quad<\quad \frac{2055}{\sqrt{F_{y}}}=\frac{2055}{\sqrt{33,000}}=11.3 \Rightarrow \text { Good }
\end{gathered}
$$

(b) Web Thickness: Check that $\frac{D}{t_{w}} \leq \frac{19,230}{\sqrt{F_{y}}}$

where $D=d-2 t_{f}=36.74-2(1.68)=33.38$ in

$$
\frac{D}{t_{w}}=\frac{33.38}{0.945}=35.3 \quad<\quad \frac{19,230}{\sqrt{F_{y}}}=\frac{19,230}{\sqrt{33,000}}=105.9 \Rightarrow \text { Good }
$$

(c) Lateral Bracing: Top flanges embedded in concrete, therefore fully braced.

- Because all of the above criteria are true, the stringers can be treated as braced and compact. Therefore:

$$
M_{n}=M_{u}=F_{y} \cdot Z_{x}=(33 k s i)\left(1260 \mathrm{in}^{3}\right)\left(\frac{\mathrm{ft}}{12 \mathrm{in}}\right)=3465 \mathrm{ft} \cdot \mathrm{kip}
$$

\section{Nominal Shear, $\mathbf{V}_{\mathbf{n}}$ :}

- From Par. 10.48.8.1, Reference 3, for sections without web stiffeners: 


$$
\begin{gathered}
V_{p}=0.58 F_{y} D t_{w} \\
=0.58(33,000 \mathrm{psi})(33.38 \mathrm{in})(0.945 \mathrm{in})\left(\frac{\mathrm{kip}}{1000 \mathrm{lb}}\right)=603.8 \mathrm{kip} \\
\text { - Check that } \frac{D}{t_{w}} \leq \frac{6000 \sqrt{k}}{\sqrt{F_{y}}}, \text { where } \mathrm{k}=5 \text { for unstiffened girders: } \\
\frac{D}{t_{w}}=\frac{33.38}{0.945}=35.3 \quad<\quad \frac{6000 \sqrt{k}}{\sqrt{F_{y}}}=\frac{6000 \sqrt{5}}{\sqrt{33,000}}=73.9 \Rightarrow \therefore \mathrm{C}=1.0 \\
V_{n}=V_{u}=C V_{p}=(1.0)(603.8)=603.8 \mathrm{kip}
\end{gathered}
$$

\section{Applied Loading Effects on Stringers}

Dead Load $\left(\omega_{\mathrm{D}}\right)$ :

- Par. 3.23.2.3.1.1, Reference 3: Sidewalk and curb poured monolithically, before slab cured. Therefore, only the exterior stringers are considered to carry these weights. Do not include these weights in dead load to interior stringers.

- Calculate dead load carried by a single stringer as follows:

Concrete Deck:

$\omega_{D}=$ thickness $(\mathrm{t}) *$ concrete unit wt. $*$ Stringer Spacing $(\mathrm{S})$

$$
=(7.0 \mathrm{in})\left(150 \frac{\mathrm{lb}}{\mathrm{ft}^{3}}\right)(94.0 \mathrm{in})\left(\frac{\mathrm{ft}}{144 \mathrm{in}^{2}}\right)\left(\frac{1 \mathrm{kip}}{1000 \mathrm{lb}}\right)=0.685 \frac{\mathrm{kip}}{\mathrm{ft}}
$$

Asphalt: $\omega_{D}=$ thickness $(\mathrm{t}) *$ asphalt unit wt. $*$ Stringer Spacing(S)

$$
=(4.0 \mathrm{in})\left(150 \frac{\mathrm{lb}}{\mathrm{ft}^{3}}\right)(94.0 \mathrm{in})\left(\frac{\mathrm{ft}^{2}}{144 \mathrm{in}^{2}}\right)\left(\frac{1 \mathrm{kip}}{1000 \mathrm{lb}}\right)=0.392 \frac{\mathrm{kip}}{\mathrm{ft}}
$$

Stringer: From Reference 6 for a W36×300 shape,

$$
\omega_{D}=0.300 \frac{k i p}{f t}
$$

Diaphragms: 4 @ 24ft o.c. composed of MC18x42.7@ 0.043kip/ft.

Distribute out over length of stringer:

$$
\omega_{D}=\frac{(4 \text { diaph. })(7.83 \mathrm{ft} \text { diaph. length })\left(0.043 \frac{\mathrm{kip}}{\mathrm{ft}}\right)}{72.0 \mathrm{ft} \text { of stringer }}=0.019 \frac{\mathrm{kip}}{\mathrm{ft}}
$$

Cover plates, stiffeners, splices, etc.: None on this bridge

$$
\text { Total } \omega_{D}=1.40 \frac{k i p}{f t}
$$


Dead Load Moment $\left(\mathrm{M}_{\mathrm{D}}\right)$ :

For a simple span beam:

$$
M_{D}=\frac{\omega l^{2}}{8}=\frac{\left(1.40 \frac{k i p}{f t}\right)(72.0 f t)^{2}}{8}=907.2 \mathrm{ft} \cdot \mathrm{kip}
$$

Dead Load shear $\left(\mathrm{V}_{\mathrm{D}}\right)$ :

For a simple span beam:

$$
V_{D}=\frac{\omega l}{2}=\frac{\left(1.40 \frac{k i p}{f t}\right)(72.0 f t)}{2}=50.4 k i p
$$

Live Load:

- Live load moments and shears are those produced from the wheel lines of the rating vehicles on a $72.0 \mathrm{ft}$. simple span. These can be obtained through basic structural analysis by placing the vehicle to produce maximum moments and shears, or more simply from Appendix A of Reference 1 (Refs. 3 and 4 also contain these values). Note in Table A3 that interpolation between a 70 and $80 \mathrm{ft}$ span is required:

$$
\begin{aligned}
& M_{L_{\mathrm{s}}}=373.0 \mathrm{ft} \cdot \mathrm{kip} \text { per wheel line } \\
& M_{L_{S S 2}}=410.0 \mathrm{ft} \cdot \mathrm{kip} \text { per wheel line } \\
& M_{L_{S_{3-3}}}=390.0 \mathrm{ft} \cdot \mathrm{kip} \text { per wheel line } \\
& M_{L_{H S 20}}=510.5 \mathrm{ft} \cdot \mathrm{kip} \text { per wheel line } \\
& \text { - From A7, Reference 1: Max. Shear at support at x=72.0, } \therefore \frac{L-x}{L}=0 \\
& V_{L_{3}}=\frac{25(x-7.44)}{L}=\frac{25(72-7.44)}{72}=22.4 \\
& V_{L_{S S 2}}=\frac{36(x-18.61)}{L}=\frac{36(72-18.61)}{72}=26.7 \\
& V_{L_{3-3}}=\frac{40(x-23.90)}{L}=\frac{40(72-23.90)}{72}=26.7 \\
& V_{L_{H S 20}}=\frac{36(x-9.33)}{L}=\frac{36(72-9.33)}{72}=31.3
\end{aligned}
$$




\section{Stringer Rating Factors:}

- As done for the deck, the Load and Resistance Factors are determined from Reference 2 as follows:

- Par. 3.3.2.3: I=Impact: Assume bumpy approach; $\mathrm{I}=0.2$

- Calculate $\phi$ from Figure 4, Reference 2 as follows:

- Steel stringers redundant since failure of one will not cause failure of bridge: $\phi=0.95$

- Some minor deterioration of the stringers: $\phi=0.95-0.1=0.85$

- An intermittent maintenance program is used: $\phi=0.85-0.05=\underline{0.80}$

- $\gamma$ factors will be same as for the deck (from Table 2, Reference 2): $\gamma_{\mathrm{D}}=1.2, \gamma_{\mathrm{L}}=1.3$

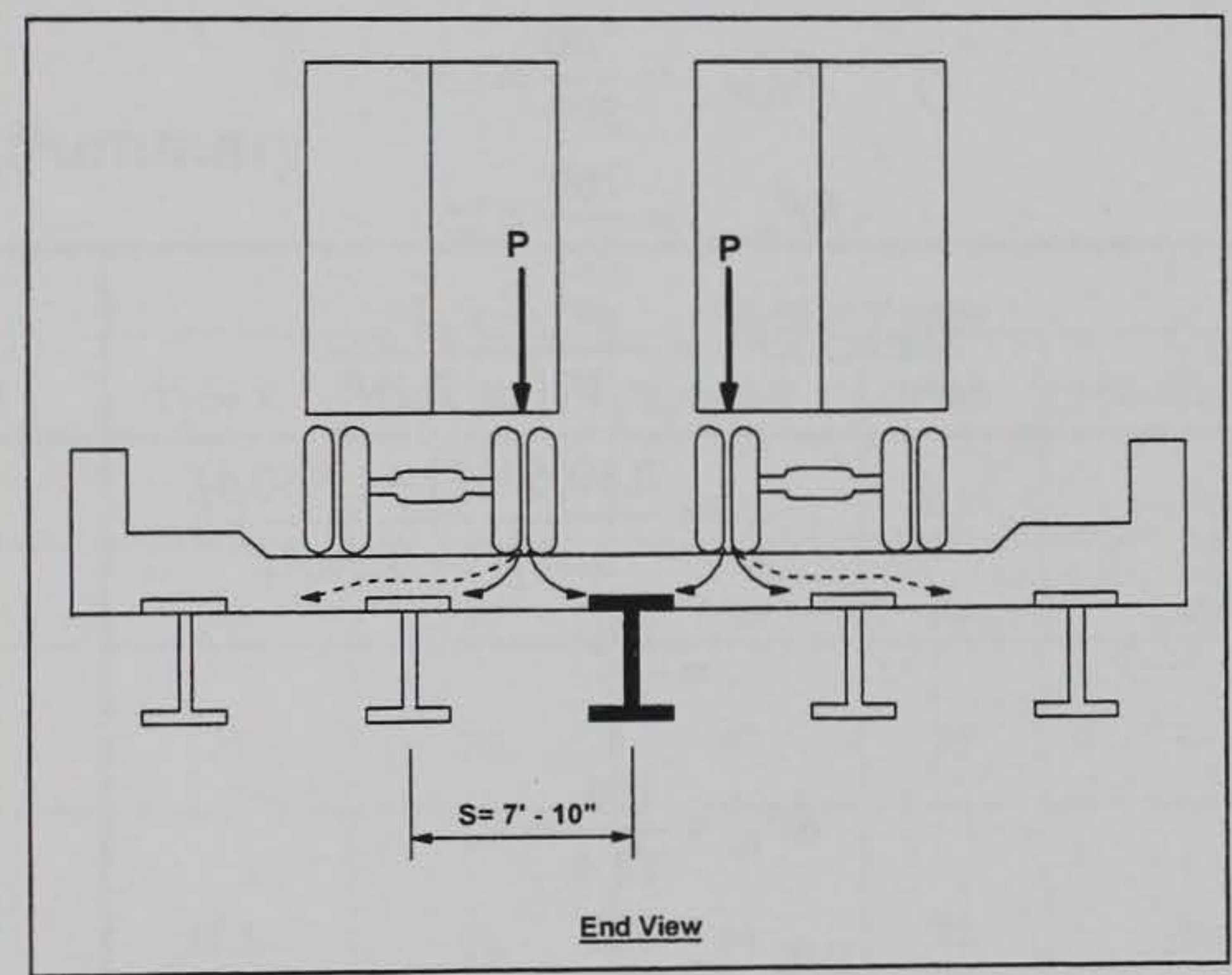

- Stringer Distribution Factor (DF): From Par. 3.23.2.2, Reference 3, for concrete deck on steel I-beam stringers (Refer to Figure above):

$$
\text { Two - Way Traffic: } D F=\frac{S}{5.5}=\frac{7.83}{5.5}=1.42
$$

- Now, plug values into the RF equations for both moment and shear: 


$$
\text { Moment: } \begin{aligned}
R F_{M} & =\frac{\phi M_{n}-\gamma_{D} M_{D}}{\gamma_{L} M_{L}(1+I) D F} \\
& =\frac{0.80(3465)-1.2(907.2)}{1.3 M_{L}(1+0.2) 1.42} \\
& =\frac{760}{M_{L}} \\
R F_{M_{3}} & =\frac{760}{373}=2.0 \\
R F_{M_{3 S 2}} & =\frac{760}{410}=1.85 \\
R F_{M_{3-3}} & =\frac{760}{390}=1.95 \\
R F_{M_{H S 20}} & =\frac{760}{511}=1.5
\end{aligned}
$$

Shear: $R F_{V}=\frac{\phi V_{n}-\gamma_{D} V_{D}}{\gamma_{L} V_{L}(1+I) D F}$

$$
\begin{aligned}
& =\frac{0.80(603.8)-1.2(50.4)}{1.3 V_{L}(1+0.2) 1.42} \\
& =\frac{191}{V_{L}} \\
R F_{V_{3}} & =\frac{191}{22.4}=8.5 \\
R F_{V_{3 S 2}} & =\frac{191}{26.7}=7.1 \\
R F_{V_{3-3}} & =\frac{191}{26.7}=7.1 \\
R F_{V_{H S 20}} & =\frac{191}{31.3}=6.1
\end{aligned}
$$

- As seen above, moment controls over shear in this example. This is generally true for long flexible steel and concrete members, but not necessarily for timber.

\section{MLC of Stringers:}

- From the previous page, moment controls. Therefore, shear will be neglected here.

- Use the same procedure as for the deck; i.e. set RF equal to 1 and solve for $\mathrm{M}_{\mathrm{L}}$. From previous page: $R F_{M}=1=\frac{760}{M_{L}}$ or $M_{L}=760 \mathrm{ft} \cdot \mathrm{kip}$ 
- Since the MLC moment curves in Reference 5 are for the total vehicle (i.e. axle loads), the $\mathrm{M}_{\mathrm{L}}$ value must be multiplied by 2 since it represents the moment from a wheel line (see RF equation on previous page):

$$
M_{L_{\text {Total }}}=2 \cdot M_{L}=2(760)=1520 \mathrm{ft} \cdot \mathrm{kip}
$$

- Use $M_{L_{\text {Total }}}$ to enter the wheeled and tracked vehicle moment curves of Reference 5. Find the vehicles that produce $\leq M_{L_{\text {Total }}}$ on a 72 -foot span.

- From the curves, the MLC for two-way traffic is $40 \mathrm{~W}$ and $40 \mathrm{~T}$. If desired, a one-way MLC may also be determined.

- After the MLC is determined, the required width for that MLC (from Table 3-3

of Reference 5) should be checked against the available deck width. If necessary, the MLC may be lowered based on deck width or a width restriction may be posted.

\section{Rating Summary}

\begin{tabular}{|c|c|c|c|c|c|c|}
\hline \multirow{2}{*}{$\begin{array}{c}\text { Bridge } \\
\text { Element }\end{array}$} & \multicolumn{6}{|c|}{ Rating Vehicle } \\
\cline { 2 - 7 } & Type 3 & Type 3S2 & Type 3-3 & HS20 & Mil. Wheel & Mil. Track \\
\hline Deck & 1.5 & 1.7 & 1.6 & 0.8 & 30 & n.a. \\
\hline Stringers & 2.0 & 1.85 & 1.95 & 1.5 & 40 & 40 \\
\hline $\begin{array}{c}\text { Veh. Wt. } \\
\text { (tons) }\end{array}$ & 25 & 36 & 40 & 36 & $\ldots$ & -- \\
\hline $\begin{array}{c}\text { Load } \\
\text { Rating } \\
\text { (tons)* }\end{array}$ & 37.5 & 61 & 64 & 28 & 30 & 40 \\
\hline
\end{tabular}

* Load Rating $=($ Lowest Element Rating $)($ Vehicle Wt. in tons $)$

- The lowest element ratings are circled in the table

- As per Par. 6.7.2 and 7.4.2, the bridge should be posted only if the RF for the three legal loads (The "Type" vehicles) falls below 1.0. Therefore, even though the HS20 RF is less than 1.0, this bridge does not require posting. Remember that the HS20 rating is mainly for purposes of reporting to the NBI and for comparison to the original design specifications.

- All bridges on military installations require MLC postings. For this bridge, the posting would be $40 \mathrm{~W}$ and $40 \mathrm{~T}$ for two-way traffic. The rating for one-way traffic would be higher. 


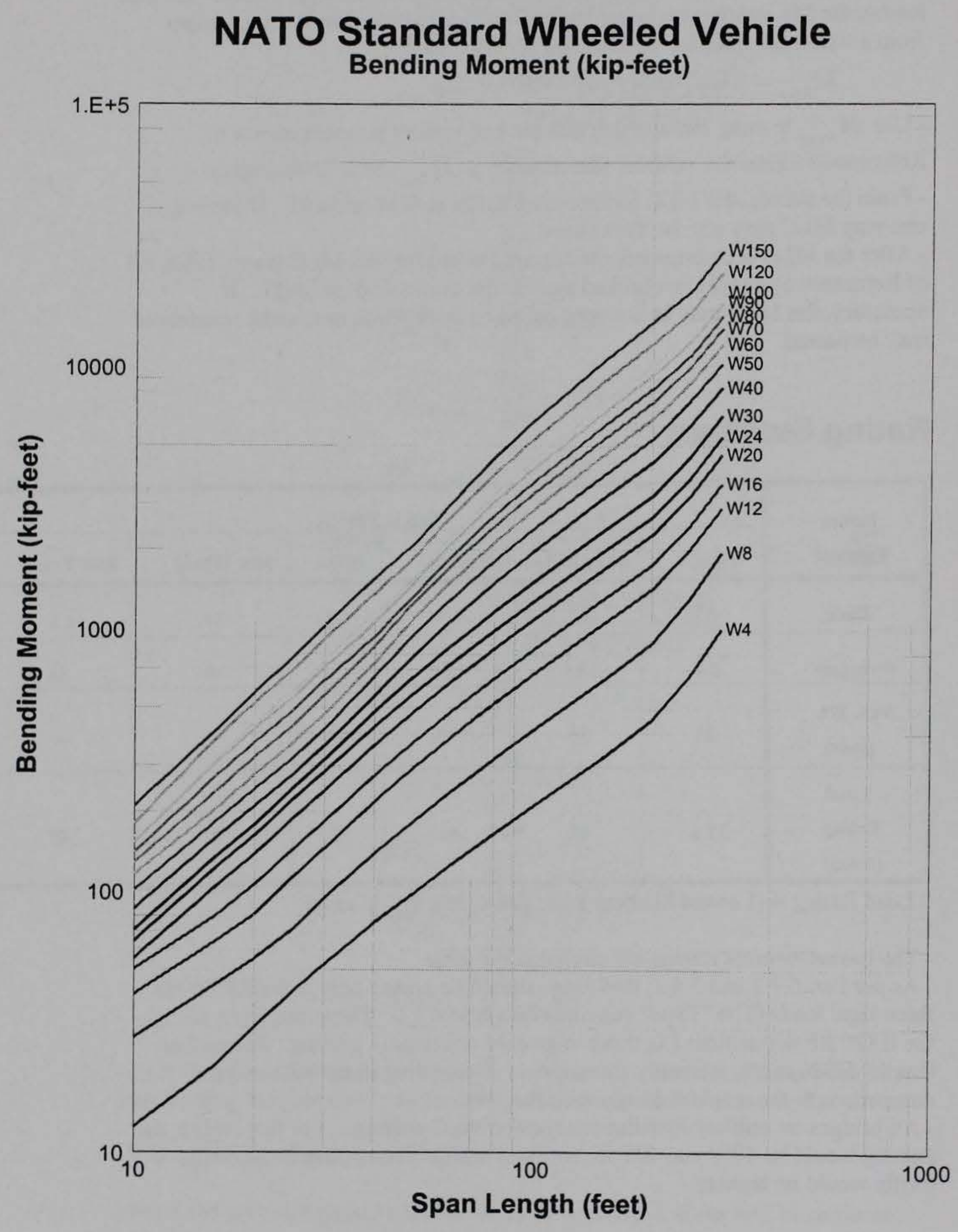




\section{Appendix C \\ Truss Bridge Example}

\section{Steel Truss, Concrete Deck Bridge Rating Example}

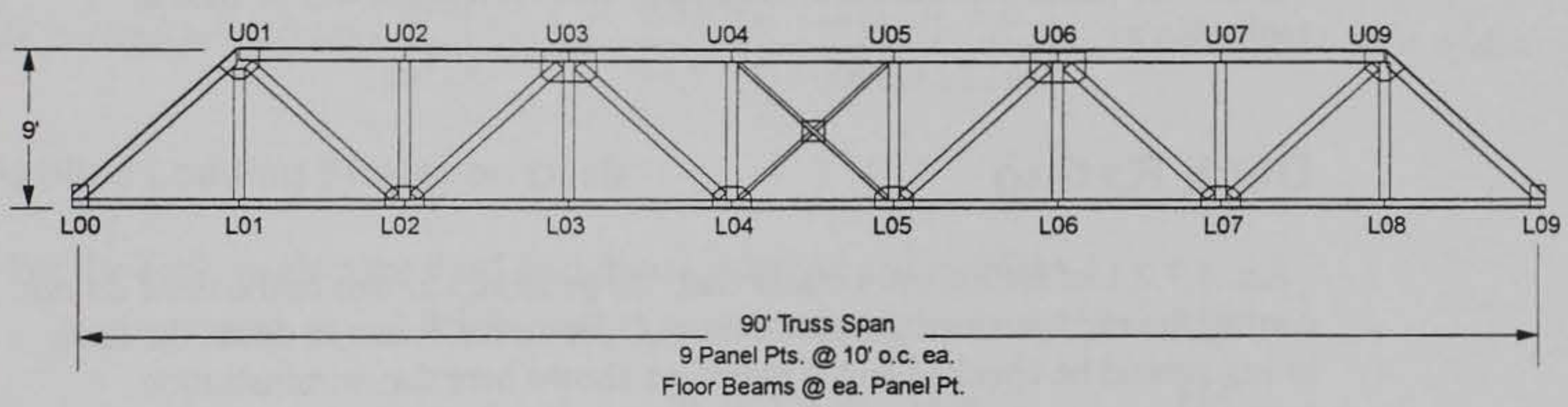

See Table on Page 20 for Truss Member Details

$16.5^{\prime}$

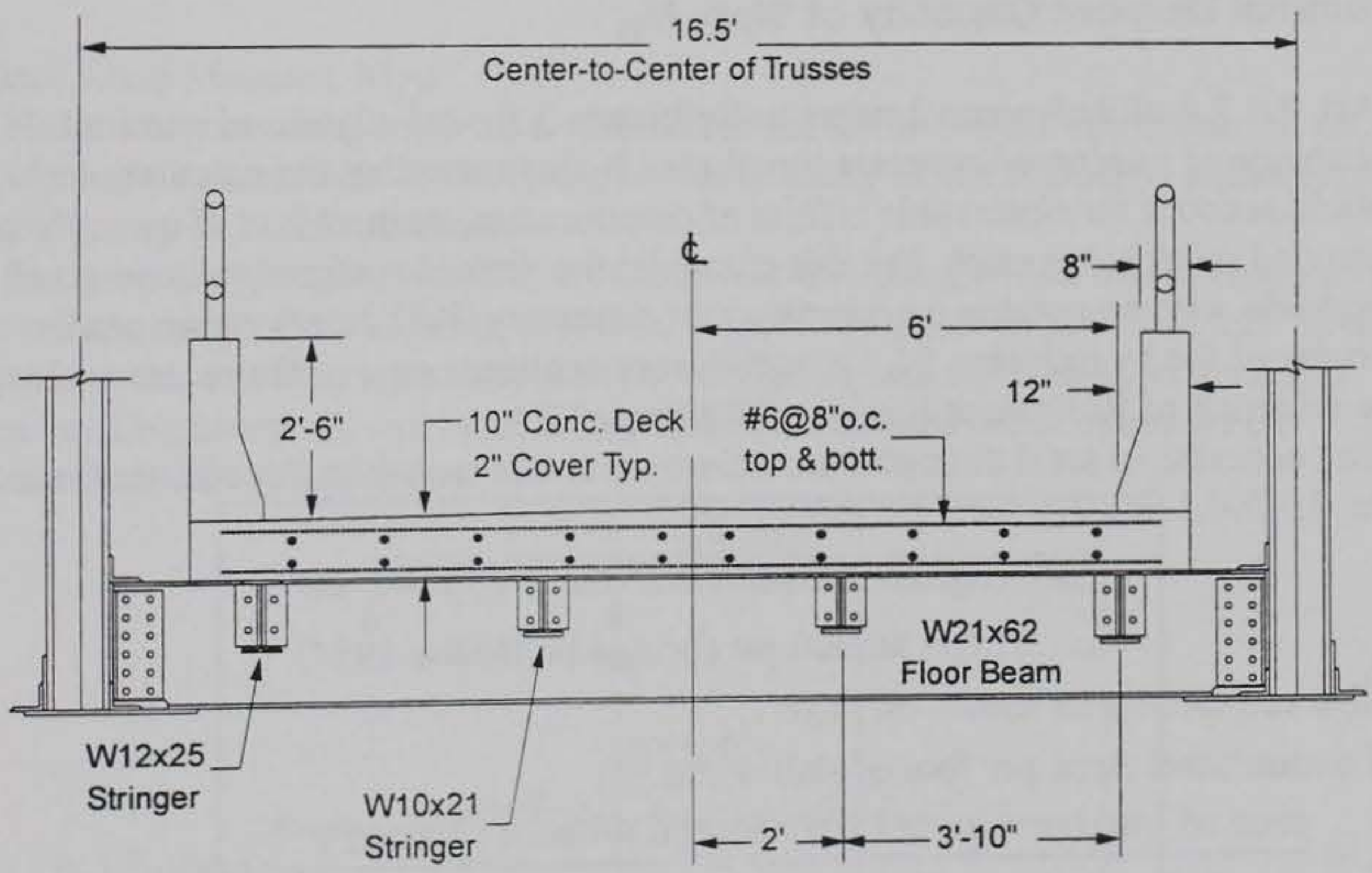

Section View 


\section{Sited References:}

1. Manual For Condition Evaluation of Bridges, AASHTO, 1994.

2. Guide Specifications for Strength Evaluation of Existing Steel and Concrete Bridges, AASHTO, 1989.

3. Standard Specifications for Highway Bridges, AASHTO, fifteenth edition, 1992.

4. Manual for Maintenance Inspection of Bridges, AASHTO, 1983.

5. Military Nonstandard Fixed Bridging, FM5-446 or TM5-312.

6. Manual of Steel Construction, American Institute of Steel and Concrete (AISC), Eighth Edition.

Reference 1 is the primary source of guidelines for load rating existing bridges. It allows a choice of load rating methods. The load and resistance factor rating (LRFR) method outlined in Reference 2 was used herein since it more accurately reflects the current condition of the bridge and the degree of inspection and analysis. For this method, Paragraph 6.1 of Reference 1 refers all guidelines to Reference 2. Thus, Reference 2 becomes the primary source for this example. Other references will be cited as applicable.

\section{Deck Rating}

- Art. 6.7.2.1 of Reference 1 states that, "In general, stresses in the deck do not control the rating except in special cases." However, when in doubt the deck rating should be checked and is therefore shown here for demonstration purposes.

\section{Nominal Moment Capacity of Slab, $\mathbf{M}_{\mathbf{n}}$}

- Art. 3.3.2.4 of Reference 2 refers to Reference 3 for calculation of nominal resistance of reinforced concrete members. It also states that the calculations should account for observable effects of deterioration, such as loss of concrete or corroded reinforcing steel. For this example, the deck is assumed to be in good condition with no notable deterioration. If necessary, $\mathrm{R} / \mathrm{C}$ deterioration can be accounted for by reducing $\mathrm{f}_{\mathrm{c}^{\prime}}, \mathrm{f}_{\mathrm{y}}$, or the cross-sectional area of the rebars and in the selection of Resistance Factors in Reference 2.

- The concrete or steel strengths are unknown in this example, therefore refer to Par. 3.3.2.4.1 and 3.3.2.4.2 for guidelines:

$$
\begin{aligned}
& f_{c}{ }^{\prime}=3,000 \text { psi } \\
& f_{y}=40,000 \text { psi (bridge built after 1954) }
\end{aligned}
$$

- Slab reinforcing as shown on page 1.

- Tension Steel Area per foot of slab width $=$

$$
A_{s}=\frac{\text { area of one bar }\left(\mathrm{in}^{2}\right) * 12 \mathrm{in} / \mathrm{ft}}{\text { bar spacing (in) }}=\frac{\left(0.44 \mathrm{in}^{2}\right)(12 \mathrm{in} / \mathrm{ft})}{8 \mathrm{in}}=0.66 \mathrm{in}^{2} / \mathrm{ft}
$$

- Compression Steel Area per foot width $=A_{s}^{\prime}=A_{s}=0.66 \mathrm{in}^{2} / \mathrm{ft}$

- Par. 8.16.2.7, Reference 3: $\quad \beta=0.85$

- Check compression steel criteria of Sec. 8.16.3.4, Reference 3: 


$$
\begin{gathered}
\frac{A_{s}-A_{s}^{\prime}}{b d} \leq 0.85 \beta_{1}\left(\frac{f_{c}^{\prime} d^{\prime}}{f_{y} d}\right)\left(\frac{87,000}{87,000-f_{y}}\right) \\
\frac{0.66-0.66}{(12)(4.1)}=0<0.85(0.85)\left(\frac{3000(7.63)}{40,000(7.63)}\right)\left(\frac{87,000}{87,000-40,000}\right)=0.10
\end{gathered}
$$

- Because the previous expression is true, the $\mathrm{R} / \mathrm{C}$ section can be treated as having tension reinforcing only (i.e. neglect compression reinforcing).

Therefore, use Par. 8.16.3.2, Reference 3 to calculate moment capacity:

$$
\begin{aligned}
& a=\frac{A_{s} f_{y}}{.85 f_{c}^{\prime} b}=\frac{0.66(40,000)}{.85(3000)(12)}=0.863 \mathrm{in} \\
& M_{n}=A_{s} f_{y}\left(d-\frac{a}{2}\right) \\
& M_{n}=0.66 \mathrm{in}^{2}\left(40,000 \frac{\mathrm{lb}}{\mathrm{in}^{2}}\right)\left(7.63 \mathrm{in}-\frac{.863 \mathrm{in}}{2}\right)\left(\frac{1 \mathrm{kip}}{1000 \mathrm{lb}}\right)\left(\frac{1 \mathrm{ft}}{12 \mathrm{in}}\right)=15.84 \mathrm{ft} \cdot \mathrm{kip} / \mathrm{foot} \text { width }
\end{aligned}
$$

\section{Applied Loading Effects on Deck}

- For the deck, neglect the dead load due to sidewalk and railings.

Concrete: $\omega_{D}=$ thickness $(\mathrm{t}) *$ concrete unit wt. $* 1 \mathrm{ft}$. width

$$
=(11.0 \mathrm{in})\left(150 \frac{\mathrm{lb}}{\mathrm{ft}^{3}}\right)\left(\frac{1 \mathrm{ft}}{12 \mathrm{in}}\right)\left(\frac{1 \mathrm{kip}}{1000 \mathrm{lb}}\right)=0.138 \frac{\mathrm{kip}}{\mathrm{ft}}
$$

Dead Load Moment, $\mathrm{M}_{D}$ :

- Note: Only bending moment is considered for the R/C deck since Sec. 3.24.4, Reference 3 states that "Slabs designed for bending moment shall be considered satisfactory in bond and shear."

- For simplicity, neglect the effect of sidewalk overhang which would only serve to reduce the positive bending moment. Therefore, the deck is treated as a threespan continuous beam (i.e. it spans four stringers) with equal span lengths and the bending moments can be obtained from the standard beam diagrams of Reference 6 as shown below:

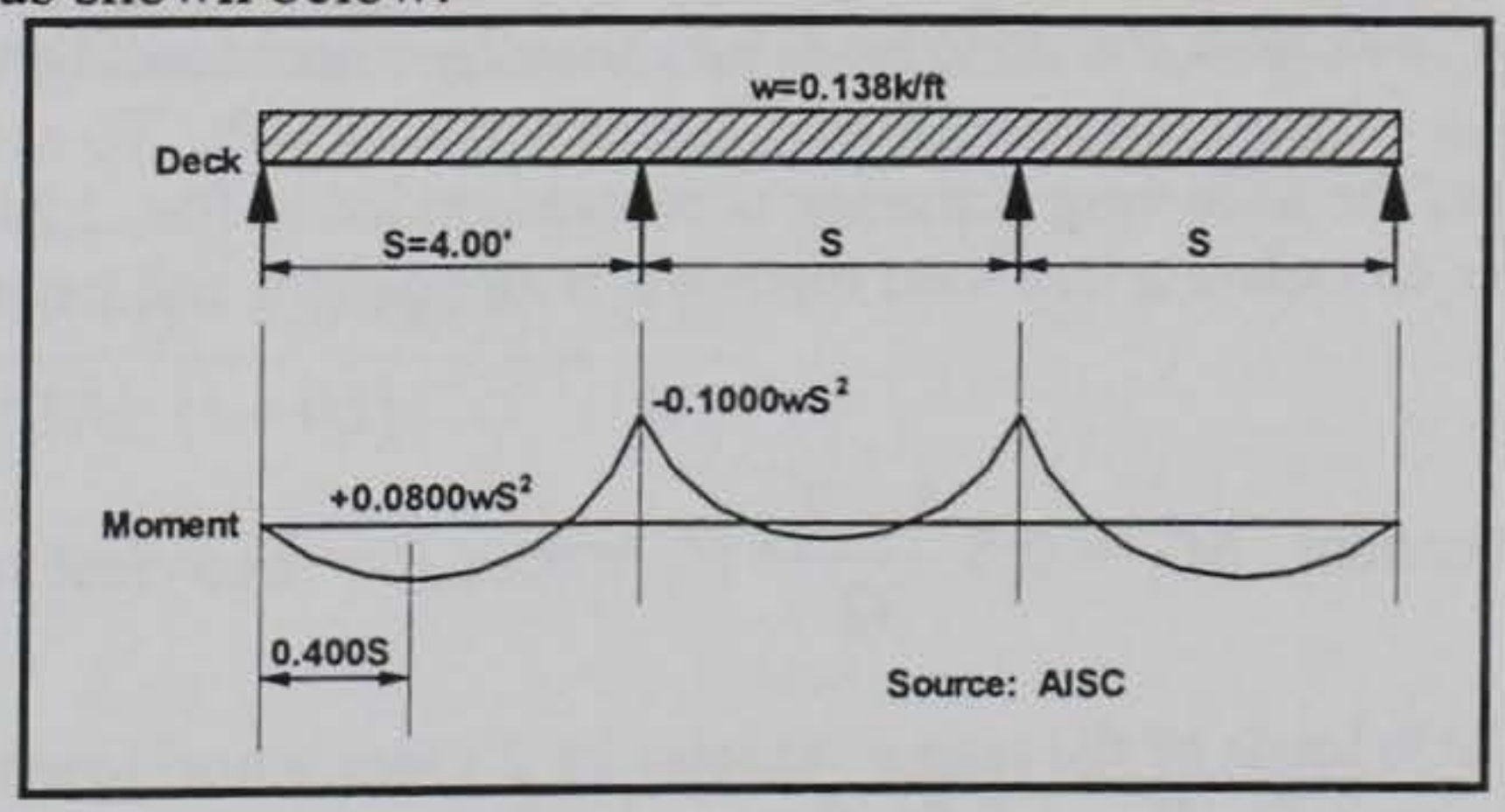


- Max. Negative DL Moment, $M_{D N}=0.10 \omega S^{2}$

$$
=0.10\left(0.138 \frac{k i p}{f t}\right)(4.0 f t)^{2}=0.221 \frac{f t \cdot k i p}{\text { foot }}
$$

- Max. Positive DL Moment, $M_{D_{P}}=0.08 \omega S^{2}$

$$
=0.08\left(0.138 \frac{k i p}{f t}\right)(4.0 f t)^{2}=0.177 \frac{f t k i p}{\text { foot }}
$$

Live Load Moment, $\mathrm{M}_{L}$ :

- Several different live loadings must be considered: Par. 6.7.2 of Reference 1 states that the HS20 loading (Figure 6.7.2.2, Reference 1) should be used to compare with original design calculations and for input to the National Bridge Inventory (NBI). The three typical legal loads shown in Figure 7.4.3.1 (discussed in Par. 7.4.2, Reference 1) should be used for determination of allowable loadings (i.e.,bridge postings). In addition, for bridges on military installations, the allowable Military Load Class (MLC) must also be obtained. These loadings are described in Reference 5.

- Recall from the drawing on page 1 that the deck is a one-way slab spanning transversely across the stringers and that slab capacity and dead loads were calculated for a 1-foot transverse width of slab. As seen in the figure below, the worst-case live loading for the 1-foot width of slab will be caused by the heaviest wheel of any of the rating vehicles centered between two stringers.

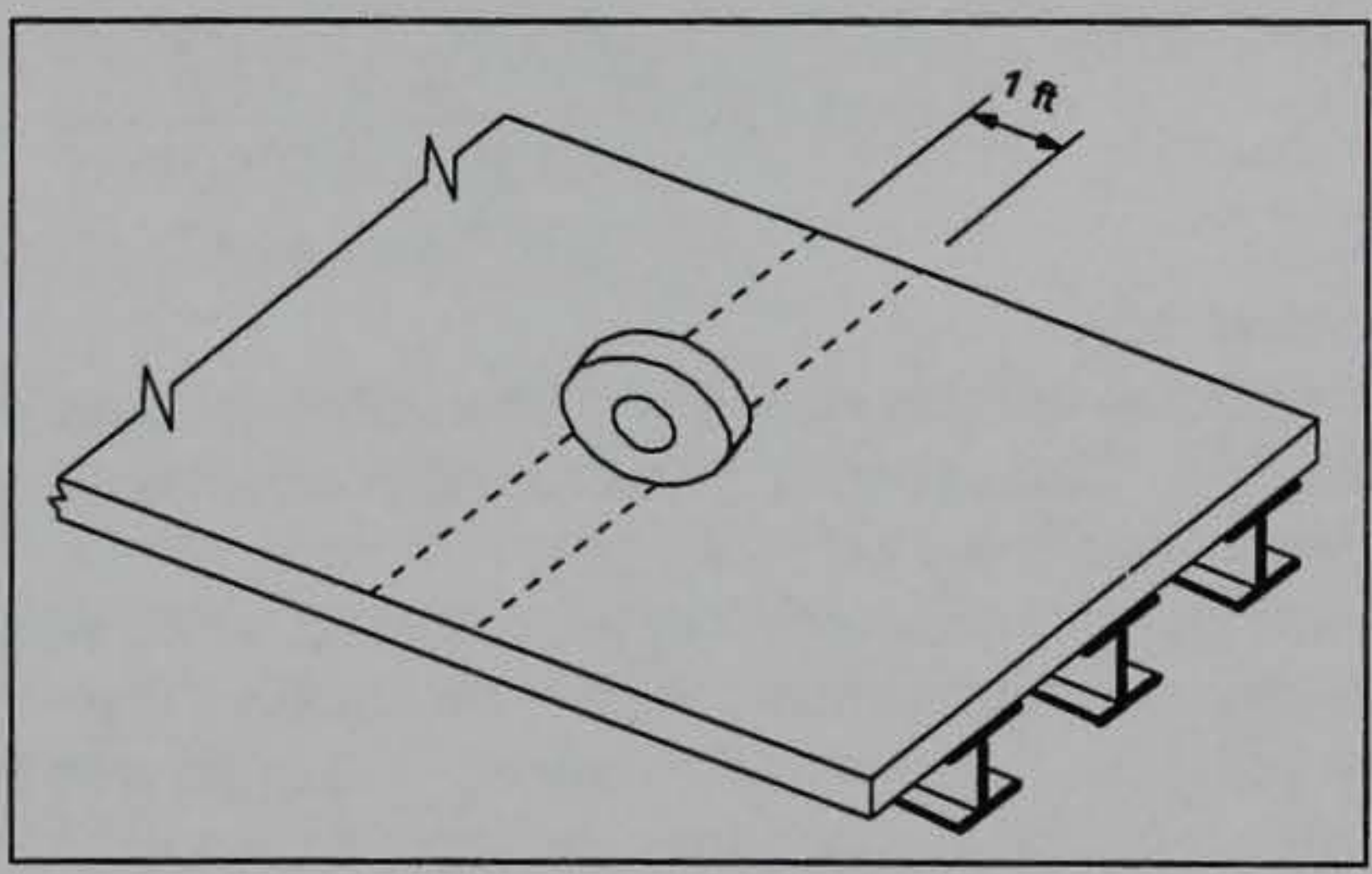

- It can also be seen from the previous figure that the wheel loading will actually be distributed to (shared by) more than a 1 -foot width of slab. To account for this distribution, the following Equation is recommended in Par. 3.24.3.1 of Reference 3 for calculating live load moment (both positive and negative) on the deck:

Live Load Moment, $M_{L}=0.8 \frac{S+2}{32} * P$, where $P=$ heaviest wheel load in kips.

-Dividing the axle loads of the rating vehicles by 2 gives wheel loads in kips:

$P_{3}=8.5 ; P_{3 S 2}=7.8 ; P_{3-3}=8.0 ; P_{H S 20}=16.0$

$$
\therefore M_{L_{3}}=0.8 \frac{4.0+2}{32} * 8.5=1.28 \mathrm{ft} \cdot \mathrm{kip} / \text { foot width }
$$


Likewise:

$$
M_{L_{3 S 2}}=1.17 \mathrm{ft} \cdot \mathrm{kip} ; M_{L_{3-3}}=1.20 \mathrm{ft} \cdot \mathrm{kip} ; M_{L_{H S 2 O}}=2.40 \mathrm{ft} \cdot \mathrm{kip} ;
$$

\section{Deck Rating Factors}

- The Rating Factor Equation shows the ratio of available live load capacity (i.e. nominal capacity minus applied dead load) to applied live load. Recall that the basic equation from Par. 6.5, Reference 1 is:

$R F=\frac{C-A_{1} D}{A_{2} L(1+I)}$,

- For the LRFR method (Reference 2) used herein, the Rating Factor Equation is defined in Par. 3.3 of Reference 2 and when applied to bending moment becomes:

$$
R F=\frac{\phi M_{n}-\gamma_{D} M_{D}}{\gamma_{L} M_{L}(1+I)}
$$

- The Load and Resistance Factors are determined from Reference 2 as follows:

- Par. 3.3.2.3: I= Impact: For a smooth approach; $\mathrm{I}=0.1$

- Calculate $\phi$ from Figure 4, Reference 2 as follows:

- Slab redundant since failure of one slab span will not cause failure of bridge: $\phi=0.9$

- Some minor deterioration of the slab: $\phi=0.9-0.1=0.8$

- An intermittent maintenance program is used: $\phi=0.8-0.05=\underline{0.75}$

- Determine $\gamma$ from Table 2, Reference 2 as follows: Assuming low traffic volume $(\mathrm{ADTT}<1000)$, reasonable enforcement and apparent control of overloads: $\gamma_{\mathrm{D}}=1.2, \gamma_{\mathrm{L}}=1.3$

- Now, plug values into the $R F$ equation. Note that since $M_{L}$ is the same on the deck for both pos. and neg. moment and $\mathrm{M}_{\mathrm{D}}$ is greater for negative moment, only the negative moment region will be rated since it will give the lowest the rating:

$$
R F=\frac{0.75(15.84)-1.2(0.221)}{1.3 M_{L}(1+0.1)}=\frac{8.12}{M_{L}}
$$




$$
\begin{aligned}
R F_{3} & =\frac{8.12}{1.28}=6.3>1.0 \Rightarrow \text { Good } \\
R F_{3 S 2} & =\frac{8.12}{1.17}=6.9>1.0 \Rightarrow \text { Good } \\
R F_{3-3} & =\frac{8.12}{1.20}=6.8>1.0 \Rightarrow \text { Good } \\
R F_{H S 20} & =\frac{8.12}{2.40}=3.4>1.0 \Rightarrow \text { Good }
\end{aligned}
$$

\section{Military Load Class (MLC) for Deck}

- The figure below demonstrates that the deck will generally not be of concern for "Tracked" vehicles since the load is spread over the entire track length. Therefore, the MLC of the deck will only be obtained for "Wheeled" vehicles. The allowable Tracked class will be obtained in the Stringer Rating section. However, if the deck rating ends up controlling the overall bridge rating, the Engineer may want to check the track rating for the deck in more detail. In that case, use an "equivalent slab width" equal to the total track length instead of the normal 1-foot beam width as shown below. A conservative track rating for concrete decks will always be the same as the Wheel Class.

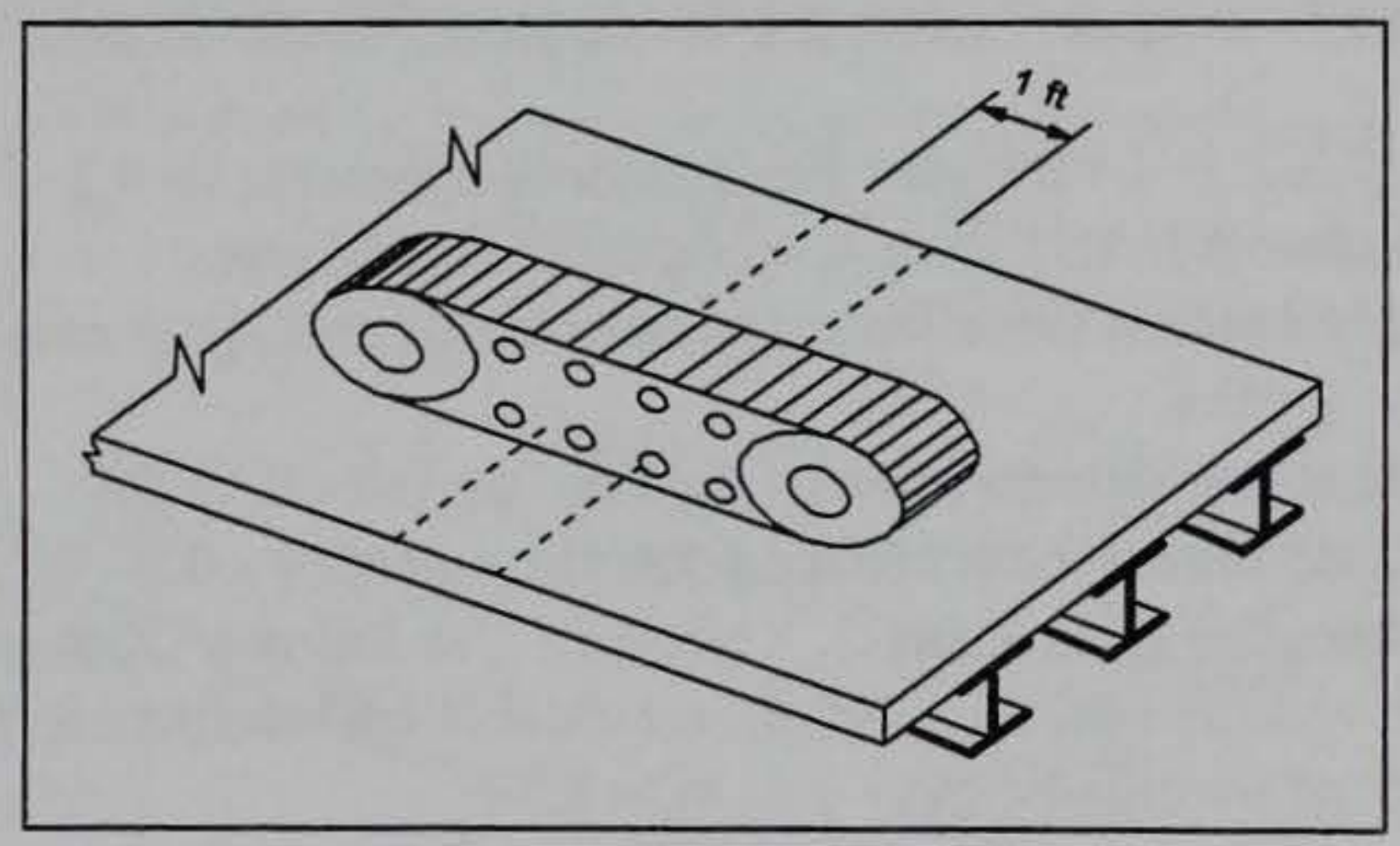

- Since with the LRFR method, a Rating Factor greater than 1.0 is satisfactory, the MLC can be obtained by setting the RF equation from the previous page equal to 1.0 and solving for $\mathrm{M}_{\mathrm{L}}$ as follows:

$$
\begin{aligned}
& R F=1.0=\frac{8.12}{M_{L}} \\
& M_{L}=8.12 \mathrm{ft} \cdot \mathrm{kip}
\end{aligned}
$$

- $M_{L}$ represents the distributed moment in the deck slab. It should now be used in the previous equation for slab moment (Par. 3.24.3.1, Reference 3) to solve for the maximum allowable wheel load, $\mathrm{P}_{\max }$, from a military vehicle as follows: 


$$
\begin{aligned}
& M_{L}=0.8 \frac{S+2}{32} * P \\
& \quad \text { or } \\
& P=P_{\max }=\frac{32 M_{L}}{0.8(S+32)}=\frac{32(8.12)}{0.8(4.0+2)}=54.1 \mathrm{kip}
\end{aligned}
$$

- The vehicle data given in Reference 5 are in terms of axle loads instead of wheel loads, and in units of tons instead of kips. Therefore, convert $P_{\max }$ :

$$
P_{\max }=54.1 \frac{\text { kips }}{\text { wheel }}\left(\frac{2 \text { wheels }}{\text { axle }}\right)\left(\frac{1 \text { ton }}{2 \text { kips }}\right)=54.1 \frac{\text { tons }}{\text { axle }}
$$

- Use Column $4^{*}$ of the Vehicle Data in Reference 5 to find the maximum allowable wheeled vehicle where any axle load does not exceed 54.1 tons.

Choose W150 with a heaviest axle of 42 tons, which is $<54.1$ tons

* Note that Column 4 of the Vehicle Data in Reference 5 is the most conservative since it lists the max. possible axle load for each particular load class. However, since we are using the LRFR method of rating, which accounts for possible overloads with the load factors $(\gamma)$, the use of Column 4 may be too conservative in some cases and the axle loads listed in Column 3 may be used instead. This decision must be made on an individual basis based on expected loadings and degree of control at the particular installation.

\section{Stringer Rating}

- Interior stringers generally control the rating and this will be assumed true herein. However, if in doubt, always check both interior and fascia stringers. - Sufficiency of connections and bearings are generally not considered in load ratings. However, if in doubt, check.

\section{Nominal Capacities of Stringer}

- Par. 3.3.2.4 of Reference 2 refers to Reference 3 for calculation of nominal resistance. It also states that the calculations should account for observable effects of deterioration, such as loss of steel cross-section area. For this example, the stringers are assumed to be in good condition with no notable deterioration. If necessary, stringer deterioration can be accounted for by reducing crosssectional area or $f_{y}$, and in the selection of Resistance Factors in Reference 2. - The bridge drawing (page 1) does not show shear connectors on top of the stringers. Therefore, the deck is assumed non-composite with the stringers for this example. This will generally be the case with truss bridges.

- The interior stringers are 10WF21 without cover plates or web stiffeners. From Reference 6 (Seventh Edition): 


$$
\begin{gathered}
A=6.20 \mathrm{in}^{2}, d=9.90 \text { in, } t_{w}=0.240 \text { in, } t_{f}=0.340 \text { in, } b_{f}=5.750 \text { in } \\
I_{X}=107 \text { in }^{4}, S_{X}=21.5 \mathrm{in}^{3}, Z_{X}=24.1 \mathrm{in}^{3}, r_{X}=4.15 \text { in }
\end{gathered}
$$

- The steel section described above comes from the current AISC manual where A36 steel has a $F_{y}=36 \mathrm{ksi}$. However, for this example, assume the yield strength is unknown. In that case, Par. 3.3.2.4, Reference2 refers to Par. 5.5.2, Reference 4 (also in Reference 1, Par. 6.6.2.1) which allows determination of yield strength based on the date built of the bridge. Since this bridge was built in 1957, Table 5.4.2.A, Reference 4 specifies $\mathrm{f}_{\mathrm{y}}=33 \mathrm{ksi}$.

- Note that for very old bridges, the steel members may no longer be listed in the current AISC manuals. In that case, consult older versions of the manual for section dimensions and properties.

Nominal Moment, $\mathrm{M}_{\mathrm{n}}$ :

- Check compact section criteria of Par. 10.48.1, Reference 3:

(a) Projecting compression flange element: Check that $\frac{b^{\prime}}{t_{f}} \leq \frac{2055}{\sqrt{F_{y}}}$

$$
\text { where } b^{\prime}=\frac{b_{f}-t_{w}}{2}=\frac{5.75-0.24}{2}=2.76
$$

$$
\frac{b^{\prime}}{t_{f}}=\frac{2.76}{0.34}=8.1<\frac{2055}{\sqrt{F_{y}}}=\frac{2055}{\sqrt{33,000}}=11.3 \Rightarrow \text { Good }
$$

(b) Web Thickness: Check that $\frac{D}{t_{w}} \leq \frac{19,230}{\sqrt{F_{y}}}$

$$
\text { where } D=d-2 t_{f}=9.9-2(0.34)=9.22 \text { in }
$$

$$
\frac{D}{t_{w}}=\frac{9.22}{0.24}=38.42<\frac{19,230}{\sqrt{F_{y}}}=\frac{19,230}{\sqrt{33,000}}=105.9 \Rightarrow \text { Good }
$$

(c) Lateral Bracing: Top flanges embedded in concrete, therefore fully braced.

- Because all of the above criteria are true, the stringers can be treated as braced and compact. Therefore:

$$
M_{n}=M_{u}=F_{y} \cdot Z_{x}=(33 \mathrm{ksi})\left(24.1 \mathrm{in}^{3}\right)\left(\frac{\mathrm{ft}}{12 \mathrm{in}}\right)=66.39 \mathrm{ft} \cdot \mathrm{kip}
$$

Nominal Shear, $\mathrm{V}_{\mathrm{n}}$ :

- From Par. 10.48.8.1, Reference 3, for sections without web stiffeners: 


$$
\begin{aligned}
V_{p} & =0.58 F_{y} D t_{w} \\
& =0.58(33,000 \mathrm{psi})(9.22 \mathrm{in})(0.24 \mathrm{in})\left(\frac{\mathrm{kip}}{1000 \mathrm{lb}}\right)=42.4 \mathrm{kip}
\end{aligned}
$$

- Check that Check that $\frac{D}{t_{w}} \leq \frac{6000 \sqrt{k}}{\sqrt{F_{y}}}$, where $\mathrm{k}=5$ for unstiffened girders:

$$
\begin{gathered}
\frac{D}{t_{w}}=\frac{9.22}{0.24}=38.4 \quad<\quad \frac{6000 \sqrt{k}}{\sqrt{F_{y}}}=\frac{6000 \sqrt{5}}{\sqrt{33,000}}=73.9 \Rightarrow \therefore \mathrm{C}=1.0 \\
V_{n}=V_{u}=C V_{p}=(1.0)(42.4)=42.4 \mathrm{kip}
\end{gathered}
$$

** Connections are normally designed to be stronger than the supported members and thus are generally not checked. They should be checked if questionable or showing signs of deterioration or distress.

\section{Applied Loading Effects on Stringers}

Dead Load, $\omega_{\mathrm{D}}$ :

- Par. 3.23.2.3.1.1, Reference 3: Sidewalk and curb poured monolithically, before slab cured. Therefore, only the exterior stringers are considered to carry these weights. Do not include these weights in dead load to interior stringers.

- Calculate dead load carried by a single stringer as follows:

Concrete Deck:

$\omega_{D}=$ thickness $(\mathrm{t}) *$ concrete unit wt. * Stringer Spacing $(\mathrm{S})$

$$
=(11.0 \mathrm{in})\left(150 \frac{\mathrm{lb}}{\mathrm{ft}^{3}}\right)(48.0 \mathrm{in})\left(\frac{\mathrm{ft}^{2}}{144 \mathrm{in}^{2}}\right)\left(\frac{1 \mathrm{kip}}{1000 \mathrm{lb}}\right)=0.550 \frac{\mathrm{kip}}{\mathrm{ft}}
$$

Stringer: From Reference 6 for a W10x21 shape, $\omega_{D}=0.021 \frac{\mathrm{kip}}{\mathrm{ft}}$

$$
\text { Total } \omega_{D}=0.571 \frac{k i p}{f t}
$$

Dead Load Moment, $\mathrm{M}_{\mathrm{D}}$ : For a simple span beam:

$$
M_{D}=\frac{\omega l^{2}}{8}=\frac{\left(0.571 \frac{k i p}{f t}\right)(10.0 f t)^{2}}{8}=7.14 \mathrm{ft} \cdot \mathrm{kip}
$$


Dead Load shear, $\mathrm{V}_{\mathrm{D}}$ : For a simple span beam:

$$
V_{D}=\frac{\omega l}{2}=\frac{\left(0.571 \frac{k i p}{f t}\right)(10.0 f t)}{2}=2.86 k i p
$$

Live Load:

- Live load moments and shears are those produced from the wheel lines of the rating vehicles on a 10 foot simple span. These can be obtained through basic structural analysis by placing the vehicle to produce maximum moments and shears, or more simply from Appendix A of Reference 1 (Refs. 3 and 4 also contain these values):

$$
\begin{aligned}
& M=(\text { max. moment per wheel line from App. A3) } \\
& M_{L_{3}}=27.2 \mathrm{ft} \cdot \mathrm{kip} \text { per wheel line } \\
& M_{L_{S S 2}}=24.8 \mathrm{ft} \cdot \mathrm{kip} \text { per wheel line } \\
& M_{L_{3-3}}=22.4 \mathrm{ft} \cdot \mathrm{kip} \text { per wheel line } \\
& M_{L_{H S 20}}=40.0 \mathrm{ft} \cdot \mathrm{kip} \text { per wheel line } \\
& V=(\text { max. shear per wheel line from App. A5) } \\
& V_{L_{3}}=13.6 \mathrm{kip} \text { per wheel line } \\
& V_{L_{S s 2}}=12.4 \mathrm{kip} \text { per wheel line } \\
& V_{L_{3-3}}=11.2 \mathrm{kip} \text { per wheel line } \\
& V_{L_{H S 20}}=16.0 \mathrm{kip} \text { per wheel line }
\end{aligned}
$$

\section{Stringer Rating Factors}

- As done for the deck, the Load and Resistance Factors are determined from Reference 2 as follows:

- Par. 3.3.2.3: I= Impact: Smooth approach; $\mathrm{I}=0.1$

- Calculate $\phi$ from Figure 4, Reference 2 as follows:

- Steel stringers redundant since failure of one will not cause failure of bridge: $\phi=0.95$

- Some minor deterioration of the stringers: $\phi=0.95-0.1=0.85$

- An intermittent maintenance program is used: $\phi=0.85-0.05=\underline{0.80}$

$-\gamma$ factors will be same as for the deck (from Table 2, Reference 2): $\gamma_{D}=$ $1.2, \gamma_{\mathrm{L}}=1.3$

- Stringer Distribution Factor (DF): From Par. 3.23.2.2, Reference 3, for concrete deck on steel I-beam stringers:

$$
\text { One - Way Traffic: } D F=\frac{S}{7.0}=\frac{4.0}{7.0}=0.57
$$


- Note that two-way traffic is not considered here. Article 3.6.1 of Reference 3 states that traffic lanes must be 12 feet wide. From the drawing on page 1 of this document, it is thus apparent that only one traffic lane exists.

- Now, plug values into the RF equations for both moment and shear:

$$
\text { Moment: } \begin{aligned}
R F_{M} & =\frac{\phi M_{n}-\gamma_{D} M_{D}}{\gamma_{L} M_{L}(1+I) D F} \\
& =\frac{0.80(66.39)-1.2(7.14)}{1.3 M_{L}(1+0.1) 0.57} \\
& =\frac{54.65}{M_{L}} \\
R F_{M_{3}} & =\frac{54.65}{27.2}=2.00 \\
R F_{M_{3 S 2}} & =\frac{54.65}{24.8}=2.21 \\
R F_{M_{3-3}} & =\frac{54.65}{22.4}=2.43 \\
R F_{M_{H S 20}} & =\frac{54.65}{40.0}=1.37
\end{aligned}
$$

Shear: $R F_{V}=\frac{\phi V_{n}-\gamma_{D} V_{D}}{\gamma_{L} V_{L}(1+I) D F}$

$$
\begin{aligned}
& =\frac{0.80(42.4)-1.2(2.86)}{1.3 V_{L}(1+0.1) 0.56} \\
& =\frac{38.07}{V_{L}} \\
R F_{V_{3}} & =\frac{38.07}{13.6}=2.80 \\
R F_{V_{3 S 2}} & =\frac{38.07}{12.4}=3.07 \\
R F_{V_{3-3}} & =\frac{38.07}{11.2}=3.40 \\
R F_{V_{H S 20}} & =\frac{38.07}{16.0}=2.38
\end{aligned}
$$

\section{MLC of Stringers}

- From the previous page, moment controls. Therefore, shear will be neglected here.

- Use the same procedure as for the deck; i.e. set RF equal to 1 and solve for $M_{L}$.

$$
\text { From previous page: } R F_{M}=1=\frac{54.65}{M_{L}} \text { or } M_{L}=54.65 \mathrm{ft} \cdot \mathrm{kip}
$$


- Since the MLC moment curves in Reference 5 are for the total vehicle (i.e. axle loads), the $\mathrm{M}_{\mathrm{L}}$ value must be multiplied by 2 since it represents the moment from a wheel line (see RF equation on previous page):

$$
M_{L_{\text {Total }}}=2 \cdot M_{L}=2(54.65)=109.3 \mathrm{ft} \cdot \mathrm{kip}
$$

- Use $M_{L_{\text {Total }}}$ to enter the wheeled and tracked vehicle moment curves of Reference 5 . Find the vehicles that produce $\leq M_{L_{\text {Total }}}$ on a 10 -foot span.

- From the curves, the MLC is $\underline{50 \mathrm{~W}}$ and $\underline{60 \mathrm{~T}}$ for one-way traffic.

- The above MLCs should be checked against the required lane widths listed in Table 3-3 of Reference 5. From the Table, a 13'-2" lane width is required for class 50 and 60 vehicles and only a 12' width is available. According to Reference 5, the MLC should be adjusted downward due to this limitation. However, this should be done only at the judgment of the Engineer based on the actual vehicles expected over the bridge since many military vehicles are actually narrower than listed in the Table. If necessary, a separate width limitation may be posted on the bridge.

- Remember that in most cases, a two-way traffic rating must also be determined. But in this case, the deck is too narrow.

\section{Floor Beam Rating}

- Both end and intermediate floor beams are the same. Normally should check both if they differ.

- The floor beams are W21 x 62 without cover plates or stiffeners. From Reference 6:

$$
\begin{array}{ll}
I_{X}=1330 & A=18.3 \\
S_{X}=127 & Z_{X}=144 \\
R_{X}=8.54 & Z_{Y}=21.7
\end{array}
$$

\section{Nominal Capacity of Floor Beam}

$$
F_{y}=33 k s i \text { due to } 1957 \text { date built, Table 5.4.2.A, Reference } 4
$$

\section{Nominal Moment, $\mathbf{M}_{\mathbf{n}}$}

- Although not shown here, the W21x62 floor beams meet compact section and lateral bracing criteria of Art. 10.48.1, Reference 3. The equations for this criteria were demonstrated previously in the "Stringer" section of this analysis.

$$
\therefore M_{n}=M_{u}=F_{y} \cdot Z_{X}=(33 \mathrm{ksi})(144 \mathrm{in})\left(\frac{\mathrm{ft}}{12 \mathrm{in}}\right)=396.0 \mathrm{ft} \cdot \mathrm{kip}
$$

* Shear check is not shown herein, but should normally be made as done for the stringers. 
** Connections are normally designed to be stronger than the supported members and thus are generally not checked. They should be checked if questionable or showing signs of deterioration or distress.

\section{Applied Loading Effects on Floor Beams}

Dead Load $\left(\omega_{D}\right)$ :

Conc. Deck (neglect parapets since they are near the ends of the floor beams):

$$
\begin{aligned}
\omega_{D} & =\text { thickness }(\mathrm{t}) \cdot \text { floorbeam spacing } \cdot \omega_{C} \\
& =(10 \mathrm{in})(10 \mathrm{ft})\left(150 \frac{\mathrm{lb}}{\mathrm{ft}^{3}}\right)\left(\frac{\mathrm{ft}}{12 \mathrm{in}}\right) \\
& =1250 \frac{\mathrm{lb}}{f t}
\end{aligned}
$$

Stringers (spread out over length of floorbeam):

$\omega_{D}=\frac{\text { (wt. per foot of stringer })(\text { floor beam spacing })(\text { no. of stringers })}{\text { floor beam length }}$

$$
\begin{aligned}
& =\frac{\left(21 \frac{\mathrm{lb}}{f o o t}\right)(10 f t)(4)}{16.5 \mathrm{ft}} \\
& =51.0 \frac{\mathrm{lb}}{\mathrm{ft}}
\end{aligned}
$$

Floorbeam: W21x62:

$$
\begin{aligned}
& =62.0 \frac{\mathrm{lb}}{\mathrm{ft}} \\
& =1360 \frac{\mathrm{lb}}{\mathrm{ft}}=1.36 \frac{\mathrm{kip}}{\mathrm{ft}}
\end{aligned}
$$

Dead Load Moment, $\mathrm{M}_{\mathrm{D}}$ :

$$
M_{D}=\frac{w l^{2}}{8}=\frac{\left(1.36 \frac{k i p}{f t}\right)(16.5 f t)^{2}}{8}=46.4 \mathrm{ft} \cdot \mathrm{kip}
$$

Live Load Moment:

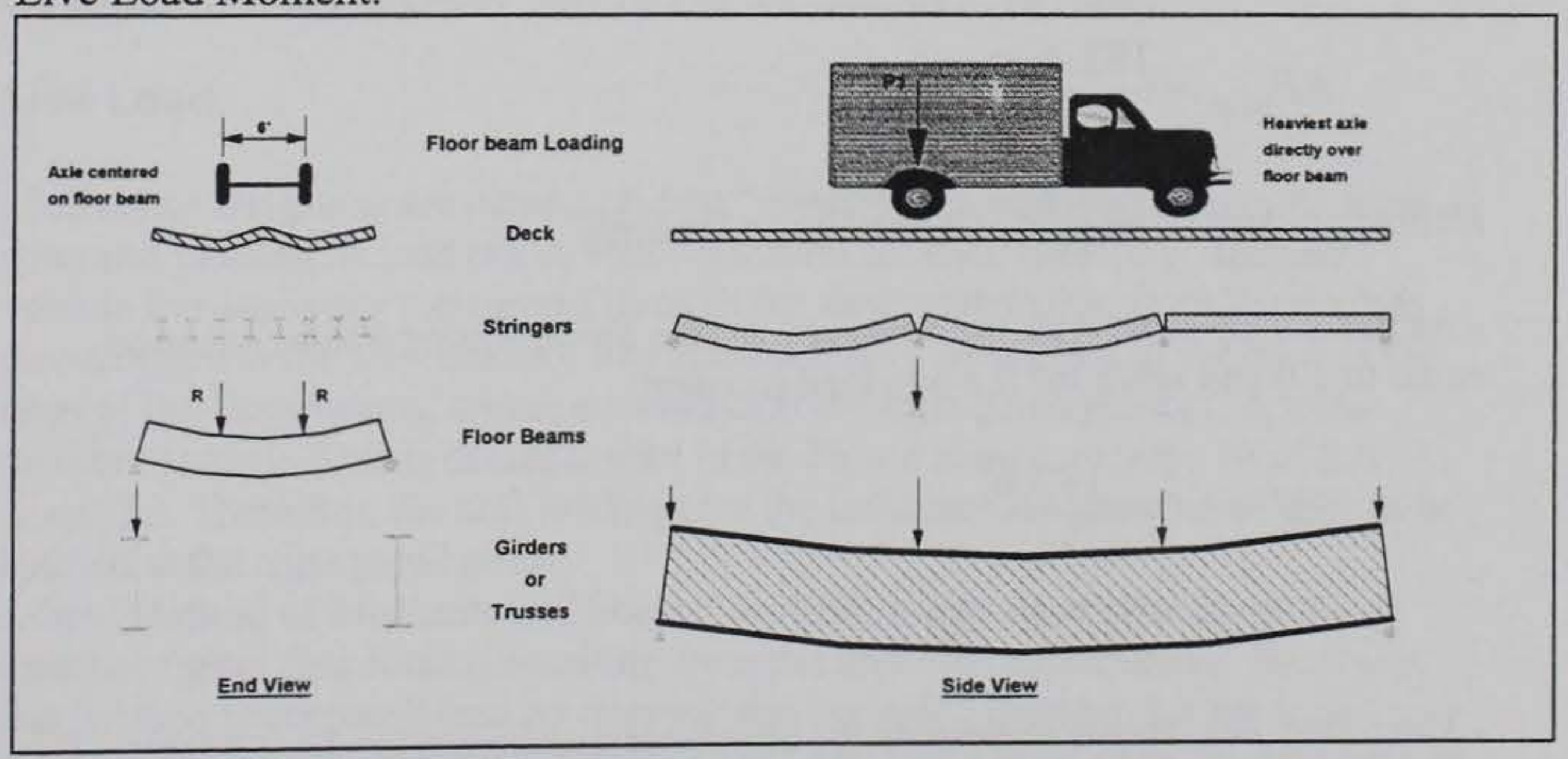


- From the diag. above, it can be seen that the worst case floor beam loading is produced by placing the rating vehicle in the longitudinal position for the greatest shear reaction and laterally for the highest bending moment in the floor beam. This can be done as shown above, or the aids in App. A4, p.81, Reference 1 can be used, as was done herein.

-From the Table, w/stringer span $=10 \mathrm{ft}$, the line load reactions $(\mathrm{R})$ per wheel line are (in kips):

$$
\frac{\text { Type } 3}{13.6 \mathrm{kip}} \quad \frac{\text { Type } 3 \mathrm{~S} 2}{12.4 \mathrm{kip}} \quad \frac{\text { Type } 3-3}{11.2 \mathrm{kip}} \quad \frac{\mathrm{HS} 20}{16.0 \mathrm{kips}}
$$

-From the formulas on the same page, for a singe lane loading:

$$
\begin{gathered}
\mathrm{M}=\text { max. mom. in floor beam }=\frac{(L-3)^{2} R}{2 L}=\frac{(16.5-3)^{2} R}{2(16.5)}=5.52 R \\
\frac{\text { Type } 3}{75.1 \mathrm{ft} \cdot \mathrm{kip}} \quad \frac{\text { Type } 3 \mathrm{~S} 2}{68.4 \mathrm{ft} \cdot \mathrm{kip}} \frac{\text { Type } 3-3}{61.8 \mathrm{ft} \cdot \mathrm{kip}} \frac{\mathrm{HS} 20}{88.3 \mathrm{ft} \cdot \mathrm{kip}}
\end{gathered}
$$

\section{Floor Beam Rating Factors}

As for the stringers: $\mathrm{I}=0.1 ; \phi=0.8 ; \gamma_{\mathrm{D}}=1.2 ; \gamma_{\mathrm{L}}=1.3$

$$
\begin{aligned}
& R F=\frac{\phi \mathrm{M}_{\mathrm{n}}-\gamma_{D} \mathrm{M}_{\mathrm{D}}}{\gamma_{L} M_{L}(1+I)}=\frac{0.8(396.0)-1.2(46.4)}{1.3 \mathrm{M}_{\mathrm{L}}(1.1)}=\frac{182.6}{\mathrm{M}_{\mathrm{L}}} \\
& R F_{3}=\frac{182.6}{75.1}=2.43 \\
& R F_{3 \mathrm{~S} 2}=\frac{182.6}{68.4}=2.67 \\
& R F_{3-3}=\frac{182.6}{61.8}=2.95 \\
& R F_{\mathrm{HS} 20}=\frac{182.6}{88.3}=2.07
\end{aligned}
$$

\section{Military Load Class (MLC) for Floor Beams}

- As previously done with the stringers, set the above Rating Factor equation equal to 1.0 and solve for the live load moment:

$$
\begin{aligned}
& R F=1.0=\frac{182.6}{M_{L}} \\
& \therefore M_{L}=182.6 \mathrm{ft} \cdot \mathrm{kip}
\end{aligned}
$$

- The value,$M_{L}$, above represents the allowable moment in the floor beams. The wheel or track line reactions which cause this moment can be determined by 
solving the previously-shown floor beam moment equation (from App. A4, p.81, Reference 1) for the reactions, $R$, as follows:

$$
\begin{aligned}
& M_{L}=182.6=\frac{(L-3)^{2} R}{2 L}=\frac{(16.5-3)^{2} R}{2(16.5)} \\
& \therefore R=34.8 \mathrm{kip}
\end{aligned}
$$

- As seen in the previous Figure, $R$ represents the wheel (or track) line reaction which will produce that maximum allowable bending moment. With this value of $R$, use the attached transverse floor beam curves to find the Wheeled and Tracked military vehicles that cause a reaction less than or equal to $R$, with a floor beam spacing of 10 feet:

From the Charts: The MLC is $\underline{\mathrm{W} 70}$ and $\underline{\mathrm{T} 50}$

Note that the Tracked rating for the floor beams is lower than that for the stringers and thus controls, even though the stringers controlled the ratings for all of the civilian loadings. This demonstrates the importance of always checking the MLC even when the civilian ratings do not control for that particular element.

\section{Truss Rating}

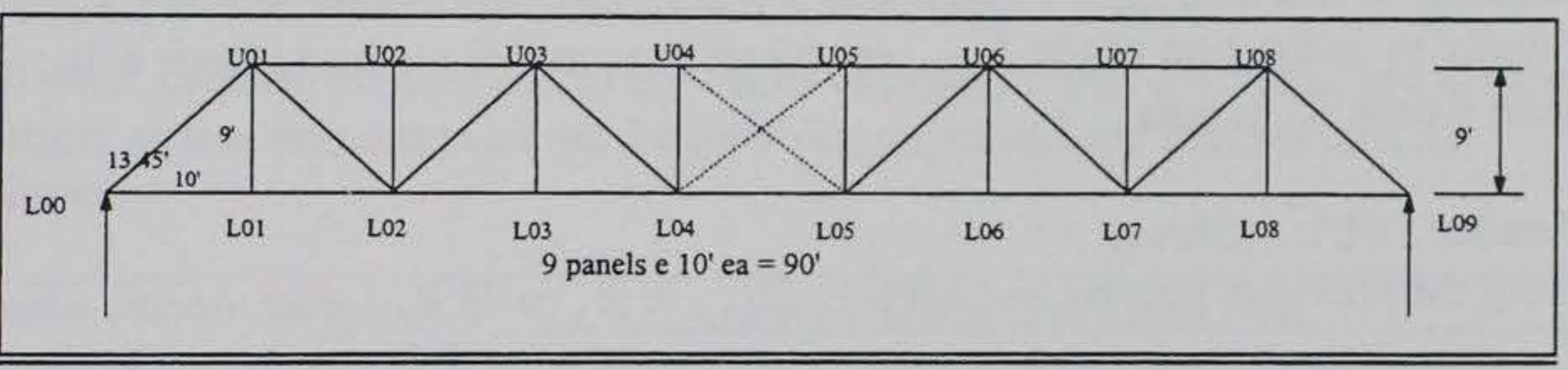

- Truss rating is very tedious because each truss member and its worst-case loading must be considered separately. Therefore, a truss rating is basically like performing $\mathrm{x} * \mathrm{y}$ separate load ratings, where " $\mathrm{x}$ " is the number of truss members and " $y$ " is the number of live load vehicles desired. This process is made simpler by use of Influence Diagrams as demonstrated herein. In addition, most trusses are symmetric and therefore only half of the truss must be rated.

\section{Live Load}

- Influence Diagrams are constructed by "marching" a unit load across the truss span and plotting its load effect versus location for each member. Because vehicle live loads are transferred through the deck system (i.e. from the deck to the stringers to the floorbeams), live loads can only be applied to the truss at the ends of the floor beams, which are always at the truss panel points (i.e. truss member joints). This is demonstrated in the Figure shown on page 14 of this example. Therefore, the unit loadings for the Influence diagrams need only to be applied at the truss panel points.

- The "Method of Moments and Shears" will be used to determine the truss member forces (bar forces) resulting from the unit load applications. Basically, this method is accomplished by drawing the free-body diagram for the truss member being considered and then deciding whether a summation of moments or 
shears will provide the unknown bar force. (Hint: Only the upper and lower chord can use the method of moments) This process is demonstrated below:

Member U1L0: (Shear)
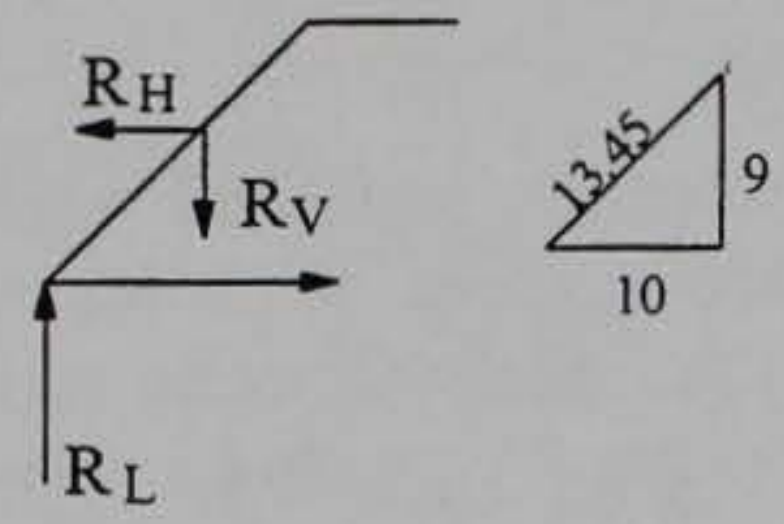

By similar triangles

$$
\begin{array}{ll}
\frac{R_{V}}{9}=\frac{F_{\mathrm{U} 1 \mathrm{~L} 0}}{13.45} & \frac{R_{H}}{10}=\frac{R_{V}}{9} \\
F_{\mathrm{U} 1 \mathrm{~L} 0}=1.49 R_{V} & R_{H}=\frac{10}{9} R_{V}
\end{array}
$$

and $\sum F_{v}=0$

$$
\therefore R_{V}=R_{L}
$$

For the Unit Load @ L0: $\quad F_{\text {UiL0 }}=0$

For the Unit Load @ L1: Solve for beam reactions: $R_{L}=R_{V}=\frac{8}{9}$;

Then, from the equation above: $F_{\mathrm{U} 1 L 0}=1.49\left(\frac{8}{9}\right)=-1.32 C$

For the Unit Load @ $L 2: R_{L}=R_{V}=\frac{7}{9}$; Then $F_{\text {U1L } 0}=1.49\left(\frac{7}{9}\right)=-1.16 C$

Continue w/unit load until a maximum is found; i.e. -max. value here is 1.32 , or actually by inspection of the $F_{\text {UILD }}$ eq. it can be seen that the max. force will occur where $R_{L}$ is max.

Member LOL1: (Shear)

Using the previous free-body diagram: $F_{\mathrm{LOLI}}=R_{H}=\frac{10}{9} R_{V} ; \max$. occurs where $R_{L}$ is maximum (i.e. at $\mathrm{L}_{01}$ ).

For the Unit Load @ $L 1: \quad R_{L}=R_{V}=\frac{8}{9} ; F_{\text {L0L1 }}=\frac{10}{9}\left(\frac{8}{9}\right)=+0.99 T$

Member U1L1: By Inspection:

$$
\begin{aligned}
F_{\text {UIL1 }} & =0 \text { for load @ L } 0 \\
& =1.0 \text { forload @ L1 } \\
& =0 \text { forload @ L2 and beyond }
\end{aligned}
$$

Member U1L2: (Shear)

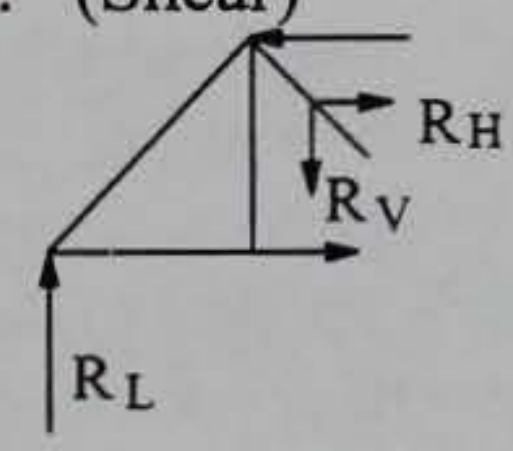

As above: $F_{\mathrm{UIL2}}=1.49 R_{V}, R_{H}=\frac{10}{9} R_{V}$

For Unit Load @ $L 1: R_{L}=\frac{8}{9}$;

$\Sigma F @ U 1=0=1.0-\frac{8}{9}+R_{V} \Rightarrow R_{V}=-0.11$

$\therefore F_{\mathrm{UIL} 2}=1.49(-.11)=-.17 \mathrm{C}$

For Unit Load @ $L 2: R_{L}=\frac{7}{9}$, since $U 1 L 1=0$, then

$$
R_{V}=\frac{7}{9} \Rightarrow F_{\mathrm{U} 1 \mathrm{~L} 2}=1.49\left(\frac{7}{9}\right)=+1.16 T
$$


Member U1U2: (Moment)

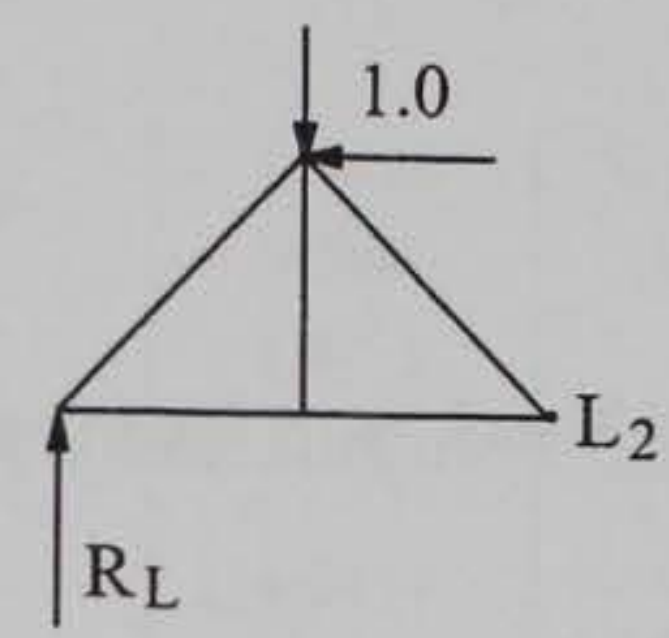

For Unit Load @ $L 1: R_{L}=\frac{8}{9}$;

$\Sigma \mathrm{M}_{\mathrm{L} 2}=0=\frac{8}{9}(20)-1.0(10)-\mathrm{F}_{\mathrm{U} 1 \mathrm{U} 2}(9)$

$\mathrm{F}_{\mathrm{U} 1 \mathrm{U} 2}=-0.86 \mathrm{C}$

For Unit Load @ $L 2: R_{L}=\frac{7}{9} ; \Sigma \mathrm{M}_{\mathrm{L} 2}=0=\frac{7}{9}(20)-\mathrm{F}_{\mathrm{U} 1 \mathrm{U} 2}(9)$

$\mathrm{F}_{\mathrm{U} 1 \mathrm{U} 2}=-1.73 C$

For Unit Load @ $L 3: R_{L}=\frac{6}{9} ; \Sigma \mathrm{M}_{\mathrm{L} 2}=0=\frac{6}{9}(20)-\mathrm{F}_{\mathrm{U} 1 \mathrm{U} 2}(9)$

$\mathrm{F}_{\mathrm{U} 1 \mathrm{U} 2}=-1.48 \mathrm{C}$

\section{Summary}

All other member forces (due to unit loads at panel points) are found in a similar manner as that demonstrated on the previous pages and are summarized as follows:

\begin{tabular}{|l||c|c|c|c|c|}
\hline \multicolumn{1}{|c||}{ Member } & \multicolumn{5}{c|}{ Force When Unit Load is at: } \\
\cline { 2 - 6 } & L1 & L2 & L3 & L4 & L5 \\
\hline \hline U1L0 & -1.32 & -1.16 & & & \\
\hline L0L1 & +0.99 & & & & \\
\hline U1L1 & 1.0 & 0 & 0 & 0 & 0 \\
\hline U1L2 & -0.17 & +1.16 & & & \\
\hline U1L2 & -0.86 & -1.73 & -1.48 & & \\
\hline L1L2 & 0.99 & & & & \\
\hline U2L2 & 0 & 0 & 0 & 0 & 0 \\
\hline U4L4 & 0 & 0 & 0 & 0 & 0 \\
\hline U3L3 & 0 & 0 & 1.0 & 0 & 0 \\
\hline U3L2 & 0.16 & -0.33 & -0.99 & -0.82 & \\
\hline U2U3 & -0.86 & -1.73 & -1.48 & & \\
\hline L2L3 & 0.74 & 1.48 & 2.22 & & \\
\hline U3L4 & & & -0.50 & +0.83 & \\
\hline U3U4 & & & -1.85 & -2.47 & \\
\hline U4U5 & & & -1.85 & -2.47 & -2.47 \\
\hline L4L5 & & & & 1.98 & 1.98 \\
\hline U4L5 & 0 & 0 & 0 & 0 & 0.66 \\
\hline U5L4 & 0 & 0 & 0 & 0.66 & 0 \\
\hline
\end{tabular}

From the above Table, group members with similar forces in order to minimize number of Influence Diagrams required: 
LOL1, L1L2

U1U2, U2U3

U2L2, U4L4

U3U4, U4U5

\section{Influence Diagrams and Maximum Member Forces Due to Live Loads}

Truss Distribution Factor:

- The portion of live load that goes into each truss is very dependent upon how close the live load can get to the truss. This is determined by the curb widths on the deck, the allowable distance of the vehicles from the curb, the number of traffic lanes, and the center-to-center spacing of the truss compared to the roadway width. Figure 6.7.2.1 of Reference 1 stipulates that wheel loads should not be closer than $2.0^{\prime}$ from curbs. Article 6.7.2.2 stipulates that roadways less than 18 feet wide carry only one lane. Based on these criteria, the DF is determined specifically for the truss in this example as follows:

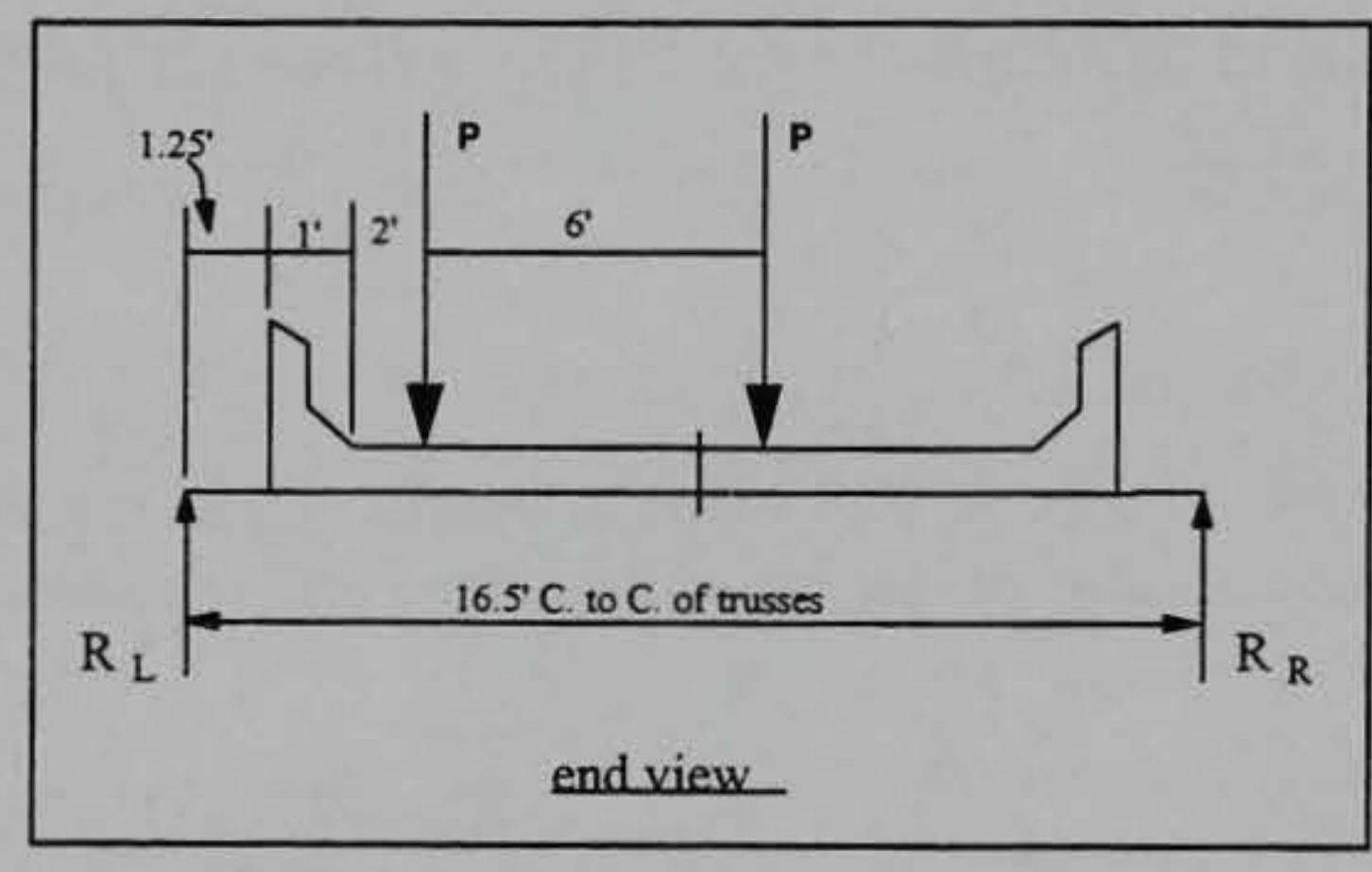

$$
\begin{gathered}
\Sigma \mathrm{M}_{\mathrm{RL}}=0=P(3.25+9.25)-R_{R}(16.5) \\
R_{R}=0.88 P \\
R_{L}=2 P-.88 P=1.12 P \Rightarrow \operatorname{Max} .
\end{gathered}
$$

Therefore, $D F=\underline{1.12}$ for wheel line loads or 0.56 for axle loads

\footnotetext{
***Note: DFs can be determined as done above, or more simply, the equations on page 81 of Appendix A of Reference 1 may be used.

Impact Factor: Same as floor membranes, $\mathrm{I}=0.1$

Influence Diagrams: The live load Influence Lines resulting from all of the above calculations are shown in the attached influence diagrams for each truss member.
} 
Dead Load Calculations

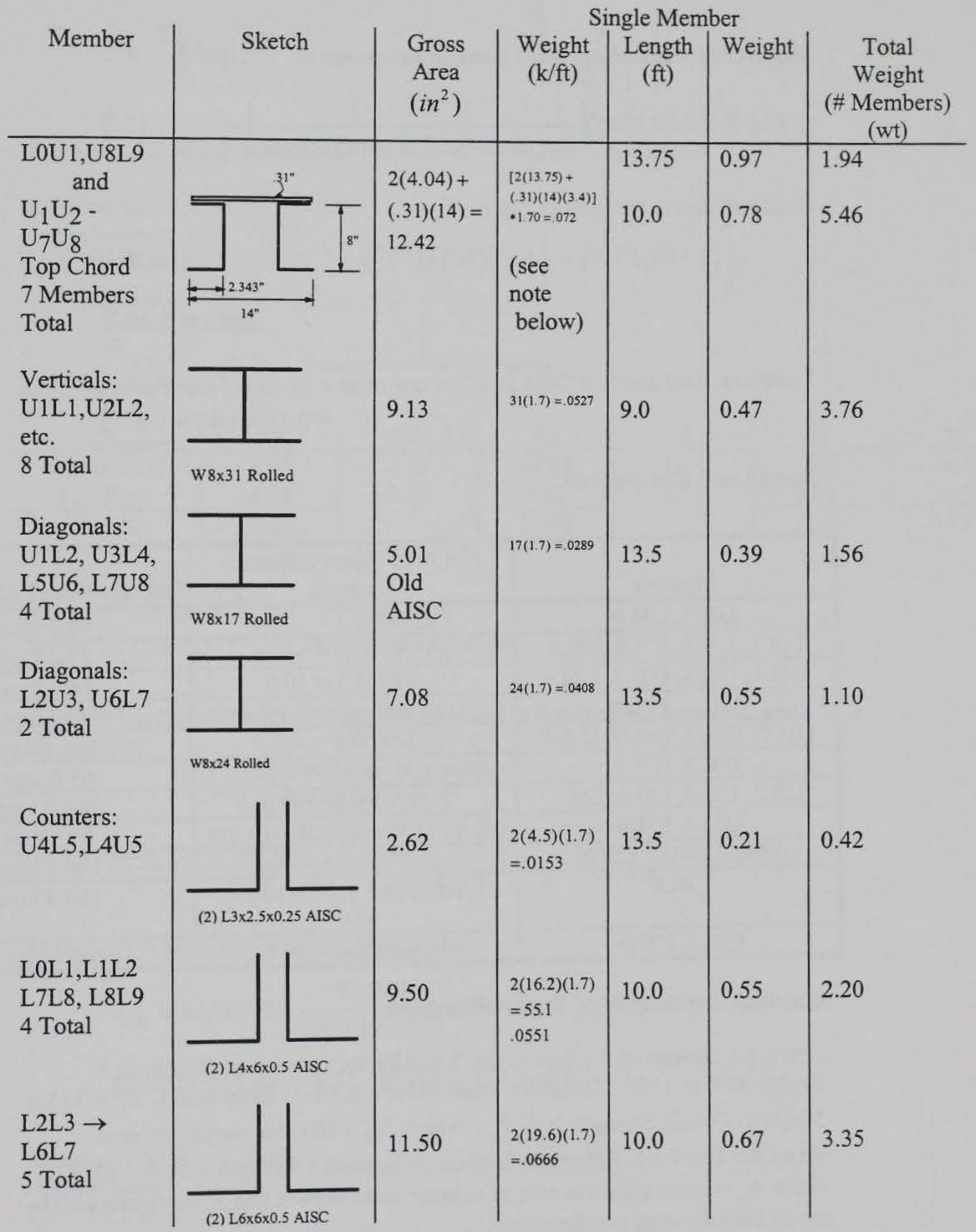

Total weight of Truss $=19.79 \mathrm{kips} \quad$ Uniform Load of Truss $=\frac{19.79}{90}=0.22 \frac{\mathrm{kip}}{\mathrm{ft}}$

Note: Weights are increased by $70 \%$ to account for gussets, rivets, etc. This may be too conservative and is at the discretion of the Engineer. 


\section{Truss Dead Load Due To Floor \& Deck System}

-From floorbeam rating, Dead Load on floorbeam $=1.36 \frac{\mathrm{kip}}{\mathrm{ft}}$ :

$\therefore 1.36 \frac{\mathrm{kip}}{\mathrm{ft}}(16.5 \mathrm{ft}$ span $)\left(\frac{1}{2 \text { trusses }}\right)\left(\frac{1}{10 \mathrm{ft} \text { panel length }}\right)=1.12 \frac{\mathrm{kip}}{\mathrm{ft}}$

-Addition due to parapets on deck:

$$
\left[(2.5 f t)(.67 f t)+\frac{1}{2}(.33)(1.0)\right] .150 \frac{k i p}{f t^{3}}=\quad \quad \text { Total }=\frac{0.28 \frac{k i p}{f t}}{1.40 \frac{k i p}{f t}}
$$

Therefore, total uniform Dead Load on one truss $=$ Truss + Floor System + Deck

$$
=0.22+1.40=\underline{1.62 \frac{\mathrm{kip}}{\mathrm{ft}}}
$$

\section{Dead Load Bar Forces}

\begin{tabular}{||c|c|c|}
\hline Member & $\begin{array}{c}\text { Net Area Under Influence } \\
\text { Diagram }\end{array}$ & Bar Force $=(1.62)$ (Net Are \\
\hline \hline L0U1, U8L9 & $1.32\left(90^{\prime}\right) 0.5=-59.4$ & $96.2 \mathrm{kips}(\mathrm{C})$ \\
\hline L0L1, L1L2, L7L8, L8L9 & $0.99\left(90^{\prime}\right) 0.5=-44.6$ & $72.2 \mathrm{kips}(\mathrm{C})$ \\
\hline U1L1, U8L8, U3L3, U6L6 & $1.0\left(20^{\prime}\right) 0.5=10.0$ & $16.2 \mathrm{kips}(\mathrm{T})$ \\
\hline U1L2, L7U8 & $0.5\left[(1.16)\left(78.7^{\prime}\right)-(0.17)\left(11.3^{\prime}\right)\right]=44.7$ & $72.4 \mathrm{kips}(\mathrm{T})$ \\
\hline U1U2, U2U3, U6U7, U7U8 & $-1.73(90) 0.5=-77.9$ & $126.1 \mathrm{kips}(\mathrm{C})$ \\
\hline U3L2, U6L7 & $0.5[0.16(12.8)-(0.99)(77.2)]=-39.2$ & $63.6 \mathrm{kips}(\mathrm{C})$ \\
\hline L2L3, L3L4, L5L6, L6L7 & $2.22\left(90^{\prime}\right) 0.5=99.9$ & $161.8 \mathrm{kips}(\mathrm{T})$ \\
\hline U3L4, L5U6 & $0.5[-0.5(33.76)+(0.83)(56.24)]=31.8$ & $51.5 \mathrm{kips}(\mathrm{T})$ \\
\hline U3U4, U4U5, U5U6 & $2.47\left(90^{\prime}\right) 0.5=-111.2$ & $180.1 \mathrm{kips}(\mathrm{C})$ \\
\hline L4L5 & $1.98\left(80^{\prime}\right) 0.5+1.98\left(10^{\prime}\right)=$ & $160.4 \mathrm{kips}(\mathrm{T})$ \\
\hline \multicolumn{2}{|c|}{99.0} & $26.7 \mathrm{kips}(\mathrm{T})$ \\
\hline U4L5, L4U5 & $0.66\left(50^{\prime}\right) 0.5=16.5$ & \\
\hline \multicolumn{2}{|c|}{}
\end{tabular}

\section{Nominal Capacities of Truss Members}

-Art. 6.6.3, Reference 1 refers to the "Load Factor" section of Reference 3

-Bridge built in 1957. Therefore, from Table 6.6.2.1-1, Reference 1, $F_{y}=33 \mathrm{ksi}$

-Nominal Tensile Strength $=A_{n} F_{y}$, where $A_{n}=$ Net cross-sectional area

-From Art 10.54.1.1, Reference 3: Max. compressive Strength $=P_{u}=0.85 \mathrm{~A}_{s} F_{c r}$ where $A_{s}=$ gross effective area of column cross section and $F_{c r}$ is determined by one of the following two formulas:

$$
\text { For } \frac{\mathrm{KL}_{\mathrm{C}}}{\mathrm{r}} \leq \sqrt{\frac{2 \pi^{2} E}{F_{y}}}, \quad F_{c r}=F_{y}\left[1-\frac{F_{y}}{4 \pi^{2} E}\left(\frac{K L_{C}}{r}\right)^{2}\right] \text { (eq. 1) }
$$




$$
\text { For } \left.\frac{\mathrm{KL}_{\mathrm{C}}}{r}\right\rangle \sqrt{\frac{2 \pi^{2} E}{F_{y}}} \quad, \quad F_{c r}=\pi^{2} E\left(\frac{1}{\left(\frac{K L_{C}}{r}\right)^{2}}\right)
$$

-From Art. 10.54.1.2, Reference 3: $\mathrm{K}=0.75$ for riveted connections

Members L0U1, U8L9:

Compression

$L_{C}=13.45^{\prime}=161.4 \mathrm{in}$

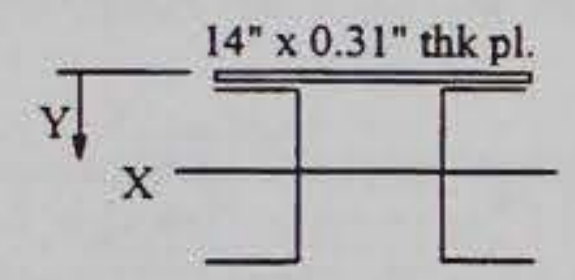

(2) C8x13.75 - Refer to AISC for Properties

\begin{tabular}{|c|c|c|c|c|c|c|}
\hline & $\mathrm{A}\left(\mathrm{in}^{2}\right)$ & $y$ (in) & Ay & d & $I_{0}$ & $\mathrm{Ad}^{2}$ \\
\hline (2) $\mathrm{C} 8 \times 13.75$ & 8.08 & \multirow{3}{*}{$\begin{array}{l}4.31 \\
0.16\end{array}$} & 34.82 & \multirow{3}{*}{$\begin{array}{l}1.14 \\
2.71\end{array}$} & 72.2 & 10.50 \\
\hline Top Plate & 4.34 & & 0.67 & & 0.035 & 31.87 \\
\hline Totals & 12.42 & & 35.49 & & 72.24 & 42.37 \\
\hline
\end{tabular}

$$
\begin{aligned}
& \bar{y}=\frac{\Sigma \mathrm{Ay}}{\Sigma \mathrm{A}}=\frac{35.49}{12.42}=2.86 \mathrm{in} \\
& \mathrm{I}_{\text {total }}=\Sigma\left(\mathrm{I}_{0}+\mathrm{Ad}^{2}\right)=72.24+42.37=114.6 \mathrm{in}^{4}
\end{aligned}
$$

-Assume buckling will occur about the $\mathrm{x}$-axis, If in doubt check both axes and take smaller.

$$
\begin{gathered}
r_{x}=\sqrt{\frac{\mathrm{I}_{\mathrm{x}}}{\mathrm{A}}}=\sqrt{\frac{114.61}{12.42}}=3.0 \mathrm{in} \\
\frac{\mathrm{KL}_{\mathrm{C}}}{\mathrm{r}}=\frac{.75(161.4 \mathrm{in})}{3.0 \mathrm{in}}=40.4<\sqrt{\frac{2 \pi^{2} E}{F_{y}}}=\sqrt{\frac{2 \pi^{2}\left(29 \cdot 10^{6} \mathrm{psi}\right)}{33,000 \mathrm{psi}}}=131.7
\end{gathered}
$$

$\therefore$ Use eq.(1) from above for buckling stress:

$$
\begin{aligned}
& \mathrm{F}_{\mathrm{CR}}=33,000\left[1-\frac{33,000}{4 \pi^{2}\left(29 \cdot 10^{6}\right)}(40.4)^{2}\right]=31,447 p s i \\
& \mathrm{P}_{\mathrm{u}}=0.85\left(12.42 \mathrm{in}^{2}\right)\left(31,447 \frac{\mathrm{lb}}{\mathrm{in}^{2}}\right)=332 \mathrm{kips}(\mathrm{C})
\end{aligned}
$$

Members U1U2 $\rightarrow$ U7U8:

\section{Compression}

$$
\mathrm{L}_{\mathrm{C}}=10.0 \mathrm{ft}=120 \mathrm{in}
$$

-same properties as L0U1 and U8L9: $r_{x}=3.0$ in

$$
\frac{\mathrm{KL}_{\mathrm{C}}}{r}=\frac{.75(120)}{3.0}=30.0<131.7
$$




$$
\begin{aligned}
& \mathrm{F}_{\mathrm{CR}}=33,000\left[1-\frac{33,000}{4 \pi^{2}\left(29 \cdot 10^{6}\right)}(30.0)^{2}\right]=32,144 \mathrm{psi} \\
& \mathrm{P}_{\mathrm{U}}=.85(12.42)(32,144)=339 \mathrm{kips}(\mathrm{C})
\end{aligned}
$$

Vertical Members U1L1,U2L2, etc.:

Tension

$$
\begin{aligned}
& \mathrm{L}_{\mathrm{C}}=9.0 f t=108 \mathrm{in} \\
& \text { W8x31 with Net Area }=9.13 \mathrm{in}^{2} \\
& \mathrm{~T}_{\mathrm{u}}=\mathrm{A}_{\mathrm{n}} \mathrm{F}_{\mathrm{y}}=\left(9.13 \mathrm{in}^{2}\right)(33,000 \mathrm{psi})=301 \mathrm{kips}(T)
\end{aligned}
$$

- Other nominal capacities calculated similarly and summarized as follows:

\begin{tabular}{|l|c|}
\hline \multicolumn{1}{|c|}{ Member } & Nominal Capacity (kips) \\
\hline \hline L0U1, U8L9 & $332(\mathrm{C})$ \\
\hline U1U2 $\rightarrow$ U7U8 & $339(\mathrm{C})$ \\
\hline Verticals: U1L1, U2L2, etc. & $301(\mathrm{~T})$ \\
\hline $\begin{array}{l}\text { Diagonals: U1L2, U3L4, L5U6, } \\
\text { L7U8 }\end{array}$ & $165(\mathrm{~T})$ \\
\hline Diagonals: L2U3, U6L7 & $166(\mathrm{C})$ \\
\hline Counters: U4L5, L4U5 & $72(\mathrm{~T})$ \\
\hline L0L1, L1L2, L7L8, L8L9 & $289(\mathrm{~T})$ \\
\hline L2L3 $\rightarrow$ L6L7 & $365(\mathrm{~T})$ \\
\hline
\end{tabular}

\section{Truss Rating Factors}

-Basic Equation from Art. 6.5, Reference 1:

$$
R F=\frac{C-A_{1} D}{A_{2} L(1+I)}
$$

where, based on the LRFR Method (Reference 2):

$$
\begin{aligned}
& \left.C=\phi P_{u} \text { or } \phi T_{u}, \text { where } \phi=0.8 \text { (Reference } 2\right) \\
& \mathrm{A}_{1}=1.2 \\
& \mathrm{~A}_{2}=1.3 \\
& \mathrm{D}=\text { Dead Load bar force } \\
& \mathrm{L}=\text { Live Load bar force } \\
& \mathrm{I}=\text { Impact (already included in truss Live Load calcs.) } \\
& \therefore R F=\frac{0.8 C-1.2 D}{1.3 L}
\end{aligned}
$$

Members LOU1 and U8L9: $\quad R F=\frac{0.8(332)-1.2(96.2)}{1.3 L}=\frac{115.5}{L}$

$$
\text { for Type } 3 \text { Vehicle : } \quad R F=\frac{115.5}{36.9}=3.1
$$


for Type 3S2 Vehicle: $R F=\frac{115.5}{44.9}=2.6$

for Type 3-3 Vehicle: $R F=\frac{115.5}{45: 6}=2.5$

for Type HS20 Vehicle: $R F=\frac{115.5}{51.7}=2.2$

- Summarizing for all members:

Live Load Force / Rating Factor

\begin{tabular}{l|l|l|c|c|c|c}
\multicolumn{1}{c|}{ Member } & $\begin{array}{c}\text { Nom. } \\
\text { Cap. }\end{array}$ & $\begin{array}{c}\text { DL } \\
\text { Force }\end{array}$ & Type 3 & Type 3S2 & Type 3-3 & HS20 \\
\hline L0U1, U8L9 & $332 \mathrm{C}$ & 96.2 & $36.9 / 3.1$ & $44.9 / 2.6$ & $45.6 / 2.5$ & $57.7 / 2.2$ \\
U1L1,U8L8,U3L3,U6L6 & $301 \mathrm{~T}$ & 16.2 & $19.8 / 8.6$ & $18.1 / 9.4$ & $16.3 / 10.4$ & $23.3 / 7.3$ \\
U1L2, L7U8 & $165 \mathrm{~T}$ & 72.4 & $31.9 / 1.1$ & $37.7 / 0.9$ & $37.6 / 0.9$ & $44.6 / 0.8$ \\
U1U2,U2U3,U6U7,U7U8 & $339 \mathrm{C}$ & 126.1 & $47.6 / 1.9$ & $56.8 / 1.6$ & $57.1 / 1.6$ & $66.4 / 1.4$ \\
L2U3, U6L7 & $166 \mathrm{C}$ & 63.6 & $26.6 / 1.6$ & $30.3 / 1.4$ & $29.3 / 1.5$ & $40.3 / 1.1$ \\
L2L3,L3L4,L5L6,L6L7 & $365 \mathrm{~T}$ & 161.8 & $59.8 / 1.3$ & $71.9 / 1.0$ & $69.3 / 1.1$ & $83.1 / 0.9$ \\
U3L4, L5U6 & $165 \mathrm{~T}$ & 51.5 & $21.7 / 2.5$ & $23.1 / 2.3$ & $21.8 / 2.5$ & $30.0 / 1.8$ \\
U3U4, U4U5, U5U6 & $339 \mathrm{C}$ & 180.1 & $66.3 / 0.6$ & $78.9 / 0.5$ & $75.3 / 0.6$ & $89.2 / 0.5$ \\
L4L5 & $365 \mathrm{~T}$ & 160.4 & $56.5 / 1.4$ & $61.4 / 1.2$ & $58.3 / 1.3$ & $79.5 / 1.0$ \\
U4L5, L4U5 & 72 T & 26.7 & $16.5 / 1.2$ & $12.8 / 1.5$ & $14.8 / 1.3$ & $22.5 / 0.9$
\end{tabular}

\section{Military Load Class (MLC) of Truss}

-From previous page, the top chord members, U3U4, U4U5, and U5U6 controlled the rating. Therefore the MLC will also be controlled by these members.

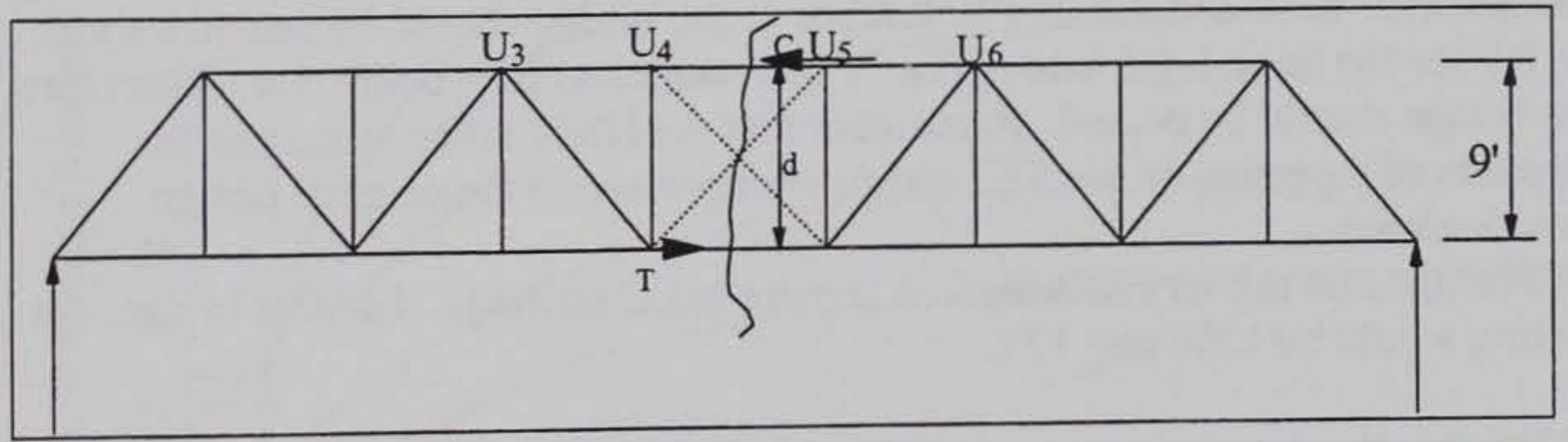

-From previous calcs, the nominal capacity of these members is $339 \mathrm{kip}(\mathrm{C})$.

$$
\therefore M_{n}=339 k i p(9 f t)=3051 \mathrm{ft} \cdot \mathrm{kip}
$$

-Also from previous, the uniform dead load on the truss is $1.62 \frac{\mathrm{kip}}{\mathrm{ft}}$.

$$
\therefore M_{D}=\frac{w l^{2}}{8}=\frac{1.62 \frac{k}{f t}(90 f t)^{2}}{8}=1640 \mathrm{ft} \cdot \mathrm{kip}
$$

-Setting the RF equation equal to 1.0 and solving for $M_{L}$ :

$$
R F=\frac{C-A_{1} D}{A_{2} L(1+I) D F}
$$




$$
\begin{gathered}
1.0=\frac{M_{n}-1.2 M_{D}}{1.3 M_{L}(1.1)(1.12)} \\
M_{L}=\frac{\phi M_{n}-1.2 M_{D}}{1.60}=\frac{0.8(3051)-1.2(1640)}{1.60}=295.2 \mathrm{ft} \cdot \mathrm{kip} \text { per truss }
\end{gathered}
$$

-Note that the DF of 1.12 used above was from previous calcs and was for a wheel line. Since MLC Moments in Reference 5 are for axle loads on the total structural system:

$$
\therefore M_{L}=2(295.2)=590.4 f t \cdot k i p
$$

-From the Moment curves of Reference 5 for a 90 -foot span:

\begin{tabular}{|c|c|c|c|c|c|c|}
\hline Bridge Element & Type 3 & Type 3S2 & Type 3-3 & $\begin{array}{l}\text { Type } \\
\text { HS20 } \\
\end{array}$ & Wheel & Track \\
\hline Deck & 8.15 & 8.94 & 8.66 & 4.33 & 150 & 150 \\
\hline Stringers & 2.01 & 2.2 & 2.44 & 1.37 & 50 & 60 \\
\hline Floor Beams & 2.43 & 2.67 & 2.95 & 2.07 & 70 & 50 \\
\hline $\begin{array}{l}\text { Truss (Limited by } \\
\text { top Chord) }\end{array}$ & $\underline{0.6}$ & $\underline{0.5}$ & $\underline{0.6}$ & $\underline{0.5}$ & $\underline{12}$ & $\underline{12}$ \\
\hline Vehicle Wt. (tons) & 25 & 36 & 40 & 36 & NA & NA \\
\hline Load Rating ${ }^{*}$ (tons) & 15 & 18 & 24 & 18 & 12 & 12 \\
\hline
\end{tabular}

$$
\mathrm{MLC}=\underline{12 \mathrm{~T}} \text { and } \underline{12 \mathrm{~W}}
$$

\section{Rating Summary}

${ }^{*}$ Load Rating $=($ Lowest Element Rating $)($ Vehicle Wt. in tons $)$

- The lowest element ratings are underlined in the table

- As per Par. 6.7.2 and 7.4.2 of Reference 1, the bridge should be posted only if the RF for the three legal loads (The "Type" vehicles) falls below 1.0. Therefore, this bridge should be posted. Remember that the HS20 rating is mainly for purposes of reporting to the NBI and for comparison to the original design specifications.

- All bridges on military installations require MLC postings. For this bridge, the posting would be $12 \mathrm{~W}$ and $12 \mathrm{~T}$.

* Note that these ratings compare well with, but are all higher than those from BRASS using the allowable stress method. This shows the benefit of the LRFR method. 


\section{Maximum Stringer Reactions on Transverse Floor Beams for Military Vehicles \\ (Intermediate Floor Beams)}
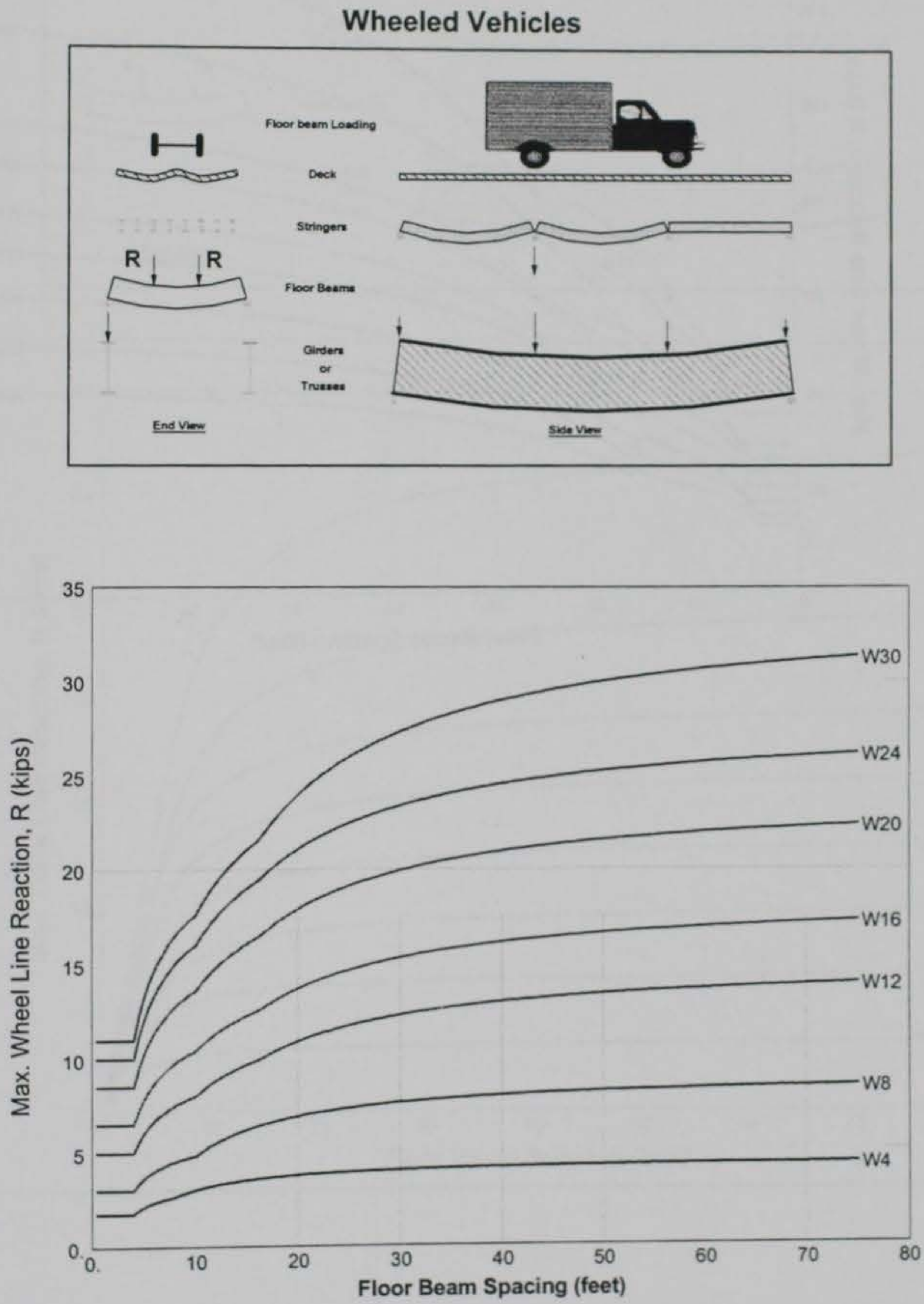
Wheeled Vehicles (Continued)

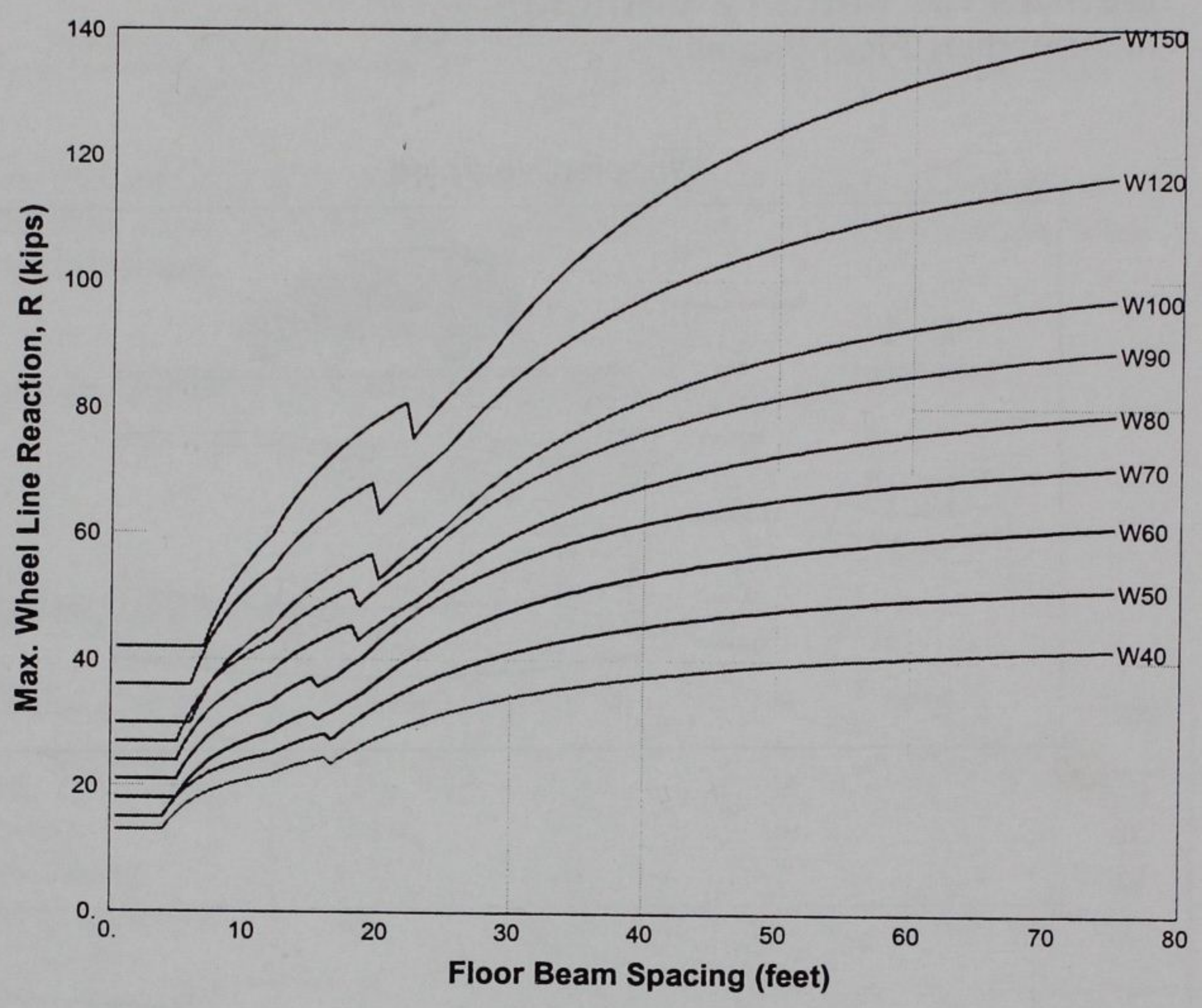


Tracked Vehicles
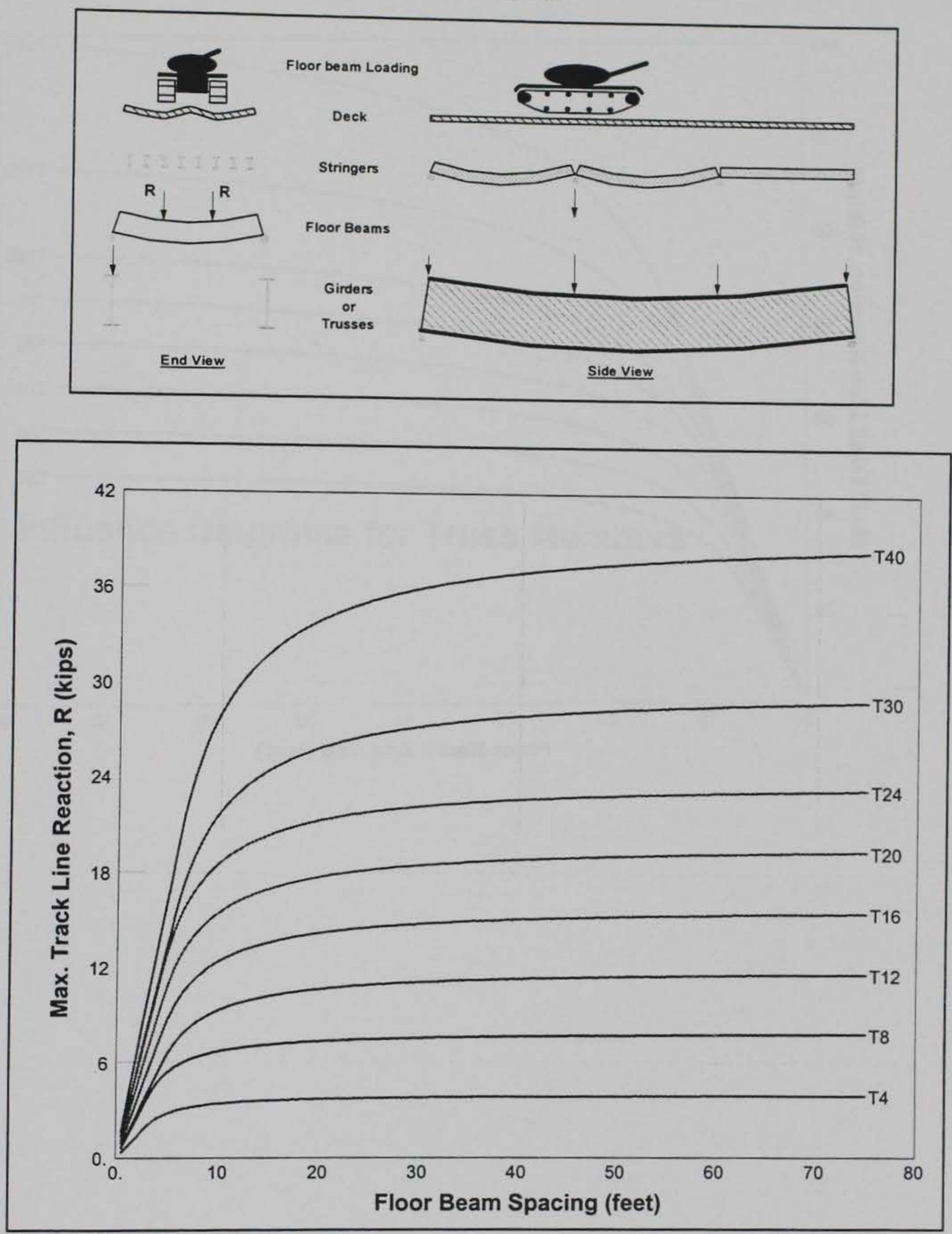


\section{Tracked Vehicles (Continued)}

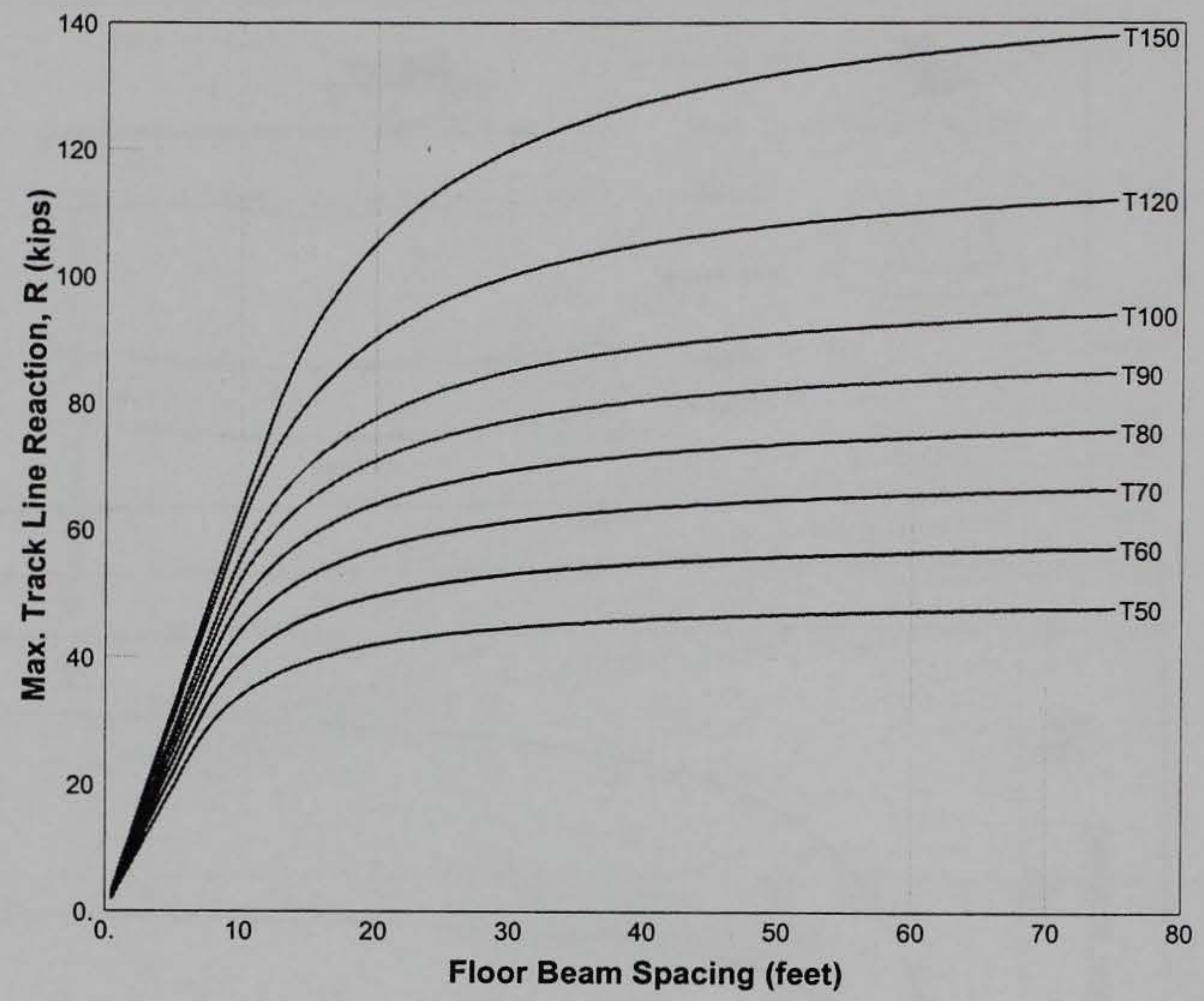




\section{Influence Diagrams for Truss Members}




\section{Members U1L0 and U8L9}

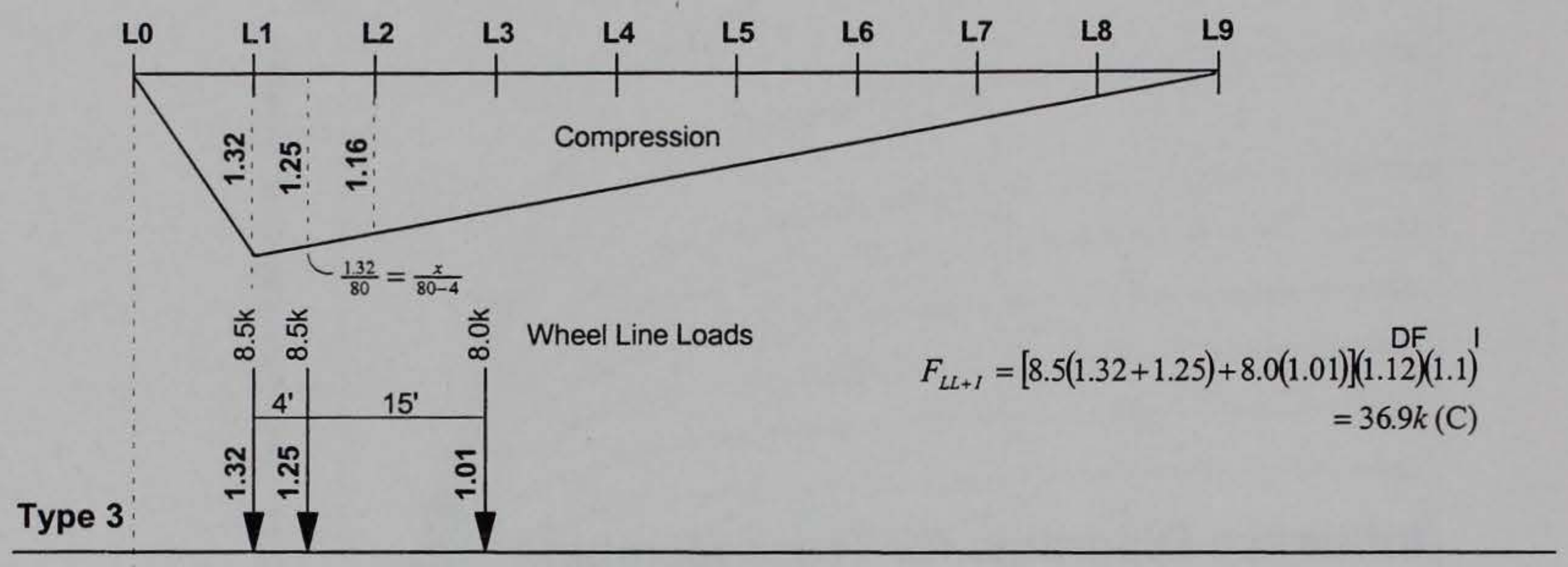

$F_{L L+I}=[7.75(1.32+1.25+.89+.83)+5.0(.64)](1.12)(1.1)$
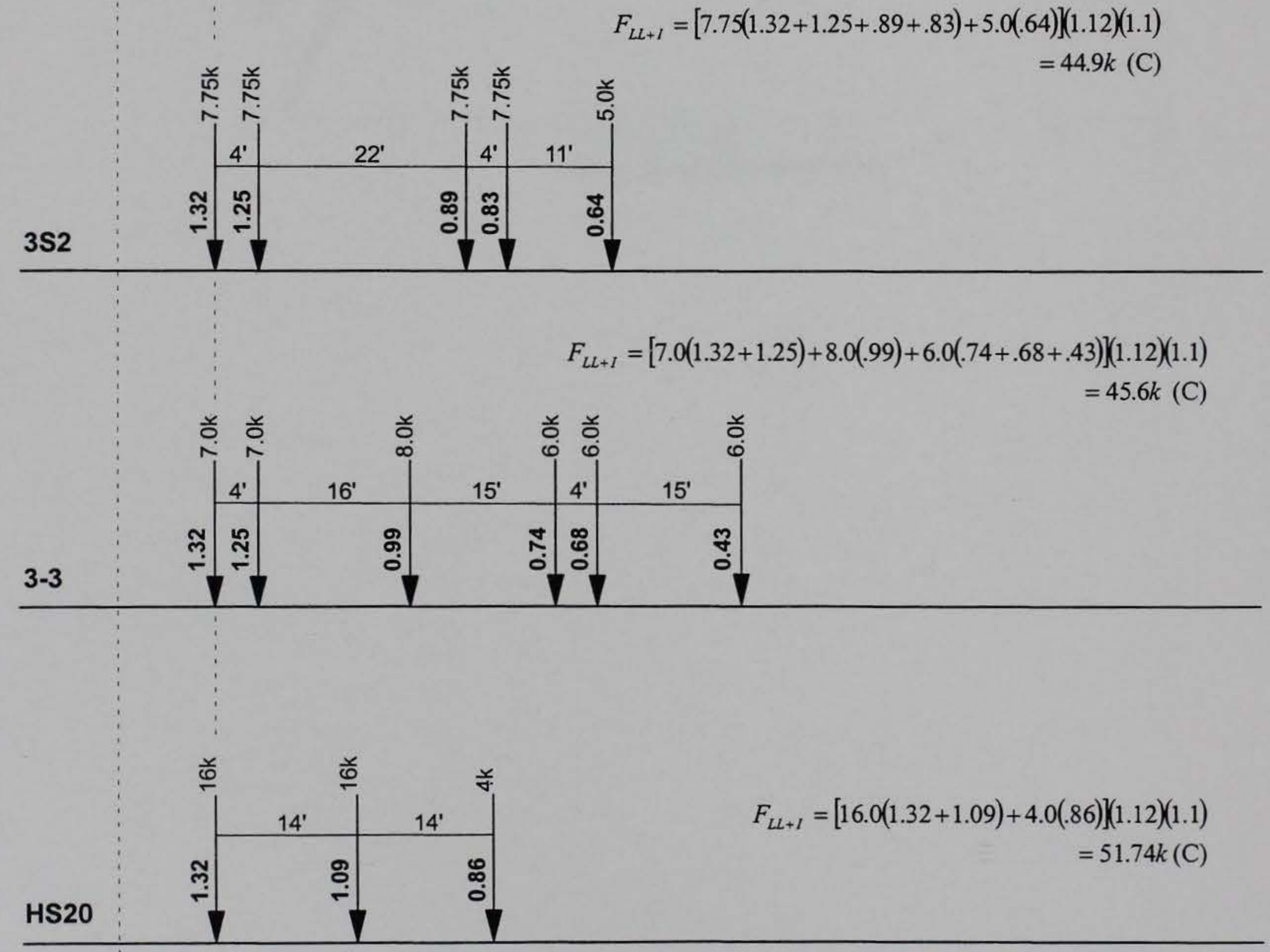


\section{Members L0L1, L1L2, L7L8, L8L9}

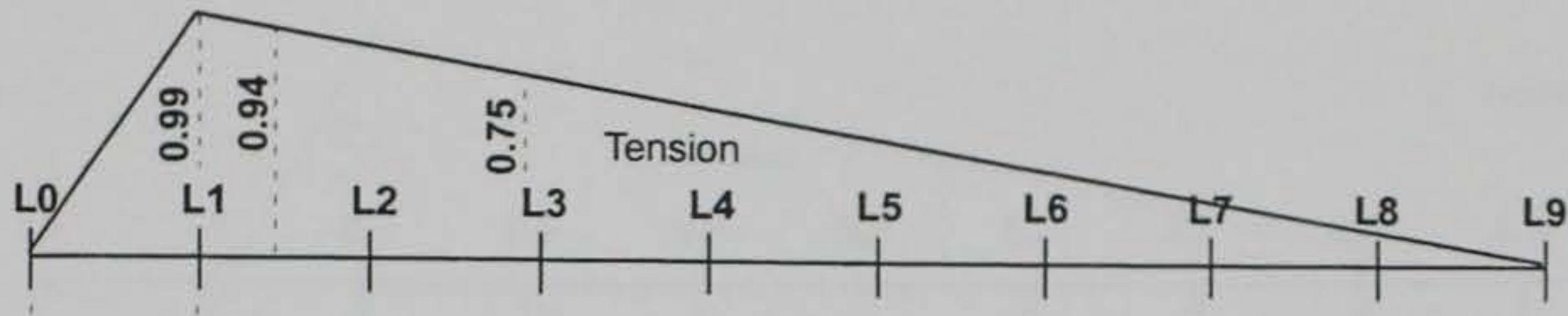

Type 3

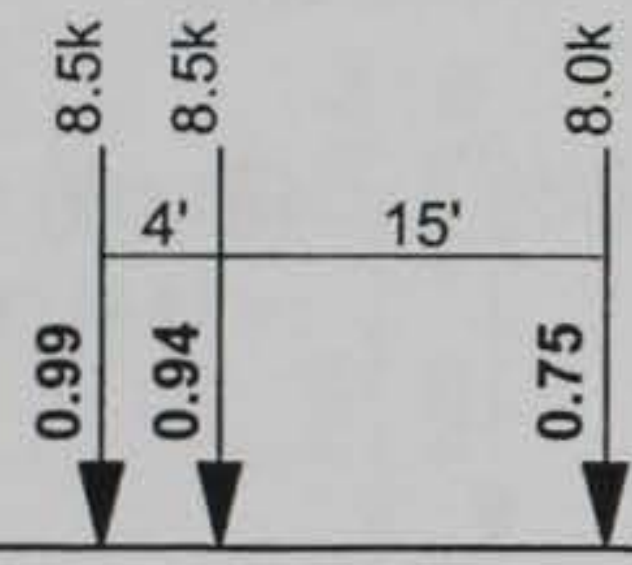

$$
F_{L L+I}=[8.5(0.99+0.94)+8.0(0.75)](1.12)(1.1)
$$$$
=27.6 \mathrm{k}(\mathrm{T})
$$

$$
F_{L L+1}=[7.75(.99+.94+.67+.62)+5.0(.49)](1.12)(1.1)
$$

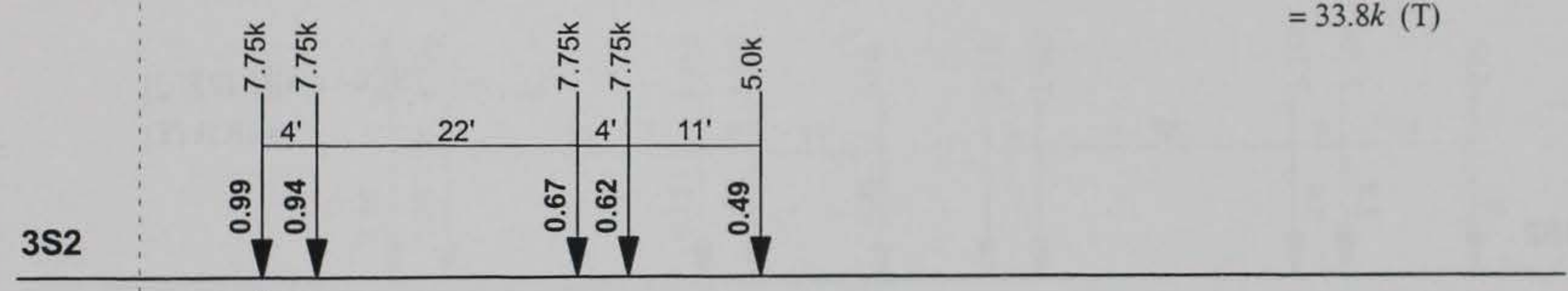

$$
F_{L L+1}=[7.0(.99+.94)+8.0(.74)+6.0(.56+.51+.32)](1.12)(1.1)
$$$$
=34.2 k(\mathrm{~T})
$$

3-3

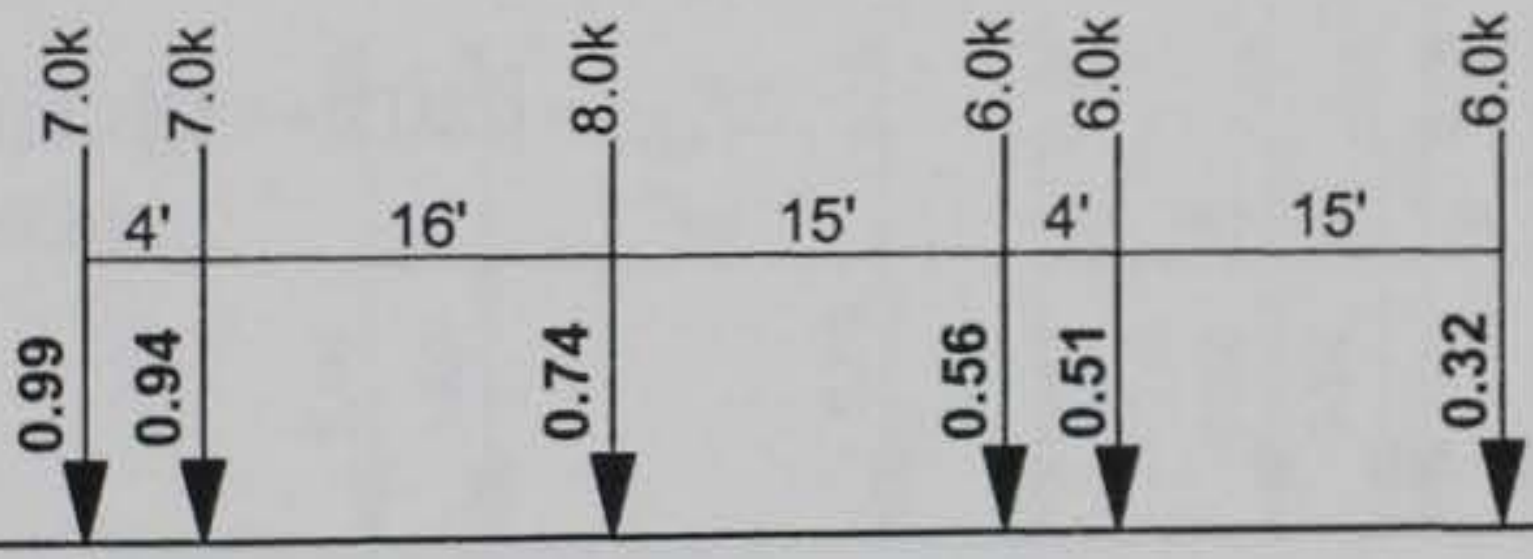

HS20

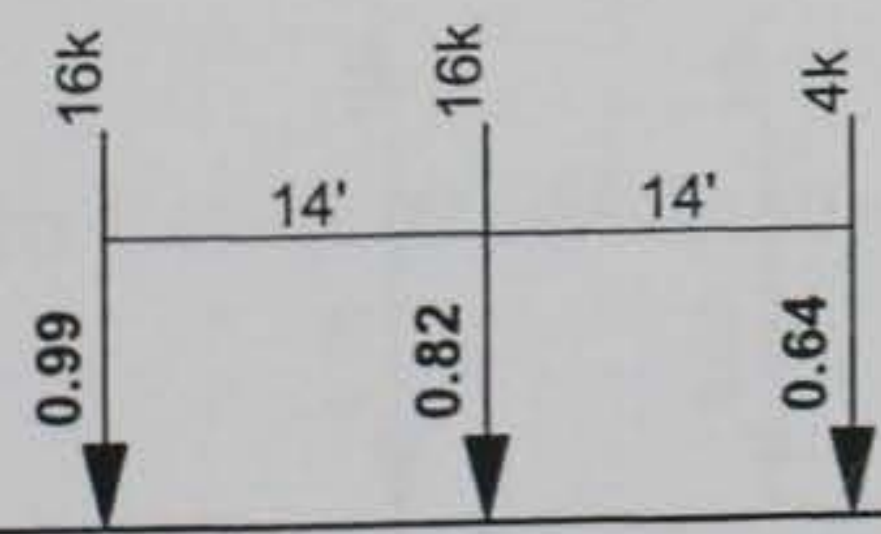

$$
\begin{array}{r}
F_{L L+I}=[16.0(.99+.82)+4.0(.64)](1.12)(1.1) \\
=38.8 k(\mathrm{~T})
\end{array}
$$


Members U1L1, U8L8 (max at L1), and U3L3, U6L6 ( $\max$ at L3)

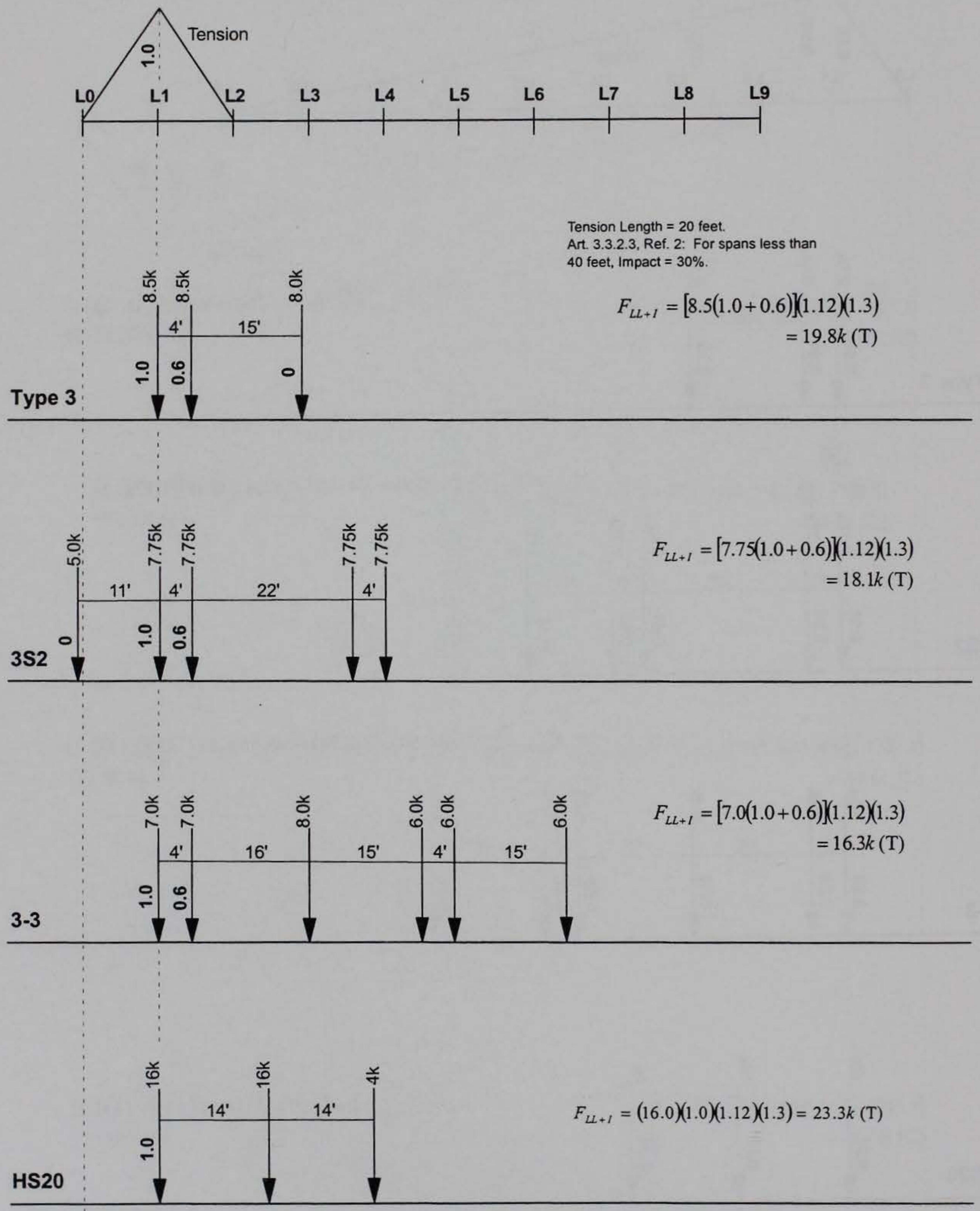




\section{Members U1L2 and U8L7}

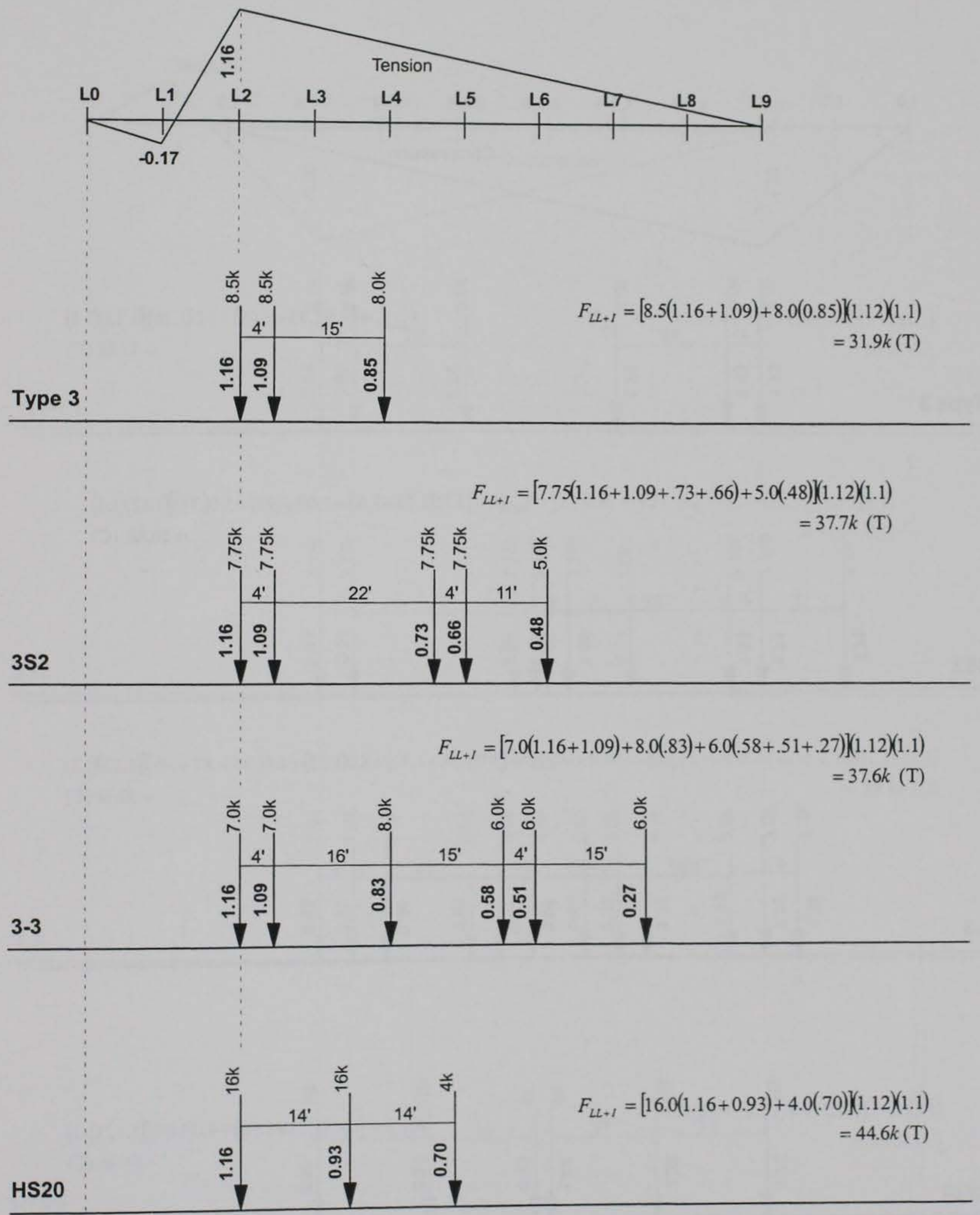




\section{Members U1U2, U2U3, U6U7, U7U8}

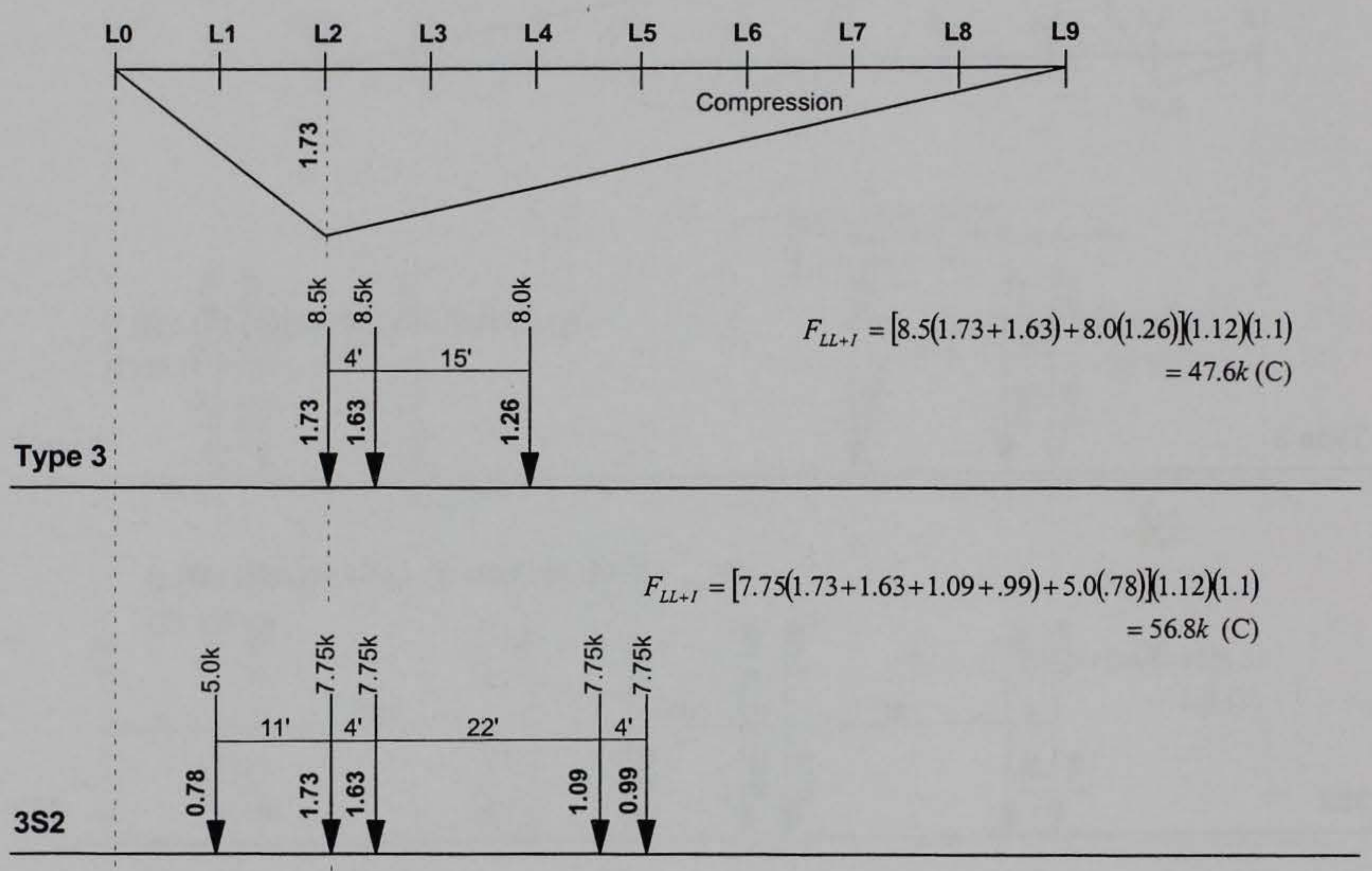

$$
F_{L L+1}=[7.0(1.38+1.73)+8.0(1.33)+6.0(.96+.87+.49))(1.12)(1.1)
$$

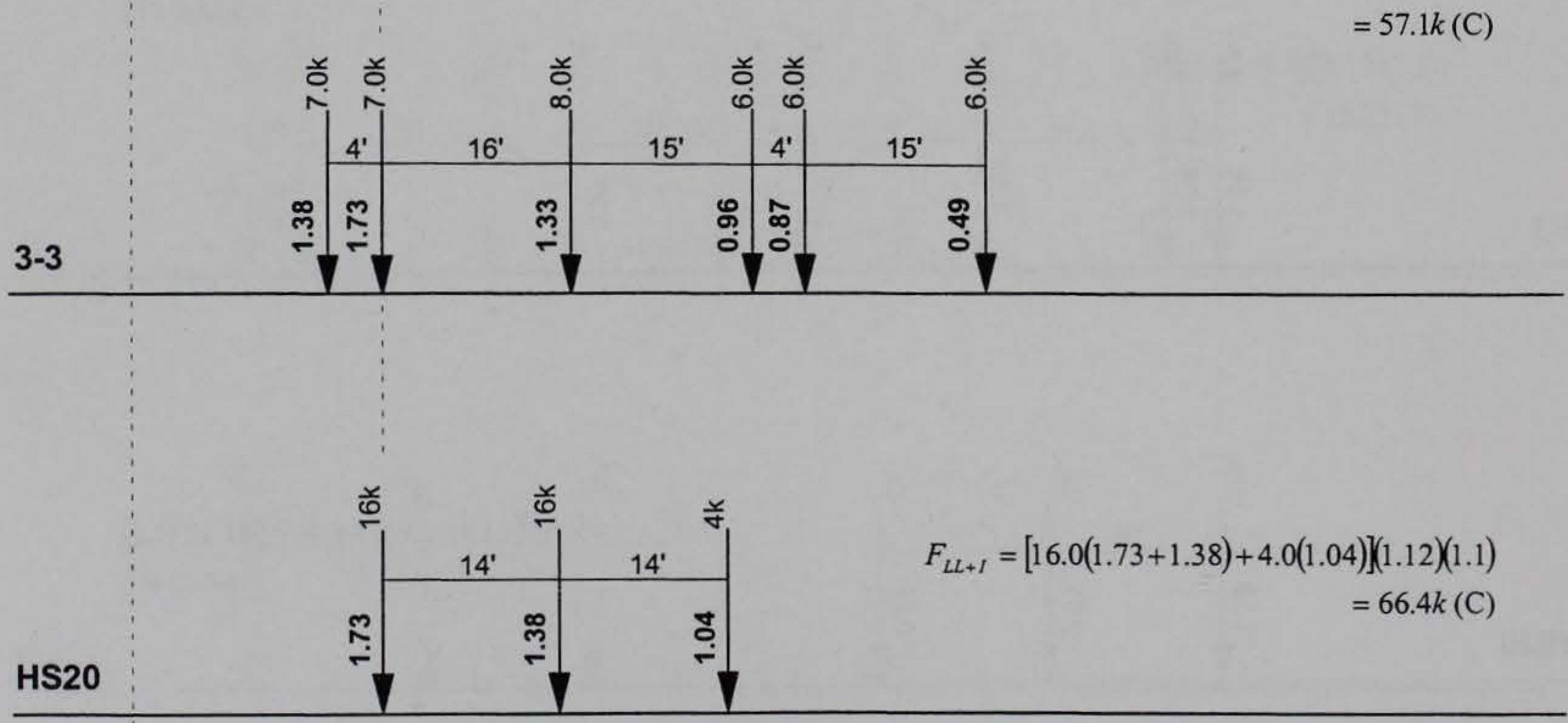




\section{Members U3L2 and U6L7}

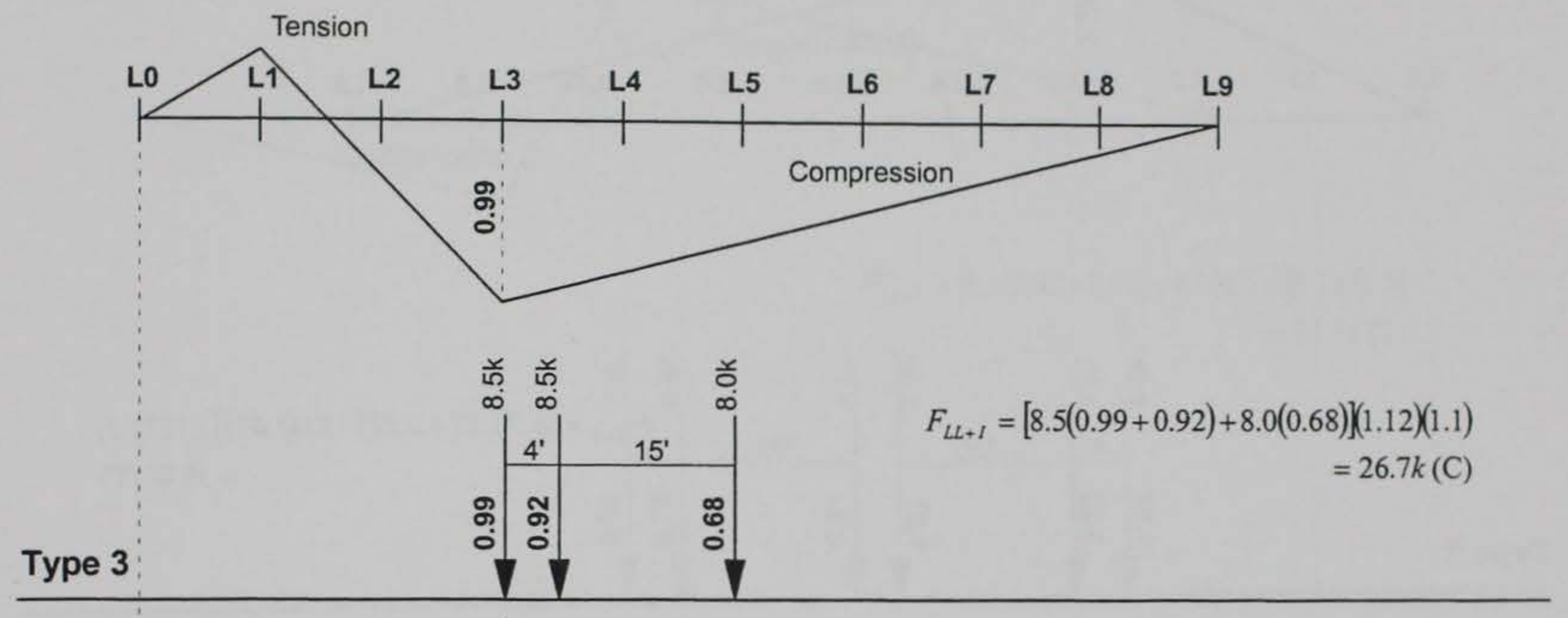

$$
F_{L L+1}=[7.75(.99+.92+.56+.50)+5.0(.31)](1.12)(1.1)
$$

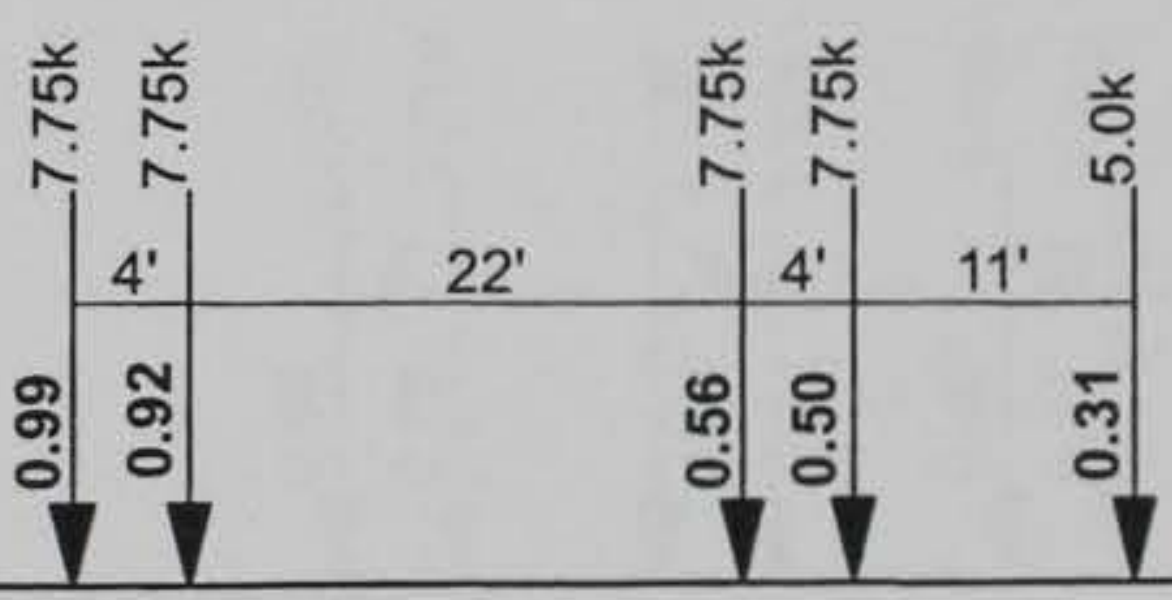

$=30.3 k(\mathrm{C})$

$$
\begin{array}{r}
F_{L L+1}=[7.0(0.99+0.92)+8.0(.66)+6.0(.41+.35+.10)](1.12)(1.1) \\
=29.3 k(\mathrm{C})
\end{array}
$$
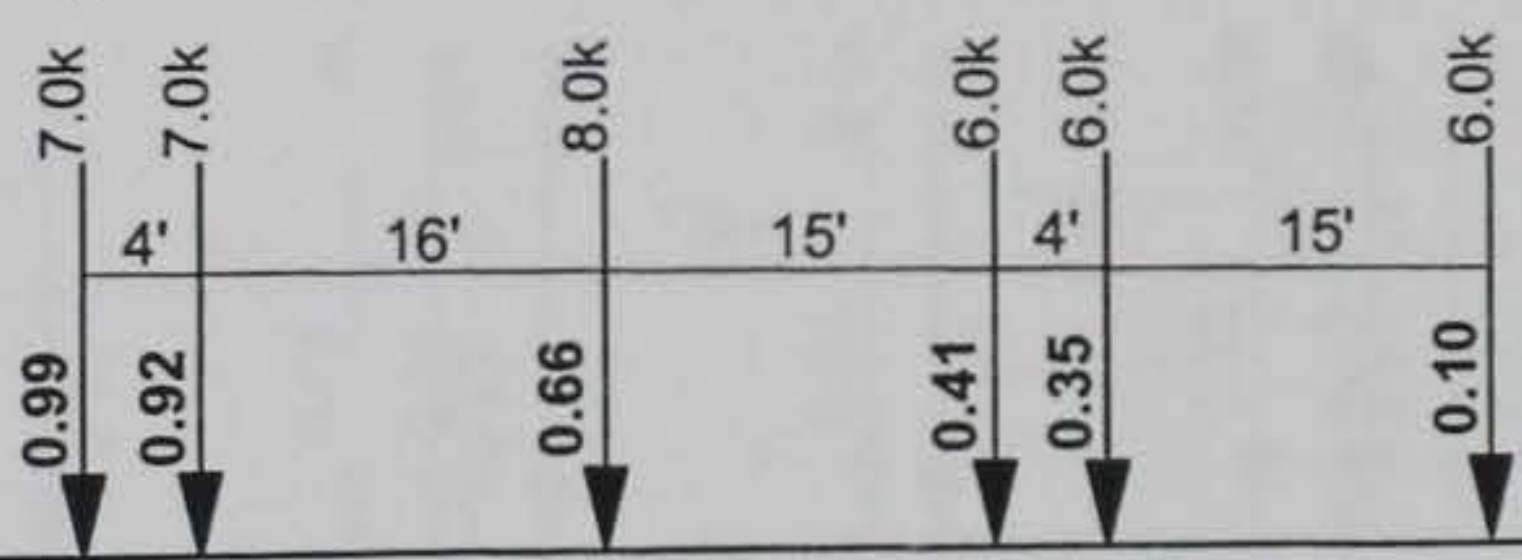


\section{Members L2L3, L3L4, L5L6, L6L7}

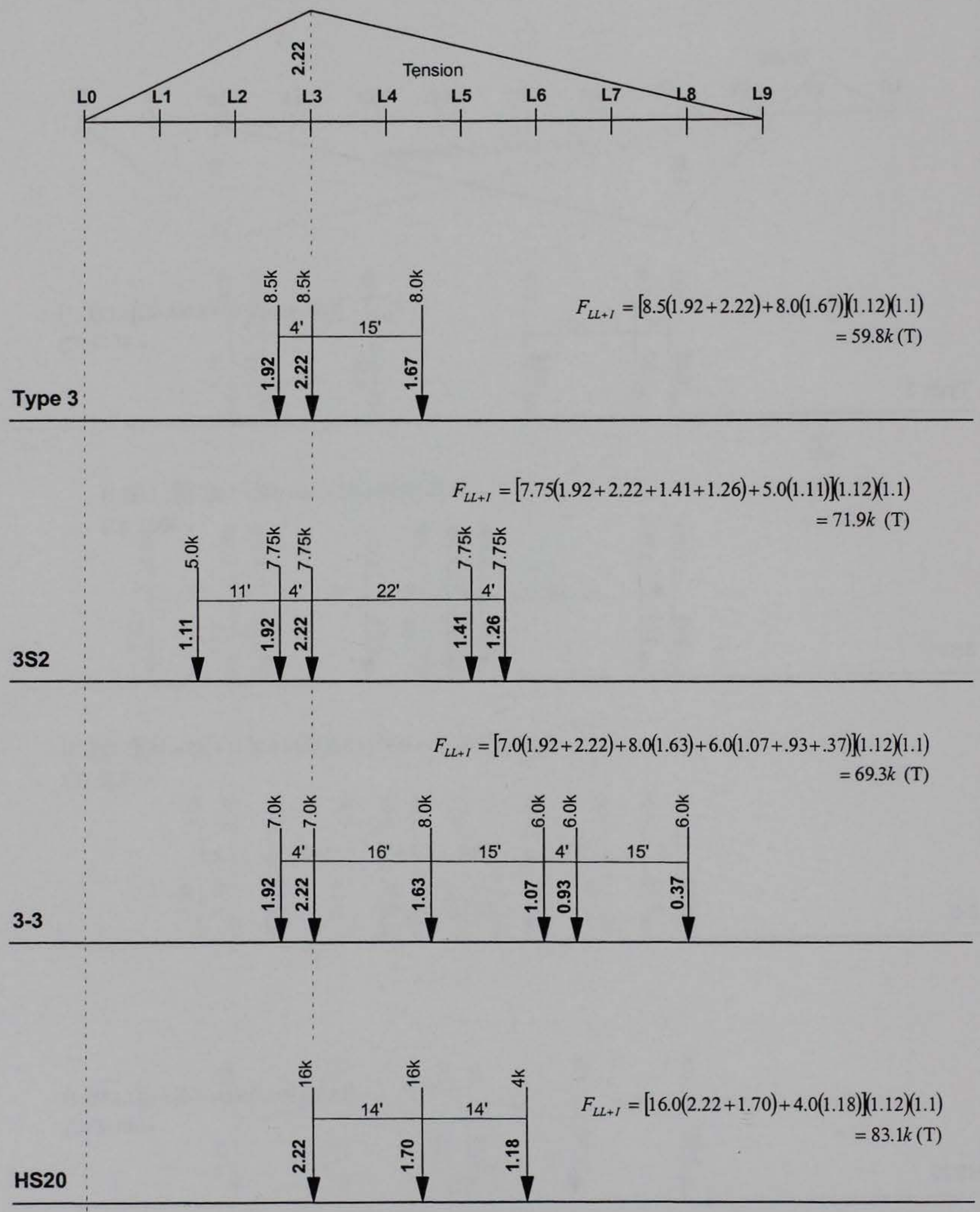




\section{Members U3L4 and U6L5}

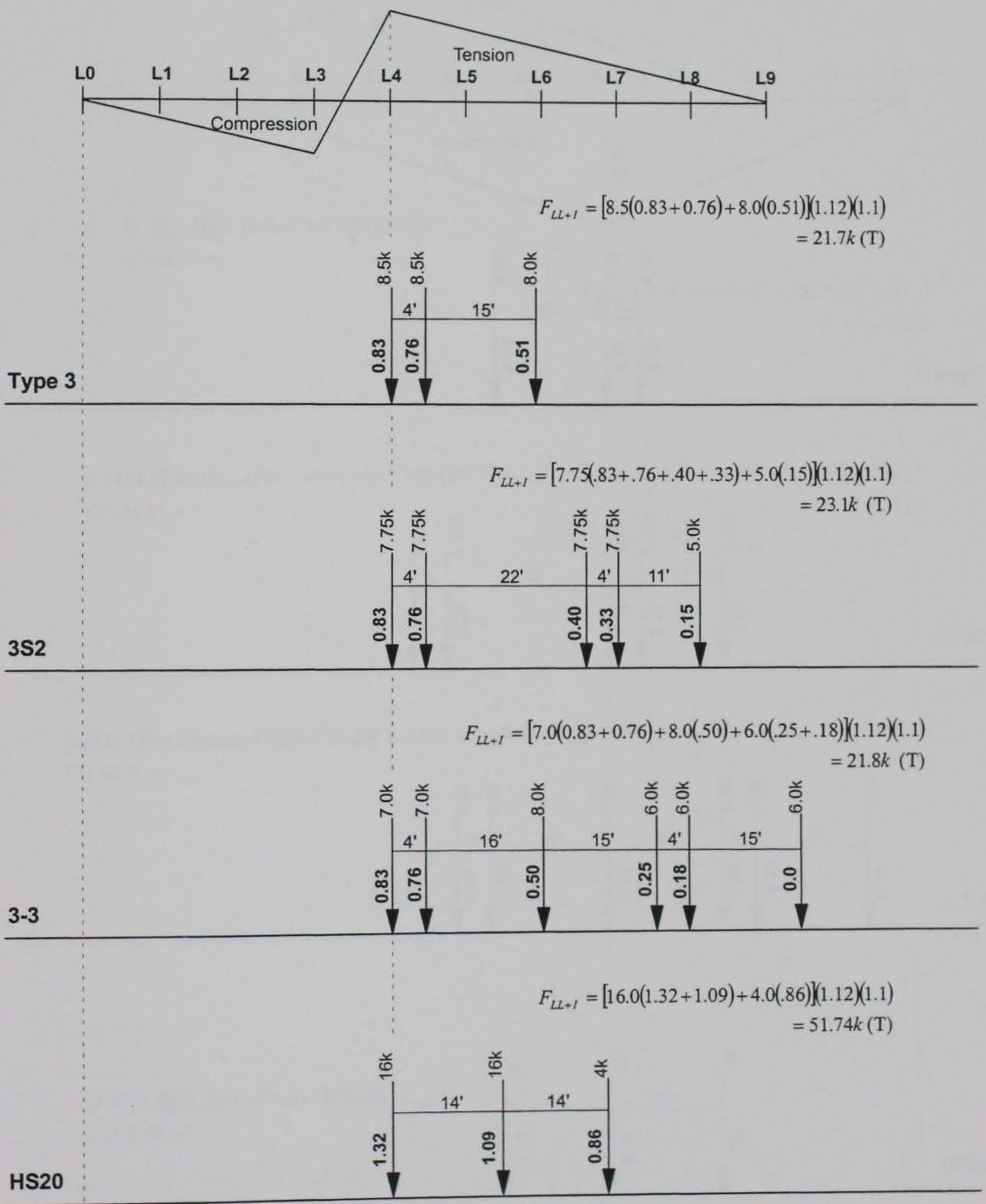




\section{Members U3U4, U4U5, U5U6}

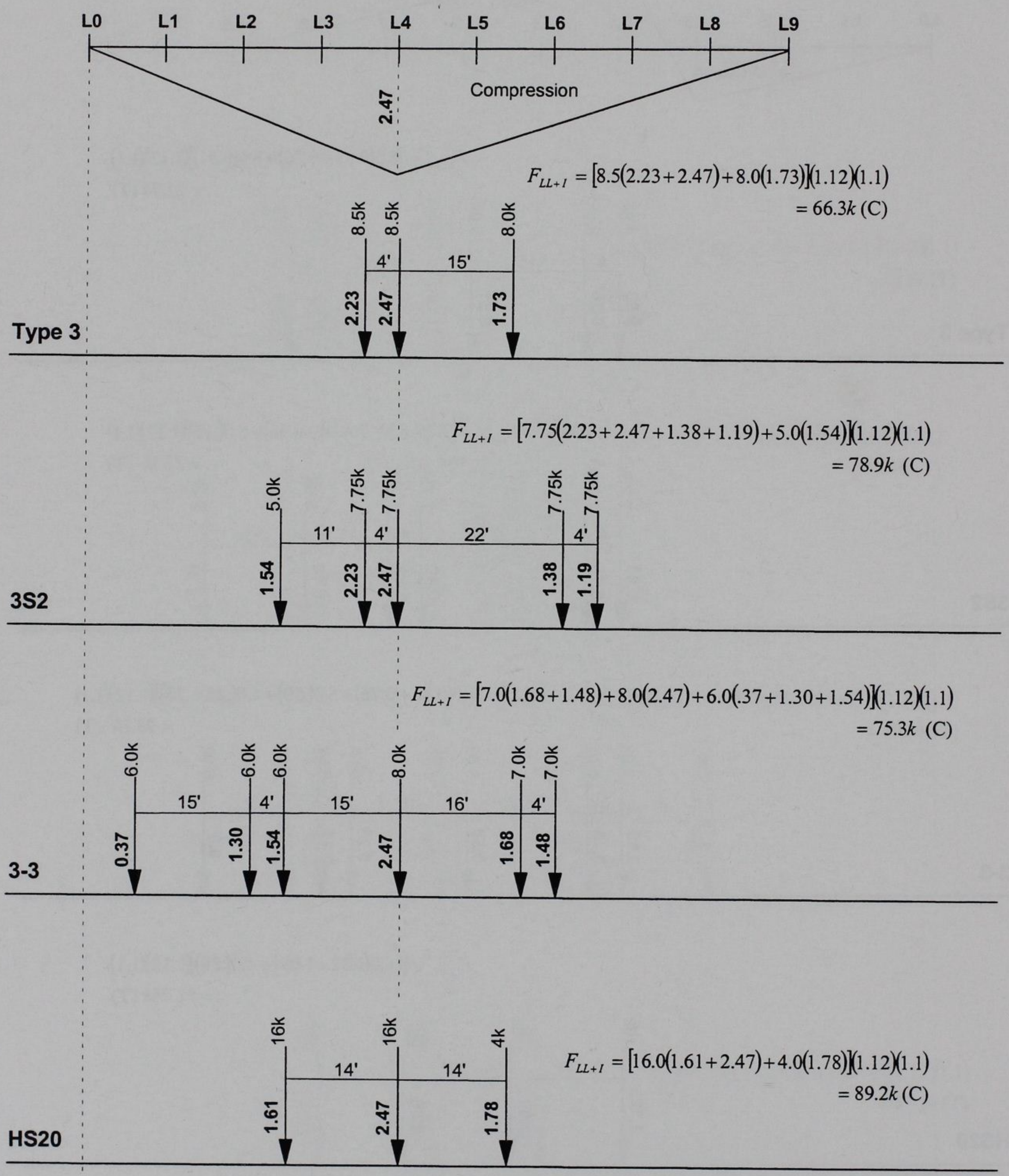




\section{Member L4L5}

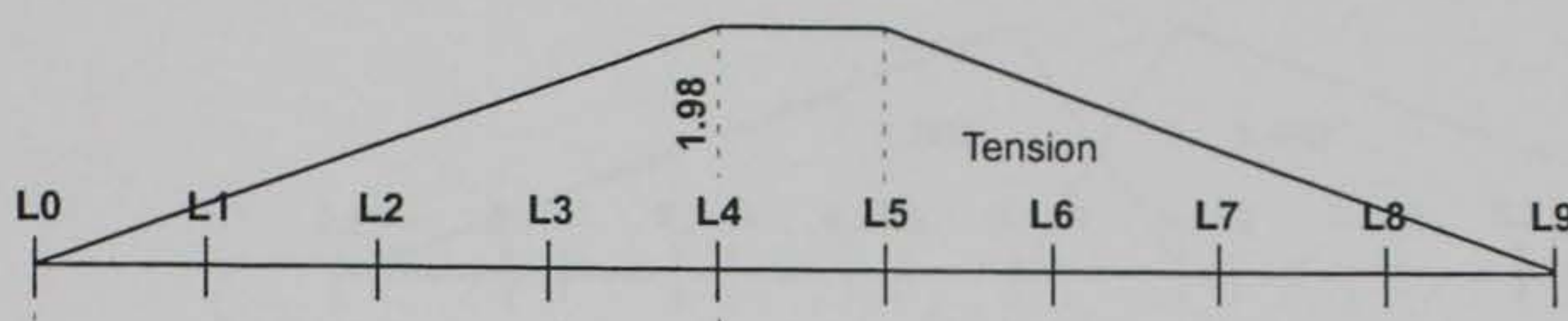

\section{Type 3}

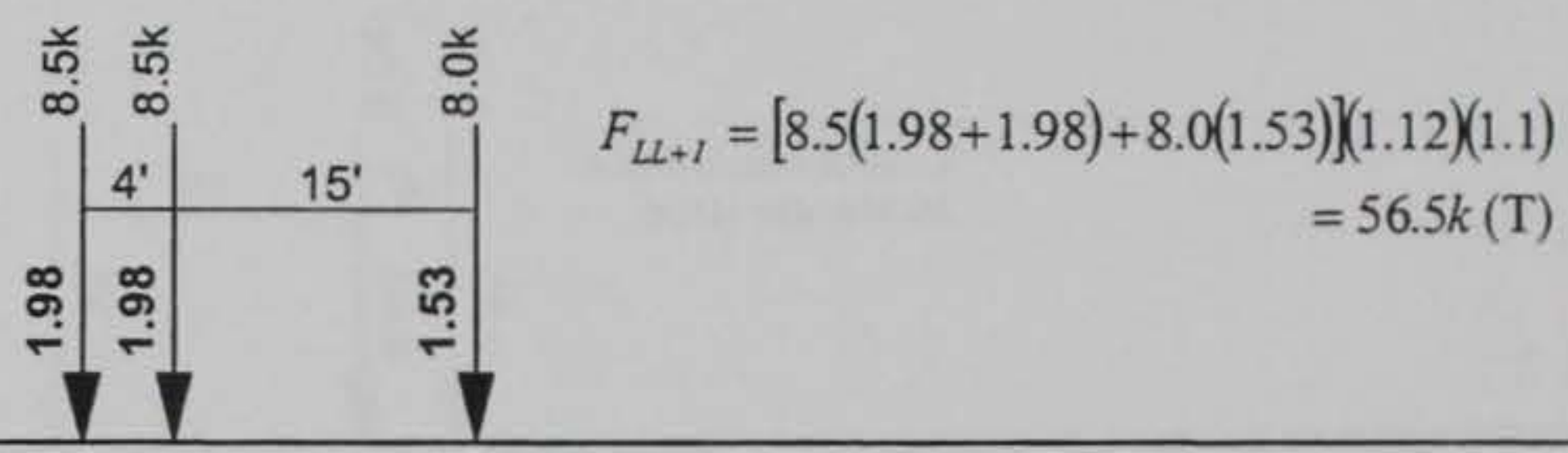

352

$$
F_{L L+1}=[7.75(1.98+1.98+1.19+.99)+5.0(.45)](1.12)(1.1)
$$

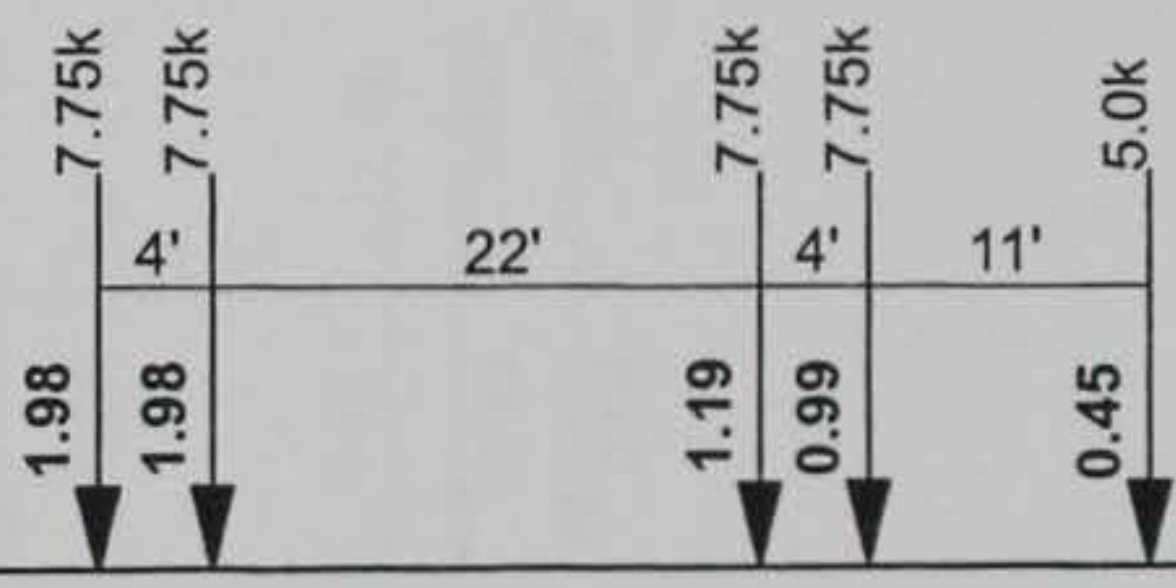

$=61.4 k(\mathrm{~T})$

$$
F_{L L+1}=[7.0(1.98+1.98)+8.0(1.49)+6.0(.74+.54)](1.12)(1.1)
$$

$=58.3 k(\mathrm{~T})$

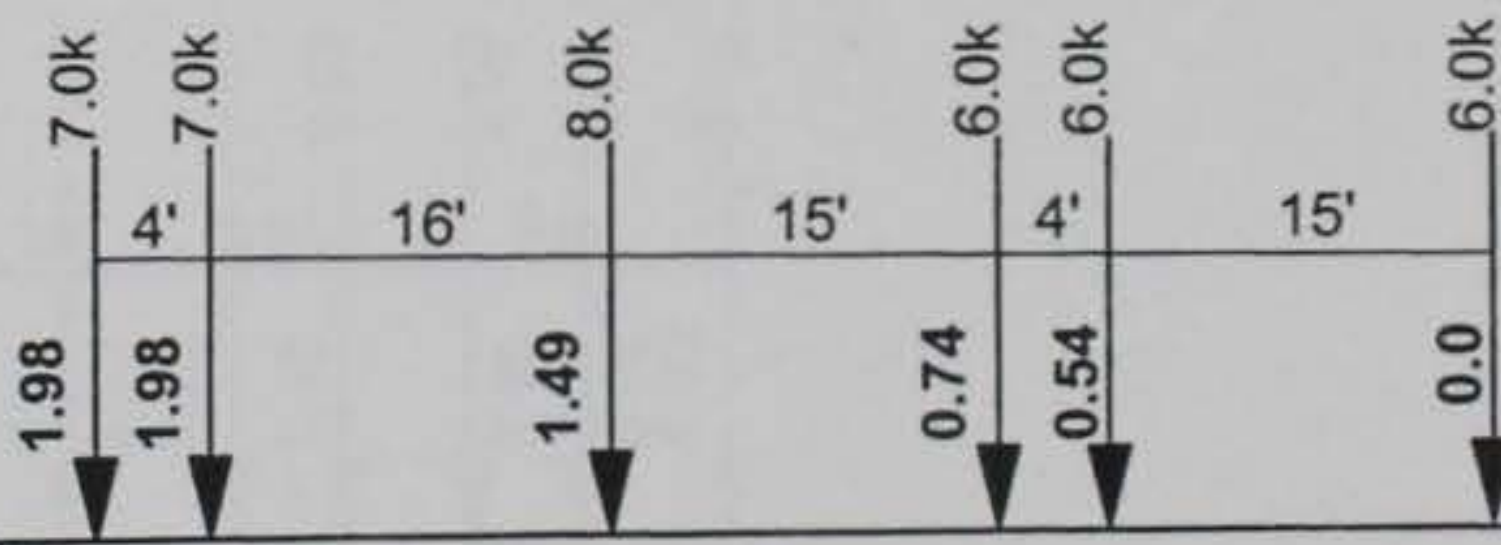

$$
\begin{array}{r}
F_{L+1}=[16.0(1.98+1.78)+4.0(1.09))(1.12)(1.1) \\
=79.5 k(\mathrm{~T})
\end{array}
$$

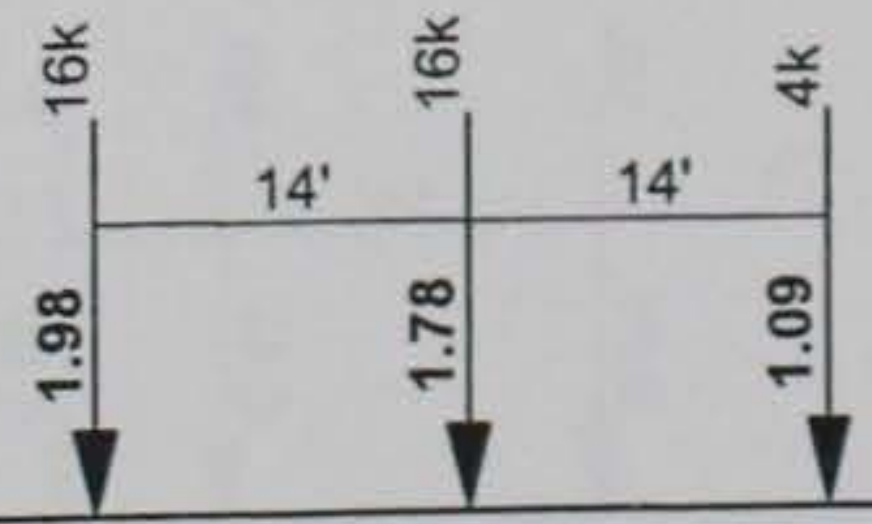




\section{Members U4L5 and U5L4}

Counters: No Compression

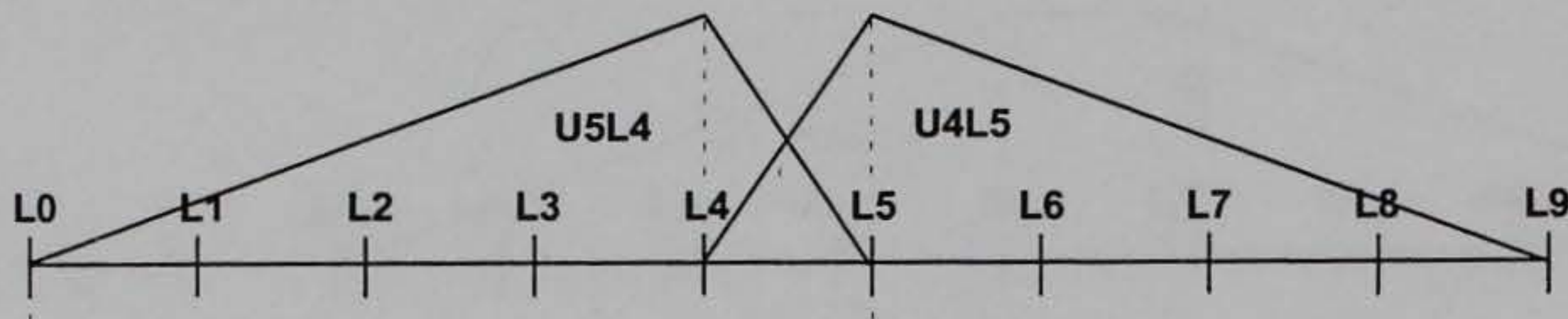

$$
\begin{array}{r}
F_{L L+1}=[8.5(0.66+0.59)+8.0(0.35))(1.12)(1.1) \\
=16.5 k(\mathrm{~T})
\end{array}
$$

Load positions shown for Member U4L5

Type 3

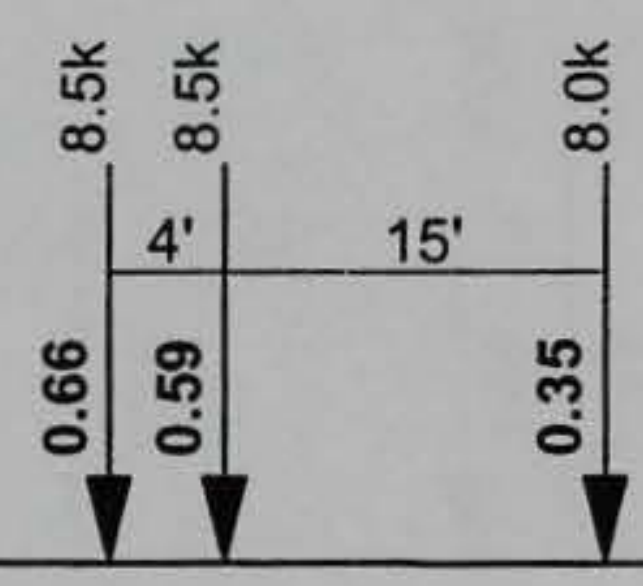

352

$$
F_{L L+1}=[7.75(.66+.59+.23+.17)](1.12)(1.1)
$$

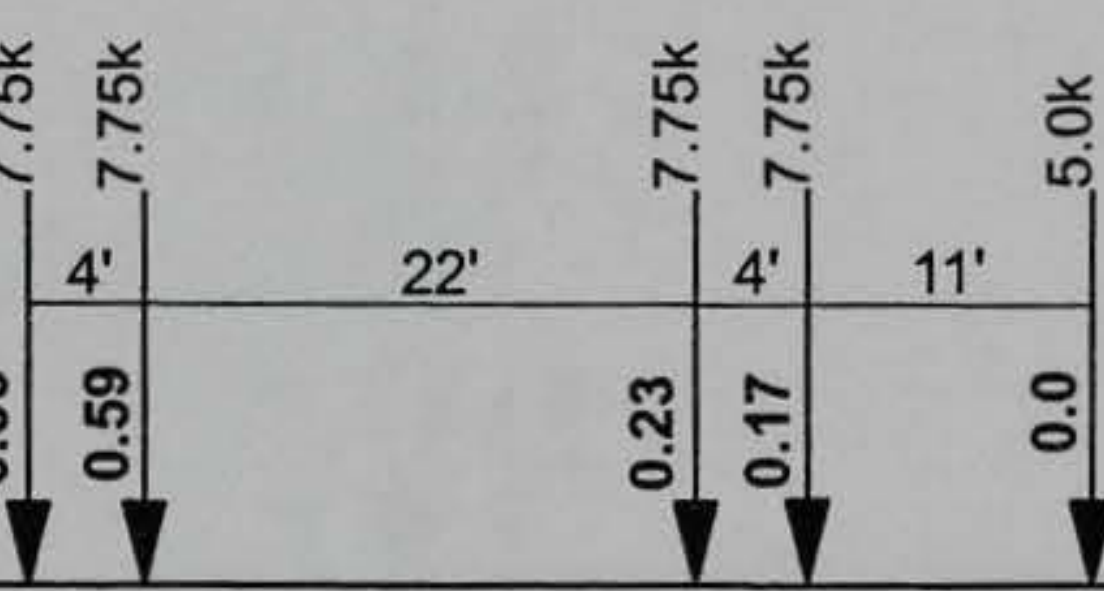

$=12.8 k(\mathrm{~T})$

$$
F_{L L+1}=[7.0(.66+.59)+8.0(.33)+6.0(.08+.02))(1.12)(1.1)
$$$$
=14.8 \mathrm{k}(\mathrm{T})
$$

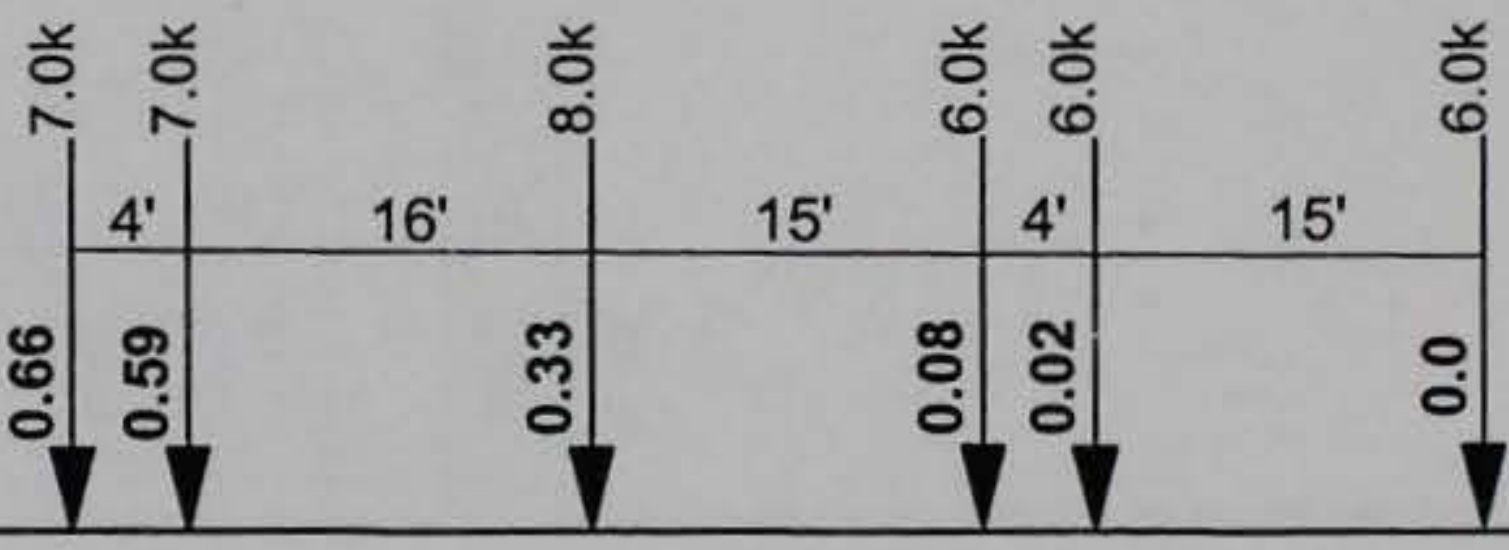

HS20

$$
F_{L L+1}=[16.0(.66+.43)+4.0(.20)](1.12)(1.1)
$$

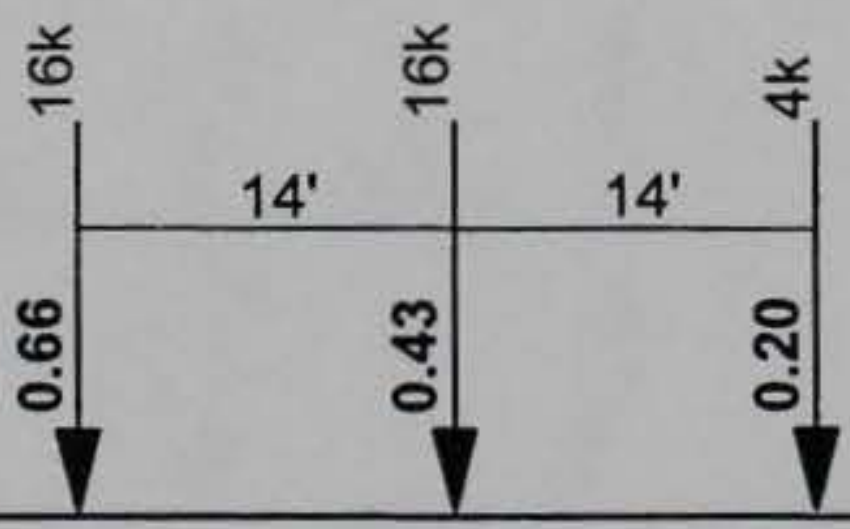

$=22.5 k(\mathrm{~T})$ 


\section{Members U1LO and U8L9}

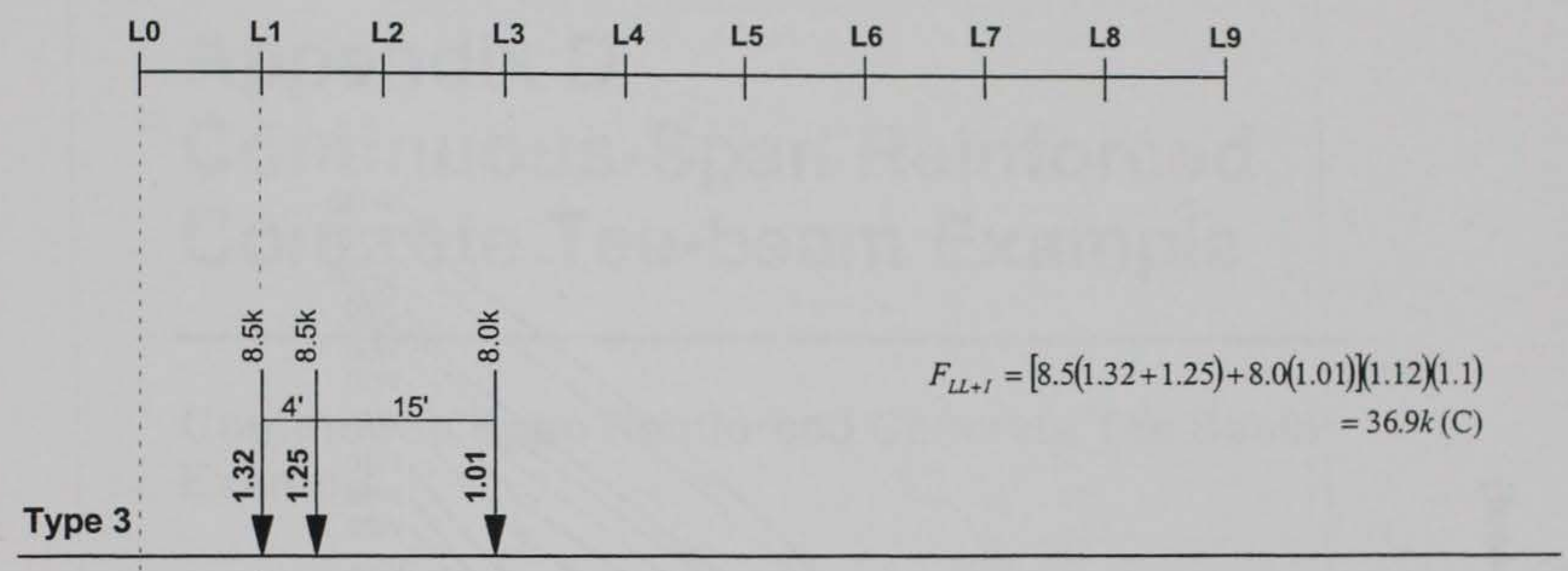

352

$$
\begin{array}{r}
F_{L L+1}=[7.75(1.32+1.25+.89+.83)+5.0(.64)](1.12)(1.1) \\
=44.9 k(\mathrm{C})
\end{array}
$$

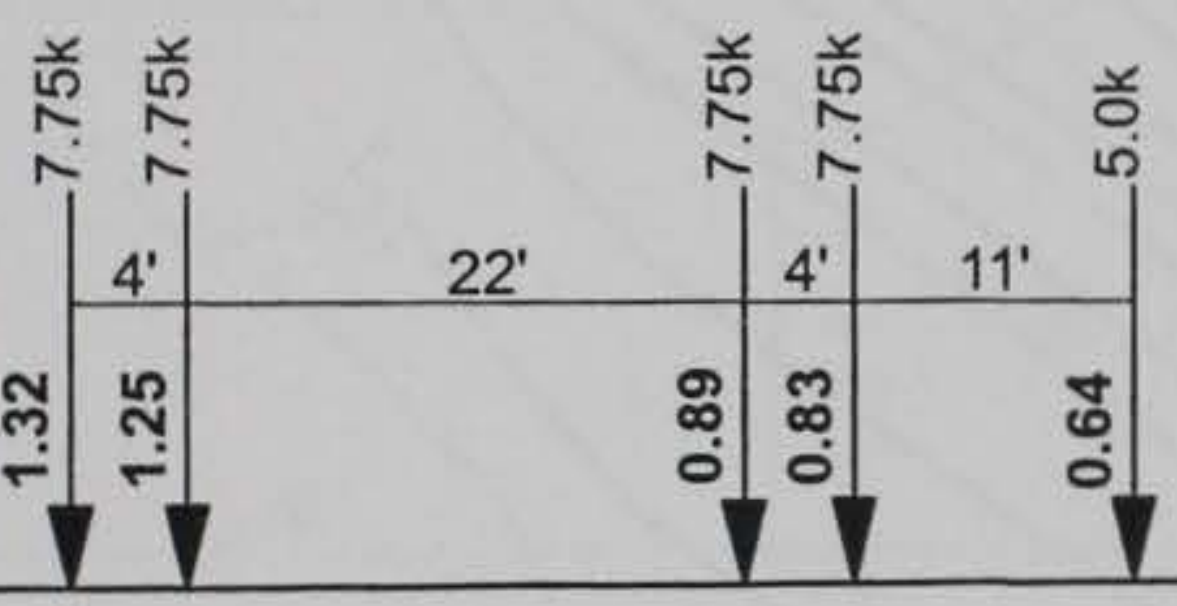

$$
F_{L L+1}=[7.0(1.32+1.25)+8.0(.99)+6.0(.74+.68+.43)](1.12)(1.1)
$$

\begin{tabular}{|c|c|c|c|c|}
\hline$\overbrace{4^{\prime}}$ & $16^{\prime}$ & $15^{\prime}$ & $\begin{array}{l}5 \\
0 \\
0 \\
0\end{array}$ & $15^{\prime}$ \\
\hline 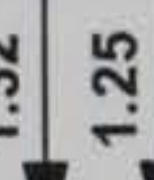 & gू & $\stackrel{5}{c}$ & $\stackrel{\infty}{0}$ & ? \\
\hline
\end{tabular}

$=45.6 \mathrm{k}(\mathrm{C})$

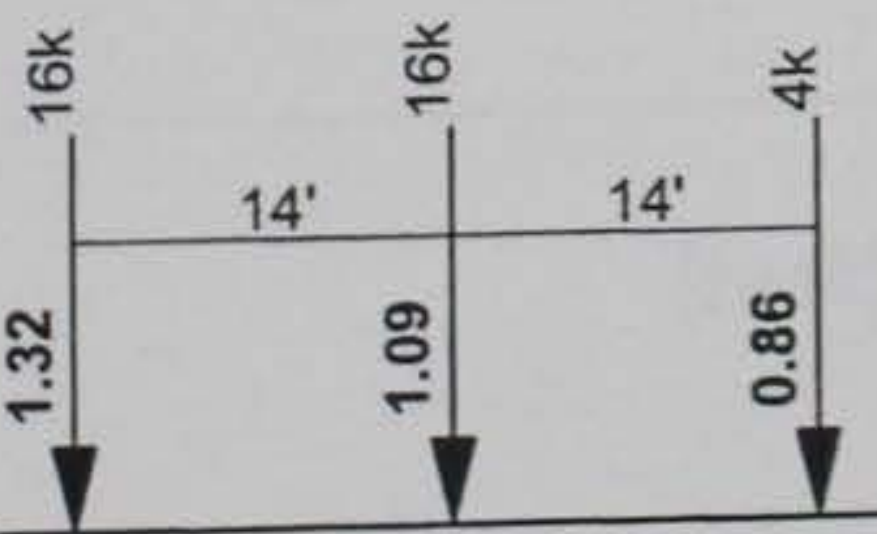

$$
\begin{array}{r}
F_{L L+1}=[16.0(1.32+1.09)+4.0(.86))(1.12)(1.1) \\
=51.74 k(\mathrm{C})
\end{array}
$$




\section{NATO Standard Wheeled Vehicle Bending Moment (kip-feet)}

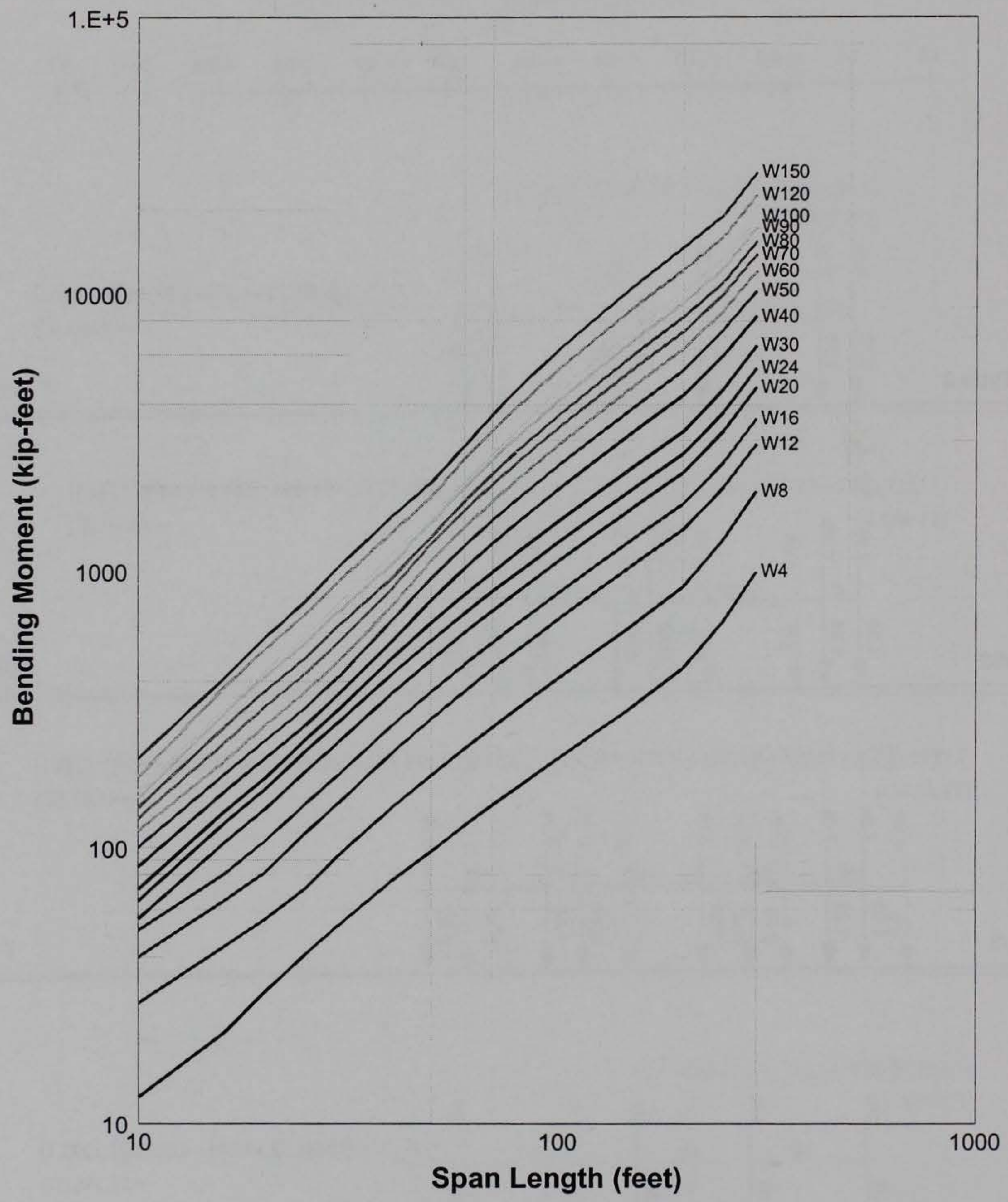




\section{Appendix D \\ Continuous-Span Reinforced Concrete Tee-beam Example}

\section{Continuous Span Reinforced Concrete Tee Beam}

\section{Example}

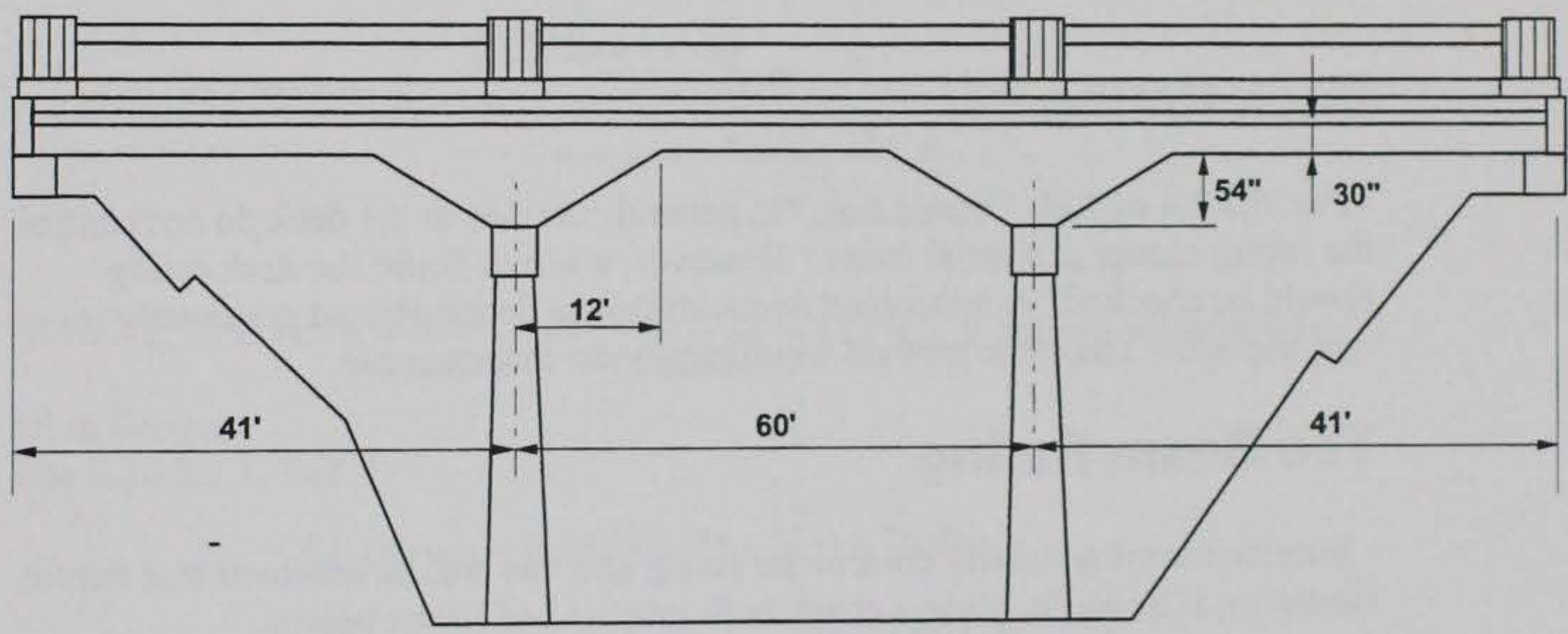

Side View

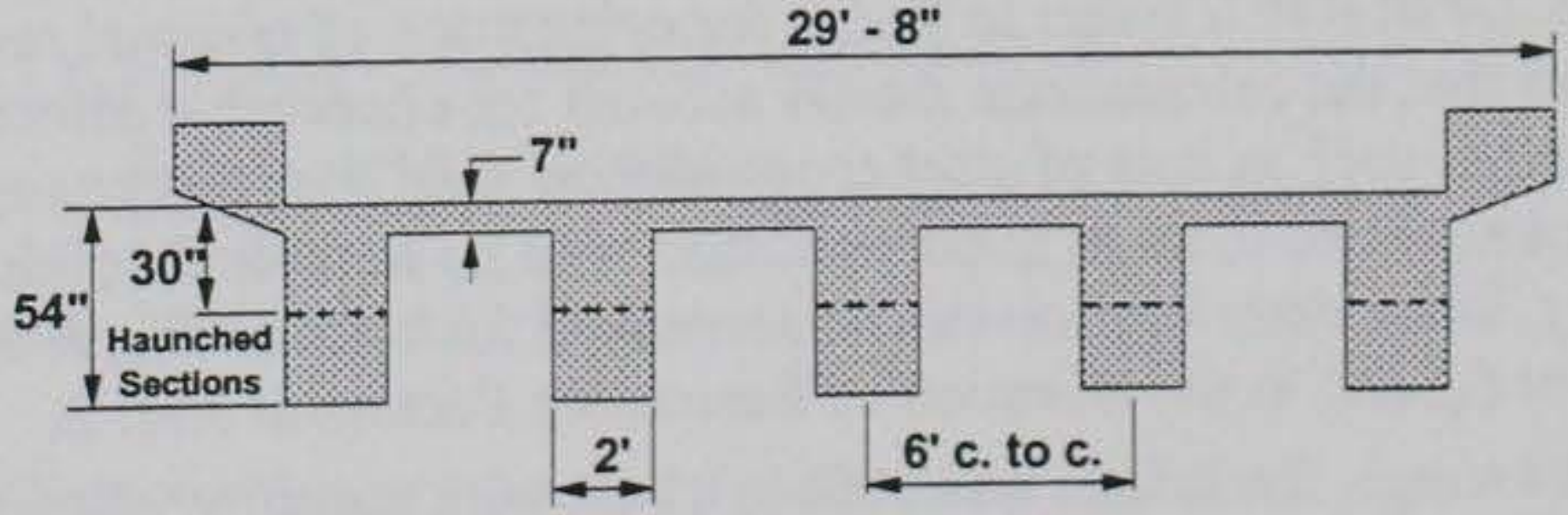

End View 


\section{Sited References:}

1. Manual For Condition Evaluation of Bridges, AASHTO, 1994.

2. Guide Specifications for Strength Evaluation of Existing Steel and Concrete Bridges, AASHTO, 1989.

3. Standard Specifications for Highway Bridges, AASHTO, fifteenth edition, 1992.

4. Manual for Maintenance Inspection of Bridges, AASHTO, 1983.

5. Military Nonstandard Fixed Bridging, FM5-446 or TM5-312.

6. Manual of Steel Construction, American Institute of Steel and Concrete (AISC), Eighth Edition.

Reference 1 is the primary source of guidelines for load rating existing bridges. It allows a choice of load rating methods. The load and resistance factor rating (LRFR) method outlined in Ref. 2 was used herein since it more accurately reflects the current condition of the bridge and the degree of inspection and analysis. For this method, Paragraph 6.1 of Ref. 1 refers all guidelines to Ref. 2 . Thus, Ref. 2 becomes the primary source for this example. Other references will be cited as applicable.

\section{Deck Rating}

- Par. 6.7.2.1 of Ref. 1 states that, "In general, stresses in the deck do not control the rating except in special cases." However, when in doubt the deck rating should be checked. A reinforced deck rating was demonstrated previously in Appendix B. The same method would apply for this example.

\section{Tee Beam Rating}

- Interior beams generally control the rating and this will be assumed true herein. However, if in doubt, always check both interior and fascia beams.

\section{Nominal Capacities of Tee Beam Sections}

- Par. 3.3.2.4 of Ref. 2 refers to Ref. 3 for calculation of nominal resistance. It also states that the calculations should account for observable effects of deterioration, such as loss of steel cross-section area. For this example, the beams are assumed to be in good condition with no notable deterioration. If necessary, beam deterioration can be accounted for by reducing cross-sectional area, $\mathrm{fc}^{\prime}$ or $\mathrm{f}_{\mathrm{y}}$, and in the selection of Resistance Factors in Ref. 2.

- From drawings, the bridge was built in 1942, with specified allowable stresses as follows: $\begin{aligned} & f_{c}=800 \mathrm{psi} \\ & f_{s}=18 \mathrm{ksi}\end{aligned}$

However, we will be using the LRFR method, so from Par. 6.6.3, Ref. 1:

$f_{i_{c}}=2,500 p s i ; \mathrm{n}=15$

$\mathrm{f}_{\mathrm{y}}=33 \mathrm{ksi}$

- Effective Flange Width (8.10.1.1, Ref. 3):

Exterior Spans: $1 / 4\left(41^{\prime}\right)=10.25^{\prime}$ 
Interior Spans: $1 / 4\left(60^{\prime}\right)=15.0^{\prime}$

$$
\begin{aligned}
& \text { Web }+2\left(\frac{\underline{\underline{\text { or }}}}{\left(\frac{\mathrm{t}_{5}}{5}\right)}=2.0+2(6)(7 / 12)=9.0^{\prime}\right. \\
& \text { Web }+2\left(\frac{\text { or }}{1 / 2} \text { clear dist }\right)=2.0+2(1 / 2)\left(4.0^{\prime}\right)=6.0^{\prime} \text { (Controls for both } \\
& \text { therefore, } b=6.0^{\prime}(12 \mathrm{in} / \mathrm{ft})=72.0^{\prime \prime}
\end{aligned}
$$
interior and exterior spans)

- Reinforced beams must be checked at each location where the section changes, either in cross-section or reinforcing. Therefore, for this bridge the following sections will be checked:

@ Midspan of Exterior Spans ( 14' form support):

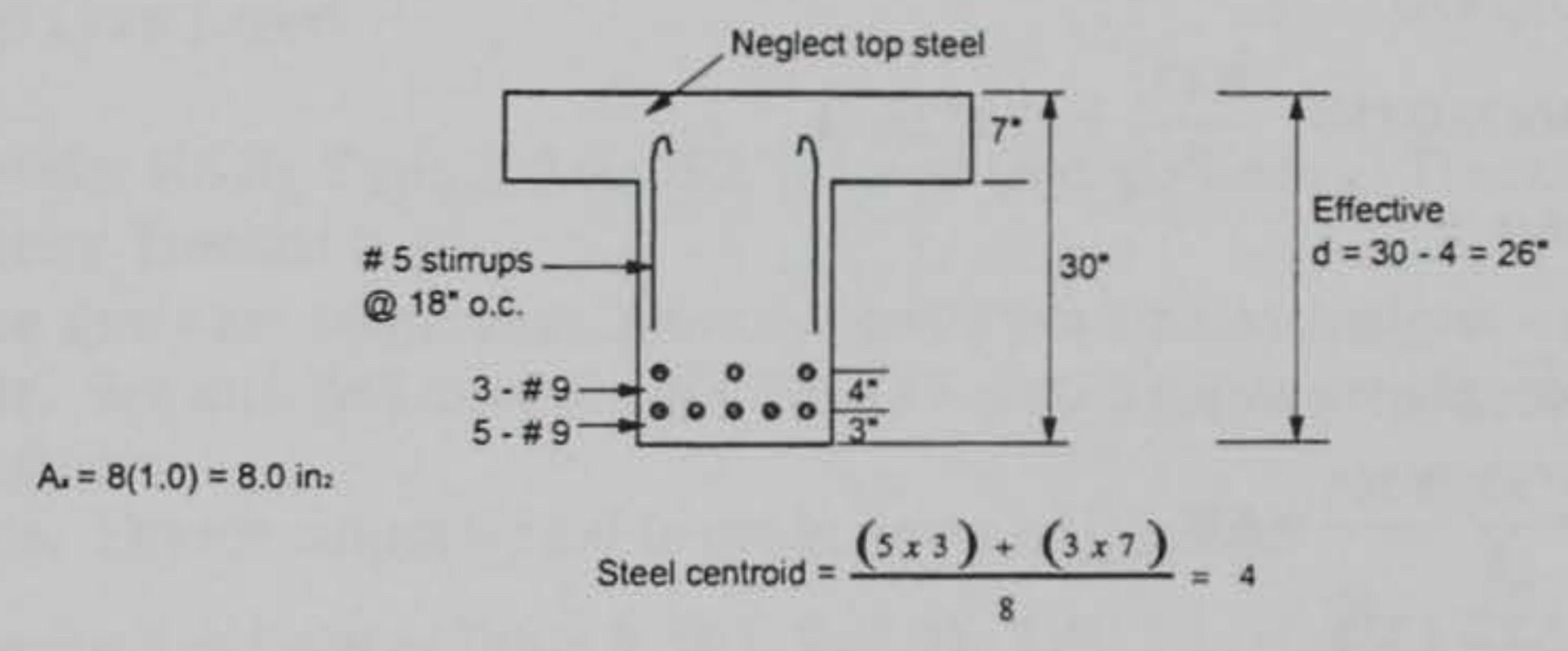

(8.16.3.2, Ref. 1): $a=\frac{A_{s} f_{y}}{0.85 f_{c}^{\prime} b}=\frac{(8.0)(33.0)}{.85(2.5)(72.0)}=1.73^{\prime \prime}<7$ " therefore, compression all in flange,

Use 8.16.3.3.1, Ref. 1:

$$
\begin{aligned}
M_{n}=A_{s} f_{y}\left(d-\frac{a}{2}\right)=(8.0)(33.0)\left(26-\frac{1.73}{2}\right) & =6636 \mathrm{in} \cdot k \\
M_{n} & =553 \mathrm{ft} \cdot k
\end{aligned}
$$

(8.16.6, Ref. 1): $V_{n}=V_{c}+V_{s}$

$$
\begin{aligned}
V_{c} & =2 \sqrt{f_{c}^{\prime}} b_{w} d=2(\sqrt{2500})\left(24^{\prime \prime}\right)\left(26^{\prime \prime}\right)=62.4 k \\
V_{s} & =\frac{A_{v} f_{y} d}{s}=\frac{(0.62)(33.0)(26.0)}{18^{\prime \prime}}=29.6 k \\
V_{n}=62.4 & +29.6=92.0 k
\end{aligned}
$$

@ Endspan of Exterior Spans: $M=0 ; V_{n}=92.0 k$

(a) Beginning of Haunch for both Interior \& Exterior Spans (same):

- Only check shear since moments are low

$$
\begin{aligned}
& V_{c}=62.4 k \\
& V_{s}=\frac{(0.62)(33)(26)}{12 "}=44.3 k \\
& \uparrow(\text { used for conservatism) }
\end{aligned}
$$




$$
V_{n}=62.4+44.3=107.0 k
$$

@ Interior Support over Pier (Neg. Moment Region):

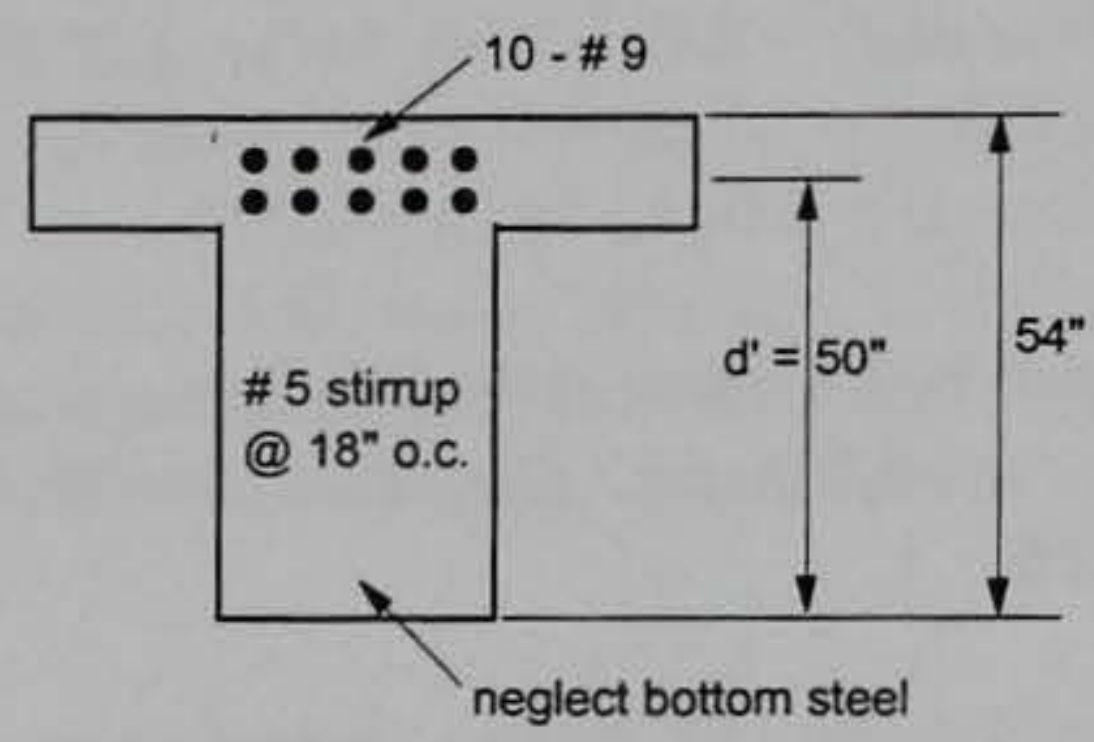

$a=\frac{(10.0)(33.0)}{.85(2.5)(24.0)}=6.47^{\prime \prime}$

$M_{n}=(10.0)(33.0)\left(50-\frac{6.47}{2}\right)=15,432 \mathrm{in} \cdot k$

$M_{n}=1,286 \mathrm{ft} \cdot k$

$V_{c}=2 \sqrt{2500}(24)(50)=120 k$

$V_{s}=\frac{(0.62)(33.0)(50)}{18}=57 k$

$V_{n}=120+57=177 k$

@ Midspan ( 30' from support) of interior span:

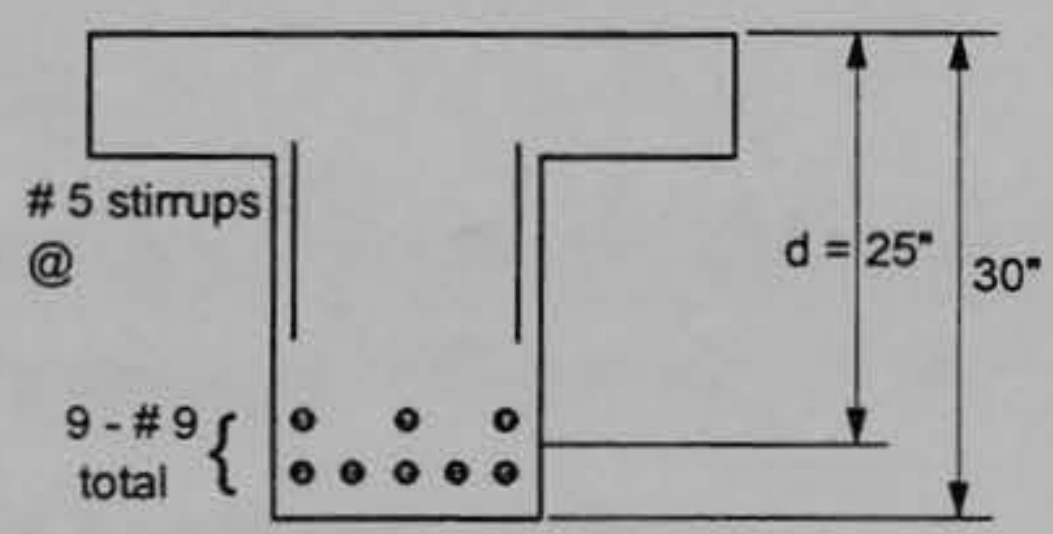

$a=\frac{(9.0)(33.0)}{.85(2.5)(72.0)}=1.94 "$

$M_{n}=(9.0)(33.0)\left(25-\frac{1.94}{2}\right)=7,137 \mathrm{in} \cdot k$

$$
M_{n}=595 \mathrm{ft} \cdot k
$$

from previous similar section: $V_{n}=92.0 \mathrm{k}$

\section{Applied Dead Load}

Tee Beam: $\left[\left(7^{\prime \prime} / 12\right)\left(6^{\prime}\right)+\left(23^{\prime \prime} / 12\right)\left(2^{\prime}\right)+\left(16 \mathrm{in}^{2} / 144\right)\right]\left(0.150 \mathrm{k} / \mathrm{ft}^{3}\right)=1.12 \mathrm{k} / \mathrm{ft}$

$\begin{array}{ccc}\uparrow & \uparrow & \uparrow \\ \text { slab } & \text { tee } & \text { fillet }\end{array}$


Haunched portion of Tee: $\left[1 / 2\left(54^{\prime \prime}-30^{\prime \prime}\right)(1 / 12)\left(2^{\prime}\right) \times 12^{\prime}\right]\left(1 / 41^{\prime}\right)(0.150)=0.09 \mathrm{k} / \mathrm{ft}$ $\uparrow \uparrow$

haunch length assume spread over length of span

Curbs \& Rails: $\left[\left(3^{\prime}\right)\left(1^{\prime}\right)+\left(3.5^{\prime}\right)\left(10^{\prime \prime} / 12\right)\right](0.150)\left(\frac{1}{5 \text { beams }}\right)=0.18$

$\uparrow$

shared equally among beams

$$
\text { Total } W_{D}=1.39 \mathrm{k} / \mathrm{ft}
$$

* Since spans are continuous, use continuous beam analysis to get dead load moments \& shears (analysis results not shown).

\section{Applied Live Load}

* Consider HS20, Type 3, 3-3, 3S2, State of Georgia Special Trucks, and Military Tracked

* Since spans are continuous, must use continuous beam analysis with moving loads. See attached example of CONSYS output for maximum moments and shears.

Note: Divide output by 2.0 to get in terms of line load

Distribution Factor (Table 3.23.1, Ref. 3): $\mathrm{DF}_{\text {Two-way }}=\frac{\mathrm{S}}{6.0}=\frac{6.0}{6.0}=1.0$

\section{LRFR Rating Factors}

(Reference 2)

Impact: Good surface \& approach $\Rightarrow \mathrm{I}=0.1$

DL Factor: $\mathrm{A}_{1}=1.2$

LL Factor: Heavy volume, reasonable enforcement: $A_{2}=1.45$

$\phi$ Factor: $\mathrm{R} / \mathrm{C}$ beams, no deterioration, inter. maintenance.: $\phi=0.85$ 
Basic Equation: $\quad \mathrm{RF}=\frac{\phi \mathrm{R}_{\mathrm{n}}-\mathrm{A}_{1} \mathrm{D}}{\mathrm{A}_{2} \mathrm{~L}(1+\mathrm{I}) \mathrm{DF}}=\frac{0.85 \mathrm{R}_{\mathrm{n}}-1.2 \mathrm{D}}{1.45 \mathrm{~L}(1.1)(1.0)}$

\begin{tabular}{|c|c|c|c|c|c|c|c|c|c|c|c|c|c|c|c|c|c|}
\hline \multirow[b]{2}{*}{ Location } & \multirow[b]{2}{*}{$M_{n}$} & \multirow[b]{2}{*}{$M_{D}$} & \multicolumn{8}{|c|}{ LL Moments / RF } & \multirow[b]{2}{*}{$V_{n}$} & \multirow[b]{2}{*}{$V_{D}$} & \multicolumn{5}{|c|}{ LL Shears / RF } \\
\hline & & & HS2O & 3 & $3-3$ & $3 \mathrm{S2}$ & M24 & G-TR3 & G-3S2 & T150 & & & HS2O & 3 & 3-3 & $3 \mathrm{~S} 2$ & T150 \\
\hline $\begin{array}{l}\text { Spans } 1 \& 3 \\
\text { Free End }\end{array}$ & $\begin{array}{c}N A \\
m=0\end{array}$ & - & - & - & - & - & - & - & - & - & 92 & 17 & $\frac{25}{1.44}$ & $\frac{16}{2.26}$ & $\frac{16}{2.34}$ & $\frac{18}{2.08}$ & $\frac{95}{0.38}$ \\
\hline \multirow{2}{*}{$\begin{array}{l}\text { Spans } 1 \& 3 \\
\text { Midspan }\end{array}$} & \multirow[t]{2}{*}{+553} & \multirow[t]{2}{*}{+102} & 174 & 129 & 106 & 113 & 170 & 216 & 122 & 729 & \multirow[b]{2}{*}{92} & \multirow{2}{*}{$\begin{array}{c}\text { @ 24' } \\
17\end{array}$} & 17 & 13 & 12 & 14 & 59 \\
\hline & & & 1.25 & 1.70 & 2.06 & 1.93 & 1.28 & 1.01 & 1.79 & 0.30 & & & 2.14 & 2.78 & 3.16 & 2.68 & 0.62 \\
\hline \multirow{2}{*}{$\begin{array}{l}\text { Spans } 1 \& 3 \\
\text { Begin of } \\
\text { Haunch }\end{array}$} & \multirow{2}{*}{$\begin{array}{c}N A \\
M=\text { low }\end{array}$} & \multirow[b]{2}{*}{-} & \multirow[b]{2}{*}{ - } & \multirow[b]{2}{*}{-} & \multirow[b]{2}{*}{ - } & \multirow[b]{2}{*}{ - } & \multirow[b]{2}{*}{ - } & \multirow[b]{2}{*}{ - } & \multirow[b]{2}{*}{ - } & \multirow[b]{2}{*}{ - } & \multirow[b]{2}{*}{107} & \multirow{2}{*}{$\begin{array}{c}\text { @ 29' } \\
23\end{array}$} & 21 & 16 & 14 & 16 & \multirow{2}{*}{$\frac{76}{0.52}$} \\
\hline & & & & & & & & & & & & & 1.94 & 2.56 & 2.84 & 2.48 & \\
\hline Interior & & & -242 & -165 & -204 & -189 & -180 & -255 & -213 & -1000 & & & 30 & 22 & 23 & 24 & 126 \\
\hline $\begin{array}{l}\text { Supports over } \\
\text { Piers }\end{array}$ & -1286 & -478 & 1.34 & 1.98 & 1.60 & 1.72 & 1.76 & 1.24 & 1.48 & 0.32 & 177 & 42 & 2.10 & 2.86 & 2.72 & 2.62 & 0.50 \\
\hline Span 2 & NA & & & & & & & & & & & @ -12' & 23 & 16 & 16 & 17 & \\
\hline $\begin{array}{l}\text { Begin of } \\
\text { Haunch }\end{array}$ & $M=$ low & - & - & - & - & - & - & - & - & - & 107 & 25 & 1.66 & 2.46 & 2.46 & 2.24 & 0.40 \\
\hline \multirow{5}{*}{$\begin{array}{l}\text { Span } 2 \\
\text { Midspan }\end{array}$} & \multirow[t]{2}{*}{+595} & \multirow[t]{2}{*}{+148} & 185 & 142 & 113 & 137 & 172 & 206 & 150 & 770 & \multirow[b]{2}{*}{92} & \multirow{2}{*}{$\begin{array}{c}\text { @ } 18^{1 *} \\
17\end{array}$} & 16 & 13 & 12 & 14 & 75 \\
\hline & & & 1.12 & 1.44 & 1.82 & 1.48 & 1.20 & 1.00 & 1.37 & 0.39 & & & 1.90 & 2.90 & 3.02 & 2.68 & 0.48 \\
\hline & & & & & & & & & & $\frac{770}{0.42}$ & & & & & & & \\
\hline & & & & & & & & & & & One - & $y R F=$ & $R n-1.2 D$ & & $P F_{1}$ & 6.0 & \\
\hline & & & & & & & & & & & & & $(11)(0.92)$ & & 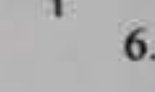 & 6.5 & \\
\hline
\end{tabular}

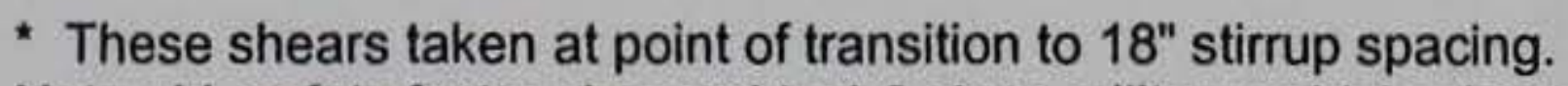

Note: LL safety factor changed to 1.0 since military vehicles have carefully controlled MLCs based on max. possible loadings 


\section{Rating \& Posting Summary}

- Based on the controlling RFs from p.5, the following ratings and postings are obtained:

\begin{tabular}{|c|c|c|c|c|}
\hline Vehicle & $\begin{array}{c}\text { Vehicle Weight } \\
\text { (tons) }\end{array}$ & Controlling RF & HS Rating (1) & $\begin{array}{l}\text { Required Bridge } \\
\text { Posting Load (tons) }\end{array}$ \\
\hline $\mathrm{HS} 2 \mathrm{O}$ & NA & 1.12 & HS22 & $\longrightarrow$ \\
\hline Type 3 & 25 & 1.44 & $\longrightarrow$ & None \\
\hline Type 352 & 26 & 1.48 & $\longrightarrow$ & None \\
\hline Type 3-3 & 40 & 1.82 & - & None \\
\hline Georgia M24 & 24 & 1.20 & $\longrightarrow$ & None \\
\hline Georgia G-TR3 & 36 & 1.00 & 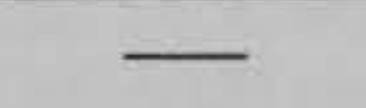 & None \\
\hline Georgia G-3S2 & 40 & 1.37 & 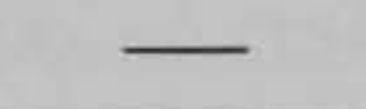 & None \\
\hline Mil. Tracked & 150 & $0.42 / 0.39^{(3)}$ & - & $63 / 59$ \\
\hline Mil. Wheeled & $36^{(2)}$ & $1.75 / 1.61^{(2,3)}$ & - & $63 / 59$ \\
\hline
\end{tabular}

Footnotes:

(1) The HS Rating is only to be used for purposes of reporting to the FHWA's National Bridge Inventory. It is not to be used for purposes of bridge posting. HS Rating $=(\mathrm{HS} 20)(\mathrm{RF})$

(2) Obtained by assuming axle configuration and weight of military wheeled to be the same as HS20 and using the same results. One-way obtained by using one-way DF in RF equation $R F_{1}=\frac{0.85(595)-1.2(148)}{1.0(185)(1.1)(0.92)}=1.61$

$\uparrow$ Note reduced LL safety factor for military
(3) One-Lane / Two-lane Traffic
(4) No posting required if RF $>1$ 


\section{Example Output from CONSYS Analysis with Moving Loads}

\section{STRUCTURE DATA}

Structure Id : Continuous Tee Beam

Elasticity $=1.0 \mathrm{Ksi}$ Spans $=3$ Segments $=19 \quad$ D.O.F. $=36$

** Due to haunched beams, must break each span up into segments as follows:

Span 1: Length $(\mathrm{ft})=41.00$ Segments $=5$

Segment 1: $\mathrm{L}(\mathrm{ft})=29.00$ M.I. $($ in 4$)=2250.0$

Segment 2: $\mathrm{L}(\mathrm{ft})=3.00$ M.I.(in4) $=3888.0$

Segment 3: L(ft) $=3.00$ M.I.(in4) $=6174.0$

Segment 4: L(ft) $=3.00$ M.I.(in4) $=9216.0$

Segment 5: L(ft) $=3.00$ M.I.(in4) $=13122.0$

Span 2: Length(ft) $=60.00$ Segments $=9$

Segment 1: L(ft) $=3.00$ M.I.(in4) $=13122.0$

Segment 2: $\mathrm{L}(\mathrm{ft})=3.00$ M.I.(in4) $=9216.0$

Segment 3: L(ft) $=3.00$ M.I.(in4) $=6174.0$

Segment 4: L(ft) $=3.00$ M.I.(in4) $=3888.0$

Segment 5: $\mathrm{L}(\mathrm{ft})=36.00$ M.I.(in4) $=2250.0$

Segment 6: $\mathrm{L}(\mathrm{ft})=3.00$ M.I.(in4) $=3888.0$

Segment 7: $\mathrm{L}(\mathrm{ft})=3.00$ M.I.(in4) $=6174.0$

Segment 8: $\mathrm{L}(\mathrm{ft})=3.00$ M.I.(in4) $=9216.0$

Segment 9: $\mathrm{L}(\mathrm{ft})=3.00$ M.I.(in4) $=13122.0$

Span 3: Length(ft) $=41.00$ Segments $=5$

Segment 1: L(ft) $=3.00$ M.I.(in4) $=13122.0$

Segment 2: $\mathrm{L}(\mathrm{ft})=3.00$ M.I.(in4) $=9216.0$

Segment 3: L(ft) $=3.00$ M.I.(in4) $=6174.0$

Segment 4: L(ft) $=3.00$ M.I.(in4) $=3888.0$

Segment 5: L(ft) $=29.00$ M.I.(in4) $=2250.0$

\section{LOADING DATA}

Truck 1 Id: HS20 Axles $=3$

Axle $1 \mathrm{load}=8.00 \mathrm{~K}$

Spacing range $=14.00 \mathrm{ft}-14.00 \mathrm{ft}$

Axle 2 load $=32.00 \mathrm{~K}$

Spacing range $=14.00 \mathrm{ft}-30.00 \mathrm{ft}$

Axle 3 load $=32.00 \mathrm{~K}$

Axle spacing increment $=2.0 \mathrm{ft}$

Lane Load: U.D.L. $=0.64 \mathrm{KLF}$ C.L. $($ moment $)=18.0 \mathrm{~K}$ C.L. $($ shear $)=26.0 \mathrm{~K}$ 


\section{INTERMEDIATE ANALYSIS - TRUCK: HS20 - FACE: LEFT}

*** Note: Remember to divide all of these answers by 2.0 to get in terms of a line load***

Loc. $\operatorname{Mmax}(+)----$ VL------VR $\operatorname{Mmax}(-)----$ VL------VR $\operatorname{Defl}(+)--\operatorname{Defl}(-)$

(ft) $(\mathrm{K}-\mathrm{ft})$

(K) $\quad(\mathrm{K}) \quad(\mathrm{K}-\mathrm{ft}) \quad(\mathrm{K}) \quad(\mathrm{K})$

(in) (in)

Vmax(+)----Mom

(K) (K-ft)

(K) (K-ft)

(K) $(\mathrm{K}-\mathrm{ft})$

Span $1 \quad$ (Support 1 R-max $11.2 / \quad-49.8$ )

$\begin{array}{ccccccccc}0.00 & 0.0 & 49.8 & 47.1 & 0.0 & 49.8 & 47.1 & 0.00 & 0.00 \\ 49.8 & 0.0 & -11.2 & 0.0 & 49.8 & 0.0 & \end{array}$

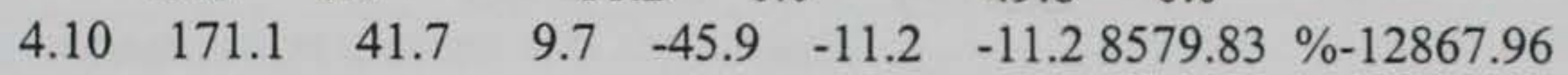

$\begin{array}{llllll}41.7 & 171.1 & -11.2 & -45.9 & 41.7 & 171.1\end{array}$

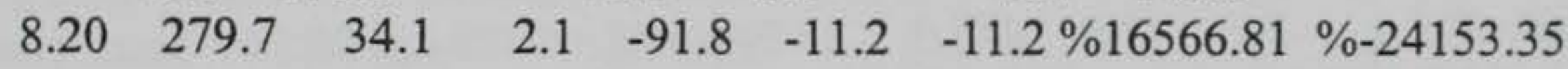

$\begin{array}{llllll}34.1 & 279.7 & -11.8 & 138.0 & 34.1 & 279.7\end{array}$

$\begin{array}{llllllll}12.30 & 332.7 & 27.1 & -4.9 & -137.8 & -11.2 & -11.2 \% 23368.09 & \%-32293.72\end{array}$

$\begin{array}{llllll}27.1 & 332.7 & -16.0 & 171.7 & 27.1 & 332.7\end{array}$

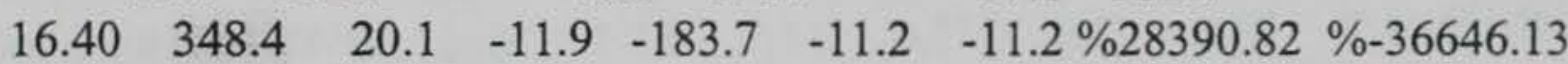
$\begin{array}{llllll}20.1 & 348.4 & -20.3 & 179.6 & -20.3 & 179.6\end{array}$

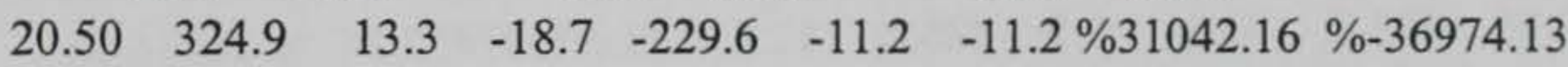

$\begin{array}{llllll}13.3 & 324.9 & -26.8 & 314.7 & -26.8 & 314.7\end{array}$

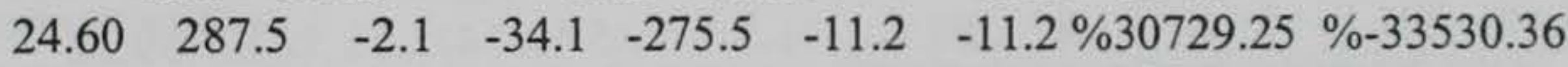
$\begin{array}{llllll}9.4 & 230.9 & -34.1 & 287.5 & -34.1 & 287.5\end{array}$

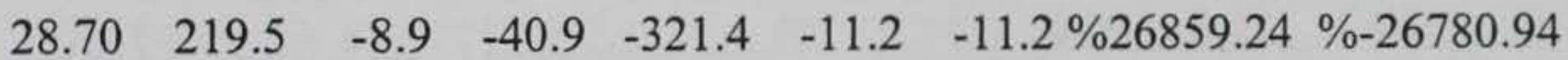
$\begin{array}{llllll}6.6 & 188.9 & -40.9 & 219.5 & -40.9 & 219.5\end{array}$

$\begin{array}{lllllll}32.80 & 123.2 & -2.6 & -20.6 & -367.4 & -11.2 & -11.2\end{array} \% 19650.13 \%-17996.54$ $\begin{array}{llllll}4.3 & 142.0 & -48.0 & 116.4 & -48.0 & 116.4\end{array}$

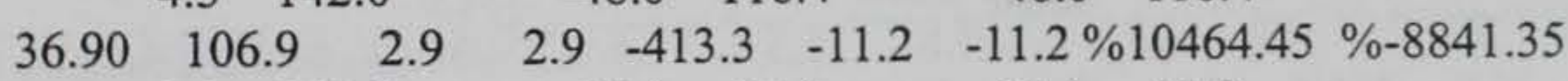

$\begin{array}{llllll}2.9 & 106.9 & -54.4 & -21.0 & -54.4 & -21.0\end{array}$

$\begin{array}{lllllllll}41.00 & 118.7 & 2.9 & 2.9 & -483.5 & -33.9 & -33.9 & 0.02 & -0.02\end{array}$ $\begin{array}{llllll}2.9 & 118.7 & -60.1 & -185.0 & -60.1 & -185.0\end{array}$

Span 2 (Support 2 R-max $9.6 / \quad-70.4$ )

$\begin{array}{lllllllll}0.00 & 118.7 & -6.7 & -6.7 & -483.5 & 34.8 & 34.8 & 0.00 & 0.00\end{array}$ $\begin{array}{llllll}59.2 & -243.1 & -6.7 & 118.7 & 59.2 & -243.1\end{array}$

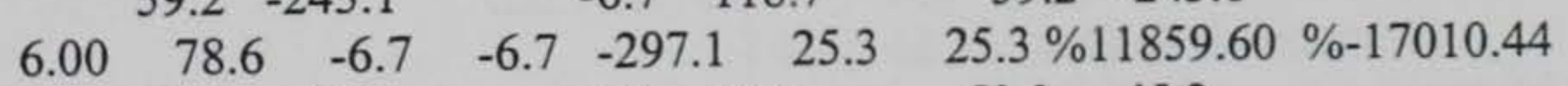
$\begin{array}{llllll}53.3 & -45.2 & -6.7 & 78.6 & 53.3 & -45.2\end{array}$

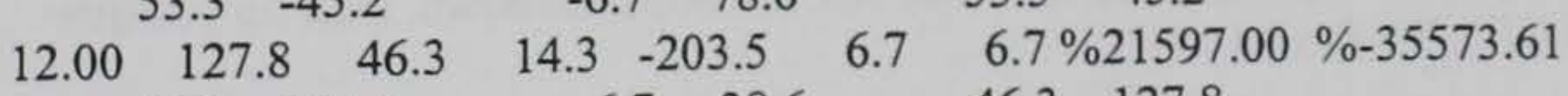
$\begin{array}{llllll}46.3 & 127.8 & -6.7 & 38.6 & 46.3 & 127.8\end{array}$

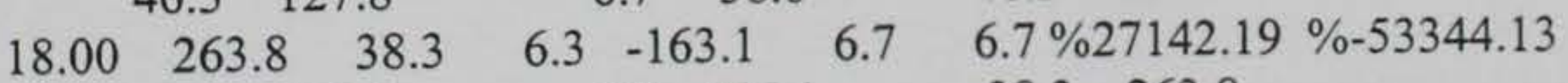
$\begin{array}{llllll}38.3 & 263.8 & -9.7 & 195.1 & 38.3 & 263.8\end{array}$

$\begin{array}{lllllll}24.00 & 347.8 & 29.7 & -2.3 & -122.7 & 6.7 & 6.7 \% 28177.86\end{array} \%-65968.88$ $\begin{array}{llllll}29.7 & 347.8 & -15.3 & 308.2 & 29.7 & 347.8\end{array}$

$\begin{array}{llllllll}30.00 & 370.3 & 21.1 & -10.9 & -102.9 & 0.0 & 0.0 \% 25820.98 & \%-70523.80\end{array}$ $\begin{array}{llll}21.1 & 370.3 & -22.9 & 350.3\end{array}$

$\begin{array}{llllllll}36.00 & 335.5 & 13.0 & -19.0 & -121.8 & -6.7 & -6.7 \% 27968.94 & \%-66371.53\end{array}$ $\begin{array}{llllll}14.1 & 233.5 & -31.4 & 335.0 & -31.4 & 335.0\end{array}$

$\begin{array}{llllllll}42.00 & 256.4 & -8.1 & -40.1 & -161.9 & -6.7 & -6.7 \% 26939.92 & \%-54193.59\end{array}$ $\begin{array}{llllll}9.7 & 195.0 & -40.1 & 256.4 & -40.1 & 256.4\end{array}$

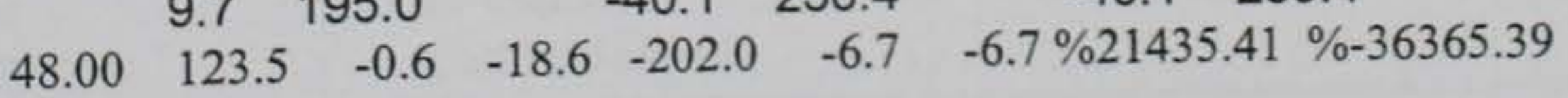




\begin{tabular}{|c|c|c|c|}
\hline & $6.7 \quad 38.9$ & $-48.4 \quad 123.1$ & $-48.4 \quad 123.1$ \\
\hline .00 & $79.3 \quad 6.7$ & $6.7-297.1 \quad-25.3$ & $-25.3 \% 11770.70 \%-17395.71$ \\
\hline & $6.7 \quad 79.3$ & $-56.0-52.5$ & $-56.0-52.5$ \\
\hline & $119.6 \quad 6.7$ & $\begin{array}{lll}6.7 & -483.5 & -34.8\end{array}$ & $\begin{array}{lll}-34.8 & 0.03 & -0.05\end{array}$ \\
\hline & 6.7119 .6 & $-62.7-262.3$ & $-62.7-262.3$ \\
\hline
\end{tabular}

INTERMEDIATE ANALYSIS - TRUCK: HS20 - FACE: LEFT

Loc. $M \max (+)-----V L------V R \quad M \max (-)-----V L------V R \quad \operatorname{Defl}(+)--\operatorname{Defl}(-)$
(ft) (K-ft) (K) (K)
(K-ft)
(K) $(\mathrm{K})$
(in) (in)
Vmax(+)----Mom
(K) $\quad(\mathrm{K}-\mathrm{ft})$
(K) $\quad(\mathrm{K}-\mathrm{ft})$
(K) $(\mathrm{K}-\mathrm{ft})$

Span 3 (Support 3 R-max 9.7/ -70.1)

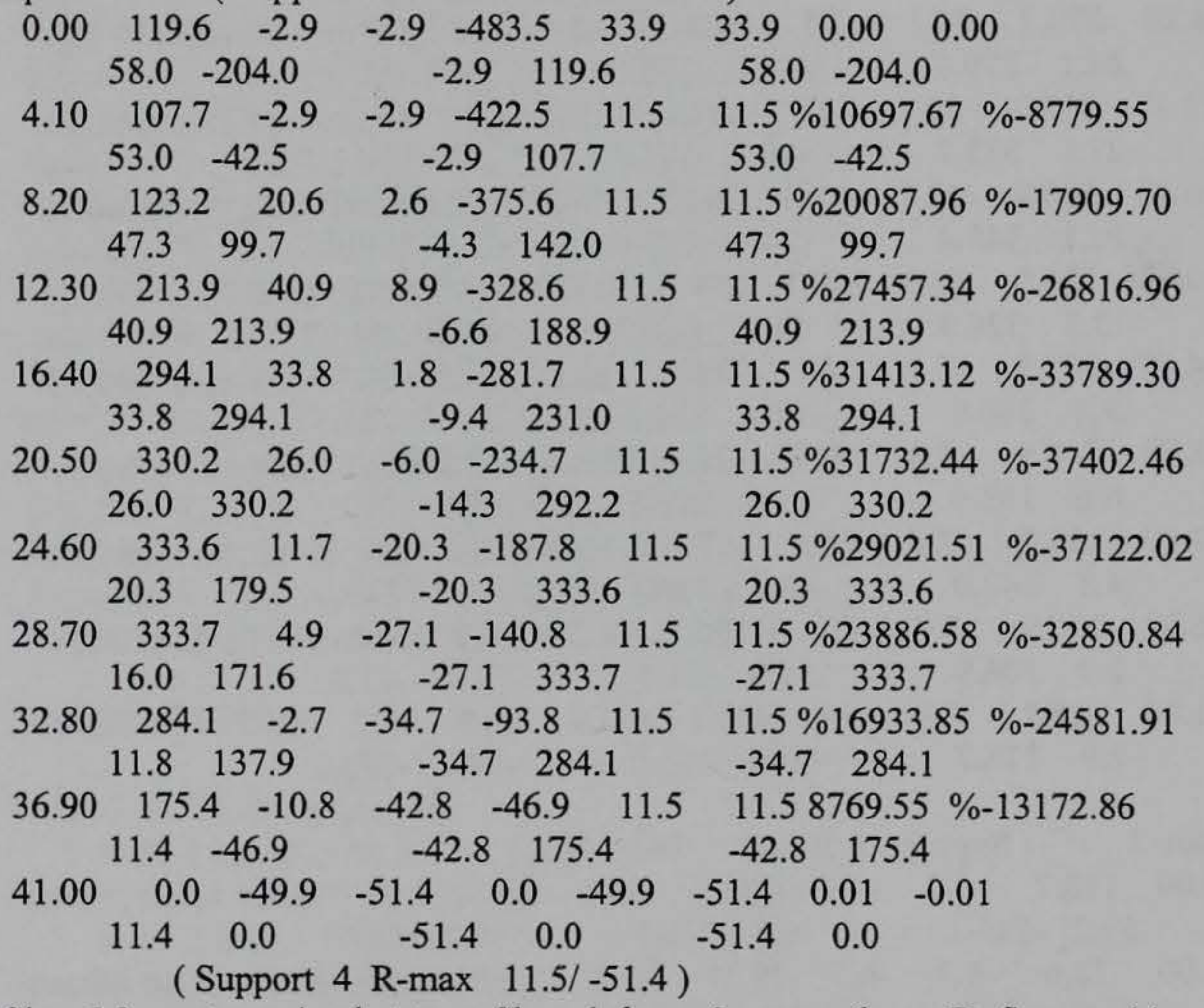

Sign: Moment causing bot tens, Shear left-up, Sup reac down, Defl up positive STRUCTURE DATA 


\section{REPORT DOCUMENTATION PAGE}

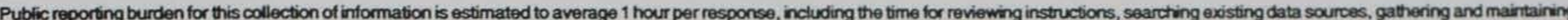

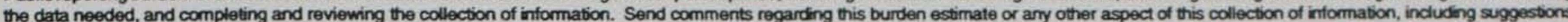

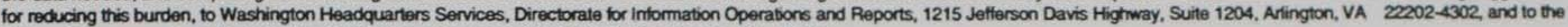
Office of Management and Budget Papenwork Reduction Project (0704-0188), Washington, DC 20503.

\begin{tabular}{|l|l|l|}
\hline 1. AGENCY USE ONLY (Leave blank) & $\begin{array}{c}\text { 2. REPORT DATE } \\
\text { April } 1998\end{array}$ & $\begin{array}{l}\text { 3. REPORT TYPE AND DATES COVERED } \\
\text { Final report }\end{array}$ \\
\hline
\end{tabular}

4. TITLE AND SUBTITLE

5. FUNDING NUMBERS

Load Rating of Permanent Bridges on U.S. Army Installations

6. AUTHOR(S)

James C. Ray, Terry R. Stanton

\section{PERFORMING ORGANIZATION NAME(S) AND ADDRESS(ES)}

U.S. Army Engineer Waterways Experiment Station

3909 Halls Ferry Road, Vicksburg, MS 39180-6199

8. PERFORMING ORGANIZATION REPORT NUMBER

Technical Report SL-98-3

9. SPONSORINGMONITORING AGENCY NAME(S) AND ADDRESS(ES)

U.S. Army Center for Public Works AGENCY REPORT NUMBER

Fort Belvoir, Virginia 22315-3862

11. SUPPLEMENTARY NOTES

Available from National Technical Information Service, 5285 Port Royal Road, Springfield, VA 22161.

12a. DISTRIBUTIONAVAILABILITY STATEMENT

12b. DISTRIBUTION CODE

Approved for public release; distribution is unlimited.

13. ABSTRACT (Maximum 200 words)

It is widely known that the United States owns and maintains many bridges throughout its highway system, and the Department of the Army owns and maintains over 1,500 bridges. These bridges are on U.S. military installations throughout the world, and they carry pedestrians, civilian and military vehicles, and trains. Like the U.S. infrastructure, these bridges require continual inspection, maintenance, and load capacity assessment. The objective of this report is to provide uniformity in the procedures and policies for determining the load capacity of these bridges and also to provide a common reference for this information. Additionally, the report provides a summary of the material developed for a short course on this subject.

14. SUBJECT TERMS

Army installations

Bridge

Bridge analysis

Bridge load rating

Bridge rating

17. SECURTYY CLASSIFICATION OF REPORT

UNCLASSIFIED
Bridge safety

Bridges

Load rating

Military installations

Safety
15. NUMBER OF PAGES

184

16. PRICE CODE 